\title{
Building Design Capability in the Public Sector Expanding the Horizons of Development
}

\author{
by
}

\section{Lisa Malmberg}

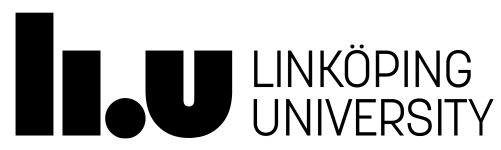

Department of Computer and Information Science

Linköpings University

SE-581 83 Linköping, Sweden

Linköping 2017 
All original photos on which illustrations are based are used with permission.

Copyright (C) 2017 Lisa Malmberg

ISBN 978-91-7685-585-0

ISSN $0345-7524$

Printed by LiU-Tryck 2017

URL: http:/ / urn.kb.se/resolve?urn=urn:nbn:se:liu:diva-134167 


\section{Abstract}

Public sector organizations are in need of new approaches to development and innovation. There is a need to develop a capability to better understand priorities, needs and wishes of public sector service users and become more proactive, in order to meet the demands on keeping costs down and quality high.

Design is increasingly put forward as a potential answer to this need and there are many initiatives taken across the world to encourage the use of a design approach to development and innovation within public sector. In relation to this trend there is a need to improve the understanding of how public sector organizations develop ability to exploit design; how they develop design capability. This is the focus of this thesis, which through an exploratory study has observed the two initiatives aiming to introduce design and develop design capability within healthcare and social service organizations.

One main contribution of this work is an understanding of the design capability concept based on a structured review of the use of the design capability concept in the literature. The concept has previously been used in relation to different aspects of designs in organizations.

Another important contribution is the development of an understanding for how design capability is developed based on interpretations founded in the organizational learning perspective of absorptive capacity. The study has identified how different antecedents to development of design capability have influenced this development in the two cases. The findings have identified aspects that both support and impede the development of design capability which are important to acknowledge and address when aiming to develop design capability within a public sector organization.

In both cases, the set up of the knowledge transferring efforts focus mainly on developing awareness of design. Similar patterns are seen in other prior and parallel initiatives. The findings however suggest that it is also important to ensure that the organization have access to design competence and that structures like routines, processes and culture support and enable the use of design practice, in order to make design a natural part of the continuous development work. 



\section{Populärvetenskaplig sammanfattning}

Sedan 2015 ställer patientlagstiftningen krav på ökat inflytande och delaktighet för patienter och socialtjänstbrukare och det pågår ett paradigmskifte mot en mer personcentrerad vård och omsorg. Detta ställer nya krav både på utveckling och leverans av tjänster inom offentlig sektor. Den ökade pressen på offentlig sektor att hålla nere kostnaderna och samtidigt hålla hög kvalité på tjänsterna skapar ett behov av nya förhållningssätt till såväl användarna av tjänster som till utveckling. Förståelsen för invånarnas behov, förutsättningar och drömmar behöver utvecklas för att ge verksamheten bättre insikt i vilka problem de knappa resurserna ska fokuseras på och att de lösningar som tas fram verkligen tillför värde.

I samband med detta lyfts allt oftare design fram som ett potentiellt angreppssätt. Runt om i Europa ses fler initiativ med syfte att få organisationer inom offentlig sektor att börja använda design som drivkraft för innovation och utveckling. Initiativen uppmuntras och stöttas ofta av så väl EU som nationella policyaktörer. Det syns också allt fler exempel på organisationer som redan börjat använda design som drivkraft för verksamhets utveckling och innovation. Även i övriga världen syns ett liknande mönster.

För många utan erfarenhet av att jobba med design går dock tankarna ofta enbart till utformning av fysiska produkter, som en ergonomisk skruvmejsel eller en lättanvänd telefon när de hör design. Men design innefattar mer än formgivning. Nobelpristagaren Herbert Simon har beskrivit design som en praktik med syfte att ändra en rådande situation till en som är att föredra. Ett vanligt angreppssätt inom design för att nå en bättre situation är att involvera de som berörs av den, användarna, och utgå ifrån deras förutsättningar, behov och drömmar i utvecklingen av nya lösningar. Design kan med andra ord ses som ett förhållningssätt till utveckling med därtill tillhörande metoder, processer och verktyg. 
Med anledning av det ökade intresset för design finns ett behov av att skapa förståelse för hur förmågan att använda och dra nytta av design kan utvecklas och stärkas i organisationer inom offentlig sektor. Det är detta den här avhandlingen handlar - om hur utvecklas designförmåga inom offentlig sektor?

En organisations förmåga att nyttja design, det vill säga dess designförmåga, beskrivs i avhandlingen som bestående av tre delar: Den första delen är att organisationen har en förståelse för vad ett designdrivet angreppssätt innebär och hur det kan bidra i organisationen. Den andra delen handlar om att ha tillgång till resurser, personer med designkompetens. Den sista delen handlar om att strukturer inom organisationen så som, rutiner, processer och kultur möjliggör användandet av ett designförhållningssätt och därmed nyttjandet av designresurserna.

Forskningen har följt två initiativ som båda syftar till att introducera och utveckla designförmåga. Genom att se på utvecklingen av designförmåga som ett organisatoriskt lärande har kunskap skapats om vilka aspekter som bör beaktas för att stötta dess utvecklingen.

Forskningen visar att det är viktigt att beakta alla tre delar som utgör förmågan att nyttja ett designdrivet angreppssätt. De två senare aspekterna är de som möjliggör för organisationen att dra nytta av design i mer än enstaka projekt. Vidare visar arbetet att ledning och mellanchefer har en stor roll i utvecklingen av designförmåga. De påverkar så väl uppfattningen av design som förutsättningarna för att göra design till en naturlig del av ett kontinuerligt utvecklingsarbete. 


\section{Acknowledgement}

Pursuing a doctorate can at times feel like a lonesome endeavor but there have of course been many people with me on this journey. People that have guided, supported and inspired me, people that have shared my experiences, who have cheered me up and kept me sane.

My supervisory team headed by Stefan Holmlid with Fredrik Tell and Johan Åberg as secondary supervisors. I couldn't have asked for a group of mentors that complemented each other and myself in a better way. I have loved to get to know all of you and to take part of your experience and knowledge. Thank you! Especially Stefan, for giving me this opportunity, which I had not really considered before you asked if I was interested. I'm so happy I took it. I have learnt so much, about doing research, about design, and not the least about myself.

My colleagues in IxS, Matti, Stefan and Johan Å, Johan B, Fabian, Eva and Mattias N, Anna from the very first day already as a master student you made me feel welcome and part of a research context. Tim and Vanessa who joined after me a while and brought new smiles and perspectives as well as consistency to the afternoon fika. I've never felt as home in a work group as I do with you guys. A special thanks to Fabian who took me under his wing and guided me into the life of a $\mathrm{PhD}$ student, you are my older brother in academia.

Thank you Katarina Wetter Edman! Writing with you and discussing our research have meant so much for my work and to me. It has given new energy, new perspectives. It has helped take the work that little extra bit further, which is difficult to reach without having someone to discuss with who is also as deep down in the data as you are yourself.

Directly related to my work I also owe a big thank you, to all informants, who have shared their reflections and experiences with me. Thank you for letting me steel some of your time, a resource worth more than gold in your contexts, I am most grateful. 
Part of what has made this a fun and enjoyable journey has been knowing that beside me I have had the rest of you $\mathrm{PhD}$ candidates sharing my experience through your own adventures. Thank you, Mattias Forsblad, Jonas Rybing, Jody Foo, Camilla Kirkegaard, Robin Keskisärkkä, Amy Rankin (especially for cheering on as we both approached the end of the tunnel), Vanessa Rodrigues, Tim Overkampf, Mathias Nordwall, Johan Falkenjack and Robin Kurtz and Sam Thellman, for the lovely lunch conversations, they have never been boring, the $\mathrm{PhD}$ pubs and the three o'clock fruit breaks.

I would like to thank Froukje Sleeswijk Visser. Meeting you and seeing your $\mathrm{PhD}$ work inspired me. I think that was when the first little tingling ideas that this might be something for me was planted in my head.

Thank you Anne, Lise and Rolf for making the technical and administrative parts of this journey as easy as possible. Having you there to ask for help has saved much time and headaches $:$;

I would also like to thank Mattias F, Tim, Katarina W-E, Matti, Vanessa and Karin for the time you have taken to look at drafts of the empirical material, helped with input on the title, sorting out issues in the formatting and last minute proof reading. Any remaining mistakes are needless to say my own.

Finally I would like to thank my family, my sister Cristin and Katta (who are not really family but close enough) you are my best friends and spending time with you soothes my soul. Talking with you always gives me energy, something that has been especially needed towards the end.

Jon, I love that you have shared this journey with me. That you have let me go on about my work over the dinner table, been interested and discussed it with me, it has meant a lot.

Finally mom and dad, thank you for raising me into a brave independent person, who has the guts to venture on a journey like this without really knowing what to expect. Mom, I remember when I was 19 and about to move to Luleå to study. I was nervous and had second thoughts, and you told me "give it a try, you can always come back home". Those words have followed me ever since. The sentiment that one can always give it a try and then turn back, made me dare to move abroad for my first job as an engineer and it supported my decision to embark on this adventure, thank you.

You have all in different ways been part of making my journey easier, more enjoyable and worthwhile.

Thank you!

Lisa Malmberg Linköping, January 2017 
This research has been funded by VINNOVA, the Swedish Innovation Agency, through the grants Design-driven work practices in regional development, DEPLOY (Dnr: 2016-02800), Embedded design capacity, SIGN (Dnr: 2013-05445), and Tilluäxtverket grant Printed Electronics Arena PEA-PPP. 



\section{Table of Contents}

ABSTRACT III

POPULÄRVETENSKAPLIG SAMMANFATTNING V

ACKNOWLEDGEMENT VII

TABLE OF CONTENTS XI

CHAPTER 1 INTRODUCTION 15

1.1 THE PERCEPTION OF DESIGN AND DESIGN EXPERTISE 16

1.2 MOTIVATION TO TRANSFER DESIGN KNOWLEDGE AND DEVELOP DESIGN CAPABILITY 18

1.3 INTRODUCTION OF DESIGN IN THE PUBLIC SECTOR 19

1.4 STRUCTURE OF THE WORK AND SOME DEFINITIONS 21

1.5 STRUCTURE OF THE THESIS 21

CHAPTER 2 PURPOSE, AIM AND METHODOLOGY OF THE WORK__ 23

2.1 PURPOSE AND AIM OF THE WORK

2.2 INQUIRIES GUIDING THE RESEARCH 23

2.3 METHODOLOGY 24 25

CHAPTER 3 RESEARCH DESIGN AND METHOD 27

3.1 APPROACH AND SETUP OF THE STUDY AND MY POLE AND POSITION AS A RESEARCHER 27

3.2 SELECTION OF CASES 29

3.3 DATA COLLECTION 33

3.3.1 Data COLLECTION CASE A: THE SOCIAL SERVICE CASE 34 
3.3.2 Data Collection CaSe B: The Health lab CASE ___ 36

3.4 LITERATURE REVIEW __ 39

3.5 ANALYSIS _ 40

3.6 A CONTEXTUALIZATION OF THE WORK AND A DISCUSSION OF THE CHOSEN RESEARCH APPROACH _

3.7 VALIDATION ___ 45

3.7.1 MULTIPLE SOURCES ___ 45

3.7.2 MEMBER CHECKING___ 46

3.7.3 THICK DESCRIPTIONS___ 46

CHAPTER 4 THEORETICAL FRAMEWORK: BUILDING DESIGN CAPABILITY —_ 47

4.1 DESIGN CAPABILITY ___ 47

4.1.1 DIFFERENT ASPECTS OF DESIGN CAPABILITY ___ 50

4.1.2 A CAPABILITY IN NEED OF CONSTANT UPDATING ___ 57

4.1.3 PRIOR AND PARALLEL APPROACHES TO THE DEVELOPMENT OF DESIGN CAPABILITY IN THE PUBLIC SECTOR____ 58

4.1.4 DEVELOPMENT OF THE DESIGN CAPABILITY CONCEPT ____ 62

4.2 ORGANIZATIONAL LEARNING THROUGH ABSORPTIVE CAPACITY ___ 66

4.2.1 ABSORPTION OF NEW KNOWLEDGE AND DEVELOPMENT OF CAPABILITY _ 67

4.2.2 THE KNOWLEDGE ABSORPTION PROCESS ___ 68

4.2.3 ANTECEDENTS TO ABSORPTIVE CAPACITY___ 70

4.2.4 IMPLICATIONS FOR ORGANIZATIONAL LEARNING AND SUCCESSFUL KNOWLEDGE ABSORPTION IN PUBLIC SECTOR ORGANIZATIONS___ 78

4.3 A TENTATIVE MODEL FOR THE DEVELOPMENT OF DESIGN CAPABILITY GIVEN AN ABSORPTIVE CAPACITY PERSPECTIVE___ 80 4.3.1 TENTATIVE IMPLICATIONS FOR DEVELOPING DESIGN CAPABILITY IN PUBLIC SECTOR ORGANIZATIONS ______ 83

4.4 CHAPTER SUMMARY____ 86

CHAPTER 5 CASE A: THE SOCIAL SERVICE CASE ___ 89

5.1 LEADING UP TO THE INITIATIVE ___ 92

5.2 MOTIVES FOR PARTICIPATION__ 97

5.3 EXPERIENCES FROM THE DESIGN PROJECT _______ 98

5.3.1 REFLECTIONS AFTER THE USER RESEARCH _ 102

5.3.2 A HALFWAY REFLECTION ON SERVICE DESIGN FROM THE INITIATORS — 104

5.3.3 REFLECTIONS ON THE IDEATION, PROTOTYPING, AND FINALE _ـ 105

5.4 MANAGING A NEW MINDSET_____ 108

5.5 REFLECTIONS ON THE SETUP ___ 112

5.6 REFLECTIONS ON THE RESULTS AND WHAT COMES NEXT____ 114

5.7 A SIX-MONTHS EXTENSION ___ 117 
CHAPTER 6 CASE B: THE HEALTH LAB CASE 123

6.1 LEADING UP TO THE ESTABLISHMENT OF THE HEALTH LAB_____ 126

6.2 THE INITIAL STRUCTURE AND ORGANIZATION OF HEALTH LAB ___ 130

6.3 THE HEALTH LAB PROJECTS ___ 134

6.3.1 THE CARE COORDINATION PROCESS PROJECT ___ 135

6.3.2 THE DESIGN TRAINING PROJECT ___ _ 155

6.4 THREE YEARS, STILL ONGOING ___ 176

CHAPTER 7 PATTERNS IN THE DEVELOPMENT OF DESIGN CAPABILITY 183

7.1 LEARNING-BY-DOING___ 183

7.2 A ROLLER COASTER RIDE: DESIGN UNFAMILIAR YET FAMILIAR ____ 185

7.3 THE FOCUS OF THE KNOWLEDGE TRANSFER ___ 187

7.4 THE BLACK HOLE: DISCORDANCE WITH THE EXISTING PRACTICE AND CULTURE

7.5 OWNERSHIP: WHO WILL ENABLE DESIGN? ___ 193

7.6 CHAPTER CONCLUSION ____ _ _ 197

CHAPTER 8 UNDERSTANDING DEVELOPMENT OF DESIGN CAPABILITY THROUGH AN ABSORPTIVE CAPACITY LENS_____ 201

8.1 DESIGN CAPABILITY, THEORY AND PRACTICE ___ 201

8.1.1 KNOWLEDGE ABOUT AND ABILITY TO DESIGN; A DEVELOPMENT OF THE UNDERSTANDING OF DESIGN CAPABILITY ___ 204

8.2 ABSORBING DESIGN KNOWLEDGE AND DEVELOPING DESIGN CAPABILITY_ 206

8.2.1 ACQUISITION OF DESIGN ___ 206

8.2.2 ASSIMILATION OF DESIGN___ 211

8.2.3 MANAGEMENT'S ENGAGEMENT AND INVOLVEMENT ___ 219

8.2.4 EXPLOITATION OF DESIGN ___ _ 222

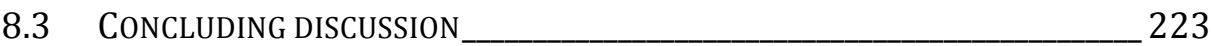

8.3.1 DIFFERENT APPROACHES ___ 223

8.3.2 THE SEQUENTIAL STRUCTURE OF THE ABSORPTIVE CAPACITY FRAMEWORK AND THE DEVELOPMENT OF DESIGN CAPABILITY THROUGHOUT AN ORGANIZATION

8.3.3 THE IMPLICATIONS ON DESIGN CAPABILITY DEVELOPMENT INITIATIVES_227

CHAPTER 9 CONTRIBUTIONS, LIMITATIONS AND SUGGESTIONS FOR FUTURE RESEARCH 231

9.1 CONTRIBUTIONS____ 231

9.2 LIMITATIONS AND SUGGESTIONS FOR FUTURE RESEARCH ___ 234

9.3 A REFLECTION ON THE QUALITY OF THE RESEARCH____ 236 
9.4 AFTERWORD

APPENDIX A LIST OF SOURCES FOR THE DESIGN CAPABILITY LITERATURE REVIEW 


\section{Chapter 1}

\section{Introduction}

The public sector faces challenges related to decreased resources while at the same time seeing an increased demand in, for example, the healthcare, as the demographic of our society continues to develop towards a reality where the aging population has outgrown that of a working age, (Ackerby, 2005; Lindström, Fogelin, Feuk, \& Eriksson, 2015). At the same time the expectations of the service users grow and in Sweden new legislations ensure an increased patient or user involvement and influence in healthcare and social services (Patientlag, SFS 2014:821, chapter 5).

These changes create a need within public sector organizations for alternative approaches to innovation and improvement than those currently available through the dominating figures of thought such as New Public Management (Hartley, 2005). There is a need to become more proactive in the development of services; to develop a better understanding of the users needs, priorities and conditions in order to spend the limited resources where they will contribute most value (e.g., Bason, 2010). Approaches to involve citizens, to work across silos and focus on value creation are gaining traction (Malmberg \& Wetter-Edman, 2016). Sangiorgi (2015) claim that the ongoing paradigm shift from New Public Management (NPM) to New Public Governance (NPG) "implies the emergence of a more cooperative form of relationship between government and citizens" (p.333). Citizens are in the NPG perspective seen as partners in the co-production of service (Sangiorgi, 2015). This perspective on the user of public sector services, is something that Bason (2010) also has argued must become better developed within public sector organizations. He has claimed that citizens or patients must be viewed as a resource in the development and improvement of public sector 
services and that the organizations must develop capability to engage users as partners (ibid.).

The demand for new ways to better understand the needs and priorities of the users has led to an increased interest in approaches and methods related to design (Bason, 2010; Bevan, Robert, Bate, Maher \& Wells, 2007). The introduction of design approaches and methods in public sector organizations are understood to successfully involve users and stakeholders and thus enhance the understanding of the users.

In Europe and elsewhere, there is an increasing interest in introduce design as part of public sector organizations' knowledge base. This interest has also led to several initiatives aimed at developing design capability within public sector organizations (see for example Swiatek, 2016; Lindström et al., 2015; Hillgren \& Szücs Johansson, 2015; Bason, 2010; Kimbell \& Macdonald, 2015; Bailey 2012). Initiatives of this sort are increasingly seen as a means to meet the public sector's challenges (e.g., Bason, 2010; Sangiorgi, 2015). Thomson and Koskinen (2012) argue for the development of the design capability of society as a whole in order to drive innovation and growth. They see design capability as a means to address and handle current and pending societal challenges. Here design capability is understood as an organization's ability to utilize design in their development and innovation practices (ibid.).

\subsection{The perception of design and design expertise}

According to Herbert Simon's definition, design is a process of developing a current situation into a preferred one (Simon, 1996). Most often when discussing design as a driver of innovation or as a means to address societal challenges, it is the human centered design perspective that is referred to. Human centered design is based on an approach that puts the user of the intended solution at the center of the development process and works in an iterative manner whereby the work diverges and converges to reach a solution (Giacomin, 2014) and achieve the preferred situation. This approach to design drives the problem framing and ideation based on the needs, desires, and conditions of the actors involved and affected by the situation. Design can thus be understood as an approach to development that brings with it methods and tools that ensure a user-centered and open mindset and attitude. In this work, when referring to design, this will be the understanding that is implied. 
Many of the challenges of the public sector are, according to Bason, (2010) and Sangiorgi (2015), of a complex nature and could thus be defined as wicked problems (Rittle, 1972; Buchanan, 1992). Cross (2004) has brought forward the ability to handle ill-defined problems as part of the design expertise, this could consequently be seen as another motivation to introduce design as a means to handle the challenges of the public sector, apart from the user-centered mindset.

However, this implies that design is understood and utilized in its full potential - where it is used to develop solutions and not just. as styling. Although design is increasingly seen as a means to drive value creation there are also challenges that have been recognized in relation to a limited understanding and thus integration and strategic use of design (Sangiorgi 2015).

Within the field of design management there has long been an interest to disseminate design and to develop the design capability, or the design maturity (Ramlau, 2004) as it also has been discussed, of design-novice organizations. However, that design is perceived as related to development of physical objects and styling by many with limited prior experience of design (European commission, 2010) is an issue. It is seen as a challenge to introduction of design, and development of design capability, within design-novice organizations (e.g., Acklin, 2011) and has been discussed and explored for along time (Cooper, Junginger, \& Lockwood, 2011).

Despite the longtime interest, what design capability or maturity actually implies is not fully clear when looking at the literature. Some scholars relate design capability to competence and activities used in relation to design (e.g., Bailey, 2012 ; Wormald \& Rvans,2009) whereas others focus on how design is perceived (e.g. Ramlau, 2004). This also implies different perspectives on how the organizations' abilities to exploit design is developed.

Junginger $(2009,2015)$ has raised the question of whether the abilities and expertise brought forward as related to design, and thus by many seen as part of design capability, are actually unique to design. She argues that when looking for evidence of design in an organization, in order to assess its design capability for example, it is often tools or activities packaged in a familiar manner for the design community that are sought after. Like customer journeys or co-design methods and when those are not found design is said to be missing in the organization (Junginger 2009) and voices are raised for a need to develop the organization's design capability. Junginger (2015) argues that many of these activities already exist albeit in the form of silent design (Gorb \& Dumas, 1987). This also resonates with Mulgan's (2014b) view that designers, in their desire to show that they 
contribute and create value, tend to reinvent the wheel without acknowledging the experiences and competence that are already present in the organization. He argues that designers too must be humble to what they need to learn and understand about the practice in which they enter (ibid.). This argument is supported by Bailey (2016) who claims that for design to actually contribute, the understanding of how it fits in with the current culture, conditions and routines must be developed.

The inconclusive discussion around how to increase the ability to exploit design, despite the longtime interest and discussions around, the topic suggests a need for further research in order to better understand what it is that should be developed and how to support this development.

\subsection{Motivation to transfer design knowledge and develop design capability}

The interest in transferring knowledge about design and its related approaches, methods and tools to develop design capability within design-novice organizations has not awoken with the interest from the public sector. Prior research and discussions about how to increase the awareness of design or develop the design capability of organizations has mainly related to private and commercial sectors. Most research on and efforts to transfer knowledge related to design has been focused on how to introduce design to small and medium enterprises (SMEs) (see e.g., Acklin, 2013a; Acklin, Cruickshank \& Evans, 2013; Ward, Runcie \& Morris, 2009; Whicher, Raulick-Murphy, \& Cawood, 2011). There are also research projects that focus on the success of policy efforts made to support the introduction of design to and the development of design capability in these kind of organizations, such as the DeEP project (Mortati, Villari \& Maffei, 2014).

The development of design capability within commercial actors, both small and large-scale enterprises, is often motivated through the description of design capability as a competitive advantage; something that is difficult for competitors to copy (De Mozota \& Kim, 2009). In the discussions about development of design capability in public sector organizations, this objective is, however, less pronounced.

Focusing on public-sector organizations, they are often accused of not being innovative at all (Mulgan, 2014a) despite the fact that there are many innovations developed within public sector (Mulgan 2014a; Bason, 2010; Hartley, 2005). However, both Mulgan (2014a) and Bason (2010) acknowledge and identify 
barriers within the public sector when it comes to development and innovation. For example, they point out the functional silo structure that is often still seen in public sector organizations as one such barrier (Mulgan, 2014a ; Bason, 2010). The result-focused culture is also brought forward as a potential barrier as it impedes idea generation and nurtures a fear of making mistakes (ibid.). One suggested reason to develop design capability within the public sector, is the potential support design capability could be in overcoming some of these barriers to development and innovation (McNabola et al., 2013; Bason, 2010). However, Bason (2010) have also pointed out that some of the barriers to development in general might also be barriers to the acceptance and introduction of design in the organizations. Other objectives to develop design capability are, as pointed out above, to develop ability to enhance the understanding of user needs and priorities or to involve users in the development.

Many initiatives aiming to introduce design and develop design capability within the public-sector context have followed the same approaches and setup that have been used in prior efforts made within the commercial sector when embedding design in SMEs (see e.g., Ward, Runcie \& Morris, 2009; Acklin, 2013a; Acklin et al., 2013; Whicher et al., 2011). The differing objectives, for commercial and public sector actors, to introduce design and develop design capability could, however, be expected to affect the development. Other characteristics that set the sectors apart, such as the competitive nature in the commercial sector or that public sector organizations are run by a political and a civil service management could also be expected to affect the motivation and how design capability is developed.

\subsection{Introduction of design in the public sector}

A possible explanation to the increased interest in design within the public sector could be found in the shift from NPM to NPG (Sangiorgi, 2015) and the parallel development of the service design field, since the foundation of service design, as co-creation of value, in many ways resonate with the new perspectives found in NPG.

The introduction of design in public sector settings has not, however, been without critique. Lack of continuity due to the use of consultants, high costs and not paying enough attention to the implementation of outcomes are some issues that have been raised (Blyth, Kimbell \& Haig, 2011; Mulgan, 2014b). These concerns suggest that only hiring or procuring design competence for individual 
projects will not ensure the ability to utilize design (Malmberg \& Wetter-Edman, 2016). Similar to Mulgan (2014b) and Blyth et al. (2011), Bailey (2012) has also noted issues in the implementation and maintenance of solutions when designnovice organizations work together with design agencies. He claims that organizations that have design capability are better equipped to maintain or take solutions developed and delivered by design agencies forward (ibid.).

McNabola et al. (2013) and Bason (2010) have suggested building design capability through the development of competence related to design among, for example, civil servants or healthcare personnel, and to make development and improvement work a natural and continuous part of their work alongside the core activities. This would address the issues of continuity cost brought forward by Blyth et al. (2011) and Mulgan (2014b). However, the concerns raised about the introduction of design in the public sector also indicate that mere introduction of design methods and tools will not suffice as design capability either (Malmberg \& Wetter-Edman, 2016).

Whether efforts that have been made to develop design capability has succeeded or if they too have become one-time projects is however still underexplored. In reports from prior efforts to transfer knowledge about design and develop design capability, little attention has been paid to how the transferred knowledge is maintained or sustained in the organization after the structure and support of the knowledge transfer initiative is gone (see e.g., Swiatek, 2016, Kimbell \& Macdonald, 2015; Lindström et al., 2015).

In relation to the trend of an increased interest in design and the growing number of initiatives taken to develop design capability within public sector organizations, there is a need to improve the understanding of how the ability to exploit design is developed in the public sector context. As discussed, most efforts to develop design capability made thus far has followed the same setup as efforts aimed at the commercial sector despite differing objectives and characteristics that are likely to affect the development. Little is also known about how the knowledge that is transferred through these efforts sustain after the initiatives have ended, suggesting a need to explore development of design capability also in the public sector context. However, the lack of consensus about what design capability implies and thus how it is developed in general suggests this too must be further explored. To explore what design capability implies in a public sector setting and how it is developed in this context will be the focus of this thesis. 


\subsection{Structure of the work and some definitions}

The knowledge presented in this thesis is developed around two cases from public healthcare and social services. The research reflects on what type of knowledge that has been transferred and developed through the approaches and set ups used in the two cases. Focusing on identifying aspects that has supported or hindered the development of design capability in each case, the research has aimed to develop an understanding of what must be addressed in the development of design capability.

In order to do this the design capability concept has first been studied through a literature review and a tentative understanding of the concept has been developed, which is then used throughout the study. In this work the development of design capability is understood as a matter of organizational learning (Levitt \& March, 1988) and the exploration of the introduction of design in the two cases will be approached from an organizational learning perspective. The focus is on how the organizations acquire and develop the new knowledge into a capability that contributes value to the organization. Specifically, this learning process will be studied through the lens of absorptive capacity (Cohen and Levinthal, 1990).

In this work design knowledge is understood as knowledge related to what design implies, how it contributes, its approach, tools and processes as well as attitude and mindset. When looking at the absorption of knowledge and development of design capability it will also, as mentioned above, be of interest to study what related or conflicting capabilities already exist in the organization in order to better understand the development of design capability.

The public sector is a wide field that offers services to citizens, patients, clients, taxpayers, customers, pupils, and users depending on the kind of public service that is referred to. For ease of presentation and discussion, in this work the term user and patient will be used consistently when referring to the actor to/for whom the service is delivered.

\subsection{Structure of the thesis}

This chapter is the general introduction, which positions the work that will be presented in the following chapters. In chapter 2, I will first describe the aim and purpose of the work and the methodology on which it has been based. This chapter also presents the inquiries that have guided the exploration. In chapter 3, the research design and method through which the study has been conducted is 


\section{Chapter 1}

presented, together with an initial presentation of the two cases and a contextualization of the work. Chapter 4 describes the theoretical framework, starting with a review of the design capability concept, the first of the two parts that make up the theoretical framework that has guided the analysis and discussion in this work. In this section, prior and parallel efforts made in relation to design capability within the public sector are also presented. This gives a background to the field in a public sector context and describes some of the characteristics and challenges in public sector organizations related to development of design capability. Chapter 4 then continues with the second section of the theoretical framework, which relates to organizational learning, the absorption of knowledge, and the development of capability. It ends with a synthesis of the theory on design capability and absorptive capacity creating a tentative understanding of the development of design capability in the public sector through an absorptive capacity perspective. In chapters 5 and 6, the narratives of the two cases are presented. This is followed by a presentation of the patterns identified in the analysis of the empirical material in chapter 7. Chapter 8 presents a discussion that relates the empirical findings to the theoretical framework. The chapter ends in a concluding discussion about the development of design capability and what to think about when initiating or planning efforts aimed at building design capability. Finally in chapter 9, the contributions are highlighted and discussed as well as limitations in the work and suggestions for future research, before a reflection on the quality of the research and an afterword. 


\section{Chapter 2}

\section{Purpose, aim and methodology of the work}

As with all work, a clear purpose and aim that can steer and guide the work is needed to produce a valuable result. In order for it to be manageable and achievable some delimitations also have to be made. Below these aspects are presented in relation to this work, leading up to the research.

\subsection{Purpose and aim of the work}

The purpose of this exploratory work is to develop an understanding of how design capability is developed within public sector healthcare and welfare organizations and to explain how design capability is developed within this context and how projects or initiatives can introduce design and support the development of design capability. It is inspired by concurrent discussions relating to the introduction of design and the development of design maturity (Ramlau, 2004) and capabilities in the field of design and design management (e.g., McNabola et al., 2013; Cooper et al., 2011; Bason, 2010; Mulgan, 2014a; Thomson \& Koskinen, 2012). The aim is to develop a richer understanding of how design capability can be introduced, accepted, and sustained in organizations within the context of public sector healthcare and social services. By understanding the aspects of design capability and how they are of interest and relevance to public sector healthcare and welfare, future efforts to develop design capability in this context can become more successful and decrease the risk of design becoming yet another tried but failed approach to development within the public sector. There are many people within the public sector who give witness to a parade of new ideas and approaches that 


\section{Chapter 2}

have just become passing fancies that have not been sustained, as exemplified in this quote

$\ldots$ and then it will stay on and hopefully not just become a passing fancy. Because there are many, I guess it's like that in many fields, but I feel that the social services are extremely sensitive to picking up new methods that are the latest thing. So, one has to be a bit critical towards the new things as well.

- Karin, development and research manager at Aland

Development Council.

\subsection{Inquiries guiding the research}

Being an exploratory work, the research has set out to understand what happens as design is introduced and design capability develops. Given the aim presented, the following inquiries have guided the search for understanding how to develop design capability that is sustainable.

\section{Inquiry 1: What is design capability?}

As mentioned in the introduction, the discussion around increasing the use of design in organizations to meet new and existing challenges focuses on several different aspects. Some focus on extending the perception of design among designnovice organizations and developing the awareness or maturity of how these organizations understand and use design (Ramlau, 2004; McNabola et al., 2013). Others argue for the development of design capability in relation to specific competences or activities (e.g., Wormald \& Evans, 2009; Beltagui, Pawar, \& Reidel, 2011; Topaloğlu \& Er, 2011) or view design capability as an understanding of how to exploit skills and methods related to design (e.g., Lin, 2014). In order to create an understanding of how to successfully develop design capability, what design capability implies must first be defined. This is, therefore, the first inquiry that guides the exploration. What is discussed as design capability in the literature and what abilities is it that public sector organizations are hoping to gain by adding design to their knowledge base?

Inquiry 2: What kind of knowledge and practice is transferred to the organizations through the setup and approaches in the studied initiatives? 
As a result of the increased interest in design in the public sector, many initiatives have been taken that aim to introduce design and develop the design capability of the organizations taking part in these initiatives. Are there certain knowledge aspects related to design capability that are in focus and how does the setup support the transfer of that knowledge? In order to understand how the development of design capability can become more successful, it will be of interest to understand both what kind of knowledge it is that the studied initiatives seek to transfer and how this transfer is facilitated.

Inquiry 3: What aspects are of importance to pay attention to and address when initiating efforts to develop design capability in public sector organizations?

Many initiatives to embed design or develop design capability within public sector have been based on the same principles as initiatives taken in relation to SMEs or other private and industry sector organizations. This has been done despite the objectives and characteristics of private and public sector are different in ways that are likely to affect both the motivation and way that design capability is developed. To be able to better structure efforts to develop design capability in the public sector it is therefore of interest to find out what aspects or characteristic that might be of importance to pay attention to when initiating efforts addressed to public sector organizations to better meet their motivations and conditions.

\subsection{Methodology}

The basis for the exploration described in this thesis is two cases. As empirical research with a focus on reflection, the work strives to create an understanding of the development of design capability rather than define a truth about it (Alvesson \& Sköldberg, 2008). Following an abductive approach, the knowledge has been developed as both the empirical and theoretical understanding evolved during the work (Alvesson \& Sköldberg, 2008). This evolution is a result of the meeting between the theory and the qualitative empirical data. According to Alvesson and Sköldberg (2008 p. 59), abduction is described from a hermeneutic perspective as a "... hermeneutic spiral: a interpretation of facts that we already have some prior understanding of."

The objective of this work is to develop an understanding of how design capability is developed within public sector organizations. This will entail creating an understanding of the actions taken as design is introduced to the organizations. 
How design is understood in terms of practice and expertise has been interpreted with an open mind in relation to both the informants' reflections and comments and the literature. According to Mantzavinos (2016, p.1), hermeneutics is a methodology that "offers a toolbox for efficiently treating problems of the interpretation of human actions", and is thus a suitable approach to develop an understanding of how design capability can be developed.

The epistemological view of the work is that the knowledge resides in the respondents and their articulations and that understanding is created through the interpretation of these articulations together with the interpretations of the theory. Applying a hermeneutic perspective as a researcher, I acknowledge that everything that is considered when developing an understanding, both empirical and theoretical, are interpretations, and that these interpretations are results of my preconceptions, prior knowledge, and agenda (Alvesson \& Sköldberg, 2008) and that $I$, as a researcher, in that manner affect the results. Because of this, there will be multiple possible interpretations some of which will be better than others (ibid.). The interpretations are formed through dialog with the material, where the material is listened to and given the possibility to argue for one interpretation or the other, not only within one source but also between sources (ibid.). In this way, knowledge and understanding are created as the interpretations are formed in a dialog that moves between the parts and the whole and between theory and empirical data in a spiral (Fig. 1). This leads to a final interpretation and understanding of the development of design capability in public sector organizations.

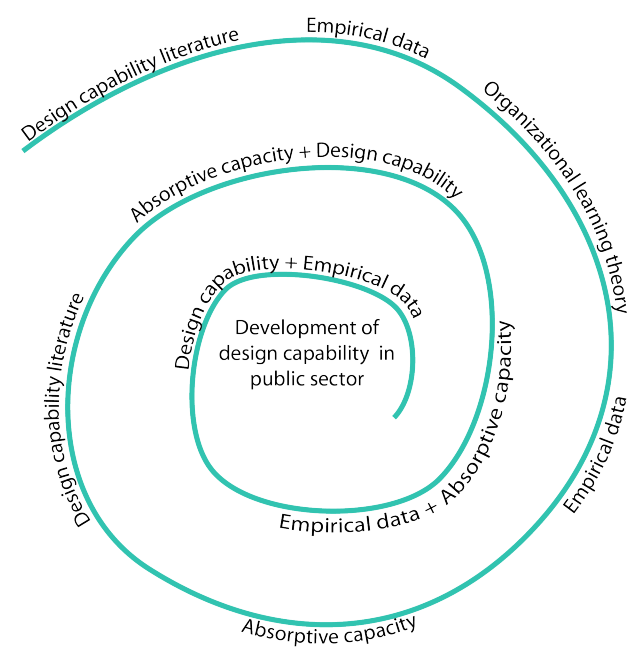

Figure 1. The theoretical and empirical material is interpreted through the hermeneutic spiral, creating an understanding for development of design capability in public sector. 


\section{Chapter 3}

\section{Research design and method}

As described in the methodology section, the inquiries guiding this work have been explored using a hermeneutic approach. Here, as a researcher I, held a reflective dialogue with both the theoretical and empirical material to develop an understanding about the development of design capability in the public sector. For the sake of readability, this chapter also provides an initial basic presentation of the two cases that have been followed in this study. The chapter starts off with a description of the setup of the study and a discussion of my role and position as a researcher in this setup. It then moves on to describe and discuss the selection of the two cases before describing the data collection process both in general and in relation to the two cases. After this, the approach and setup of the literature review on design capability (one of the two foundations of the theoretical framework) is described as well as how the analysis of the material, both theoretical and empirical was conducted. The chapter ends with a contextualization of the work and a discussion on some of the choices made related to the approach, before a short comment on validity.

\subsection{Approach and setup of the study and my pole and position as a researcher}

As mentioned above the purpose of this study was to find models that explain how design capability is developed within a public sector context and how projects or initiatives taken to introduce design and support the development of design capability. To achieve this, an exploratory approach, with observations made through interviews and project documentation from two different cases, was 


\section{Chapter 3}

chosen. A common approach among studies focusing on the introduction of design and development in, for example SMEs (see e.g., Acklin et al., 2013) is otherwise action research (Cohen, Manion, \& Morrison, 2007). However, there is currently little generic knowledge about design capability and how this is developed within the public sector. Generic knowledge is important to support future development, find effective models that support the development of design capability within this context, and to develop such generic knowledge the exploratory approach is suitable. The multiple case study approach (Yin, 2009) gives an opportunity for an in depth study of the different approaches made by the organizations to introduce design and the development of design capability through these efforts, and to develop a broad understanding that is transferable. In this study, I have followed two different initiatives and the organizations that have been involved in these. This has allowed the recognition of patterns and differences between the approaches and setups of the initiatives, thus creating a broader understanding of aspects related to design capability and its development.

By not intervening or taking an active part or in other ways intervening in the initiatives, it has been possible to follow their natural development and gain an understanding of what influences the development of design capability in an organization. As a researcher, I have thus not affected the motivation and opportunities within the cases. In both cases, the initiatives involve or to some extent are dependent on actors external to the public sector organizations, but the interactions and relations are based on the organization's initiative and conditions, not the external actor. Being a passive observer allows for changes in the projects to be documented and analyzed in an unbiased manner (in the sense that the actions taken have not been initiated or affected by the researcher). However, the researcher always affects the analysis as it is based on the researchers interpretations of the data (Alvesson \& Sköldberg, 2008). From a hermeneutic perspective, the interpretations are understood to be affected by, for example prior experiences and knowledge, agendas, expectations (ibid.) The interpretations are part of the hermeneutic circle, which moves from parts to wholes and back again. Taking a hermeneutic perspective, the data is also understood to be affected in the sense that the answers informants give in interviews also are based on their interpretations of the questions and expectations of the interviewer's interest (ibid.).

In addition to the two cases, the study is based on a theoretical framework developed through a synthesis of theory related to both organizational learning and to design capability. These two main theoretical foundations for the work and the synthesized framework are further presented in the chapter 4 . The illustration 
in Figure 2 shows how the understanding of design capability developed in the case studies evolved through a dialog between and interpretation of the different segments of theory and empirical data material.

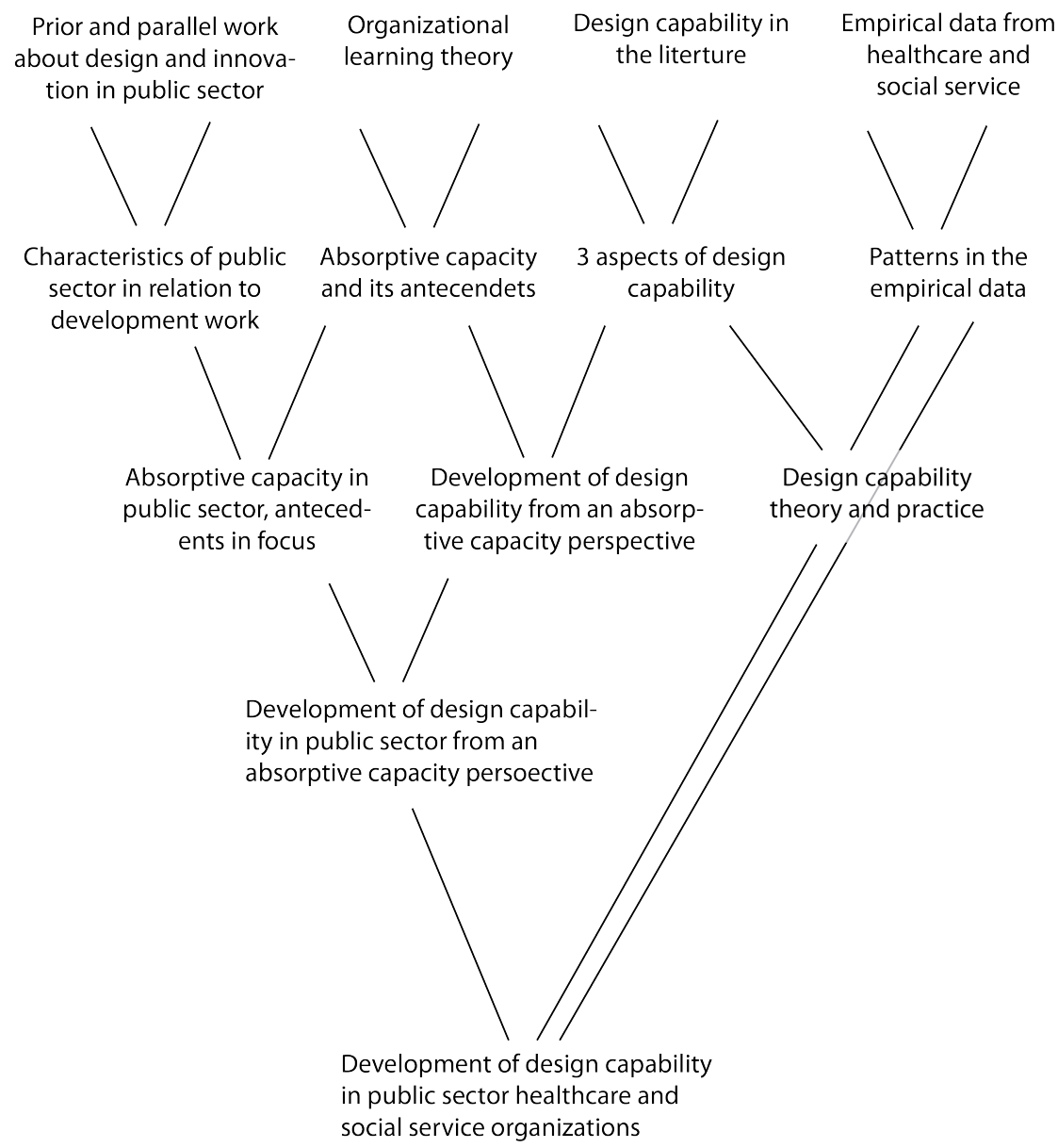

Figure 2. The understanding of development of design capability has evolved through the dialog and interpretation of the different segments of this work.

\subsection{Selection of cases}

The work presented in this thesis is based on the study of two cases Case A is The Social Service case and follows the introduction of design in the development work 


\section{Chapter 3}

of social services. Case B is the Health Lab case which follows the embedding of design in a county council healthcare organization through the establishment of an in-house design department. Both cases focus on the setup and approach of the two initiatives as well as the reactions in the organizations involved. This section discusses the selection of the two cases for this study and presents the characteristics of the organizations and initiatives on which the selection is founded

When the two initiatives were chosen as cases for the study in 2013, they could both be described as first movers. Both organizations behind the initiatives were among the first in the nation to note and explore the use of design in public sector development. In the years that have followed, several other initiatives involving design as part of operational development work have been taken. Both initiatives taken directly within municipalities and county councils (although not always articulated as design driven) and initiatives taken by organizations promoting design or supporting public sector research and development. The two organizations that initiated the ventures that are studied in this work were, however, among the first to take this step.

Another characteristic that informed the choice of cases was the fact that the initiatives taken came from the organizations themselves. They were not based on demand from external actors such as policy organizations, academia or invitations to be part of policy or academic projects as in many other early initiatives. This meant that the organizations had some intrinsic motivation to introduce design to their organizations. Although the initiatives in both cases were funded through grants that they had applied for, the organizations themselves planned and executed the projects without direction or intervention from external stakeholders.

A further motivation in the choice of cases was that neither used a predefined approach or model promoted by an external actor such as the innovation guide (Innovationsguiden n.d.) promoted by the Swedish Association of Local Authorities and Regions (SKL), IDEO's design kit (IDEO n.d.), or the introduction of experience based design (EBD) in the British National Health Service, NHS (Carr, Sangiorgi, Büscher, Junginger, \& Cooper, 2011; Bate \& Robert, 2006). In both cases the approaches to introducing and using design were developed in collaboration between the project managers and their respective design resources in the initiatives. This mean that the organizations have had an opportunity to tailor how design is introduced in relation to the objectives, needs, and priorities of the respective organizations. 
Although they have much in common, the two initiatives followed also have big differences in their setup, approach, and conditions (see Table 1 for a brief presentation of the two cases). The background knowledge about design among the people driving the initiatives is one aspect that differs in the cases. In the Social Service case (A), no one in the development council that is leading the project had prior experience of working with or in relation to design. Conversely, in the Health Lab case $(\mathrm{B})$, the people driving the initiative had extensive experience of working with and in relation to design. The scope of the cases is another differentiating factor. The Health Lab initiative was a three-year venture that entailed several different projects and involved different actors across the county council organization. The Social Service case was a much smaller initiative in scale, entailing one project running over only six months. In the Health Lab case the knowledge transfer and the development of internal awareness and competence in design was an articulated objective. In the Social Service case the main objective was to introduce design and test its potential as a means for development in the social service context.

The differing aspects and characteristics of the cases make them interesting to study together as they represent different approaches to introducing design as a mean for development work within public organizations.

In the presentations of the cases in chapter 5 and 6 a more detailed description of the aims, approaches and conditions in each case is given as well as a report of how the initiatives developed. 
Chapter 3

Table 1. A brief introduction of the cases.

\begin{tabular}{|c|c|c|}
\hline Case & A: The Social Service case & B: The Health Lab case \\
\hline Initiator & $\begin{array}{l}\text { Regional development council, the } \\
\text { head of research and development } \\
\text { and a project manager }\end{array}$ & $\begin{array}{l}\text { County council, Head of } \\
\text { Health Lab and partners in } \\
\text { funding application }\end{array}$ \\
\hline Design experience & $\begin{array}{l}\text { All participants in the project, } \\
\text { including the initiators are design- } \\
\text { novices }\end{array}$ & $\begin{array}{l}\text { The organization and its } \\
\text { personnel are design-novices } \\
\text { apart from the head of Health } \\
\text { Lab and the in-house } \\
\text { designers }\end{array}$ \\
\hline Design competence & Procured & In-house and procured \\
\hline Number of projects & One & Multiple projects \\
\hline $\begin{array}{l}\text { Involved } \\
\text { organizations }\end{array}$ & $\begin{array}{l}\text { Regional development council and } \\
\text { three member municipalities }\end{array}$ & County council \\
\hline $\begin{array}{l}\text { Participants in the } \\
\text { projects }\end{array}$ & $\begin{array}{l}\text { One pilot municipality represented } \\
\text { by one manager and frontline staff } \\
\text { Two observing municipalities } \\
\text { represented by two frontline staff } \\
\text { per municipality }\end{array}$ & $\begin{array}{l}\text { Various healthcare personnel } \\
\text { and civil servants. From six to } \\
\text { thirty per project }\end{array}$ \\
\hline
\end{tabular}




\subsection{Data collection}

The empirical material was mainly collected through semi-structured interviews in both cases. In total 22, interviews with 20 informants were conducted over a total of three years (see Figures 3 and 4 for timeline illustrations of the data collection in the two cases). The interviews have been recorded and lasted between 40 minutes to two-and-a-half hours. All interviews were conducted in situ apart from two in case A that were conducted via Skype and one in case B that was done over the phone (see Table 2 for a detailed listing of the empirical material collected). In case A, project diaries were also collected during the project time from two key informants (this is further described in the section below detailing the data collection from case A). The official project reports were also collected from the Social Service case project and one of the Health Lab case projects.

For both cases, the initiators of the initiatives were first approached and interviewed in relation to the background to the initiatives, the setup, purpose, and the objectives of the organizations' initiatives. Based on these interviews, the managers were then asked to connect the researcher with participants from projects within the initiatives. In case $B$, which had several projects within the initiative, the head of operations decided which projects to follow in agreement with the researcher, the care coordination process project and the design training project.

The initial interviews with the initiators were conducted at the same time in the study. For the remainder of the interviews and other types of data collection, the focus was first set on the Social Service case. This allowed for some modifications to the focus of the inquiries made when talking to the informants in the Health Lab case. These modifications were the result of the empirical material showing which questions were of interest to ask as part of a hermeneutic dialog with the material (Alvesson \& Sköldberg, 2008). The initial interpretations of the empirical material articulated which inquiries to pursue as the study continued with the Health Lab case.

In all projects, informants with the role of participants - frontline staff for example - were sampled by contacts in the observed organizations.

In case $\mathrm{B}$, all projects were followed retrospectively. This affected the kind of data that it was possible to collect, as well as the potential influence of memory on the reports given. However, as the projects had ended 4-6 months prior to the 


\section{Chapter 3}

interviews, there was an opportunity to learn what had happened with both design results and the knowledge developed through the projects.

Table 2. Collected data.

\begin{tabular}{|c|c|c|}
\hline Data corpus & Case A: The Social Service case & $\begin{array}{l}\text { Case B: The Health Lab } \\
\text { case }\end{array}$ \\
\hline $\begin{array}{l}\text { Interviews } \\
\text { (number of } \\
\text { interviews) }\end{array}$ & $\begin{array}{l}1 \text { with project manager and } \\
\text { development manager } \\
1 \text { with project manager (Skype) } \\
2 \text { with designer (of which the second } \\
\text { was via Skype) } \\
1 \text { with municipality manager } \\
2 \text { with municipality staff }\end{array}$ & $\begin{array}{l}2 \text { with head of operations } \\
3 \text { with project manager (of which } \\
\text { the final was via phone) } \\
2 \text { with designers care } \\
\text { coordination process project } \\
1 \text { with designer design training } \\
\text { project } \\
3 \text { with participants care } \\
\text { coordination project } \\
4 \text { with participants design } \\
\text { training project }\end{array}$ \\
\hline $\begin{array}{l}\text { Project dairies } \\
\text { (number of } \\
\text { entries) }\end{array}$ & $\begin{array}{l}12 \text { from the project manager } \\
7 \text { from the designer }\end{array}$ & Was not used \\
\hline Project reports & The pilot project & The care coordination project \\
\hline
\end{tabular}

\subsubsection{Data collection case A: The Social Service case}

In the Social Service case, the initial interview about what had led to the initiative to introduce design and the aim and setup of the initiative was conducted with the head of the research and development unit at the regional development council together with the project manager for the initiative. Together, they were the initiators of the project. This was followed by an interview with the procured design competence, focusing on the same topics to create an understanding of the project from the designer's perspective. The interview with the initiators also touched upon how results from the project would be taken forward. Both these 
interviews were conducted about three months into the project, which was almost six months long.

As a complement to the interviews, the project manager and the designer were both asked to individually send a description (project diary) by email of what had happened in the project since the previous description and reflect upon the development of the project and the experiences of the project group. To remind the informants about this, emails were sent to them bi-weekly with open questions about the project. The project diary approach was taken to get an understanding of the ongoing work and progress of the project.

Through the project manager, two interviews were set up with representatives from the participating municipalities. One was with a manager and a frontline employee from the pilot municipality and one was with a frontline employee from one of the observing municipalities. These interviews focused on prior experience with design and expectations of the design approach and the project. It also addressed which actors from the municipality took part and how participants in the project had been selected. The experiences of the project thus far and reflections about the future were also discussed and the potential future use of design or the implementation of the design results. These interviews were conducted about half-way through the project.

About one month before the project ended, a follow up interview was conducted with the designer. This interview addressed experiences throughout the project, the involvement of the personnel from the municipalities, and their influence on the project and project setup. Shortly after the project ended, a follow up interview was also conducted with the project manager. This interview focused generally on the experiences of the project, how it had been presented and legitimized in the municipalities, how the aims of the project had been met, reflections about the future, and what would happen now that the project had finished. Both follow up interviews were conducted via Skype.

Contact was maintained with the project manager over a period of about six months after the project ended. This was done to gain insight into what happened after the project with regards to implementation of the design results and diffusion of the knowledge developed through the project. The primarily purpose was to find out what happened to the knowledge of working with design that was developed throughout the project. The project manager continued to send project diaries, although now on an irregular basis, and answered follow up questions by email. Email conversations were collected and documented together with the 


\section{Chapter 3}

project dairies for the analysis. Figure 3 illustrates when the data was collected in relation to the project.

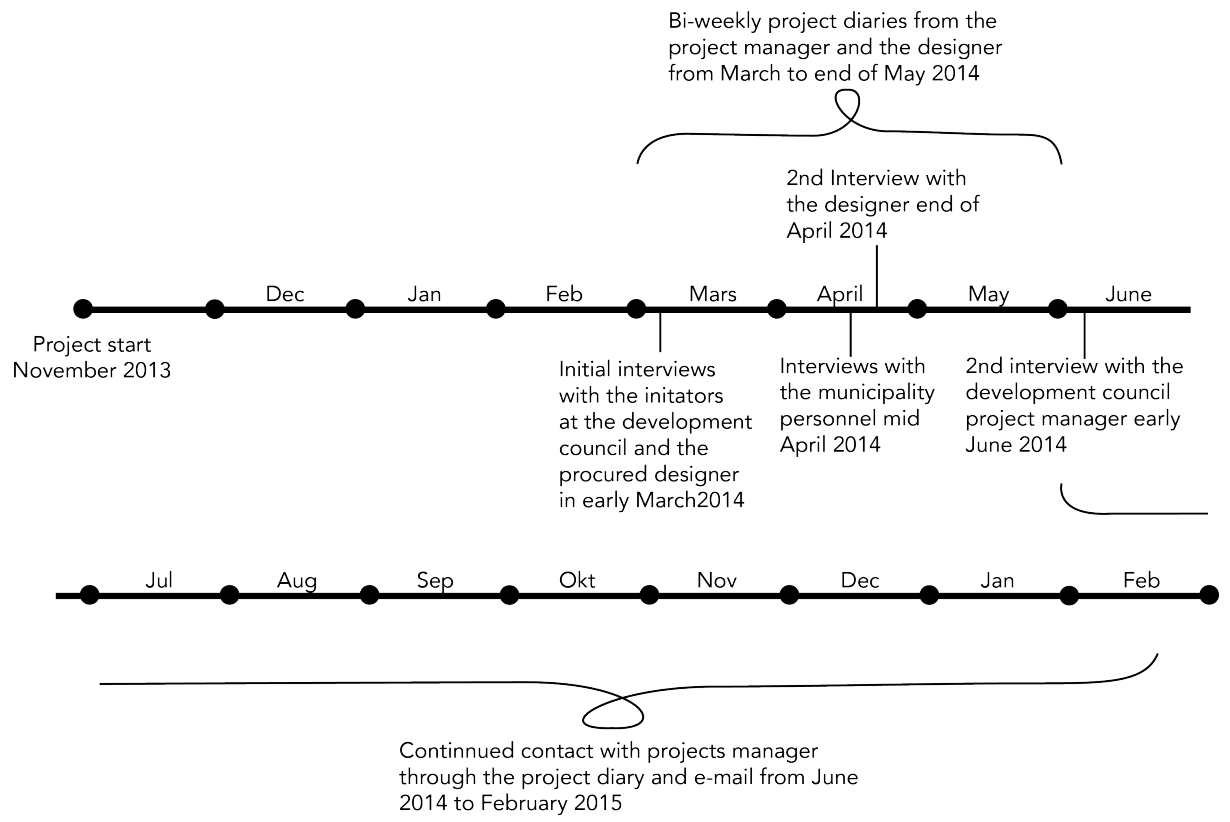

Figure 3. Timeline over the data collection in the Social Service case.

\subsubsection{Data collection case B: The Health Lab case}

In the Health Lab case, initial contact was made with the head of operations of the newly established in-house design resource in the healthcare organization of Beland county council.

An initial interview was held, focusing on what led to the initiative to start an in-house design department, the organization, and the aims and expectations of the initiative. It also addressed which actors were involved, funding, the organization, and the setup of projects carried out within the initiative. At the time of this interview, the design department was new and had not conducted more than a few projects. In agreement between the researcher and the head of operations of the Health Lab (the in-house design department), contact was made with one of the county council's development leaders, who had project managed one of the first projects that the Health Lab was involved in and who was now working as a project manager with the Health Lab. This project aimed to map out 
the patient journey cross-silos and primarily to identify pain points, but also ending with suggestions for potential solutions. This project (project 1) was conducted in parallel with the formation of the in-house design department.

On request from the researcher, the project leader helped set up interviews between himself and the three participants from the project as well as the project owner. Due to changes in the organization, the person who initiated the project now had a new position; thus, this interview was conducted with both the initial and the current persons responsible for the issues addressed in the project. All other interviews were conducted individually with the participants. All interviews were conducted retrospectively (although in situ) as the project had ended about eight months earlier. Two interviews were also conducted with the two in-house designers who facilitated the project.

The interviews with the project leader and the project owner focused on the background to the project and the aims and expectations of using a design driven approach. They also touched upon the results and what had happened after the project. Areas of development in the organization or the design approach for it to be used further by the organization were also addressed. The interview with the project leader also went into the setup and planning of the project. The interviews with the designers focused solely on the setup and facilitation of the project.

The interviews with the participants addressed their experiences in the project as well as their initial thoughts and expectations of the setup. They also discussed if and how the organization or something in the design approach needed to be developed for design to remain and contribute as an approach in the organization.

Through the relationship built up with the project leader during this study, the researcher got to know about another project (project 2) that had ended a few months earlier. This project focused specifically on the transfer of service design knowledge and practice to healthcare personnel. With the help of the project leader from project 1 - who had also participated in the design training projectfour interviews were set up with healthcare personnel who had participated. One was also the initiator of the project together with the in-house design department. The interviews covered the aim and purpose of the project, the expectations of the project, and its setup. This addressed how both design results and the knowledge developed would be handled after the project and also covered areas of improvement in order to continue working with design in the organization. In addition to the participant interviews, two interviews were conducted with representatives from the in-house design department, the head of operations for Health Lab, and the project leader. The project leader took part in this project as 


\section{Chapter 3}

a participant to also learn design methods and tools, as he had no previous design experience. These interviews had the same focus as the participant interviews with the addition of how the project had been planned. In total, seven interviews were conducted around this project. A final interview was conducted with a designer from the design agency, which the project had been set up in collaboration with. The design agency ran and facilitated the design training. This interview focused on the same things as the interviews with the design department representatives, but did not cover the topic of what had or would happen with the results after the project ended.

To capture potential insights within the in-house design department and the diffusion of knowledge from the projects studied in the organization, a follow up interview was conducted with the project leader. This interview was held about one year after the interviews about the design-training project, when the design department had been running for circa two-and-a-half years. The interview focused on his reflections on the integration of design in development work based on experiences from several different projects that the design department had been part of since they started. The connection between projects, the implementation of the results, and the maintaining and diffusion of knowledge that had been developed through the projects.

In addition to the interviews, the researcher had intermittent contact with the head of operations of the Health Lab, the project manager, and other members of the in-house design team since the in-house design department was established. The researcher also took part in teambuilding workshops arranged by and for the design team. These contacts contributed to the overall interpretation of the events and actions that took place in relation to the initiative, but they did not form part of the active analysis. Figure 4 illustrates when the data that went into the data set was collected in relation to the initiative. 

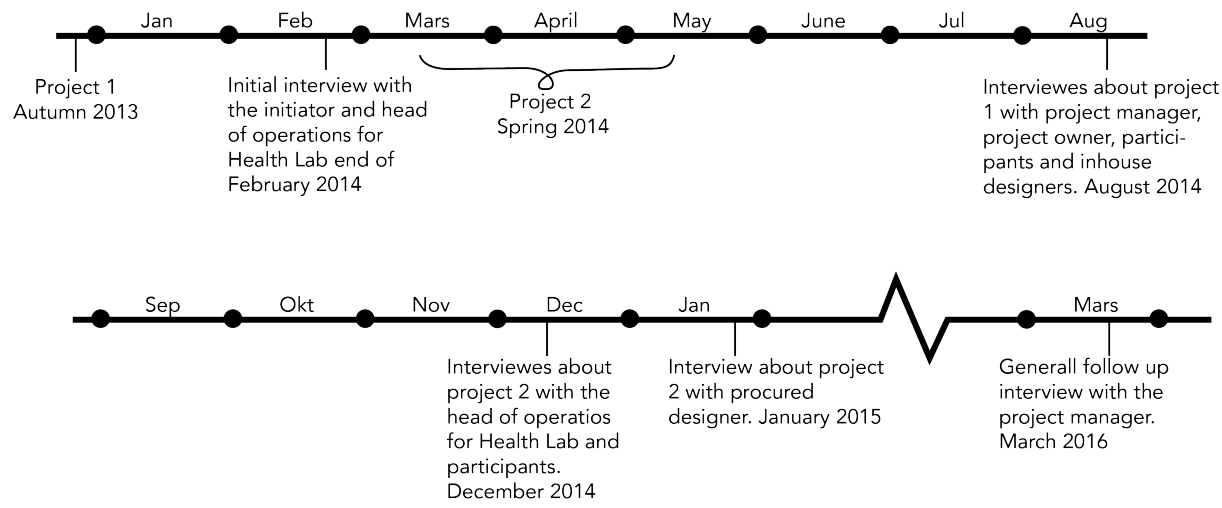

Figure 4. Timeline over the data collection in the Health Lab case.

\subsection{Literature review}

To be able to develop an understanding of the development of design capability within the public sector, it has been crucial to first get an understanding of how design capability is described and discussed in the literature. This helps identify what to look for and what to look at when observing the actions and development in the two cases. As there is no agreement on the definition of design capability in the literature this understanding had to be developed through a review of the usage of the term in the literature. For this purpose, a literature review was made based on articles from the main design and design management journals as well as reports and other documentation such as the webpages of actors active in the discussion about design and the increased use of design (see appendix A). In each journal, a search was made for "design cap*." Adding a wildcard to the search term in this way returned results on design capability, capacity, and capabilities. The decision to include articles discussing or using adjacent terms was based on the diverse and interchanging use of the terms in discussions about the development of the use of design by design-novice organizations. The search returned a total of 123 articles containing at least one mention of design capability, capacity, or capabilities. The articles were skimmed through to get an idea of their relevance. Articles that only mentioned design capability, capacity, or capabilities in the passing without articulating what was implied by it or that used it with a clear relation to something specific were put aside at this stage. Texts using design capability in this manner were, however, still documented under the label reified 


\section{Chapter 3}

use. By sorting the remaining articles into an affinity diagram based on which design capability, capacity, or capabilities were defined or described, patterns of use of the terms were created. Additionally, articles that did not give an articulated description of design capability, capacity, or capabilities, but put these terms in clear relation to something were included in the diagram. Design capability were identified as the term most commonly used and best suited for the concept given the aspects that were discussed in the literature. After this articles discussing capabilities or capacity were only included if the term was used in a manner consistent with the use of design capability in other articles.

The affinity diagram revealed three distinct clusters of aspects discussed in relation to design capability and increasing the use of design in design-novice organizations. At this stage, no distinction was made in relation to the context that the articles were focusing on - for example, if they were positioned in relation to private or public sector, technology or service industry, design management, or design execution. These factors were acknowledged when looking more closely at the three clusters, but were not deemed to influence the clusters to a significant degree. For example, none of the clusters were identified in relation to just one specific context. The results of the analysis and the decision to use the term design capability for the concept will be presented and further discussed in chapter 5. Here, the concept design capability is presented and discussed as part of the theoretical framework for the study.

\subsection{Analysis}

As with the work in general, the analysis of the two cases and the theoretical material about both design capability and organizational learning followed a hermeneutic approach and the understanding was developed through abductive reasoning (Alvesson \& Sköldberg, 2008). To interpret and understand the material, the analysis moved between theory and empirical data to identify patterns (ibid.).

The complete analysis for the work was made in several different stages, focusing on the parts separately and in dialog with each other. The main theoretical foundations for the work, design capability, and organizational learning were first analyzed separately. This work was done in relation to and in parallel with the collection of the empirical data. Therefore, these analyses have, to some extent, been affected by the initial observations and insights from the empirical material. Using a hermeneutic vocabulary, it could be expressed that the insights from the initial observations, as part of the preconceptions, have influenced the 
interpretations of the theory thus affecting the understanding developed of the theory (Alvesson \& Sköldberg, 2008). The empirical cases are examples of the contextual whole, which the part (e.g., the organizational learning) needs to be understood in relation to (ibid.). The empirical material highlighted and at times supported certain aspects of the theoretical material, influencing the interpretations and helping to identify what is important. This has especially been the case in the analysis and development of understandings of the design capability concept. The empirical material resonated with certain perspectives and aspects brought up in the literature, giving these aspects extra substance. Prior theoretical knowledge about the specific context of the public sector played an important role in the interpretations of both organizational learning and design capability.

In the same way, the two theoretical foundations also affected the interpretation of one another, as they became part of the prior understanding that influenced the respective interpretations. The results of the interpretations of the two theoretical foundations - design capability and organizational learning - are found in chapter 4.1 and 4.2. These interpretations have then been put into dialog with each other and created a synthesis and a tentative model of how design capability develops in the public sector (see chapter 4.3). Figure 2 illustrates the hermeneutic spiral through which the analyses were conducted and the understanding developed.

As with the theoretical material, the empirical material was also initially considered separately, although with a prior understanding of the theory influencing the interpretations of what is happening, why, and how. The analysis of the empirical material is, to some extent, an ongoing endeavor from the moment one begins collecting the material as seeing or hearing things will spark connections to prior knowledge or understandings, which will influence the remainder of the observations. However, as a foundation for the structured analysis of the empirical material, a method inspired by thematic analysis (Braun \& Clark, 2006) was used. The material went through five different steps during the analysis, starting with (1) familiarization with the transcribed material, during which (2) initial patterns become apparent. The material was read several more times while (3) searching for aspects related to the identified patterns. In their process, Braun and Clarke (2006) describe review and elaboration-during which the identified themes are also named - as two separate steps. However, in this work (4) the review and elaboration of the themes occurred simultaneously. The final step of the analysis was (5) to write up the results, which are presented in chapter 7 . 


\section{Chapter 3}

The main objects of analysis were the projects conducted within the initiatives rather than the initiatives as a whole. In case A, there was only one project, whereas in case B there were several projects over the period of the observations and of these two have been studied. The decision to focus on the projects rather than the initiatives as a whole was made because the projects, although having similar approaches, all had somewhat different setups. The knowledge transfer was also understood as taking place as part of the projects; this was an assumption that was made. The different setups in the projects could imply different results relating to the absorption of design knowledge and the development of design capability. However, the foundation of the projects lay in the foundation of the broader initiatives which meant that the whole cannot be discarded when interpreting and building an understanding of how design capability is developed and what influences this development.

For the analysis of the empirical material, the data corpus for both cases entailed interviews with several different actors and roles as well as project reports and project dairies (see Table 2). The analyzed data sets were interviews with the initiators, participants in the studied projects, managers, and designers (transcribed by the author), as well as project dairies and project reports.

In the final part of the analysis the tentative model developed from the analysis of the theoretical framework has been connected to the empirical material. Here the empirical material and the model were put into a into dialogue with obe another through the identified themes and the theoretical model. The themes from the empirical material were thus understood in light of the theory, and the tentative theoretical model was sharpened by insights from the observations. The result of this is presented in chapter 8 . Here, no formal method was used, but rather the hermeneutic perspective, making the material ask and answer questions (Alvesson \& Sköldberg, 2008).

\subsection{A contextualization of the work and a discussion of the chosen research approach}

This work focus on the development of design capability within public sector organizations rather than organizations at large. As pointed out in the introduction, the incentives and prerequisites for public sector organizations differ from those of SMEs, large enterprises, or non-governmental organizations. However, the public sector is also a large sector spanning different levels of organization such as governmental, regional, and municipal. The objectives and 
conditions for the taxations office, which serves every citizen within a country regardless of whether they want to be a customer or not, and a healthcare center or nursing home are fundamentally different. Even though these are all public sector organizations, their motivations and ways of utilizing design may therefore differ, implying different incentives and conditions for the development of design capability.

This research has focused on the development of design capability within healthcare and social services; practices that work directly with people and are significantly affected the changing demands and expectations related to the services they provide. On a holistic level this means developing design capability within regional and municipal organizations. The work has, however, focused on the parts of these organizations working specifically with healthcare or social services, as that is where the initiatives took place.

As the set up of the work was exploratory and based on observations through interviews and project dairies, the research has followed the natural development of design capability within the organizations without intervening. This also means that the diffusion of design knowledge and capability within the organization has been observed from the starting point in the respective organizations.

The decision to focus on healthcare and social services was made because these types of practices were among the first within the public sector to show interest in design and its approaches and methods. An example is the British National Health Service's (NHS) Institute for Innovation and Improvement, working with experience-based design (Carr, Sangiorgi, Büscher, Junginger, \& Cooper, 2011; Bate \& Robert, 2006); the Mayo clinic in the US (Duncan \& Breslin, 2009) or Service Innovation Lab Kent (Social Innovation Lab Kent, n.d.) for an example from social services.

In the work, I have chosen to keep an open mind towards the practices and expertise related to design (see e.g., Dorst, 2015; Schön, 1993) as well as the practices and expertise already present in the organizations. In accordance with the exploratory nature of the work I have looked at the what practices and expertise from design that are brought forward in the setup and approach of the initiatives taken by the organizations to introduce design. I observed how these and existing practices meet and are assimilated, acknowledging that some design related practices might already exist as capabilities in the organization. Thus developing design capability does not necessarily imply adding new capabilities unique to design to existing practices and capabilities in the organization; this may also arise though a shift in the way in which existing capabilities are used. 


\section{Chapter 3}

Another important characteristic of the two cases is that the projects studied in the two cases were all early attempts to introduce design. The study will not, in other words, be able to say anything about how the uptake of design and the development of design capability were sustained in the organizations over time. However, it will be possible to describe how the initial efforts and approaches looked and worked and the extent to which the projects succeeded in transferring design knowledge. The results of the study will be relevant to other new initiatives taken to develop design capability within an organization and are seen as relevant in relation to current discussions in the fields of design management and service design that focus on the development of design capability and the use of design in public sector organizations.

As mentioned many studies on the development of new capabilities use an action or intervention research approach. This because the development of new capability implies some sort of change for the organization, which is one of two central aspects in action research ${ }^{1}$ (Cohen, Manion, \& Morrison, 2007). However, an action research setup creates a dependency between the studied object and the researcher. This is, to some extent an artificial situation that risks creating or missing issues that would or would not occur had the organization self-organized the initiative. As the objective of this study was to develop a generic understanding of the development of design capability, one of the reasons for selecting the two cases was their independence in relation to set agendas about design capability.

The action research approach would have been more suitable had the aim been to develop an approach to introduce design and develop design capability. Given that the aim for this study is to understand what is happening rather than to drive any development, the passive position as an observer was more appropriate. Action research can be sensitive to changes in conditions such as motivation, resources, or loss of key actors since it requires a stable relationship between the researcher and the observed organization as well as a mutual commitment to see the project through.

The focus on the organizations and their perspective is another characteristic of this work. Other studies have taken the perspective of the designers or design to show how and what design can contribute (e.g., Ward et al., 2009; Bailey, 2012). As this work seeks to develop an understanding of how the organization can develop design capability, it consequently looks at the introduction of design from the organization's perspective. Therefore, most interviews were conducted with

\footnotetext{
${ }^{1}$ Change and understanding of that change are two central aspects in action research (Cohen, Manion, \& Morrison, 2007).
} 
healthcare and social service employees in the organizations. The interviews with designers, both in-house and procured were mainly conducted to give a contextual understanding about the setup or facilitation of the projects.

The perspective taken in the observation of knowledge absorption also connects to a delimitation caused by the choice of theoretical framework. The absorptive capacity focus mainly on the receiver end of knowledge transfer - the capability of the absorbing organization. It does not take into consideration the influence that the sender of the new knowledge might have on the way in which the knowledge can be absorbed by the receiver (Abecassis-Moedas \& MahmoudJouini, 2008). In these studied cases the designers are senders whether they are inhouse or procured resources.

\subsection{Validation}

Creswell (2014) recommends using multiple means of validateing the findings of a study to assure the researchers ability to assess their accuracy and to enable the reader assess the results. The approaches used to ensure the validity of the findings that are presented and discussed in this work are presented below.

\subsubsection{Multiple sources}

In hermeneutics, it is important that research objects are interpreted in relation to their context (Alvesson \& Sköldberg, 2008). In this work much of the theoretical material is based on findings and discussions framed within a private and industrial context rather than that of the public sector and services within healthcare and welfare. The knowledge from private and industrial contexts, both regarding organizational learning and design capability, is related to a public sector context throughout the work, and the interpretations made have been supported by other studies that have previously studied design capability or absorptive capacity from a public sector perspective such as Lin (2014), Body (2008), and Richards and Duxbury (2014). In this way, the theoretical material and the interpretations made from it has been validated through the comparisons with other texts within the same domain, as suggested by Hirsch (1967).

Hirsch suggests that the interpretations of a text should initially be validated by other texts from the same author and then by texts from of the same style, culture, and era (Alvesson \& Sköldberg, 2008). In this work, with regards to the empirical 


\section{Chapter 3}

material, this has involved finding support for interpretations first within other reflections or comments from the same informants and second within comments from other informants related to the same project or event. To find support for the transferability of the interpretation to other organizations or similar situations, interpretations based on data from one of the cases was also reviewed in relation to the other case and to the interpretations of the theory.

\subsubsection{Member checking}

The interpretations of the empirical material were also validated through member checking (Creswell, 2014). The initial interpretation of what happened in the projects and how and why was shared and discussed with key informants in both cases. This was done both as part of the later interviews and through direct discussions with the project manager in case A and with the with the project manager and the head of operations for Health Lab in case B.

\subsubsection{Thick descriptions}

To maintain transparency around the interpretations presented and to give the reader an opportunity to make his or her own interpretations, I have chosen to work with a thick description of the cases (Creswell, 2014.), leaving room for other perspectives and interpretations to be taken. 


\section{Chapter 4}

\section{Theoretical framework: building design capability}

The development of design capability within a design-novice organization is essentially a matter of organizational learning - a process where knowledge that is new to the organization, in this case design, is absorbed and developed into a capability (Levitt \& March, 1988).

This chapter first takes a closer look at the concept of design capability and its implications, and the kind of knowledge that organizations should thus learn in order to advance there ability to utilize design. It then moves on to present absorptive capacity (Cohen \& Levinthal, 1990), an organizational learning construct. The absorptive capacity construct will support and guide the analysis of how design capability is developed within the public sector. The chapter ends with a synthesis of the two theoretical foundations, design capability, and absorptive capacity, which forms a tentative model of how design capability is developed within the public sector.

\subsection{Design capability}

The concept of design capability is eclectic. A review of the literature related to design and management that discuses or is related to design capability shows that the concept is used in relation to many different aspects of an organization's ability to utilize design.

Design capability is, for example, used in relation to design expertise - the knowledge and skills of a designer (e.g., Rae, 2015; Wormald \& Evans, 2009; Beltagui, Pawar, \& Reidel, 2011; Topaloğlu \& Er, 2011)-or in relation to 


\section{Chapter 4}

discussions about design maturity or awareness of design in the organization (e.g., Ramlau, 2004; Moultrie, Clarkson, \& Probert, 2007). It can also be found in relation to design management (e.g., Acklin, 2013b; Koostra, 2009; Hesselmann \& Walters, 2013; Wrigley \& Bucolo, 2012). In many articles or texts the term is, however, also used in a reified manner. The authors refer to design capability, but neither define nor describe what they mean by it or what exactly it is that they are referring (see e.g., Walton, 2004; Best, Wolf, \& van Wijk, 2012)).

The fact that design capability is referred to without a clear description or definition would not be an issue if there was a generally agreed definition of the concept. In the absence of such a definition, there is a lack of consistency in the discussions around design capability and related terms such as design competence, skill, capabilities, or capacity (Acklin, 2013b). Mortati et al. (2014) argues that there is a need for empirical studies of design capability and the development of an agreed definition of the concept.

In addition to the inconsistency in how design capability is used or what it is related to, there is an inconsistency in what terms are used in relation to the aspects most often referred to as design capability. In order to get a full view, I have held an open mind and in the literature review initially also included adjacent terms such as design capacity and design capabilities (for a description of how the literature review was conducted see chapter 3). The terms are often treated as synonymous, but there are also instances of opposite uses, as in the work of Storvang, Jensen, Christensen, and Storgaard (2014) and Hesselmann and Walters (2013). Storvang et al. (2014), developed a framework to assess and discuss an organization's ability to take in and use design in its innovation activities. They call this ability an organization's design capacity. The aspects discussed as influencing the organization's design capacity in Storvang et al.'s framework are consistent with aspects other authors have described as design capability and to this point the inconsistent use is not overly problematic. However, Storvang et al. (2014) also refer to design capability as one of five dimensions in their framework. The design capability dimension relates to employed or procured designers (ibid) - in other words, the amount of design competence recourse that are available to the organization. This relation between design capacity and capability is in direct contrast to the description of design capability based on Koostra's (2009) design management staircase) presented by Hesselmann and Walters (2013). They also make a distinction between the two terms but describe design capacity as a quantitative measure of the human resources with design competence in an organization. Listing five factors, one related to each step in Koostra's staircase 
model: 1. Factor Awareness: degree of awareness of benefits. 2. Factor Planning: whether design plans and objectives are developed. 3.Factor Resources: people (design staff), funding (budgets) and means of production (facilities). 4. Factor Expertise: the level of DM experience, skills and expertise. 5. Factor Process: whether an effective process is followed (Hesselmann \& Walters, 2013, p. 50).

The third factor they say "is mainly about the right design capacity (the number of people), but also about the ability to adequately budget for design projects." (ibid. p,50) thus contradicting the description of Storvang et al. 2014). From Hesselmann and Walters' (2013) perspective, design capability is related to the qualitative aspects of the organization's ability in relation to design. When the terms are used in a direct contradiction as these cases, there is a great risk of misunderstandings.

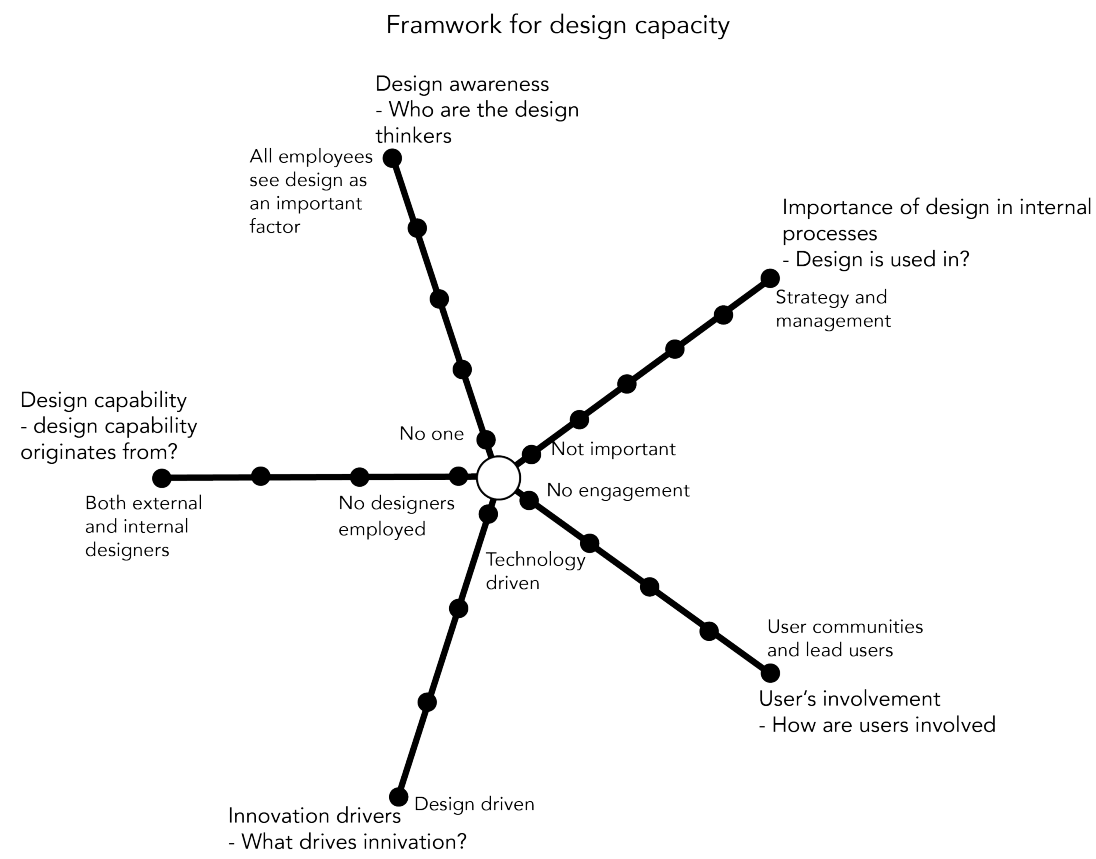

Figure 5. A simplified model of Storvang et al.'s (2014) framework for design capacity.

The thesaurus definition of the terms capability and capacity shows that the terms are synonyms, but that capability is more related to the ability to perform, whereas capacity is more closely related to volumes and quantitative measures². The

\footnotetext{
${ }^{2}$ http://www.merriam-webster.com/thesaurus/capability and http://www.merriam-webster.com/thesaurus/capacity (viewed: 2016-07-21)
} 
literature review also shows that the term design capability is the most commonly used in relation to an organization's use or the development of use of design. Design capability is used both in relation to the qualitative and quantitative aspects related to an organization's acceptance, understanding, and use of design. Based on this I have chosen to use the term design capability consistently in this work as it is about an organization's ability to utilize design.

In relation to the many definitions of design, Buchannan (2001) argues that the diverse definitions are not a problem per se. On the contrary, he argues that they create a dynamic character for the concept that is open and invites renewed thinking. A distinct definition of a concept can with time lead to stagnation (ibid.). The same should be true for design capability. However, he also notes that articulating a description or defining a concept gives the reader an understanding of the perspective taken and the focus of the discussion; as such, the definition guides the reading and understanding (ibid.). Herein lies the issue of reified use in connection to the lack of an agreed definition of design capability. The diversity of aspects related to design capability is not a problem, but the use of the concept in a reified manner despite this diversity is. It makes it difficult for readers to assess and discuss results and conclusions that are presented or to develop knowledge further. It also is problematic for actors that want to follow calls to action and develop their design capability. What is it that they are encouraged to develop, how do they start, and what should they focus on?

This section will focus on design capability, first presenting and discussing patterns found in the use of design capability after a review of the literature. The section will end in the development of the concept based on what has been found in the literature review. This development is not an attempt to create yet another definition; it aims to present a description of the understanding of the concept and the perspective that has guided the analysis and discussion in this work.

\subsubsection{Different aspects of design capability}

Following Hesselmann and Walters' (2013) distinction between design capability and capacity presented above, an organization's design capability can be understood as a set of design capabilities; and the design capacity as the quantitative resources that are needed for these capabilities. Here, design capabilities would be specific skills, competences, processes, and so on needed in the organization's work with design. However, as discussed, design capability has also been used in relation to the perception, management, and competence of 
design in relation to both quantitative and qualitative aspects. In the literature review three patterns could be recognized: design capability as design resources; as awareness of design; and as structures that enable the use of design. These three patterns will now be further presented.

\subsubsection{Design resources}

A common use of design capability in the literature is in relation to the design competency, skills, or activities brought by trained designers or the use of a design methodology. Integrative thinking, creativity, and empathic skills are examples of skills that are mentioned in relation to design capability (Rae, 2015). The ability to handle ambiguity and work with open-ended issues (Cross, 2004; Saviranta \& Eloranta, 2014), to frame and reframe problems (Dorst, 2015), and for reflection in action (Schön, 1983) also appear in relation to design expertise. User or context research, design facilitation, and visualization are other competencies and activities brought forward as design capabilities that make up design capability (e.g., Saviranta \& Eloranta, 2014; de

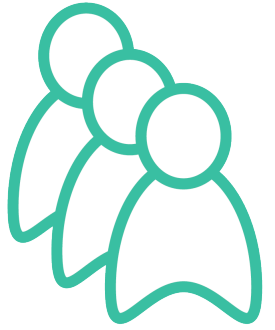

Figure 6. Design capability understood as number of people with design competence can be seen as access to design resources. Mozota, 2008; Le Mason, Hatchuel, \& Weil, 2011; Body 2008). Body (ibid.) also stresses a holistic mindset and prototyping as important aspects of design capability.

Design capability is thus not defined as specific skills, competences, or activities but is used in relation to these kinds of aspects. From this perspective, design capability could be understood as referring to skills or competences specific to design.

Also, the concept design capability may be used in relation to the processes, methods, and tools that form part of design activities and their associated skills and competences - in other words design practice (e.g., Bailey, 2012; Wormald \& Evans, 2009; Beltagui, Pawar, \& Reidel, 2011). Gericke and Maier (2011) relate design capability to the ability to design; in other words the skill and competence to design.

When focusing on skills or competences related to design, design capability becomes closely connected to human resources; i.e. to those individuals in or around the organization that hold these skills and competences. For example, Bucolo, Wrigley, \& Matthews (2012) describe design capability in relation to a 
person with design training. By adding this person to a team, they add design capability to the team. They also argue that the management within an organization needs design capability - in other words, knowledge about design (ibid.).

This perspective implies that an organization can develop its design capability by hiring in-house designers or procuring design competence as needed (Malmberg \& Wetter-Edman, 2016). Access to design competence could also be developed by training existing personnel in design activities and developing their knowledge and skills in design methods and tools (McNabola et al., 2013). In the report Design for Public Good, design capability is described as developing as public sector personnel start using design methods and tools. The design resources have then been transferred from external to internal resources.

From the perspective where design capability is related to design competence or skill, hiring design competence or training employees in design methods and tools, to develop the design capability can be described as increasing the design resources available in the organization. Design capability is thus understood as design resources, which is another common way to discuss design capability in the literature. In t Design capability is in these discussions related to employees with design training and competence, as for example in Storvang et al.'s (2014) framework, as a human resource that is internal or external depending on whether the design competence is employed in the organization or procured (e.g., Liu \& Bolton, 2011; Micheli \& Gemser, 2016; Rosensweig, 2011). Bailey (2012) suggests that ensuring access to design competence is an important part of the development of design capability in a design-novice organization.

Design capability has also been discussed as being related to other-than-human resources. For example, access to specific tools or facilities such as CAD programs and design studios (Millward, Bryne, \& Lewis, 2006). Studying different organizations that have taken part in design policy programs in Europe, Mortati et al. (2014) identified three main design capabilities: design leadership, design management, and design execution. In relation to design execution (design practice) they discuss design capability as being related to human resources with design competence and skills as well as design facilities.

Taking a resources perspective on design capability, whether competence-, skill-, or facility-based, implies that design capability is developed through the acquisition of or increase in design resources. However, there are also scholars who argue against this understanding of design capability or at least the equation between design capability and design resources. Also, discussing the skills or 
capabilities of designers in relation to design capability, Lin (2014) argued that the development of design capability is not just a matter of copying the abilities of trained designers. Focusing on public sector organizations, she meant that design capability is about gaining the trust of citizens and making problem solving and development visible and accessible to all stakeholders with the help of these skills and abilities (ibid.). Design capability does according to Lin (2014) not imply the ability to use the skills of designers then, but rather to understand how and why these skills are used. This view is supported by Body's (2008) notion that access to design resources is not enough and that design capability should also be understood as knowing how to use the available resources.

An awareness of design and design practice, as related to design capability, is the second pattern found in the literature review. This pattern will be further explored in the following section.

\subsubsection{Awareness of design}

Bailey (2012) has argued that the development of awareness in relation to design is the first step towards design capability in a design-novice organization. Over the years, several models have been developed to assess the understanding and use of design in organizations and support its development (e.g., Ramlau, 2004; Koostra, 2009; McNabola et al., 2013; Moultrie, Clarkson, \& Probert, 2007).

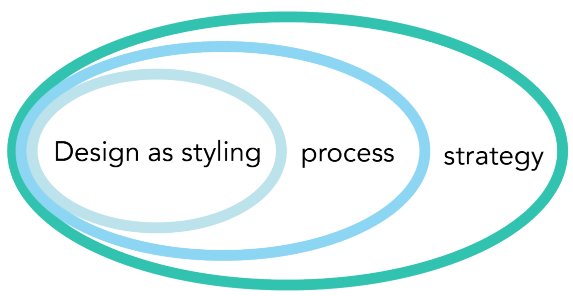

Figure 7. Design capability as related to an organization's perception and understanding of design and design's potential contributions can be described as its awareness of design.

Many of these models are based on a

process perspective, viewing the development of understanding and use of design as an increase in capability or maturity as it has also been discussed as (Ramlau, 2004; McNabola et al., 2013; Moultrie, Clarkson, \& Probert, 2007). A classic example of a maturity model is the design staircase from the Danish Design Center (Ramlau, 2004). Other models specific for design management (Kootstra, 2009) or design in the public sector and policy (McNabola et al., 2013) (see Figure 8) have later been developed following a similar framework. The staircase models assess and describes how design is perceived and used within an organization and its awareness of design. 
Kootstra's (2009) model is developed with the aim to assess the practice of design management capabilities among European businesses and to identify potential obstacles to increasing their design management capability. This again is an example of ambiguity in the use of the terms. The aspects considered

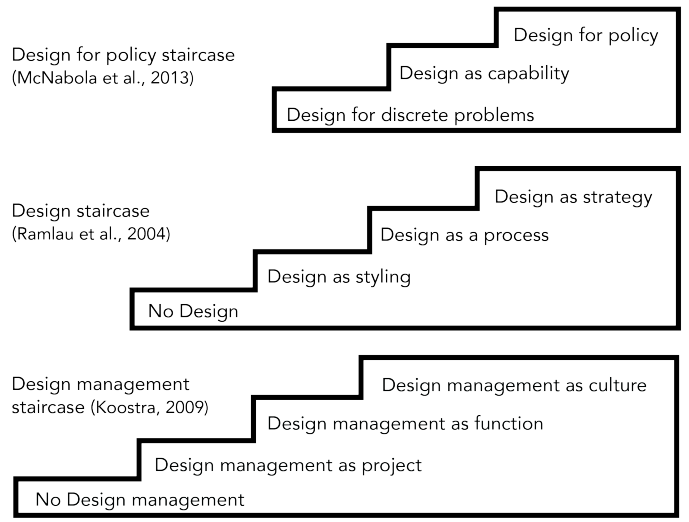

to be specifically design management capabilities in Koostra's framework are found in other models as design

Figure 8. Three different perspectives on design maturity from Ramlau et al. (2004), Koostra (2009) and McNabola et al. (2013). capability or design capacity, and are not related to any specific field of design (e.g., Heskett \& Liu, 2012: Storvang et al., 2014).

Most audit models developed to assess the use of design in an organization consider the organizations design maturity in some way or another. This indicates that the perception of design within the organization is an important aspect of design capability (e.g., Heskett \& Liu, 2012; Storvang et al., 2014; Moultrie, Clarkson, \& Probert, 2007)

The importance of the perception of design and the understanding of how a design approach, methods, and tools work and contribute is also brought forward in literatures other than those that focus on assessment models. The perspective on design capability described by Lin (2014) puts emphasis on the understanding of design, and how and why design skills and abilities are used. This perspective suggest that an organization's design capability would increase as the understanding of the design approach, methods and tools is developed in the organization.

Body (2008) and Mutanen (2008) describe the development of design capability within two different kinds of organizations: a large public sector organization (Body, 2008) and a large industry corporation (Mutanen, 2008). Both describe the development of design capability over time in the two organizations and point to the development of an understanding of design and how it contributes as part of the development of the respective organization's design capability. Body (2008) stresses that the introduction of design functions for visualization, user research, 
and design facilitation (i.e. the introduction of design resources) was not enough in the development of design capability in the Australian taxations office. According to him the most important aspect was the development of an understanding of how these function and how their related skills and activities worked and contributed (ibid.) This importance for an organization of understanding what design implies and its potential contribution as being part of the organization's design capability has also been highlighted by Beltagui et al. (2011).

The perception and understanding of design put forward as an important element in design capability by Body (2008), Mutanen (2008), Beltagui et al. (2011), and Lin (2014) differs, to some extent, with that put forward in the assessment models discussed above (Ramlau, 2004; Koostra, 2009; McNabola et al., 2013; Heskett \& Liu, 2012; Storvang et al., 2014; Moultrie et al., 2007). However, the essence of all descriptions can be understood as the perception of the design approach and its methods in an organization can play an important role in determining how design will actually be used. It could also affect what objectives that are brought forward for using design.

From this perspective, the development of knowledge about design, the design approach, methods, and tools and its potential contributions - in other words development of an awareness of design - is thus understood to play an important role in the development of design capability.

\subsubsection{Structures enabling design practice}

Structures that enables the use of design (i.e design practice) is also brought up in the literature related to design capability. This perspective highlights an organization's ability to make use of design practice. What Hesselmann and Walters (2013) describe as design capability spans aspects related to both the design resources and structures that enable design practice. They perceive design capability as that which enables an organization to utilize design. Alternatively, according to Cantamessa (1999), design capability is the intermediate layer between techniques, skills, methods, and tools that supports design and the use of these resources in a design

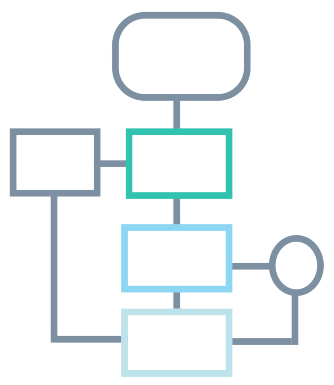
Figure 9. Having structures that enable design practice is understood as part of an organization's design capability. process. Cantamessa argues that resources may support the development and use of design capability, but that this is not the same as design capability (ibid). 
In their respective descriptions of the development of design capability in organizations, Body (2008) and Mutanen (2008) both discuss the ability of organizations to make use of design competence that has been procured as part of the organizations design capability. Also, Beltagui et al. (2011) have discussed an organization's ability to utilize design resources as part of its design capability.

Mutanen (2008) highlighted the importance of making the design practice integrated and accepted alongside the other core practices of the organization, thus making sure the practices match and complement each other. The importance of creating acceptance for the design practice has also been noted by Bailey (2012). He concluded, after having followed the introduction of design and the development of design capability in a public sector setting in Scotland for eight years that only developing design resources was not enough; work is also needed on the rest of the organization's acceptance and understanding of ways of working related to the design approach. Body (2008) draws similar conclusions from his observation of the Australian taxations office. Thus, the process of integrating the design practice could be understood as developing the intermediate layer that Cantamessa (1999) describes.

For Acklin (2013b), the ability to support and manage the use of design resources is a vital aspect for SMEs as they work to exploit design successfully; she discusses this as design management capabilities. In labeling this as design management capabilities, in a similar way to Cantamessa (1999), she makes a distinction between the management of design resources and the design resources as an organization's design capability. The distinction between design management capability and other design capabilities is also made by Mortati et al. (2014), for example. They present three sets of design capabilities, of which one is related to management (ibid.). The design management capability is, they argue, related to the management of an organization's design resources and the collaboration between design and other functions in the organization with regards to economy, personnel, and facilities. It is also related to the development of strategic relationships for innovation (ibid.). This description of design management capability is consistent with the support and management aspects relevant to an organization's design capability described by both Mutanen (2008) and Body (2008).

Most aspects described in relation to design management and enabling design practice are not directly associated with the practice of design, but are related to managing design as part of the organization's practices. To understand how the 
design resources available can contribute value to the organization and making sure that there are structures, routines and processes that enable them to do so.

As already noted, from the perspective where design capability is related to managing design resources and the integration of design into current practices, design capability is closely connected to management. From this perspective, design capability cannot be developed directly by adding resources, but requires the development of structures, routines, or processes that enable the use of design competence and the assimilation of design practice as an organizational function.

\subsubsection{A capability in need of constant updating}

Scholars like Body (2008) and Mutanen (2008), who have studied the development of design capability in organizations over time, point out that design capability is not something that can be acquired once and then be expected to persist in the organization. When following the development of design capability in the Finish paper industry organization Metso paper, Mutanen (2008) noted that the required design capabilities evolved as the organization's experience with design grew and their awareness of the benefits that design could bring to the organization's objectives developed. Another factor influencing the development over time were changes in the conditions of the paper manufacturing market (ibid.).

Changing conditions, which the organization's design capability must adjust to, could be caused by market shifts, new technological possibilities, or new legislations, for example (Body, 2008). Metso paper developed its design capability both in terms of employing and procuring design trained personnel (resources) and developing structures and routines for design to work alongside the other functions (i.e. enabling structures). The development of these aspects evolved alongside the development of the organization as the needs and objectives changed (Mutanen, 2008). Body (2008) has made similar observations in his studies of the Australian taxations office and noted that the acquired design capability must thus continuously evolve, be added to, and transformed so that it can continue to work with and alongside the other functions in the organization. He has described the development of design capability within the Australian taxations office as a continuously ongoing endeavor (ibid.).

Beltagui et al. (2011) have also argued that design capability is not an ability that is acquired once and then persists in the organization. However, contrary to the general argument that organizations should be encouraged to develop their design capability to be better equipped to pursue or manage change, Beltagui et al. 
(2011) claims that design capability is developed as a result of change. Further development of design capability as a response to changes in conditions is seen in the observations of both Body (2008) and Mutanen (2008). However, they both suggest that the actions taken in the development of design capability were both a response to change and a proactive measure to pursue change (Body, 2008; Mutanen, 2008).

Regardless of the understandings of what drives the development of design capability, these authors all agree that design capability has to be maintained and continuously developed within the organization in relation to changing needs and interests of both the organization and the surrounding society.

\subsubsection{Prior and parallel approaches to the development of design capability in the public sector}

Design, as a part of public sector development, is not new although interest and awareness has increased considerably over the past few years. Examples are the NHS's Institute for Innovation and Improvement (Carr, Sangiorgi, Büscher, Junginger, \& Cooper, 2011; Bate \& Robert, 2006), Service Innovation Lab Kent (Social Innovation Lab Kent, n.d.), Skills Development Scotland (Bailey, 2012) or Mindlab (Bason 2010), all of which have been working to embed or apply design in public sector development since the mid-2000s. Looking beyond Europe, the Australian taxations office (Body 2008) had already started their attempts to embed design and develop design capability within the organization in the late 1990s.

However, over the last few years this interest increased as the perspectives that lay behind the objectives and drivers of development and innovation changed. As a result, many initiatives have been made that introduce design and develop design capability into public sector. The report Public Policy Labs in European Union Member States (June 2016) claims that there are currently thirty labs around Europe working with public sector innovation and policy using design oriented approaches (Fuller \& Lochard, 2016). According to Hillgren and Szücs Johansson (2015), in 2015 there were about fifty ventures spread over the world focusing on societal challenges or development of the public sector using a design driven approach and methods.

Design labs have been one way to address the need to develop design capability within the public sector. Design labs comprise design resources and can 
collaborate with and support organizations as they explore the potential contributions of design and utilize design approaches. The motivations and foundations for these labs or similar ventures is often stated as being the need for increased understanding of user needs and desires; the development of competence and leadership that enables development and innovation; and the need for collaborative platforms (Hillgren \& Szücs Johansson, 2015). Mindlab in Denmark (Bason, 2010), the UK policy lab (Kimbell \& Macdonald, 2016; Bailey, 2016) in the UK, La 27e Région (La 27e Région, n.d.) in France, Service Innovation Lab Kent in England, and Experio Lab in Sweden (Hillgren \& Szücs Johansson, 2015) are examples of this kind of ventures that utilize design and aim to develop design capability within the public sector.

Another way to address the increased interest in design and the demand for more open and user-centered development has been to develop knowledge about design and access to design competence directly within the organization in different ways. For example, in the case of the Australian taxations office (Body, 2008) design competence was directly embedded within the organization, thus developing the design resources. Through design driven projects, the awareness of design within the organization as well as the enabling structures were also developed successively (ibid). Also, in the NHS design was embedded through the introduction of an experience-based design mindset and methods (Carr, Sangiorgi, Büscher, Junginger, \& Cooper, 2011).

Other initiatives have focused on transferring knowledge about design, its approach, methods, and tools to public sector organizations through design driven projects that the public sector personnel participate in to develop design capability. The SPIDER project (Supporting Public Service Innovation using Design in European Regions) is one such example. The SPIDER project aimed "To demonstrate the value of service design as a process for public service innovation that can achieve cost savings for providers and better user experiences for citizens through the pilots" (Swiatek, 2016, p.8) in a project that ran over almost three years between 2013 and 2015. During the project, public sector personnel took part in design driven development projects through which they gained experience in the design approach, mindset, and methods and developed an understanding of how design could contribute in the public sector context (Swiatek, 2016). The Swedish initiatives Förändra Radikalt (Radical Change) (Lindström et al., 2015) and Innovationguiden (The Innovation Guide) (Innovationsguiden, n.d.), both initiated by the Swedish Association of Local Authorities and Regions, are other examples of projects with a similar character. These kind of knowledge transfer 


\section{Chapter 4}

projects could also be found within some of the design labs as part of their capability building efforts. In many design labs, capability building is an important part of the lab's objective (Hillgren \& Szücs Johnsson, 2015) to not only provide support for development work but also to educate civil servants and other personnel in the design approach and methods.

The development of design labs or the initiation of knowledge transfer projects are often encouraged and supported by policy actors, such as the European Commission or local actors such as the Swedish national funding agencies Vinnova and Tillväxtverket ${ }^{3}$, through the funding of projects and academic studies. The development of design capability within the public sector is thus, as discussed in the introduction, encouraged by policy actors both on a global level such as the European Commission (Thomson \& Koskinen, 2012) and, in many countries, on a national level, articulated in national design strategies for example. In Europe, initiatives to set up design labs or knowledge transfer projects have also often been supported by networks or interest groups working with and supporting the design sector such as the British Design Council or the Swedish Industrial Design Foundation, SVID ${ }^{4}$.

The knowledge transfer initiatives that are seen in Europe have often been set up from a design perspective. Design is a reflective practice, as discussed by Schön (1983), and it is often taught through experiential learning where students are trained in design methods and tools, developing a design mindset through an action learning setup (Wetter-Edman \& Malmberg, 2016) This approach is also recognized in many of the knowledge transfer initiatives made over the last few years. Civil servants and other public sector employees learn design by participating in design driven development projects where design methods and tools are applied with support and coaching from trained designers (see e.g., Swiatek, 2016; Lindström et al., 2015).

By setting up a design driven project facilitated by designers, the initiatives aim to develop awareness of design and its potential contributions. In some cases, the initiatives also aim to transfer knowledge about tools and methods. This approach is not only used in ventures driven by a policy agenda or by organizations lobbying for design such as the EU funded SPIDER project (Swiatek, 2016). The setup is also common in courses given by design agencies, as a way to spread awareness of

\footnotetext{
${ }^{3}$ Vinnova is the Swedish innovation agency. www.vinnova.se and Tillväxtverket is the Swedish agency for economic and regional growth. www.tillvaxtverket.se

${ }^{4}$ Design Council, www.designcouncil.org.uk/

SVID, www.svid.se
} 
design and thus expand their market; IDEO's online course design kit ${ }^{5}$ is one such example.

In this kind of action learning setup, focus tends to be on the development of awareness of design and design resources through the application of methods and tools in projects. In the SPIDER project for example, the articulated aim was, as described above, to develop awareness of the value that a design approach could bring organizations, reaching a critical mass that would then carry on the further development of design capability by diffusing their experiences and the knowledge gained (Swiatek, 2016). Projects with this setup are process focused and have an inherent preconception of knowledge about design approach, methods, and tools as being transferable only through application (Wetter-Edman \& Malmberg, 2016), "what kind of capabilities that is built into these methods, how and if the knowledge is transferrable are rarely discussed" (Wetter-Edman \& Malmberg, 2016, p.517). They pay little attention to how design practice fits with current functions and practices in the organization (Malmberg \& Wetter-Edman, 2016).

The focus on awareness and resource development in the development of design capability is also suggested in the report Design for Public Sector (McNabola et al., 2013) and the report Design for Growth and Prosperity (Thomson \& Koskinen, 2012, p.10):
Build the capacity of public sector administrators to use design methods themselves and to procure design effectively: // Through design toolkits, case studies and designers in residence for EU institutions and Member States and regions. // Through developing a design curriculum for public administrators' education and professional development, with attendant Master Classes in design for effective policy-making and procurement.

Attention to aspects related to how design practice fits with the current functions and practice of the organization does not seem to be addressed in the development of design labs either, as the labs provide knowledge and resources for the organizations to use when needed. Bailey (2016) identified several important aspects to consider as design is introduced into policy development through her studies of the UK Policy Lab, for example, she points out that the political and cultural context of policy making, the timescale, and what is considered knowledge

\footnotetext{
${ }^{5}$ IDEO: http://www.designkit.org
} 
in this context, are aspects that to some extents are conflicting with the culture and approach of design (ibid.).

After four years, Bailey (2012) concluded that the service design and innovation team, which was set up as part of the Skills Development Scotland organization, had by then understood that successfully developing design capability was not only a matter of developing an in-house design team, but had to involve the whole organization. Kimbell \& Macdonald (2015) pointed out that the next step of the organizational learning in the UK Policy Lab was for individuals who had been part of the pilot to diffuse their experiences and the knowledge that had been created to the larger organization. However, how these ventures continue and how the transferred knowledge is further diffused and maintained within organizations is seldom described or discussed in project reports and studies (Malmberg \& Wetter-Edman, 2016). This was also the case for these two cases.

Many of the initiatives to increase the design capability of the public sector are thus focusing on only some of the three aspects related to design capability seen in the literature: awareness of design and development of design competence (i.e. resources). They do not address assimilation of design in the organizations or how the design work is managed. This implies that they do not address the third aspect of design capability identified in the literature, the need for structures that enable design practice. In the best practice guidelines from the SPIDER project, an argument for developing design capability within the public sector is to make design a natural and reoccurring part of the development work in an organization (Swiatek, 2016). With reference to the arguments put forward by scholars that view management of design activities and resources as part of the design capability, to achieve this goal it will be important to also focus on the diffusion and assimilation of design in public sector organizations in order to develop enabling structures.

\subsubsection{Development of the design capability concept}

As seen in the theoretical background above, depending on the perspective taken on design capability, the understanding of how it is developed or increased in an organization differs. It can be understood as being developed by ensuring access to external design resources or increasing the internal resources for design work; as developing in relation to an increased awareness of design; or as dependent on structures within the organization that enable design practice and thus through the establishment or development of such structures (Figure 10). 

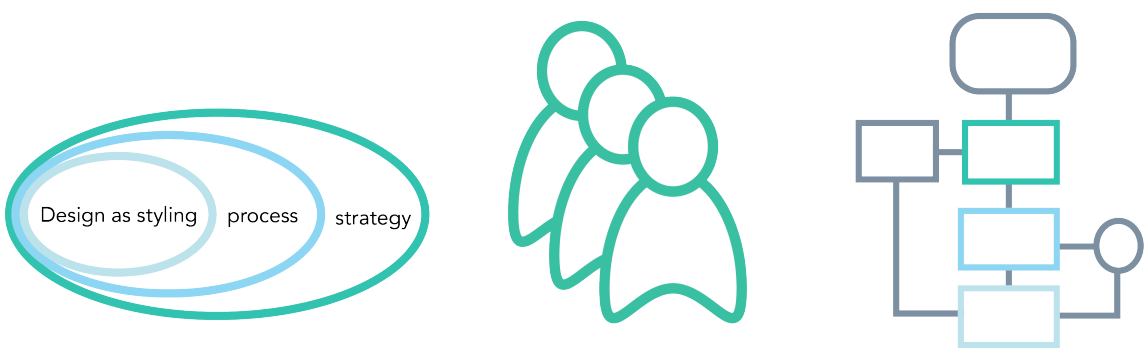

Figure 10. Design resources, azeareness of design and enabling structures, are the three aspects related to design capability identified in the literature.

Connecting design capability to design related skills and expertise raises questions about which skills or expertise are design specific and thus design capabilities. The ability to handle ill-defined problems (Rittle, 1972; Cross, 2004), to handle ambiguity, and frame or re-frame problems (Dorst, 2015) are described as specific areas of design expertise. The visualization of thoughts, observations, or ideas as part of reflective practice (Schön, 1983) is another skill often recognized in relation to design and thus design capability. Junginger (2009; 2015), however, argues that many of the capabilities attributed to design, such as problem framing, are not unique to design. According to Junginger (2009), organizations are often criticized for lacking design capability with reference to skills or activities expected as part of design practice, when in fact these activities do go on in all organizations since they are all producing something. They might just not be articulated in a manner expected by the design field (Junginger, 2009). They are part of an ongoing silent design as put forward by Gorb and Dumas (1987). The efficiency and effectiveness of the way that silent design is carried out in development work might, however, not be as good as the design packaged versions (Junginger, 2015).

Based on this, Junginger (2015) argues that the activities and capabilities already present in the organization in the form of silent design should be acknowledge and taken advantage of in the efforts to increase the design capability of the organization. She criticizes many designers initiatives that aim to develop design capability in design-novice organizations as too narrow minded, looking only for skills or capabilities as they are packaged in design, and therefore missing the capabilities that need to and could be developed (Junginger, 2015).

The argument that some of the abilities put forward as design specific are in fact already present but not articulated in organizations suggests that design capability is not only matter of holding specific skills and competence or executing certain activities. Design capability must also entail an understanding of what 
value these skills could potentially contribute and the ability to enable the exploitation of the skills to create that value and ensure the effective use of design, as argued by Beltagui et al. (2011), Body (2008), Mutanen (2008).

Recognition of the relation between the ongoing silent design and the skills related to design could be understood as a development of awareness of design within the organizations. However, it can also be seen as a development of awareness among designers of the current work in the organization. Referring to studies showing that the mere application of tools and methods (i.e. design resources) is not enough unless there is also a diffusion of understandings of why and how these tools or mindset work, Bailey (2012) emphasizes that the development of awareness of design alongside the development of design resources is necessary to develop an organization's design capability. Similarly, Hesselmann and Walters (2013) argue that an understanding within management of how design works and contributes is important for design to be able to contribute effectively, "management's attitude towards design is a critical factor affecting whether design actually contributes to the success of a product or not. A lack of awareness of the possibilities and potential benefits forms a barrier preventing effective use of design" (Hesselmann \& Walters, 2013, p.50). In order to be able to acknowledge the relation between current practice and design practice, an awareness of design practice must be developed within management in order for them to assess the two.

Also, focusing on management's role in the design capability of an organization, Wrigley \& Bucolo (2012) note that the recent hype around design thinking has led to an increased interest in and understanding of the value of developing design capability within project teams and organizations. They argue, however, that the efforts made to increase design capability are impeded by a lack of insight that these efforts also entails developing an awareness of design in the organization. That it might also imply adjusting or even potentially disrupting the current leadership abilities (ibid.). These aspects, Wrigley and Bucolo (2012) say, cannot be handled by contracting a design consultant as they have to be built up from the inside. These reflections about the development of design capability support the understanding of design capability as dependent on structures that enable the use of a design approach and at the same time point to the importance of diffusing awareness of design to the whole organization. Studying the application and legitimization of the use of design approaches in large organizations Rauth, Carlgren, and Elmquist (2014) have also noticed the need to make sure the approach match with and is accepted in the culture of the 
organization. They point out that design cannot be expected to fit directly of-theshelf, some adjustments to the organizational context must be expected (ibid.). Developing an awareness of design could be seen as a first step towards developing a culture and mindset within the organization that enables the use of design in an effective manner. This adaption or development of a culture that enables design practice would be part of the third aspect of design capability identified in the literature.

Most literature addressing design capability discusses it based on a commercial sector context and studies of commercial organizations (e.g., Hesselmann \& Walters, 2013; Wrigely and Bucolo, 2012). However, arguments that management's role, the acknowledgement of awareness, culture, and mindset are important aspects of design capability resonate with arguments made by scholars such as Lin (2014) and Body (2008) who have focused on the development of design capability from a public sector perspective.

Although some scholars focus on only one of the identified aspects related to design capability in the literature - equating design capability with access to design resources or awareness, for example - many, as seen in this discussion, understand design capability as a synthesis of two or all three of the identified aspects. The discussion above suggests that the three aspects influence and affect each other and that design capability cannot therefore be developed by focusing on only one of them.

\subsubsection{A tentative understanding of design capability}

The understanding of design capability guiding this work will accordingly be that an organization cannot develop its design capability by only developing its awareness of design (its understanding of how design can contribute) or investing in design resources (through employment, procurement, and training of design competence for example or other design facilities such as workshops or computer programs) (Figure 11). In addition to these aspects, the organization must also ensure that its structures enable the use of the design resources. The ability of an organization to utilize design in its development work (i.e. its design capability) is dependent on both its awareness of design and the structures that enable design (qualitative aspects), and its resources (quantitative aspects).

As pointed out by Body (2008) as well as Mutanen (2008), the design capability of an organization is not static. It must evolve and adjust as the conditions in and around the organization change. For example, the design competence that is needed may vary over time both in quantity and competence. Therefore, the 


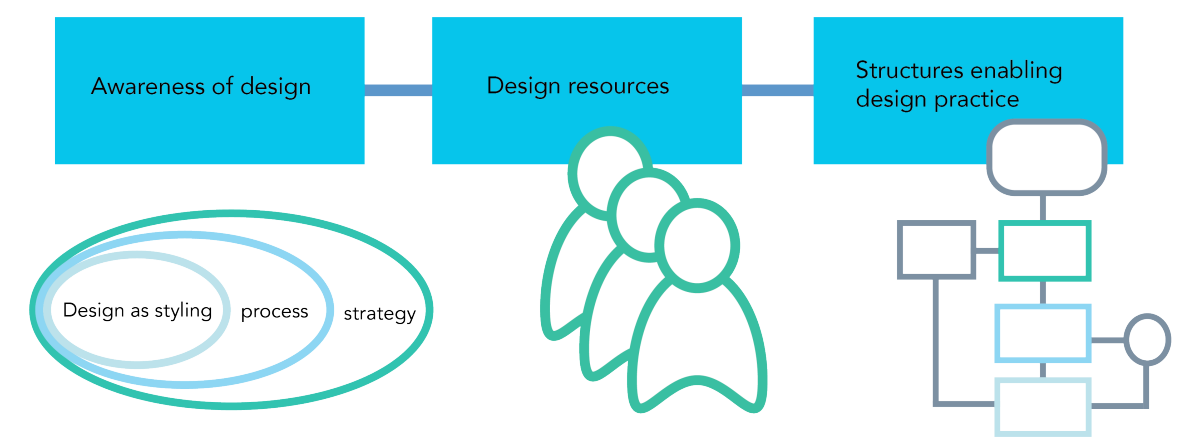

Figure 11. A tentative model of design capability derived from the use of the concept in the literature.

design capability of each organization will also, to some extent, be unique. Some organizations will have a need for competence and skill within specific design disciplines while others have a more general need. Thus, for some organizations it is most feasible to build up design competence internally while for others it will be better to procure the competence. However, a common need for all organizations is to assimilate the design they choose to use with the other functions of the organization, regardless of whether the design resources are internal or procured. They will also all have to maintain the design capability in accordance with the ongoing changes both inside and outside of the organization.

In this work design capability is thus understood as implying the organization's awareness of design and how to use it, as well as its ability to access relevant design resources and enable these to deliver a valuable result.

\subsection{Organizational learning through absorptive capacity}

Developing a capability implies learning. Organizational learning is a wide field focusing on how an organization learns and adapts to something that is new to it (Levitt \& March, 1988), such as new societal conditions, new technology, or new approaches. Absorptive capacity (Cohen \& Levinthal, 1990) represents one perspective within organizational learning that focus on how an organization recognize and asses new information as potentially valuable to the organization before assimilating the knowledge and developing capability to exploit it. 
In this work, the absorptive capacity perspective is taken to develop an understanding of how design knowledge is absorbed and developed into design capability within the public sector organizations studied.

\subsubsection{Absorption of new knowledge and development of capability}

Surviving changes in the market and staying ahead in the competition is a challenge facing all commercial organizations. While studying why some organizations were more innovative and successful in coping with changes, Cohen and Levinthal (1990) found that the successful organizations seemed to be better at recognizing value in external information, assimilating, and exploiting it than less successful organizations. Based on this finding they developed the absorptive capacity construct, which they defined as an organization's ability "to recognize the value of new, external information knowledge, assimilate it and apply it to commercial ends" (Cohen \& Levinthal, 1990, p.128). The construct has since been used and developed by many scholars (e.g., Van den Bosch, Volberda, \& De Boer, 1999; Zahra \& George, 2002; Jansen, Van den Bosch, \& Volberda, 2005; Lane, Koka, \& Pathak, 2006; Todorova \& Durisin, 2007). Although it originates from and, to a large extent, has been developed based on studies of commercial organizations, it has lately also been applied to and studied in non-market contexts (Harvey, Skelcher, Spencer, Jas, \& Walshe, 2010; Richards \& Duxbury, 2014).

The relation between design and absorptive capacity in prior research has, for example, focused on the absorption of new knowledge in the product development process - new ways to produce, new materials, or other new knowledge that can be used in concepts and in the context of new product development (NPD) (e.g., Stock, Greis, \& Fischer, 2001).

However, research relating design and absorptive capacity in the sense that design is the new knowledge that is to be absorbed is scarce. Making a parallel with absorptive capacity and an organization's ability to absorb new technology, Bailey (2012) discussed design readiness as a measure of the organization's awareness of design and the potential to embed design in its structures. Acklin (e.g., 2013b) used the construct as a foundation for developing a model of how design-novice SMEs absorb and develop design management capability. Badding, Leigh, and Williams (2014) suggested an extended model of design thinking that includes absorptive capacity as a support for organizations to understand how to transform new knowledge into sources of innovation and success. 


\section{Chapter 4}

In this work, the absorptive capacity construct the second part of the theoretical framework that have supported the exploration of the absorption of design knowledge and practice by the public sector organizations and the development of this knowledge into design capability. To facilitate this, an understanding of the absorptive capacity construct was first developed through a structured reading of the literature in the field. This reading consisted of articles picked out from a search for the most cited texts, the most cited review articles, the latest published texts on absorptive capacity, texts focusing on absorptive capacity and design, as well as texts focusing on absorptive capacity and public sector organization.

The following presentation of the absorptive capacity construct is based on the understanding developed through this reading. The structure of absorptive capacity is discussed first, followed by what influences the organization's ability to absorb new knowledge according to the absorptive capacity perspective, and ending with a short discussion about the implications of knowledge absorption in public sector settings.

\subsubsection{The knowledge absorption process}

Cohen and Levinthal's (1990) original definition of absorptive capacity was, as mentioned above, the organization's ability to recognize value in external knowledge, and to assimilate and exploit that knowledge (Figure 12). This definition described, according to Lane et al. (2006), a single-loop learning process (see e.g., Argyris \& Schön, 1978).

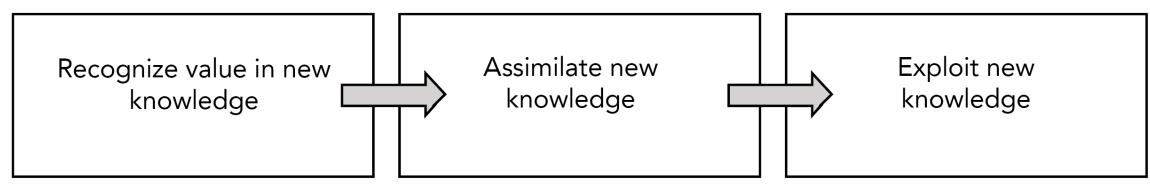

Figure 12. Model of absorptive capacity based on Cohen and Levinthal (1990).

Taking a learning perspective, rather than viewing absorptive capacity as sets of capabilities, Lane et al. (2006) instead defined absorptive capacity as an organization's ability to utilize new external knowledge through three sequential learning processes (Figure 13). 


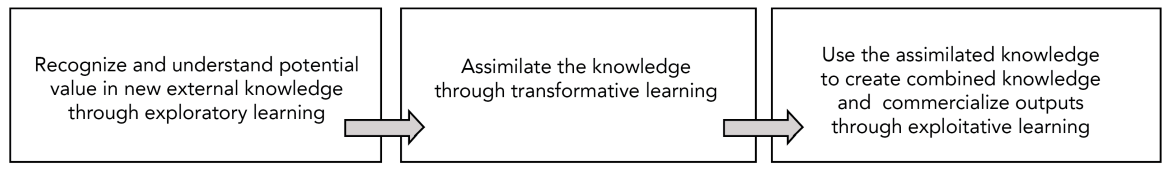

Figure 13. An organization's absorptive capacity is made up of three sequential learning processes through which the organization utilizes new external knowledge (adapted from Lane et al., 2006).

Arguing that an explicit separation is vital, as the three phases require different processes (ibid. p.857), they use the same three stages as in the original definition by Cohen and Levinthal. Recognition and understanding of potential value in external knowledge is achieved through exploratory learning where the value of the external knowledge is assessed. The second sequence involves different processes that disseminate the acquired knowledge to different parts of the organization through transformative learning. Through the sharing and transfer of the knowledge, it is assimilated in the organization and can be combined with existing knowledge and practices. The last sequence is where the new knowledge is applied and used through exploitative learning (Lane et al., 2006). Lane et al. (2006) describe transformative learning as creating links between exploratory and exploitative learning, combining new and existing knowledge so that the old can be used in new ways.

Todorova and Durisin (2007) have argued that when assimilation cannot happen because the new knowledge is too different from the old knowledge, it is preceded by a transformation stage before being assimilated. New knowledge that clearly fits in the organization is assimilated directly (ibid.). In the transformation stage, the new and old knowledge adjust to each other (ibid.) (Figure 14). Todorova and Durisin (2007) meant that knowledge can move back and forth between the transformation and assimilation stages several times before they are successfully integrated and can be exploited.

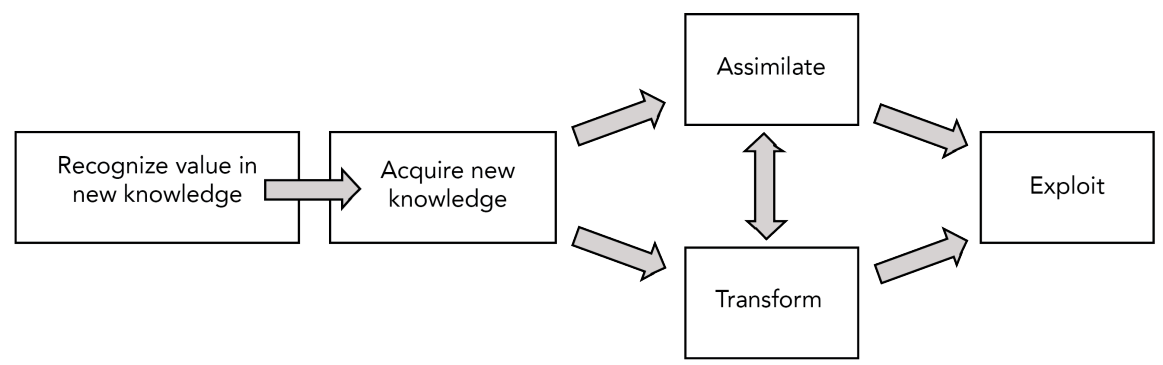

Figure 14. Model of absorptive capacity based on Todorova and Durisin (2007). 


\section{Chapter 4}

This description can be understood as the transformative learning process by which the organization learns through iterations between transformation and assimilation and where links between exploratory and exploitative learning are developed as described by Lane et al. (2006).

Through exploratory learning, Lane et al. (2006) take into consideration the need to recognize and understand potential in the new external knowledge, which is a central component in the absorption of new knowledge in Cohen and Levinthal's (1990) original model. Todorova and Durisin (2007) also recognize this component as central to the organization's absorptive capacity, arguing that the assessment of knowledge has to be made for the absorption to even begin (ibid.).

Zahra and George (2002) argued that there is a distinction between potential and realized absorptive capacity. Seeing the absorptive capacity as a set of capabilities, they meant that an organization could have a well-developed capability for finding and assessing the potential in new knowledge, but still lack the capability to internalize and make use of the knowledge and thus realize the absorption. Similarly, Lane et al. (2006) acknowledge in their model that an organization could go through one of the sequential learning processes, but not be able to fully absorb the knowledge. This also resonates with other models of organizational learning that make a distinction between the stage where the organization is exploring new knowledge or exploiting it (Brady \& Davies, 2004).

The main discussions around the absorptive capacity construct have, however, not been about the components or stages in the construct, but about the aspects that influence the organization's absorptive capacity and thus its ability to absorb new external knowledge. These aspects will be further presented and discussed in the following section.

\subsubsection{Antecedents to absorptive capacity}

To develop an understanding of how design capability is developed and can be supported in design-novice public sector organizations, it is important understand what might influence the different stages of the knowledge absorption and how.

\subsubsection{Prior related knowledge}

In their original description and definition of the construct, Cohen and Levinthal (1990) described absorptive capacity as path dependent and domain specific. With support from results from cognitive and behavioral science, Cohen and Levinthal 
(1990) argued that it is easier to recognize and understand the potential in new knowledge if it can somehow be related to the prior knowledge base. The prior knowledge increases the ability to store new memories, what Cohen and Levinthal (1990) referred to as the acquisition of knowledge. It also supports the ability to recall and use it (ibid.).

These arguments are based on an individual level and not on the capability of the organization, however, in addition to prior knowledge, Cohen and Levinthal (1990) also emphasized the role of individuals in the organization in relation to its absorptive capacity. They argued that individuals act as gatekeepers or boundary spanners, scanning, assessing, and translating the external new knowledge (ibid.). Individuals and their ability to acquire knowledge is understood to play an important role in the acquisition part of an organization's absorptive capacity. The importance of the individuals in an organization has also been stressed by Lane et al. (2006); for them, individual cognition is the foundation for the organization's absorptive capacity. The prior knowledge base can be viewed as a function of individual mental models within the organization that are used when assessing the external knowledge (Lane et al., 2006).

The absorptive capacity of the organization is not, however, equal to the sum of the individual's abilities. The organization's ability to communicate and share knowledge between individuals and units is also a main aspect in the success of knowledge absorption (Cohen and Levinthal, 1990; Zahra \& George, 2002). The ability to exploit assimilated knowledge is also part of an organization's absorptive capacity; if it has only been acquired in a limited part of the organization, Cohen and Levinthal (1990) believe that it would not be possible to exploit it. The absorptive capacity of the organization is thus dependent on processes and routines that share, communicate, and transfer the absorptive capacity of individuals across units in the organization (Van den Bosch et al., 1999; Lane et al., 2006). It is also dependent on the organization's ability to communicate with external actors to take the absorption of the knowledge to an organizational level (ibid.). Van den Bosch et al. (1999) have thus argued that the absorptive capacity of the organization resides in the links and network of individual capabilities.

In the early work and definitions of absorptive capacity, much of the focus has been on prior related knowledge (Lane et al., 2006). The prior knowledge base is also described as being of primary importance in relation to the acquisition of new knowledge (Lane et al., 2006). Given the importance of prior knowledge for the acquisition of new knowledge, and the cumulative nature of learning, recognition of potential value in new knowledge is understood as dependent on the prior 


\section{Chapter 4}

knowledge base (Cohen \& Levinthal, 1990). Thus, a diverse knowledge background in an organization is understood to have a positive influence on its absorptive capacity (ibid.). It will both open the organization to contact with a broader spectrum of knowledge and increase the chance of finding connections and associations and seeing the potential value in the new knowledge. This understanding is shared in most literature in the field; however, in public sector organizations, Richards and Duxbury (2014) have found indications that homogeneity of the prior related knowledge can have a positive influence on knowledge sharing. They argue that a homogeneity in the prior knowledge base enables "cognitive hooks" to enhance the dissemination of the new knowledge between group members (ibid.). Apart from the homogeneity on a group level, the perception of the applicability of the knowledge was found to have influence on the assimilation of new knowledge (ibid.). Richards and Duxbury (2014) believed that this difference in result (related to the influence of prior related knowledge) was because the private sector "engage in an ongoing competitive race to develop new products and services. Public-sector organizations by contrast tend to be process focused" (Richards \& Duxbury, 2014, p.17). They argued that once the current state of knowledge supports the intended performance according to the given directives, the incentive to renew knowledge might be less pronounced (ibid).

The ability to relate the new knowledge to that already present in the organization's knowledge base is, however, not unconditionally seen as a support for the absorptive capacity (Lane \& Lubatkin, 1998). According to Lane and Lubatkin (ibid.), for knowledge transfer to be effective creatively, the sender's knowledge must be different from the recipient's prior knowledge. If this is not the case, it becomes difficult to create valuable combined knowledge. Thus, knowledge must be similar to facilitate learning, but diverse enough to make absorbing it worthwhile (ibid.).

Lane et al. (2006) warn that the strong focus on prior knowledge in many of the earlier studies is simplifying absorptive capacity to the extent that it is only being related to relevant prior knowledge. They have criticized early research on absorptive capacity for focusing mainly on the recognition and acquisition of new knowledge whilst ignoring the assimilation and exploitation of new knowledge (ibid.).

Lane et al. (2006) argue that rather than viewing absorptive capacity from a structural perspective it should be viewed as a dynamic capability (Teece, Pisano, $\&$ Shuen, 1997). The view on absorptive capacity as a dynamic capability is shared with Zahra and George (2002). Moving towards a dynamic capability perspective, 
Lane et al. (2006) argue would extend the focus to the processes, routines, and policies in an organization that affect the sharing and integration of new knowledge rather than focusing on the knowledge itself, its type, or its similarity to prior knowledge. Taking this perspective could, they argue, influence the efficiency and effectiveness of the absorption of knowledge (ibid.).

\subsubsection{Organizational structure and combinative capabilities}

Even though prior knowledge was emphasized in their seminal work, Cohen and Levinthal (1990) also highlighted the importance of the diffusion and assimilation of the acquired knowledge as part of the absorptive capacity. Later studies and definitions of absorptive capacity have paid more attention to antecedents related to these aspects. Jansen et al. (2005) develop the discussion around what influences the absorptive capacity and claim that prior knowledge is not enough for an organization to develop good absorptive capacity. They argue that the absorptive capacity is, to a large extent, also affected by organizational aspects (ibid.). Culture, common skills, and strategy as well as knowledge base and similar cognitive structures have been put forward as aspects that influence the acquisition and assimilation of knowledge (Lane et al., 2006).

Referring to Cohen and Levinthal's (1990) brief reflection on which organizational aspects might influence the absorptive capacity, Van den Bosch et al. (1999) argue that it is important to distinguish the organizational factors of absorptive capacity. Van den Bosch et al. (1999) saw that apart from prior knowledge, also the structure of the organization affects its knowledge absorption as the structure influences the knowledge process system, as well as its combinative capabilities. The former is also supported by Lane et al. (2006).

Combinative capabilities are another type of organizational determinant of absorptive capacity described by Van den Bosch et al. (1999). They presented three types of combinative capabilities: system capabilities, coordination capabilities, and socialization capabilities. These capabilities are made up of, for example, processes, routines, or culture in the organization and are important in relation to the links and networks of individual capabilities that make up the organization's absorptive capacity (Van den Bosch et al., 1999). Van den Bosch et al. argued that the influence of organizational characteristics on the absorptive capacity could be bypassed depending on the combinative capabilities of the organization, stating that, "New knowledge is often the product of a firm's combinative capabilities to generate new applications from existing knowledge components" (ibid. p.552). This understanding supports that of Cohen and 


\section{Chapter 4}

Levinthal according to Lane et al (2006). Cohen and Levinthal originally described the assimilation of new knowledge as a result of how processes and policies facilitate the diffusion of the new knowledge in the organization (Lane et al. (2006).

Coordination capabilities are path dependent and accumulate in the organization as a result of training, job rotation, and participation (Van den Bosch et al., 1999). Through the relations between members of a group, they support the implicit absorption of knowledge (ibid.). These relations encourage the sharing of information between disciplines and hierarchies and thus supports the diffusion of knowledge absorption (Jansen et al., 2005). Jansen et al. (ibid.) argued that coordination capabilities, such as cross-functional interfaces, promote non-routine and shared information processing, which can support the interpretation of problems, overcome differences, and build understanding for the new knowledge.

Socialization capabilities refer to an organization's ability to present a shared ideology from which collective interpretations of reality can be made (Van den Bosch et al., 1999). The social capabilities relate to organizational culture, system ideas, and values (ibid.). Van den Bosch et al. (ibid.) argued that social capabilities can both support and hinder knowledge absorption as they on the one hand give rise to social integration, but on the other hand risk creating mental prisons, which can have a negative influence on the value attributed to new knowledge. Strong culture, as an example of social capabilities, is often hesitant with respect to change, which can slow down the change process (ibid.). As examples of social capabilities, Van den Bosch et al. (1999) pointed out a high degree of shared values, a common language, and a strong consensus regarding appropriate behavior. These examples can be a barrier to the absorption of new knowledge depending on the character of the new knowledge in relation to the old (ibid.). However, social capabilities can also support knowledge absorption depending on their character (Noblet, Simon, \& Parent, 2011). Jansen et al. (2005) showed that social capabilities have little or no impact on acquisition, but have positive influence on assimilation and are generally positive for achieving a fully realized absorptive capacity.

System capabilities are, for example, policies, procedures, or manuals and reflect the extent to which rules, procedures, or communication are documented and formally systemized (Van den Bosch et al., 1999). They provide the organization with a shared memory so that it can react quickly in 
routine situations (Van den Bosch et al., 1999; Jansen et al., 2005). Lane et al. (2006) argued that from a short-term perspective, existing structures and processes could impede or hinder the knowledge that is assimilated and applied. Routinization and other similar system capabilities are also understood to have a negative effect, in this case, on the acquisition of new knowledge as they may hinder exploration (Jansen et al., 2005). System capabilities in general relate to explicit knowledge absorption and can be helpful in breaking down barriers put up by social capabilities, although this takes time (Van den Bosch et al., 1999).

Jansen et al. (2005) argued that combinative capabilities such as coordination capabilities or socialization capabilities affect the organization's ability to synthesis, apply and exploit the new and old knowledge. They concluded that "organizational mechanisms associated to coordination capabilities (cross-functional interfaces, participation and job rotation) primarily enhance potential absorptive capacity, while organizational mechanisms associated with socialization capabilities (connectedness and socialization tactics) primarily strengthen realized absorptive capacity" (ibid. p.1009). They have also claimed that dense networks within units are needed in addition to external connections for the units to assimilate, transform and exploit external knowledge. Networks allow for twoway interaction and cooperation between colleagues, supporting interpretation and understanding of new external knowledge (ibid.). Table 3 lists the different combinative capabilities and their influence on the absorptive capacity. Focusing on public sector organizations, Richards and Duxbury (2014) saw that antecedents connected to combinative capabilities and organizational structures, such as culture, processes, or silos, are of more importance than prior related knowledge. This is also supported by Harvey et al. (2010), who claimed that for information to be used in decision making and improving performance, both organizational and psychological barriers have to be overcome. They suggested that this requires an organization that has an ongoing commitment to learning and development, with an open mind-set and climate that accepts debate (ibid). Organizations where members are encouraged to speak up and acknowledge mistakes also tend to learn faster than organizations where the members are expected to just follow the current routines (Richards \& Duxbury, 2014). In relation to these aspects, management plays an important role in upholding such a culture and setting good examples (ibid). 
Table 3. Combinative capabilities affecting the absorptive capacity.

\begin{tabular}{|c|c|c|}
\hline $\begin{array}{l}\text { Combinative } \\
\text { Capabilities }\end{array}$ & Examples/ Character & $\begin{array}{l}\text { Influence on the absorptive } \\
\text { capacity }\end{array}$ \\
\hline $\begin{array}{l}\text { Socialization } \\
\text { capabilities }\end{array}$ & $\begin{array}{l}\text { Organizational culture, } \\
\text { System ideas and values, } \\
\text { Shared language, Agreed- } \\
\text { upon view of appropriate } \\
\text { behavior (Van den Bosch et } \\
\text { al., 1999) }\end{array}$ & $\begin{array}{l}\text { Support or hinder knowledge absorption } \\
\text { as they on the one hand give rise to social } \\
\text { integration but on the other hand also risk } \\
\text { creating mental prisons, which can } \\
\text { negatively influence the valuing of the } \\
\text { new knowledge (Van den Bosch et al., } \\
\text { 1999). Have little or no influence on } \\
\text { acquisition and a positive influence on } \\
\text { assimilation of new knowledge (Jansen et } \\
\text { al., 2005) }\end{array}$ \\
\hline $\begin{array}{l}\text { System } \\
\text { capabilities }\end{array}$ & $\begin{array}{l}\text { Policies, routines, legislations, } \\
\text { manuals, formally systemized } \\
\text { and documented } \\
\text { communications, procedures } \\
\text { or rules (Van den Bosch et al., } \\
\text { 1999) }\end{array}$ & $\begin{array}{l}\text { Can be helpful in breaking down barriers } \\
\text { put up by socialization capabilities given } \\
\text { time (Van den Bosch et al., 1999) } \\
\text { Some e.g. routinization have a negative } \\
\text { effect on acquisition as it hinders } \\
\text { exploration (Jansen et al, 2005) }\end{array}$ \\
\hline $\begin{array}{l}\text { Coordination } \\
\text { capabilities }\end{array}$ & $\begin{array}{l}\text { Networks, relationships (Van } \\
\text { den Bosch et al., 1999) } \\
\text { Cross functional interfaces } \\
\text { (Jansen et al., 2005) }\end{array}$ & $\begin{array}{l}\text { Relations between members of a group } \\
\text { support implicit absorption of knowledge } \\
\text { (Van den Bosch et al., 1999) } \\
\text { Relations encourage sharing of } \\
\text { information between disciplines and } \\
\text { hierarchies (Jansen et al., 2005). Promote } \\
\text { non routine and shared information } \\
\text { processing which can support the } \\
\text { interpretations of problems, overcome } \\
\text { differences and build understanding for } \\
\text { the new knowledge (Jansen et al., 2005) }\end{array}$ \\
\hline
\end{tabular}

\subsubsection{Management's influence on knowledge absorption}

Similar to Richards and Duxbury, Van den Bosch et al. (1999) also found that management plays an important role in the absorptive capacity of an organization. Through management decisions and actions, organizational structures and combinative capabilities can be adapted (ibid.). Studies of the public sector show that management's role is particularly emphasized in this context (Richards \& 
Duxbury, 2014). Apart from the potential influence that Van den Bosch et at. (1999) had identified, the activities of middle management are important as they influence the perception of the applicability of the new knowledge (Richards \& Duxbury, 2014). By providing contextual information, middle managers can support group members' understanding of the relevance of the new external knowledge (ibid.), and thus support assimilation.

This relates to role of gatekeeper and boundary spanners in the diffusion of new knowledge discussed by Cohen and Levinthal (1990). Richards and Duxbury (2014) argued that these roles are typically played by middle managers and that it is therefore important that "middle managers understand the organization's strategy and their role in the knowledge-utilization process" (ibid., p.1). This is an argument that stresses the importance of viewing management as a relevant antecedent for absorptive capacity within the public sector.

\subsubsection{Characteristics of the new knowledge}

A final factor that could also influence absorptive capacity is the character of the knowledge that is to be absorbed. In their extensive literature review on absorptive capacity, Lane at al. (2006) identified three patterns related to how the characteristics of knowledge are discussed so as to influence absorption: tacitness, complexity, and knowledge content.

Knowledge content such as similarity in culture, strategy, or skills are, as with prior related knowledge, believed to have a positive influence on knowledge absorption, both in terms of the acquisition and assimilation of new knowledge (ibid.).

Knowledge embedded in complex processes or routines such as implicit skills or know-how (in other words tacit knowledge), can be perceived as ambiguous, creating barriers to imitation and making it difficult to absorb (ibid.).

According to Lane et al. (2006), as the complexity of knowledge increase so too does the level of difficulty related to absorbing it. The multiple actors, routines, and resources that are involved imply several areas that must be absorbed and linked, making the knowledge more difficult to absorb (ibid.). 


\subsubsection{Implications for organizational learning and successful knowledge absorption in public sector organizations}

As can be seen in the description above of absorptive capacity and its antecedents, there are many different aspects that influence the absorption of new knowledge in an organization and many of the antecedents can act as either a support or a barrier depending on the characteristics of the organization and the knowledge.

The prior knowledge base and the relation between new and existing knowledge is, as Lane et al. 2006 conclude, mainly related to the acquisition of the new knowledge. However, according to Richards and Duxbury (2014), in a public sector setting it does not seem to have the same influence - although this does not mean that prior knowledge does not have an influence on the absorption of new knowledge in the public sector. Richards and Duxbury's (2014) notion that a shared knowledge base within the organization will support the diffusion of new knowledge suggests that new knowledge that relates to the existing knowledge base should be easier to disseminate and assimilate than knowledge that lies outside the existing knowledge base. Also knowledge that has characteristics, which are similar to the existing culture or skills in the organization, would be easier to assimilate, as put forward by Lane et al. (2006). Prior knowledge and knowledge characteristics are thus expected to influence the assimilation, and potentially the acquisition, of new knowledge in a public sector setting.

Both Lane et al. (2006) and Zahra and George (2002) acknowledge that an organization could be successful in the initial phases of knowledge absorption, but still struggle to fully absorb the knowledge to the point where it is being exploited. The reasons behind this are clear when looking at how different antecedents influence different aspects of the absorption of new knowledge. Following the model of Lane et al. (2006), the organization could have well-developed support for the exploratory learning sequence in relation to the specific knowledge in the sense that the potential value of the new knowledge is recognized when assessed against the existing knowledge base. Going through the acquisition phase awareness of the new knowledge (i.e. knowledge about) would have been developed within the organization. However, for full absorption this is not enough. The organization also has to understand how to use the new knowledge and perhaps make adjustments to its structures and processes to enable the use the new knowledge and develop knowledge how to exploit it. If the new knowledge has knowledge characteristics that are easily assimilated by the organization, further 
absorption should not be a problem as long as the coordinative capabilities of the organization are such that the new knowledge can be disseminated throughout the organization. However, if it is complex knowledge or the knowledge content is of a character that does not go with the skills or socialization capabilities of the organization, then going through the transformative learning sequence would be more difficult.

The antecedents related to transformative and exploitative learning are, as seen in in Figure 15, to a much larger degree connected to routines, processes, social structures, and the culture of the organization. In the public sector setting, these kinds of antecedents have also been proven to be important in exploratory learning (Richards \& Duxbury, 2014).

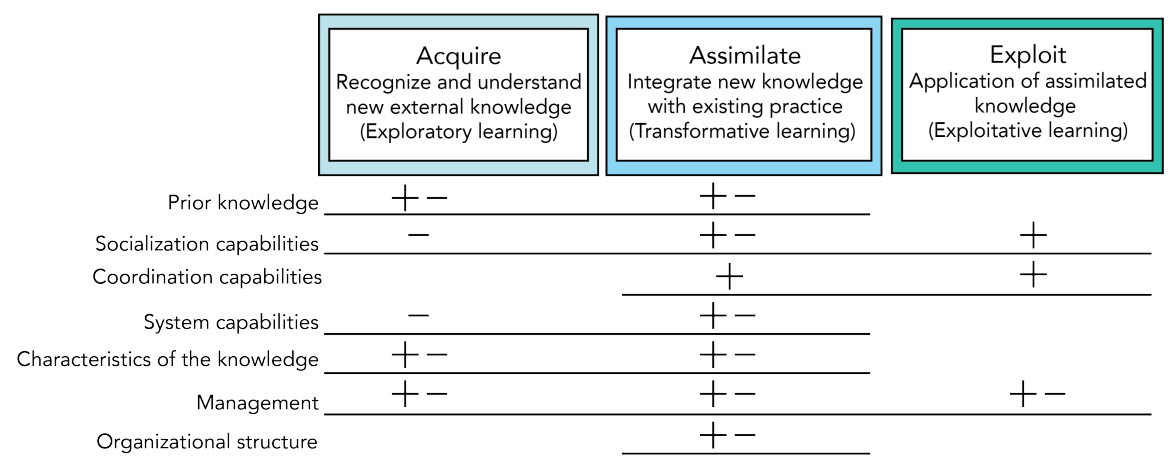

Figure 15. The learning sequences of absorptive capacity the influencing antecedents as understood and guiding the analysis and discussion in this work.

Based on this, it can be concluded that it is important to pay attention to and cater for both the antecedents related to the organization and those that are knowledge specific when setting up projects aimed at transferring knowledge or building capabilities within an organization. It is clear that successful knowledge absorption will be dependent on both antecedents related specifically to the knowledge and to the absorbing organization. The exploratory learning phase is a precondition for the transformative and exploitative learning sequences and to fully absorb the new knowledge antecedents influencing all sequences must be catered for. Based on studies conducted by Richards and Duxbury (2014) and Hervey et al.'s (2010), it can also be concluded that in the public sector, an organization's antecedents will have a larger role compared to those in a commercial context. The theoretical framework that has guided the analysis and discussion of the work that follows is based on the definition and description of absorptive capacity as a learning process 
made up of three sequential phases put forward by Lane et al. (2006). The iterative movement of knowledge between assimilation and transformation, as described in Todorova and Durisin's (2007) model, has been understood as part of the transformative learning sequence in Lane at al.'s model. The understanding of how different antecedents influence the absorption has been mapped to the threestage model described by Lane et al. (2006).

\subsection{A tentative model for the development of design capability given an absorptive capacity perspective}

Taking an absorptive capacity perspective on the development of design capability in an organization, the development of awareness of design could be understood as the acquisition of design as new knowledge. This would suggest that awareness of design is developed through exploratory learning in the first sequence of the absorptive capacity. Through exploratory learning, public sector personnel form an understanding of what design is and its potential value to the organization and their work. This is done through a comparison of what is presented in relation to design and the potential experiences of design they get to the approaches and processes they have prior knowledge of. Through this process, their awareness of design is developed. Following the absorptive capacity perspective, the exploratory learning and assessment of design will be mainly influenced by prior knowledge and the knowledge characteristics, but socialization and system capabilities could also influence the acquisition of design and the development of design awareness.

However, in the acquisition phase, the developed awareness of design is on an individual level as it has not yet been disseminated and assimilated by the organization. Thus, the knowledge cannot yet be understood as acquired on an organizational level. As Cohen and Levinthal (1990) and other scholars (e.g., Van den Bosch et al., 1999; Lane et al., 2006) point out, in order to be absorbed by the organization, awareness must be communicated and shared throughout the organization. According to Lane et al. (2006), this happens in transformative learning as part of the assimilation of new knowledge. The development of awareness of design on an organizational level is understood to be influenced mainly by socialization and coordination capabilities. These capabilities relate to the shared values and culture in the organization and thus the organization's ability to communicate and share knowledge between individuals and units. Prior 
knowledge and system capabilities could also influence the recognition of value in design among those parts of the organization that were not included in the initial acquisition.

During the assimilation phase, when the organization shares and tries to fit design into its current knowledge and practice through transformative learning, the awareness of design will not only be developed on an organizational level, it will also deepen. As the design approach and its accompanying mindset, methods, and tools is fitted into the existing structures and routines, the organization will develop a better understanding of what working with design implies in its own context. It will also reveal how the practice of design fits with current routines and structures in the organization.

An understanding develops of how current structures, routines, and practices fit with design, enabling the exploitation of design. This fit will be assessed and through the iterative move between assimilation and transformation described by Todorova and Durisin (2007), the enabling structures that make up the third identified aspect of design capability will be developed. This will entail the creation of new structures, processes, or routines; the adaptation of current ones; and, in some cases, the disruption of old structures in order to enable the use of design in a way that contributes value. This aspect will be influenced by system capabilities as the creation and adjustment of structures and processes might entail adapting these. However, socialization and coordination capabilities will also influence the development of enabling structures in relation to the acceptance and legitimization of new structures and the diffusion of these within the organization.

Also, the development of access to design resources could be understood as part of the assimilation of design. Once the organization's gatekeepers have assessed design as a valuable new knowledge, developing access to design resources will form one aspect of enabling the use of this knowledge. This could, as discussed earlier, be achieved by hiring personnel with design competence, training current personnel in design, or ensuring the possibility of procuring external design competence when needed. In what way the organization choose to ensure its access to design resources will depend on how design is best assimilated given the specific conditions of the organization.

If the organization chooses to train its existing personnel in design, the knowledge related to design competence would also have to be absorbed on an individual level before it can be absorbed on the organizational level. However, for the design recourses to become part of the organization's knowledge base rather than just individual competences, the awareness of their existence in the 


\section{Chapter 4}

organization must be diffused throughout the organization in the same manner as the awareness of design. This step will be the same regardless of whether the design competence is trained, hired, or procured.

The development of access to design resources will be influenced mainly by socialization and coordination capabilities. This is because developing it as an organizational resource will mainly be about legitimizing and diffusing knowledge about the competence within the organization. Bailey (2012) observed the successful dissemination of design knowledge when personnel got to pass their knowledge to colleagues through new projects or workshop. Teaching others reinforced their own knowledge base and their confidence in applying design approach and methods in everyday work. This supports the assumption that coordinative capabilities play an important role in the development of design resources.

As management is understood to play an important part in the absorption of new knowledge in the absorptive capacity construct (Van den Bosch et al., 1999; Richards \& Duxbury, 2014), their understanding (i.e. acquisition) of design will affect its potential use. Management is, in other words, understood to play an important role throughout the absorption of design in their role as gatekeepers (Cohen \& Levinthal, 1990; Richards \& Duxbury, 2014) and through their ability to influence the combinative capabilities (Van den Bosch et al., 1999). See Table 4 for a mapping between the three identified aspects of design capability and the phases of the knowledge absorption according to the absorptive capacity construct. 
Table 4. The different aspects of design capability are understood to be developed in different phases of the knowledge absorption.

\begin{tabular}{|l|l|l|l|}
\hline $\begin{array}{l}\text { Awareness about } \\
\text { design }\end{array}$ & $\begin{array}{l}\text { Acquisition } \\
\text { Develops on an } \\
\text { individual level }\end{array}$ & $\begin{array}{l}\text { Assimilation } \\
\text { ovelops on an } \\
\text { organizational level }\end{array}$ & $\begin{array}{l}\text { Continuous } \\
\text { development and } \\
\text { updating of the } \\
\text { awareness through use }\end{array}$ \\
\hline Design resources & $\begin{array}{l}\text { Develops on an } \\
\text { individual level }\end{array}$ & $\begin{array}{l}\text { Develops on an } \\
\text { organizational level }\end{array}$ & $\begin{array}{l}\text { Continuous } \\
\text { development and } \\
\text { updating of the needed } \\
\text { competence and } \\
\text { resources through use }\end{array}$ \\
\hline Enabling structures & process & $\begin{array}{l}\text { Develops on an } \\
\text { organizational level }\end{array}$ & $\begin{array}{l}\text { Continuous } \\
\text { development and } \\
\text { updating of the } \\
\text { enabling structures } \\
\text { through use }\end{array}$ \\
\hline
\end{tabular}

\subsubsection{Tentative implications for developing design capability in public sector organizations}

As presented in the introduction, the objective of developing design capability within public sector organizations is to increase their ability to work successfully with innovation and development so as to handle current and future societal challenges. Many of the barriers to innovation and development within a public sector context can be recognized and understood as antecedents when taking the absorptive capacity perspective. A reflection on which of these and how that might influence the absorption of design will therefore be of interest in the tentative understanding of how design capability is developed.

Junginger (2015) argues for the recognition and utilization of the silent design already present in organizations, as a support when developing design capability. From an absorptive capacity perspective, silent design is understood as part of the prior knowledge base, and design would thus be assessed against it. As already 


\section{Chapter 4}

discussed, prior knowledge could serve as both a support and a limitation in the absorption of new knowledge depending on how it differs from the new knowledge. As Lane and Lubatkin (1998) argue, new knowledge must be assessed as similar but still different to be seen to be worth absorbing. This implies that for design to be recognized as new knowledge worth absorbing it must be considered to contribute a new value that is in addition to the skills and competences that constitute silent design in the organization.

Related to the influence of prior knowledge, Bailey (2012) has claimed that there is a barrier to the assimilation of design and thus the development of design capability. He argues that "it is insufficient to introduce design tools and methods without equipping people with a common vocabulary and with it the confidence to understand and communicate the use, process and outcomes of using these new tools" (Bailey, 2012 p.34). From an absorptive capacity perspective, the need for a common vocabulary could be understood as a need to relate the practices of design to the prior related knowledge of the organization.

The culture associated with design differs in many ways from that of a public sector organization; social capabilities can therefore be expected to play an important role in the absorption of design in this setting. The development of awareness of design and of structures that enable design practice implies the acceptance and understanding of aspects such as a user-centered mindset and an open-ended approach to idea generation and problem solving. The bureaucratic structure and culture of many public sector organizations creates a context in which ideas are dismissed rather than nurtured (Mulgan, 2014a). Narrowly and deeply prescribed objectives imply it is easy to dismiss ideas for not fulfilling the objectives (Bason, 2010). Bason (ibid.) suggests this is related to a risk-averse culture, which is present in many public sector organizations. There is a fear of failing and a pressure to not act recklessly with taxpayers' money (Mulgan, 2014a). These characteristics of the public sector imply a context that may have difficulty accommodating the divergent approach of design and open-ended approaches to problem solving may struggle. The knowledge characteristics of design does in other words on many accounts not fit with the characteristics of the public sector which according to Lane et al. (2006) could have a negative influence on the absorption of knowledge and thus in this case on the development of design capability.

A risk-averse culture and a fear of failing is also likely to have a negative influence on the absorption of design because organizations with this type of 
culture tend to be less successful in absorbing new knowledge in general (Richards \& Duxbury, 2014).

The discord described above between the characteristics of design can that of the prior knowledge base and culture in the public sector suggests that design cannot be directly assimilated, but will require the transformative learning phase to move between transformation and assimilation a few times as suggested by Todorova and Durisin (2007).

Although risk avoidance and adherence to legislations are important in many public sector contexts, Bason (2010) argues that the view of failure and risk is often very narrow and affects the ability of civil servants and other personnel to act on new ideas and solutions. This exemplifies how socialization capabilities (in terms of culture and values) and system capabilities (in terms of routines and legislations) play an important role in a public service context.

Other than the influence of systems and socialization capabilities, another antecedent that could have a negative influence on knowledge absorption in the public sector is the organizational structure. Van den Bosch et al. (1999) have argued that organizational structure may influence the organization's absorptive capacity. Many public sector organizations, especially within healthcare, have traditionally been structured in functional silos according to competence or area of responsibility (Mulgan, 2014a; Bason, 2010). This type of organizational structure has, according to Van den Bosch et al. (1999), a negative influence on the dissemination of new knowledge within the organization as it makes communication and knowledge sharing between different organizational units more difficult. A way to handle this is to have well-developed coordinative capabilities (Van den Bosch et al., 1999).

As Richards and Duxbury (2014) have argued, management plays a key role in knowledge absorption in public sector organizations. Here, management's attitude towards the new knowledge will influence the personnel's perception of it (ibid.). This is supported from the design perspective by Bailey (2012), who argues that support from management on all levels in the organization is vital for a cultural change, such as the one development of design capability would imply, to come about and sustain. He argues that it is therefore important that managers are given the time and opportunity to develop an awareness of design so that they are able to support their personnel throughout this cultural change (ibid.). The importance of the role that management plays in the absorption of new knowledge also relates to the arguments about management's role in the efficient use of design and the 


\section{Chapter 4}

successful development of design capability brought up by Wrigley and Bucolo (2012) and Hesselmann and Walters (2013).

Many of the efforts made to introduce design in the public sector are, as discussed, made in the form of project based knowledge transfers, both as standalone projects and as part of design lab activities. Previous research has, however, shown that project based learning can be difficult (Brady \& Davies, 2004). In many cases, the organizations had difficulties transferring knowledge gained from the projects to the larger organization (ibid). Viewing this dilemma from an absorptive capacity perspective, it could be understood that the organizations did not have sufficient coordination capabilities to assimilate the knowledge developed through the exploration in the projects. Brady \& Davies (2004, p.1601) said that "there is a risk that knowledge and experience gained is lost when the project finishes, the team dissolves, and its members move on to other projects or are reabsorbed into the organization." In many cases, there is a lack of time or motivation to reflect on and document what has been learned after the projects (Brandy \& Davies, 2004). The issues related to project based learning suggest a further emphasis on the importance of management actions in absorption as management have a mandate to facilitate time for reflection and documentation as well as making sure team members can stay in contact.

One objective for development of design capability within public sector organizations brought forward has been the belief that design could mitigate some of the barriers to innovation and development that are seen in this context (e.g., McNabola et al., 2013). However, the tentative model of development of design capability in the public sector suggests that many of these barriers will also have a negative influence on the absorption of design and consequently the development of design capability. This suggests the need to keep these antecedents in mind and address them in the planning of design capability building efforts. The synthesis suggest a need to pay attention, handle, and make use of the organizations socialization capabilities and to make sure that management is involved and engaged in the development of design capability.

\subsection{Chapter summary}

The review of literature related to design capability brought out three different aspects. Design capability is understood as design resources; that the organization has access to relevant design competence and skill. Design capability is understood as the awareness the organization has of design; its perception of design and its 
understanding of the approaches, methods, and tools related to design as well as an understanding what design can contribute. Design capability is understood as related to the structures in the organization that enable the use of design.

Although some authors discuss design capability in relation to only one of these aspects, most see design capability as a synthesis of them all (e.g., Hesselmann \& Walters 2013; Bailey, 2012; Body, 2008; Mutanen, 2008). This is also the understanding of the concept used in this work. Here, design capability is understood as an organization's ability to utilize design; this entails all three aspects identified in the literature. As discussed by Body (2008) and Mutanen (2008) design capability is also understood as a capability that has to evolve with developments in the organization and societal changes.

The understanding of absorptive capacity guiding this work is mainly based on Lane et al.'s (2006) model, which views absorptive capacity from a learning perspective and describes it as three sequential learning phases. In the first sequence, the new knowledge is acquired through exploratory learning. Here, the new knowledge is recognized and its potential value to the organization is assessed. In the second sequence, knowledge is diffused and assimilated in the organization through transformative learning before being exploited in the third sequence through exploitative learning. The absorption of new knowledge is influenced in the different phases by different antecedents (Van den Bosch et al., 1999; Jansen et al., 2005; Lane et al., 2006). The antecedents are related to prior knowledge, the organizational culture, the organization's ability to disseminate and share information within the organization, and structures or regulations, for example. Also management is understood to play an important role in the absorption of knowledge in an organization (Van den Bosch et al., 1999), especially so in a public sector context (Richards \& Duxbury, 2014).

A synthesis of the two theoretical foundations gives a tentative model of how design capability is developed in the public sector. In the first learning sequence, an awareness of design is developed on an individual level through exploratory learning. In the second transformative learning sequence, this awareness is diffused through out the organization and the design resources, and enabling structures are developed. In the third exploitative sequence, the organization continuously develops its design capability based on insights related to opportunities and needs that develop as design is used. This implies that it is not enough for the knowledge absorption to only focus on the exploratory learning, all three phases of the absorptive capacity must be addressed in order to develop all aspects of design capability fully. An organization that only acquires design and develops awareness 
Chapter 4

of design will not be able to exploit design and thus will not be able to benefit from the full value and potential of its contribution. 


\section{Chapter 5}

\section{Case A: The Social Service case}

In the Social Service case, we follow the introduction of design as a means for increased user involvement and influence in the social services for people with severe cognitive disabilities and in the development work within the social services. The initiative to pursue this was taken and led by a regional development council together with a design consultant whom they procured. A regional development council is a platform for collaboration between municipalities and the county council in a region. Its main task is to disseminate current research and knowledge relevant to the activities of the municipalities and the county council as well as acting as a support for the implementation of, for example, new knowledge, systems, or processes. The objective of the regional development council is to increase the knowledge base in the region.

The initiative was set up as a six-month long pilot design project in one of the member municipalities, later called the pilot municipality. The design driven project aimed to develop a solution that would increase the involvement and influence of the social service users in their day center activities. Other than the pilot municipality, two other member municipalities also took part in the project; although they did not have their own projects, these will be referred to as observing municipalities (see Figure, 16 for an overview of the involved actors). At the end of the six months, the project was extended to give time for the implementation and follow-up of the solution.

In this chapter, a narrative of the initiative is presented, based on the accounts given by the informants through interviews and project diaries (for a detailed account of the data collection see chapter 3). Here, we hear the voices of the procured design consultant; the project manager and her colleague at the regional development council (who initiated the project); two representatives from the pilot 


\section{Chapter 5}

Table 5. Information box the Social Service case.

\begin{tabular}{|c|c|c|c|}
\hline Duration & $\begin{array}{l}\text { Actors involved } \\
\text { in the initiative }\end{array}$ & $\begin{array}{l}\text { Roles involved in } \\
\text { the project }\end{array}$ & Informants \\
\hline \multirow[t]{5}{*}{$\begin{array}{l}\text { Approximately } 6 \\
\text { months }+ \\
\text { additional } 6 \\
\text { months for } \\
\text { implementation } \\
\text { and follow up }\end{array}$} & $\begin{array}{l}\text { Regional } \\
\text { Development } \\
\text { Council }\end{array}$ & Project manager & and research manager \\
\hline & Design agency & Designer & \\
\hline & $\begin{array}{l}\text { Norfors: Pilot } \\
\text { municipality }\end{array}$ & $\begin{array}{l}\text { Manager + frontline } \\
\text { personnel, } \\
\text { occupational and } \\
\text { physiotherapists }\end{array}$ & personnel \\
\hline & $\begin{array}{l}\text { Fruberg: } \\
\text { Observing } \\
\text { municipality } 1\end{array}$ & Frontline personnel & $\overbrace{\text { personnel }}$ \\
\hline & $\begin{array}{l}\text { Observing } \\
\text { municipality } 2^{\star}\end{array}$ & Frontline personnel & Not applicable* \\
\hline
\end{tabular}

*The second observing municipality has not been included in the study

municipality (one manager and one front-line staff member); and a frontline staffmember representing one of the two observing municipalities. The narrative presents the uninterpreted reflections of the informants. The interpretation and 
analysis of the events and reflections on the case are presented, together with the analysis of case B, in chapter 7 .

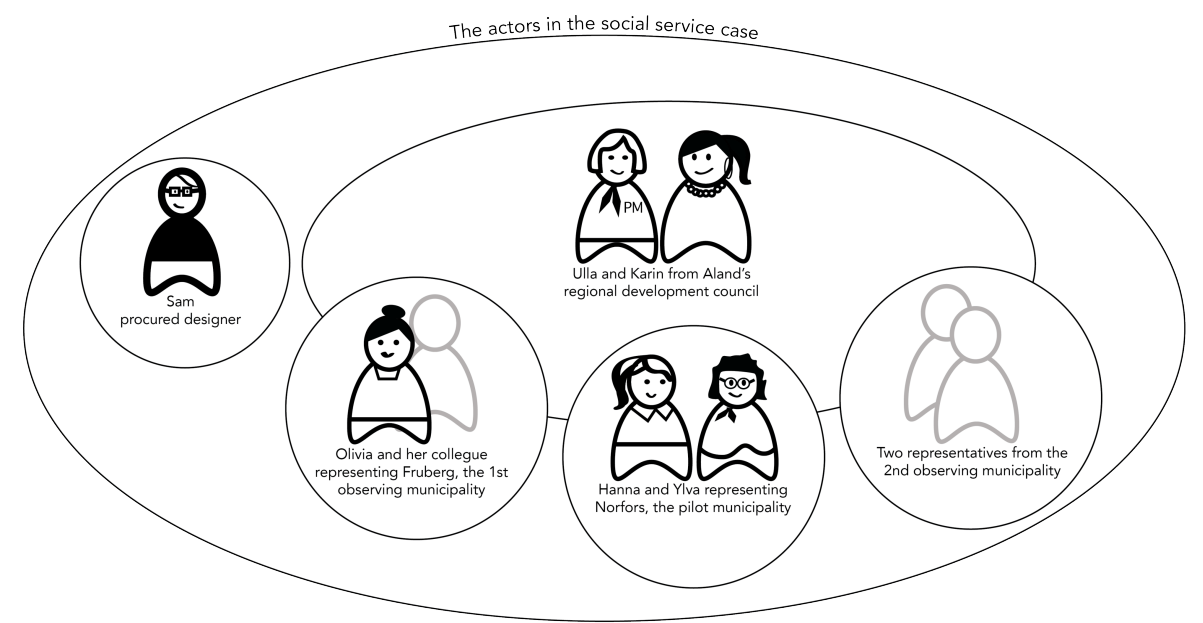

Figure 16. The initiative in the Social Service case involved Aland's regional development council, three of its member municipalities and a procured designer.

The narrative takes us through the project based on the informants' reflections on the different phases of the project as well as their reflections on expectations, experiences, and the results. In the initial part of the narrative, the designer, the project manager, and the development and research manager from the regional development council describe the background and what led up to the initiative and its setup. This is followed by reflections of the participating personnel on how they became involved and what motivated their organizations to participate. There follows some reflections from all informants on their experiences of the design driven project and its different phases; this section also includes a halfway reflection on service design by the initiators. Then follows a reflection by the project manager and the municipality personnel on one of the results of the project, namely the introduction and managing of a new mindset. This is followed by the reflections of all the informants relating to the setup of the project, its results, and what will happen next. The narrative ends with a description of what happened during the project extension and some concluding reflections from the project manager and the designer regarding the results and legacy of the project. 


\subsection{Leading up to the initiative}

$\mathrm{Sam}^{6}$ is a design consultant at a small design agency. In 2013 he approached Karin, the development and research manager within the social services at the development council of Aland, suggesting they should do some kind of project together. Sam's design agency had prior experience of working with public sector actors and was looking to not only find a new client, but also to spread awareness about the potential contribution of design. He had been referred to Karin through another contact in the region. Being referred through contacts often helped, Sam explained, as service design was still unknown in this sector.

Sam met with Karin and one of her colleagues, Ulla, to present an explanation of service design and his vision for how it could contribute in a social service context. Neither Karin nor Ulla had any prior experience of working with design and had never heard of service design before Sam approached them. However, as he presented it to them, they saw connections to other approaches and processes that they had experienced, although the user-centeredness of design stood out and felt new.

The first thing I thought of, and I think that was what you thought of too [Ulla nods agreeing], was the design school and that there it is different physical products that are designed, that is the first you think of. And then he tells about a process that you could both recognize a bit in relation to breakthrough methods in profound knowledge of improvement ${ }^{7}$ and such. But what he really emphasized was that you follow the user in their steps and this user-centric

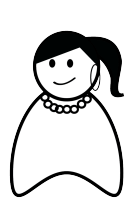
perspective. ${ }^{8}$

Karin, development and research manager, Aland development council.

\footnotetext{
${ }^{6}$ All the names of individuals, organizations, and places mentioned in the case are fictionalized to ensure the anonymity of the informants.

${ }^{7}$ Profound Knowledge of Improvement entails systems knowledge, change psychology, leadership and learning driven development work. It is described and developed by William Edwards Deming and related to quality development and technology that is often used in industry and production contexts. https://deming.org/management-system/sopk ${ }^{8}$ All quotes are translated to English by the author.
} 
Later, after the meeting with Sam, Karin also came in contact with service design through a network of people working with research and development in municipalities, county councils, or regions. Karin felt that it was the user focus that sets service design apart from other development processes. She said that other processes, such as LEAN, focus on finding and fixing problems and moving ahead as quickly as possible without ensuring that the actual problem was rectified, whereas service design had more focus on the user rather than on becoming more effective and efficient; Ulla agreed with her.

In the social service setting, Sam saw an opportunity for design to contribute to more active work with social service users, both through mindset and methods. Karin and Ulla were curious, finding the user focus especially compelling, but could not find an opportunity or platform for collaboration when they first met. Sam, however, was persistent and after some consideration, service design felt more and more rooted in their minds, and the idea of using it felt like an interesting opportunity. The selling point had been the user perspective.

In parallel with their increased interest in trying out service design, the government, together with the association of local authorities and regions, presented an opportunity to apply for governmental funding for projects aiming to increase user involvement in the disability sector. The regional development council answered the call and sent in an application for funding for a three-year project to increase user influence and involvement in the disability area of the social services. Here Karin, Ulla and Sam saw an opportunity to do something together, and Sam was procured for a six-month design project, within the the overall three-year project. Within the overall plan, the design project was called process work with users and personnel.

Karin says, it was a combination of things that made it evident that they had to try out service design: Sam knocking on their door; the user-centeredness; and that the funding they received was for work on increased user participation. They also understood that they were among the first in the country to approach the user perspective with the help of service design within the social service sector.

The aim of the six-month project was twofold: The first aim was to develop a chosen service-an activity day center for people with severe cognitive disabilities - and produce concrete results based on a user involvement perspective. Karin and Ulla stressed that for the design project to be perceived as successful, it was important that it made a difference for the day center users, since they are whom the service is about and for. They believed that the contribution of service design would be to ensure that they kept the users' focus rather than the 


\section{Chapter 5}

organization's, as it would provide a method for maintaining a user-centered mindset.

We have seen in many other situations when we work that there is a focus on the organization in the development work and in general. The users of our services are forgotten, the people for whom the organization exists. //:...:// So, this is definitely a new way to work and an exciting way to think, a way we actually need to be better at. We need to implement the mindset in our backbone, to think from the perspective of

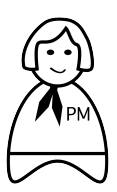
the user.

Ulla, project manager, Aland development council.

Yes, and we need a method, something concrete that makes us stop and think in new ways. Because it is easy to talk about the importance of user influence and involvement, but how does it really look in practice, and what do we mean by it? It is not completely easy when put into

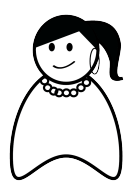
practice...

Karin, development and research manager, Aland development council.

The second aim had a more civil servant focus, where the goal was to teach developmental leaders, and other personnel involved in developmental work, methods and approaches that achieve user involvement. The idea was to test this in some municipalities through the design project; if perceived to be successful they would continue and disseminate it to the other municipalities in the region. Ulla explained how, during the project, she absorbed knowledge about service design and that the knowledge transfer was part of the contract with Sam. However, because the most important thing was that the project was valuable to the users, Karin was clear from the beginning that if the setup and design approach did not achieve this, it would be stopped.

When planning the project together with Karin and Ulla, Sam noticed that what felt like the obvious approach from his perspective - to address the issue of user involvement and participation directly on an operative level in contact with the 
social service users in a bottom-up approach - seemed new and unfamiliar for Karin and Ulla. They were used to a more top-down approach, work started on a general level in the region, with results then disseminated down to the member organizations. Sam, however, managed to convince the development council that they needed to work on an operative level with the personnel and the day center users as the aim of the project was to increase user involvement and try out and legitimize working with design as a means achieve that. Then, when they had the results from a pilot municipality and knew how it would work, they could continue and disseminate the user-centered mindset and design approach further in the region.

Karin, therefore, contacted one of the development council's member municipalities, Norfors, and presented the project idea. She asked if Norfors municipality would be interested in developing user involvement and participation in their activity day center for people with severe cognitive disabilities. The day center in Norfors operated, for example, a café and offered the day center users other work activities with support and coaching from personnel. In addition to Norfors, two municipalities without their own development projects were invited to take a passive role in the project. This way, the municipalities could exchange experience and knowledge about how they had arranged their day-activity services and their reflections on user involvement. The knowledge developed in the project would also be disseminated to more municipalities directly.

The project was set up based on a generic design process with research, analysis, ideation, and prototyping (Figure 17). For each phase, Sam facilitated workshops with both theory and practice, which the personnel from all municipalities took an active part in. The project ran for six months, from November 2013 to May 2014, and was led by the designer Sam together with Ulla as a project manager.

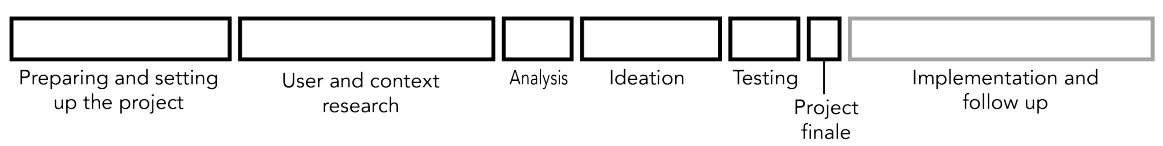

Figure 17. The project was structured based on the four phases in a design process: research, analysis, ideation and testing. The time for implementation and follow up was added during the project. 
Chapter 5

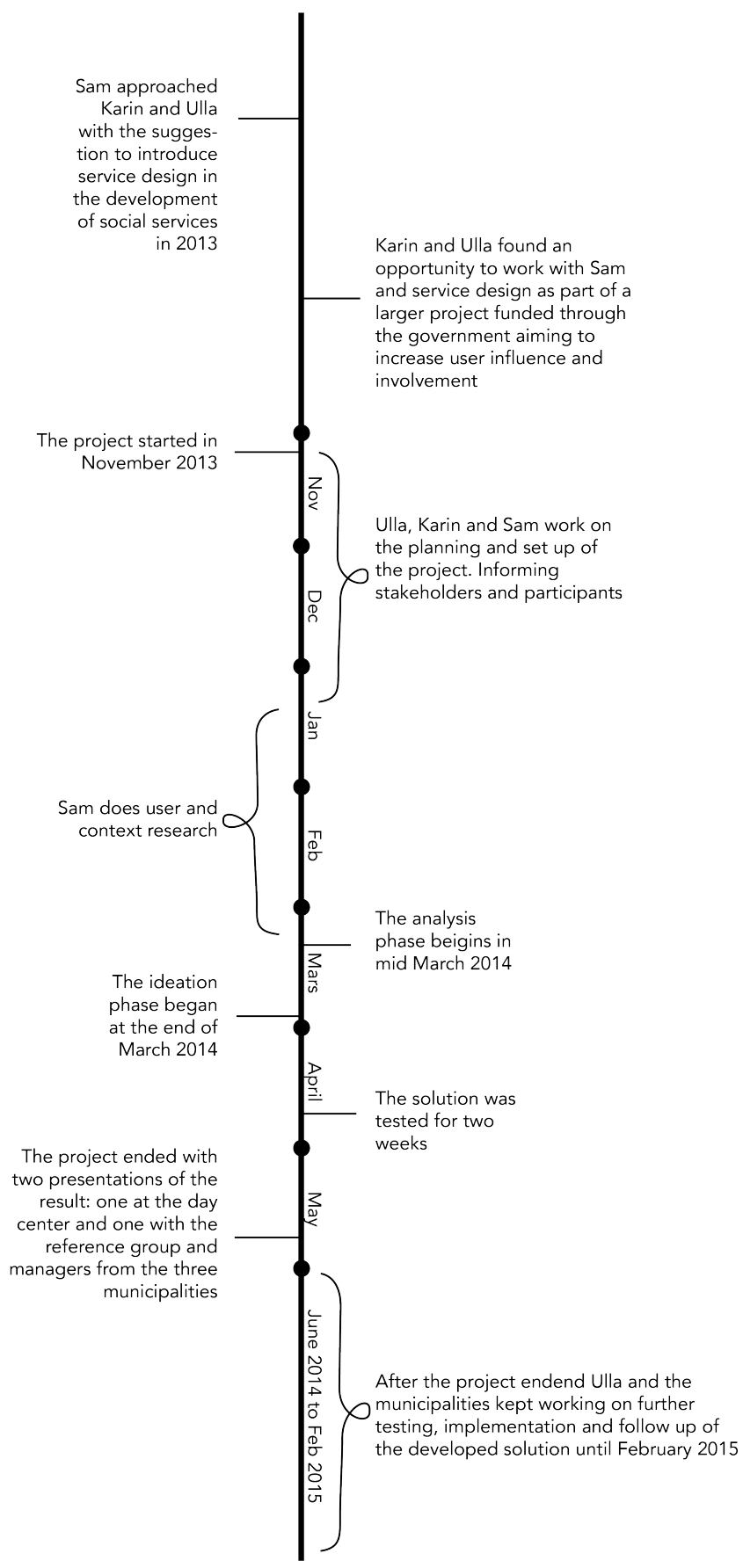

Figure 18. Sam first approached Karin and Ulla during 2013 the project that then followed went on for approximately six months with an extension for implementation and follow up. 


\subsection{Motives for participation}

Karin made the initial contact with Ylva, who is the division manager of disability related questions in Norfors municipality. When Karin asked if they would be interested in participating in the project, Ylva instantly felt that this was something to which they should say yes. She had prior experience of working with user participation and influence from another municipality, albeit not in this manner, and felt that Norfors needed to address these questions too. She saw a need to work with these questions in Norfors as old habits and the culture in the organization did not give room for user involvement. She thought that this project could present an opportunity to break old patterns and find methods that could support increased user influence and involvement. However, Ylva did not manage the day center activities and did not work specifically with the target group of the project and so persuaded her colleague, Oscar, who managed the day center activities, that they should take part. Oscar, however, did not have time to participate in the project himself, so Ylva stayed on in the project as a representative at a management level. In addition to Ylva, two members of the operative personnel at the day center took an active part in the project by attending the workshops. Although, to some extent, all operative personnel at the day center were involved as the practical work was carried out among them and results, insights, and tests were discussed among the personnel between the workshops.

Karin and Ulla also contacted the managers of similar services in two other municipalities and asked if they would be interested in following the project, taking part in workshops and designing work, but as observers without their own design project. The manager of the day center in Fruberg (one of the two observing municipalities) asked the personnel if they were interested in taking part of the project. Olivia, one of the operative personnel at Fruberg's day center, described that when asked if they wanted to participate they all felt that, yes, this was a chance they had to take as it was not often they were offered any kind of competence development. 
We have never been offered something like this before. Everything is usually targeted towards the elderly care. So, it's an opportunity to take part and a chance to meet other

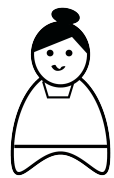
municipalities, it doesn't happen very often.

Olivia, day center personnel, Fruberg municipality.

Karin and Ulla stressed that it was important that the municipalities wanted to take part in the project themselves. Like Olivia, they also noted that most efforts and initiatives related to competence development within social services were directed to areas other than the competence field working with people with cognitive disabilities.

The manager of the day center in Fruberg supported the participation and considered the project to be important; she thus ensured that the personnel would be able to take part in the workshops. The personnel at the Fruberg day center saw the project as an opportunity to meet and exchange experience with other municipalities. Therefore, the entire personnel group, including the manager, took part in the first workshop. As they understood the setup better and saw that the other municipalities were only represented by a few members of staff, they only sent one or two representatives to the workshops, and the manager did not take part again until the final project presentation in May.

Karin and Ulla think that, other than its user-centeredness, the appeal of the service design approach is that it keeps close to practice. They see it as a structured and concrete way of working that is accessible for the personnel who work with the target group daily.

\subsection{Experiences from the design project}

The project began with a start-up phase during which the different actors that were to be involved were informed about what service design was, why they were working with it, and the project setup. Both Ulla and Sam said that this phase took more time than expected. They wanted to introduce everything properly and to ensure in particular that the users and their trustees and relatives felt comfortable with what would happen during the project-interviews, observations, design 
probes, ${ }^{9}$ and video recordings, for example. Ulla says that it was necessary to take the time for this to ensure the day center users' integrity and prepare them, as many of them have problems with new things and people.

After the start-up phase, they went on to the research phase, during which Sam conducted interviews with users, personnel, and management as well as making observations in the day center context. The initial intention was that all municipalities, including the observing municipalities, would take an active part in the design activities. Sam explained that this would ensure that the personnel were given a hands-on opportunity to try out and experience different methods - such as user observation, interviews, service blueprinting, ideation, and prototyping methods - in all phases of the design process. However, due to the cognitive disabilities of the day center users, meeting lots of new people could be difficult; thus, it was decided that the observing municipalities would not actively participate in this part. The Norfors personnel also did not participate, even though the day center users already knew them, because of the dependency situation between the users and the personnel. The design team (consisting of the Sam, Ulla, and the personnel from the three municipalities see Figure 19) feared that the dependency of the users in relation to the personnel would affect the user research if the personnel conducted it. Therefore, it was decided that Sam would carry out the user research alone to limit the number of new people the users had to meet. He documented the interviews and observations by video and presented the research to the entire design team. Sam also visualized the material in a mind map that showed the connections between the day center users, personnel, thoughts, dreams, needs, et cetera, and the different activities at the day center (Figure 20).

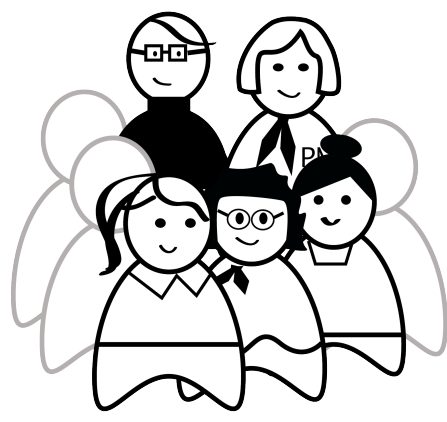

Figure 19. The design team consisted of Sam, Ulla and the representatives from the three municipalities.

\footnotetext{
${ }^{9}$ See Mattelmäki (2006) for a thorough description and discussion about different kinds of design probes and aspects around design probes.
} 


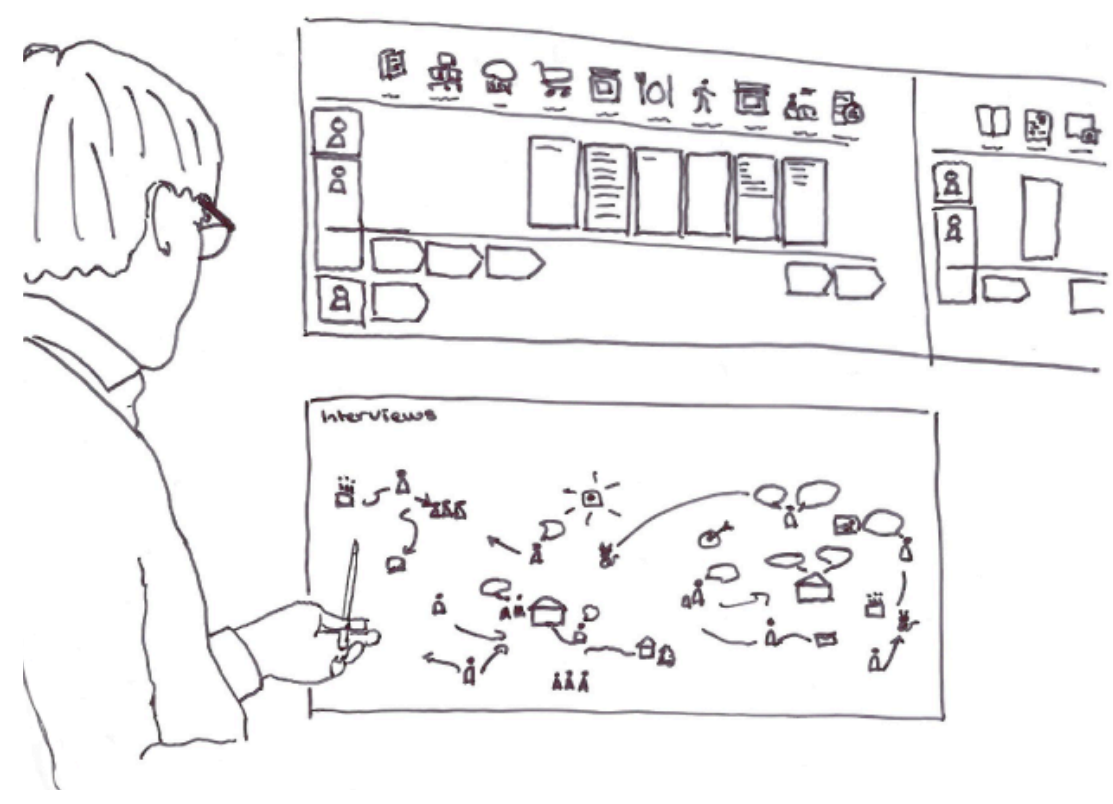

Figure 20. Sam presents the result from the blueprinting exercise (above) and the visualization he made from the interviews and observations (below).

As the project went into the analysis phase, the video documentation and the visualizations were discussed by the design team as they tried to create an understanding of what it was they saw. As a support in this work, they used sense of coherence ${ }^{10}$ as an analytical framework. Ulla thinks that the visualization Sam had made gave the personnel a new view of their practice as it was presented through the eyes of Sam, an outsider. This was probably both exciting and frustrating for the personnel, she says, since they felt that they were doing a good job, but someone else had noticed things that they had not noticed or reflected on. Ulla says that this presented a challenge and thought that it was good that they had Sam, who came from the outside and could be the one that points to or questions challenges rather than someone from inside the organization. Ulla says that the personnel were proud of their work and that this was a feeling the project had to maintain while also presenting new perspectives. She also thinks that working with visualizations, which is normal in service design, was a strength in

\footnotetext{
${ }^{10}$ Sense of Coherence is a theory originally developed by Antonovsky it refers to how humans function and relate to, for example stress. https://en.wikipedia.org/wiki/Salutogenesis\#Sense_of_coherence. The theory is commonly used in social service and welfare but also within county council operations...
} 
relation to the day center users. She thinks that Sam's use of visualizations in his interactions with the users supported communication since many of them have a limited spoken or written language. Hanna, Ylva, and Olivia all confirmed that the visual material supported their understanding and reflection on the users' needs and involvement.

During the discussions, Ulla noticed some caution among the personnel from the two observing municipalities. They did not seem to really dare to articulate what they saw in the material or fully share their own experiences. Ulla also felt hesitancy from all personnel groups when she asked how the project thus far had affected their work with the users. She thinks that they had not really thought about this and that she should probably have prepared them for the quest so that they could have reflected a little on it beforehand.

In connection to each phase of the design process, Sam held workshops in which he introduced the phase and the tools and methods used in it before they all did exercises connected to the phase. In the research phase, they looked through the videos of the interviews and observations and discussed what they had seen; they also mapped the information in a service blueprint ${ }^{11}$ exercise. The personnel were first asked to map the actions and tasks in the activities the day center users could take part in at the day center in Norfors. They were also asked to differentiate between the tasks and actions the users performed in these activities and what the staff did.

... it was one [exercise] that was a bit of an aha-moment that I had not thought of. //: ... :// We were to think of [the café service] from start to finish. What was needed and who did what. What the personnel does and what the users does. And it became pretty clear when he [the designer] had placed on the top half what the personnel did and on the lower half what the users did. But the question is which of the tasks can we move down so the users get more to do [become more

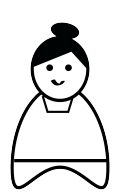
involved]. It was a good thing, easy to survey.

Olivia, day center personnel, Fruberg municipality.

\footnotetext{
${ }^{11}$ A service blueprint is a design tool for mapping the events occurring in a service both on and off stage. See, for example, http://www.servicedesigntools.org/tools/35 for a description of the tool.
} 


\section{Chapter 5}

Sam then made a visualization of their mapping (Figure 20), and they discussed which actions or tasks could potentially be moved from the staff to the users in order to increase the users' activity, involvement, and participation in the activities. This exercise made a big impression on the staff from both Norfors and Fruberg.

\subsubsection{Reflections after the user research}

Ylva and Hanna from Norfors both expressed that the insights from user and context research triggered reflections about how the activities they provide in the day center were set up. Ylva and Hanna say it was an eye-opening experience when they realized the difference in mindset between how they had worked with the users before and how they worked in this project. Sam says that when the design team met in the middle of March to go through the compiled research material, the personnel from Norfors told him that they had already started to make changes to their practice based on insights gained from discussing the research material. Ylva and Hanna describe the difference they experienced with an example from another project that they did in parallel to the design project. They were moving one of the day centers activities to new facilities. In this project the users had not been involved and did not participate at all in the planning or decision-making. Changes were normally just discussed between the staff and Oscar, the operative manager of the day center. The users were only informed when everything had been decided. Ylva explained that, in general, the users were hesitant to change as it could upset them and cause disturbance. Influenced and inspired by their insights from the design project, the personnel started to reflect on the possibility of involving the users at an earlier stage and so this time involved the users in the move. They let them come along and look at the new facilities before the move and take part in packing boxes. The results were good; the users accepted the change well.

The Norfors personnel were also inspired by insights from the service blueprint exercise and the encouragement to test and try things out during the design project. The Norfors personnel saw that many of the tasks carried out by personnel in the activities could actually be done by the users if they had some support; after reflecting on the results from the service blueprint exercise, the Norfors personnel reviewed the activities. They started to look at possible changes in day-to-day routines that could make the day center users more active and involved in the activities. They also started to try out and prototype these changes. 
Hanna: ... it became interesting when we started to look at each moment and activity during a workday, what was done by the user, where is he or she involved in the work. That's when we saw that the staff were actually doing most of the work. So, when I started to work on that, it was more and more that we could let the user do if we only get the tools.

Ylva: It's possible to work with simple tools to make them more involved. It sounds big, but as you say it could be just changing some materials...

Hanna: Yes, and not take the simple way and do it yourself because it will be faster. It's for the users we work. This is

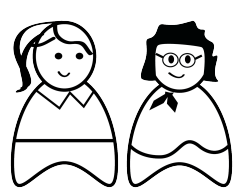
their workplace.

Hanna, day center personnel and Ylva, division manager, Norfors municipality.

Olivia also says that the personnel in Fruberg realized that their users could be more actively involved in many of the activities at their day center. Although they have always tried to keep the users in focus when planning the activities and other services at the day center, she explains, they realized that given the right support the users could do many of the tasks done by the staff. She thinks that it could be old habits, but also a lack of time at that particular moment, which makes the personnel do things that the users could have done, instead of making changes that would enable the user.

... sometimes you probably don't reflect on it. Many times, it's lack of time that makes me, as staff, do something when it would be better to try and change the routines or what the problem is and make it possible for the user to do

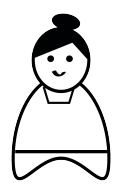
it. That would make them more involved.

Olivia, day center personnel, Fruberg municipality.

The insight that the users could be more involved and active in the day center activities if they were just given the right conditions led to the expansion of the design team with people that had occupational therapy or physiotherapy 


\section{Chapter 5}

competence from Norfors municipality. With the added competence, the design team would more able to assess which tasks and activities would be possible for a user to participate in, given the right support.

\footnotetext{
Yes, because often times I experience that the management only says no, that won't work, and then it is stop instead of thinking about why it won't work. Well it might need adjustments in the work environment, well, then let's bring in the ones that have that competence. And if it then turns out no, it won't work, well then that has to be accepted, but that we at least give the users a chance to fulfill what they want to work with.

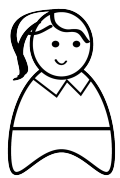

Hanna, day center personnel, Norfors

Municipality.
}

Ylva says that these competences have always been available to the day center, but now they wanted to become better at using them. They should start assessing what is possible and not in terms of support to enable the users to do things instead of the personnel.

\subsubsection{A halfway reflection on service design from the initiators}

The start-up, research, and analysis phases together took up the first four months of the project, and some participants had already started to practice some of the design mindset, tools, and methods outside the project.

Ulla said, about three months into the project, that even though at first she had not been able to fully pinpoint service design, now as the project had commenced and she had started to experience the process, methods, and tools she noticed that some of the parts were familiar. They reminded her of other approaches or methods such as process mapping. She felt it was process work, but with a new touch and new expressions, that the tools related to design could be kept and used even with other processes if they did not like the whole design approach.

It's the tools in the toolbox that can be kept actually.

Regardless if you buy it all, you can work with all of them or 


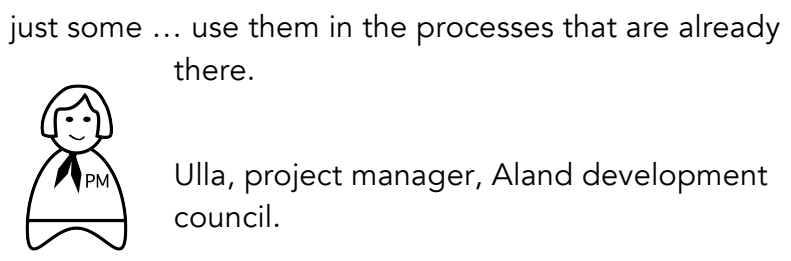

At the same time, Ulla and Karin also reflected that most of what they saw of service design was the tools and methods. They had not taken in or discussed the theory behind these. In the project, they focused on the practical and trusted Sam's competence. Karin, however, believed that if they were to take it further and continue and disseminate service design inside their own organizations and those of the municipalities, then at least some of them would also need the theoretical background. Ulla felt that the way the project had run thus far had been enough to introduce the tools and create a platform where the personnel could exchange knowledge and experience, put words on things, or reflect on their professional role and the services. She noted that none of the participants had yet asked about any of the theory and she thought this might be because they were too busy with what they had in front of them.

\subsubsection{Reflections on the ideation, prototyping, and finale}

The analysis phase ended with a problem area on which they focused as they went into the ideation phase at the end of March. When Ulla first mentioned the problem area to Oscar, the operative manager for the day center, she was surprised by his reaction. She explained that he almost gave a defense speech for the way they currently worked with this issue, and she thought that it would have been good if he had participated in the project.

In hindsight, I can see that it is a pity that the manager has chosen not to take part in this process together with his staff. This is something for us to think about. A group leader and also the division manager is taking part. I think anyway that I managed to explain that it is not criticism, it is about seeing development opportunities and improvements. But I will 


\section{Chapter 5}

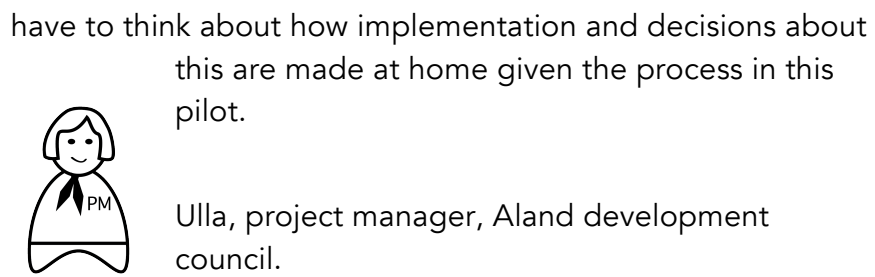

The vision for the work is to make a difference for the day center users on different levels she explains. The design project is working on an individual level, which, Ulla says, is also the level the day center personnel can affect. However, she thinks there is other work going on in parallel on a structural level. Ylva, the division manager, has mentioned this Ulla says.

To gather examples that could inspire and support the continued ideation work, Ulla conducted desktop research based on the problem area. She felt that a recurring challenge as they worked with ideation was maintaining focus on the individual level where the day center users could be part and influence. The discussion easily fell into focusing system level issues where the users are not involved and the day center personnel did not have a mandate to influence either. Ulla also saw another challenge - the ideation during the workshop became more of a discussion and comparison of how things worked in the different municipalities rather than a means of generating new ideas. Because Ulla and Sam thought that they did not quite get enough new ideas to work with from the workshop, Ulla asked the personnel to continue thinking about solutions after the workshop when they were back home and email them to her. This was successful, and they got many new ideas; she thought that the format for generating ideas together might have been unfamiliar and a little uncomfortable for the personnel.

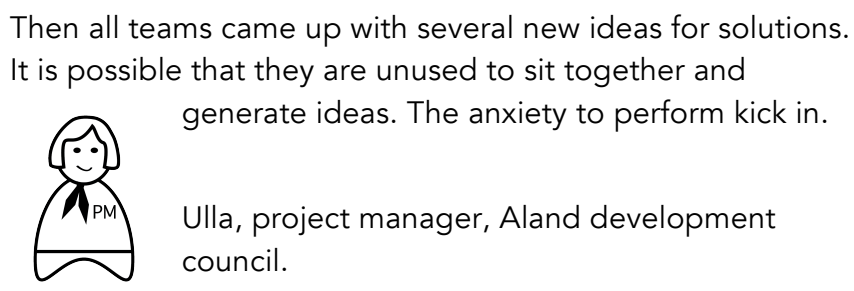

The personnel were asked to add ten ideas, but sent in twenty while they were at it, Olivia says. Because there are slight differences between the organizations across the municipalities, the concept they were working on did not feel as relevant Fruberg as it did in Norfors, Olivia says. She thought that it had probably been 
easier for them to start user focused working than it had been in Norfors. In Fruberg, they did not have the same historical cultural baggage that Norfors had with its focus on care from the old institution, which affected how the services for the user group were organized Olivia explained. Despite the differences, she says that it was valuable to get input on how they could think when they plan their service to maintain user focus. For example, she reflects on how they put themselves in the shoes of the users when they generated ideas. It is easy to slip into a personnel or organizational focus and perspective she says.

Based on the ideas the personnel had generated, Sam and his colleague at the design agency developed a concept that they presented to the personnel as the design project went into the final prototyping phase. Based on the concept, the design team discussed and built a prototype that the personnel from Norfors then took with them for a two-week test period before the project ended. Ulla says that two weeks was much too short for the test period, but the start-up, research, analysis, and ideation phases had taken most of the project time. The personnel only managed to have some initial conversations and invite a few users to test the concept.

I can state that the start-up, research, analysis, and development phases took about $85 \%$ of the time we had at our disposal. Now the time to test the new user-centered

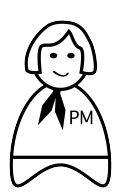
concept is only two weeks.

Ulla, project manager, Aland development council.

Although two weeks was a tight timeframe for testing the prototypes, Ulla was convinced that the design team, including herself and Sam, had needed the time spent prior to this to fully get to know and understand the context, the users, and the personnel in order to get ideas that could be developed into a concept.

Sam explains that the testing in Norfors went a little up and down. The personnel were positive in general, but had a little difficulty in finding the time to test the new concept as it also implied explaining it to the day center users, which was at times difficult. Their impression, however, was that, to the extent they had been able to test, the users had liked it and had also become more involved. The personnel from Fruberg and the other observing municipality did not take an active part in the testing of the prototype for the same reason they were not 


\section{Chapter 5}

actively involved in the user research, i.e. to ensure there were not too many new people for the users.

The next challenge for the personnel in Norfors, as Ulla saw it, would be to communicate the idea and vision of the concept to other actors that would be influenced by it.

The results from the test period and a final solution were presented in two final meetings: one for the day center users and their trustees and relatives, and one where the design team invited other personnel and the managers from the different municipalities. During the meeting with the municipality personnel and managers, Sam gave a brief presentation of the different phases in the design project, and the final concept was presented. The concept and the project were very well received both in Norfors and by the management of the other municipalities.

Oscar, who was initially a little hesitant towards the problem area, was now very positive and proposed that the personnel group from the day center that had been part of the project should present the work to other day centers and related services within the municipality. He said:

We thought we worked with the users at the center, but it turned out we could do so much more.

Oscar, operative manager at the day center, Norfors municipality. ${ }^{12}$

Also, the managers from the other municipalities expressed interest in continuing the work towards the implementation of the solution in their own municipalities, Ulla says. She thinks that the fact that it resulted in something concrete, which could be used, had a big influence on the experience of the project among the day center users who had been involved through the user research and prototyping. They felt that they had been part of developing this, she says.

\subsection{Managing a new mindset}

One of the project's objectives was, as mentioned in the beginning of the presentation, to introduce user involvement as a mindset and as a transfer tools for

\footnotetext{
${ }^{12}$ Quote given in Ulla's project diary 27/6-14 and in the project report.
} 
achieving this in the services for the day center users. Historically, in Norfors there had been an institution where people with severe cognitive disabilities were placed and taken care of. A new perspective on and regulations relating to the support and service for people with cognitive disabilities led to its closure in the $199 \mathrm{os}$. At the institution, the focus had been primarily on care rather than support or coaching. Although it was long since the change, Ulla says that the paradigm shift was in some aspects still ongoing. Remnants of the old mindset focused on nursing and care still shone through at times. At the same time, new users who had grown up as part of society and were used to support rather than care were now coming to the day center, as were new personnel with experiences, training, and perspectives that differed from those of the old mindset. Thoughts about how to be user focused had lived in the back of, at least parts of, the organization's head for a long time, Hanna said, but it was difficult to articulate and put into practice.

Lena, who I work with now, has these ideas in the back of her head all the time but has not been able to get through. She has had a wish that it should work kind of like this. So, when we now began and I came on board and had the same ideas

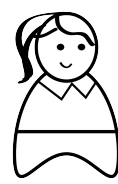
as her, she became overjoyed.

Hanna, day center personnel, Norfors municipality.

It becomes easier when you have someone else who shares you vision, Ylva says. The organization was stuck in old habits and a mindset of care rather than coaching and support, she explains. Hanna means that there is a routine and everyone does the same thing they have always done. Ylva and Hanna felt that the design project had legitimized a more user focused mindset and that they had become two in the operative personnel group that shared these thoughts. It made it easier to make changes that challenged the old mindset. Also, Olivia from Fruberg reflected on the value of there being more than one person in a work group that hears and sees the same things; this enables them to discuss and share their reflections. From the beginning, almost the whole personnel group from Fruberg had taken part in the project and could thus discuss the experiences from the workshops and relate them to their own practice. Halfway through the project, only Olivia and one other colleague remained. The others had not been able to follow the project through for various reasons - one had retired; one only worked part-time so it did not work; and for one, the work schedule did not match with 


\section{Chapter 5}

the workshops, which were always on Mondays. Despite this, in general Ulla was positively surprised that the personnel took the time to be part of the project and that, despite fairly short notice, they had attended all the different workshops she and Sam had run.

A focus upon user involvement required a shift in mindset and culture for the organizations. Thus, one aspect of the design project was to understand and articulate what user involvement implied.. This was the main topic for one of the workshops that focused on the personnel in the initial research and analysis phases. Ulla explains that the personnel were confronted with different leadership styles that could be used in relation to the users - the coach, the teacher, and the boss. Based on these, they then discussed what user involvement implies and how it relates to different mindsets and leadership styles as well as what this meant for their professional roles.

Ulla says, at times, it was difficult to push the agenda of a user-centered mindset. She was worried that the personnel could interpret it as a critique of the way they worked. The discussions in this workshop, she felt, helped them understand how their roles would fit in the new mindset. There was also a fear among the day center personnel that the new concept that they developed and the new user-centered mindset would not be welcome among other personnel - such as physiotherapists, nurses or other roles with a professional title - as it would imply less power and mandate for them, Ulla noted. She repeatedly had to remind them of how they could think about their own role; how they were working with a user perspective; that it was the users who were in focus; and that they, as personnel, were there to enable and support.

We have talked quite a lot about this and I have also tried to problematize it when we have met. And I did it again at the project finale. This, with seeing oneself as a resource for the planning and not just a key actor in one's profession. That, when the user has decided or chosen an area that they want to work with then one should say, how can we then work to support this, and that this is when you become involved as an occupational or physiotherapist. One should not see this as being excluded, but that one has a different role [compared 
to before]. Go from the one that makes decisions to the one that enables the user to do what he or she has chosen.

Ulla, project manager, Aland development council.

Halfway through the project, the new mindset was, in Ylva and Hanna's opinion, the most important lesson from the project for reflecting on what user involvement implies. Hanna thought that this might have been easier for her to absorb as she began as a new employee in the middle of the project. Because of that, she did not have any of the old routines or culture to relate to. She could take in the user focused mindset directly. Otherwise, she thinks it is easy to get stuck in old habits. Just the other day, one of her colleagues, with many years of experience working in day centers, said that this mindset is what they have always worked by, Hanna explained. She and Ylva, however, do not agree and pointed to the changes they have already made during the project. Ylva said that this is an example of why they need to discuss in the personnel group what user involvement implies and continue to work based on those discussions. Now they reflect on what they are doing, why they are doing things the way they do them, and how they could be done in a different way; she felt that this was a result that showed that they had developed during the project.

Being part of a project like this - focusing on increasing the user involvementwill upset the old balance and will be a little uncomfortable, Ylva and Hanna explained. They felt, however, that the staff opened up to it as they were given the opportunity to take part in the design team and test the new mindset and methods. Ylva thought that now everyone was onboard. She says that the new mindset that the design project brought with it made it easier and faster to make changes that would probably have been made eventually regardless, but it would have taken more time.

It became more accepted, somehow, to get started. //: ... :// And because we are in a project, one can't say 'no, we don't

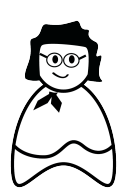
want to.' Everyone has to be on board.

Ylva, division manager, Norfors municipality. 


\section{Chapter 5}

She also thinks that it might have been a provocation for some that she and the designer came as outsiders to the day center and asked uncomfortable questions about how and why they did things the way they did. That some of the personnel might initially have felt: do not come here and mess with our way of working. However, she believes that when they became part of the design team, testing and experiencing the new mind set, the personnel turned around and now they were all onboard and no one acted as a barrier.

\subsection{Reflections on the setup}

Sam describes the project setup as focusing on the design methods and tools. He had the impression that, on an operative level at the day centers in the municipalities, they did not have a process for improvement or development work. Olivia says that in Fruberg, prior to this project, they had not structured their work through development work, confirming Sam's impression. There had always been ideas for improvements over the years, but there had never been a structure for creating ideas or exploring how to go forward, she explains. Usually someone had an idea that the personnel group then discussed, she says.

Therefore, each workshop had a theoretical part in which Sam presented the phase they were in and some methods and tools before they started working. He hoped the design project would create the conditions for the personnel working with the users to become more active in the improvement and development work of their services and practices; and to make them feel that it is okay and welcome to propose and test ideas. To encourage this, he made sure that the whole design team, the personnel from the three municipalities, Ulla, and himself were involved in the ideation phase and in the creation of the prototypes. Through including the personnel he wanted to show them that this was something they could also do on their own, pen and paper is all you need. Sam explains that when he described the different phases, methods, and tools in the workshops he tried to avoid using expressions or jargon used in the design field. He tried to play it down and make the personnel dare to build, test, and assess - an approach he wanted to anchor. At the same time, Sam noted that giving the personnel the tools with which to work with change and development was not enough; the organization also had to enable them to use these tools.

... It is important because it is partly about making change more accessible I think ... To dare to try things by building 
them, then the idea becomes available to more people. And when you build, it becomes more concrete. So, I think we will put a little extra focus on this, on prototyping. Or testing as we call it when talking to the non-designers. Try to inspire and open their eyes to testing. //: ... :// I saw during the workshop [with personnel focus] that there was a lack of a platform for this. They say that in order to be better at user involvement they need to be more ... they said for example, dare to try more ideas. But then, that also has to be part of their work. When should you do it? It is not so easy to just say: 'leave the room, now we shall not be so reactionary, now

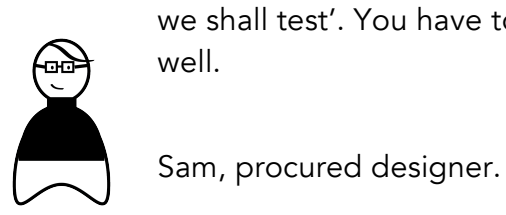

Towards the end of the project, just before the testing began, Sam thought that the design project seemed to have succeeded in increasing confidence in trying, testing, and realizing new ideas as well as in questioning how they used to work before, at least amongst the personnel from Norfors. When they started the project, the personnel had said that change was something they tried to avoid, he says. He was happy to have created some space for trying new things and for having shown that trying and failing does not have to be a big thing.

In addition, he had also noticed a shift in mindset among the personnel that had been part of the project. He noticed this in the contrast between the reflections on the user focus among those who had been part of the design project from the beginning and those who had become part of the project midway. Ulla also noticed that the personnel had a new mindset and a new perspective on the service they provided. She felt that they had opened up for both themselves and the users. Before the project, the personnel would probably have set goals for the activities based on what they thought the users wanted and could do rather than what they actually knew about the users, she reflects. Ulla said that in hindsight, the personnel had said that it was probably their own worries that created boundaries rather than the users' actual capabilities and conditions, confirming her reflections.

Setting up and running the workshops during the design process entailed a close collaboration between Ulla and Sam; here Sam had the design experience and competence, and Ulla had the domain specific experience and knowledge. Karin thinks that this cooperation and combination was part of the success of the project. Ulla agrees and says that Sam was the one who had the design tools, but 


\section{Chapter 5}

that she also recognized some of them. She had used similar tools in other projects, but not with this exact setup-diaries, for example, which they now used in the user research. She feelt that there is a red line that goes through the design project, a line that you do not see at first because it is not straight, but meanders; you first understand this when you are involved in the project.

\subsection{Reflections on the results and what comes next}

In Norfors, at the end of the project, the personnel testify that the design project had been a success even before the developed concept had been implemented. They saw a clear difference in the work environment at the day center as a result of just having been part of the project as the personnel started to use a more user focused mindset and began to test ideas. Both the users and the personnel said they were happier, and the users took more initiatives. Hanna describes how the users now welcome new users themselves and show them how to do some of the tasks.

Despite the experience of good results, Sam says that one of the personnel told him that her biggest issue was how she would be able to disseminate all these positive experiences to colleagues who had not been part of the project. Sam said that this was an issue that he and Ulla needed to think about, but he thought it was more a part of Ulla's responsibility and expertise. They had however agreed in the design team that the managers from the different municipalities would be invited to the grand-finale at the end of the project, when the final concept would be presented.

With about two months of the project left, there were no concrete plans for how the results - both in terms of developed solutions and knowledge - should be taken forward and implemented, Ulla and Karin said; Ulla says that she wishes she could say there was. She had some ideas about including the three municipalities that had been part of the project in a workshop with the other municipalities in the region, to share their experiences. Karin explained that they had not made any plans about to proceed after the project, since the aim of the project was to try out design as an approach; they have not known whether the result would turn out well and whether there would be anything to take forward. They were now reaching a point where they needed to assess the project and make a plan for the future, she says. In Ulla's opinion, the participating municipalities will have an important role in how they take it further and disseminate the results. She says that she has to involve them and listen to how they think it should be disseminated, so 
that the other municipalities that have not participated have something to relate to.

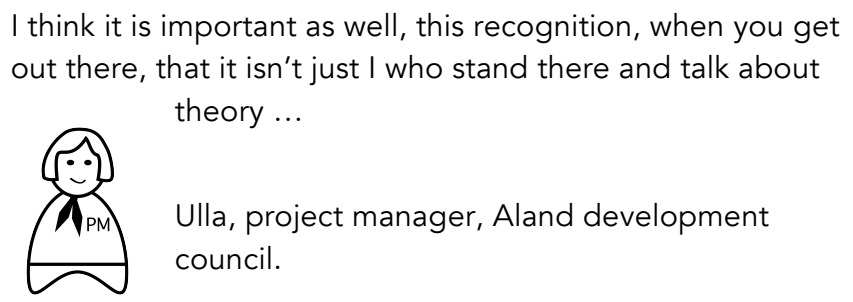

Both Ylva and Hanna had already expressed, halfway through the project, the fear that once the project ends they would fall back into old habits and lose the acquired user focus.

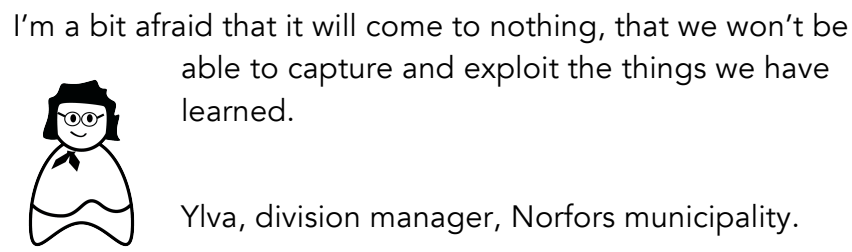

This fear was also noticed by Ulla, who said that the personnel were nervous about how they would manage on their own after the project ended. They wondered who would support them and enable the kind of work they had now done. Despite this worry, they had not discussed how to prevent this from happening. Ylva said that she hoped the inspiration that Hanna and her colleagues had gained would rub off on the personnel in other functions in the organization. They need to become good at disseminating information, she says. More directly, Ylva says that how things are taken forward or how to maintain the results from the project is a question for Oscar, the operative manager, to address together with the day center personnel, even though she too is part of the discussions about how the knowledge and experiences they have gained should be disseminated to colleagues. Oscar has been indirectly involved throughout the project through reports from both Ylva and Ulla as well as through the regular workplace meetings where the staff have shared their experiences. Ylva says that as she has shown him what they have done she has also tried to explain and transfer the mindset and tools to him. Questions about the implementation of results or potential budget issues are also a matter for Oscar, Ylva says. However, she thinks that since the process mainly implies a new 


\section{Chapter 5}

mindset, there should not be any direct costs for using this approach. Discussions about the implementation of results should be between Oscar and the personnel, she says. Ylva feels that not being the operative manager was a disadvantage in the project as it has meant she could not participate and influence the result the whole way. Sam also noted that the direct management had not directly involved in the project and that this was a disadvantage. Nevertheless, he thought that they had been able to handle it this time because the operative manager had a positive attitude toward the project.

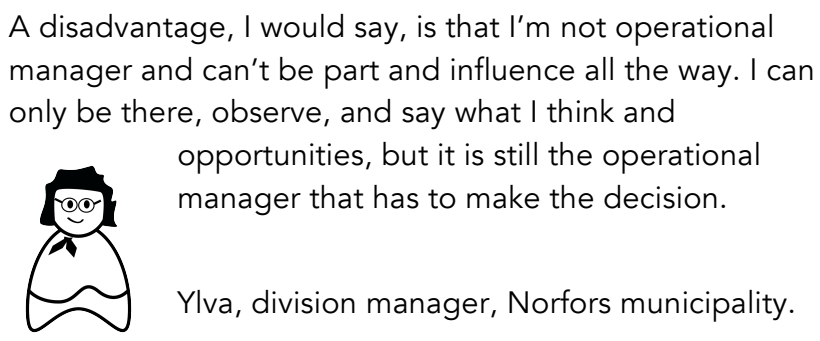

Ylva informed the political management in the municipality that the day center would be part of this project as a way to also get them on board. After the project she will report back to them with the results and that it was a valuable experience, ensuring that they are informed and hopefully have a positive view on it in case they should need to ask for funds, she says.

Reflecting on the project Hanna feels that the only negative aspect was that they did not have enough trained substitutes that could go in when the personnel were away on workshops. At first, the ambition had been that the time taken by the project would not impact on the daily operations. However, the lack of substitutes meant that the personnel who stayed had to cope alone on the workshop days. Ylva thinks that they were good at supporting each other despite this so that they were able to work with this project; they prioritized it and found it important. Hanna agrees that it worked out even though it did not go as intended with the substitutes.

Similarly, in Fruberg the thought and expectations of how to proceed after the project were not clear. The manager, as mentioned supported, the personnel's participation, but Olivia was not sure what was expected of them afterwards. She herself did not have any clear expectations of how they should proceed either; maybe in the future they will go back to some of what they have done, she reflects. 
I'm thinking of the workshop things ... maybe something will turn up in the future when we need to develop something

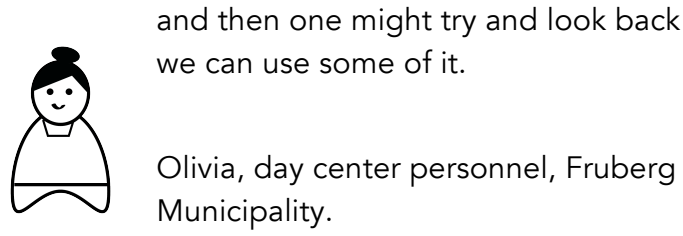

When referring to the workshops, it is mainly the blueprinting exercise she think of, she says. Similar to Ylva and Hanna, she describes it as an aha-moment when they saw the compiled result of their mapping of the tasks.

At first, when we sat there and discussed, it was a jumble, but then, when he [Sam] had done this compilation, then one understood the purpose. Then it became very clear. So it was

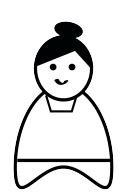
probably quite good.

Olivia, day center personnel, Fruberg municipality.

Both Ulla and Sam say that they had hoped that the municipalities would start reflecting over the process that had been used, and that Fruberg and the other observing municipality also would think about the things that had been addressed and relate it to their own practice. However, they did not want to push this reflection during the project since they thought it could be difficult to think about these things before the whole process was complete. Towards the end of the project, Sam says that with the setup and their time with the project his hope and expectation was that the personnel would take with them the user-centered mindset. If they also like and want to implement the developed concept that is a positive bonus, as he saw it.

\subsection{A six-months extension}

Halfway through the design project, the design team had already realized that they would not get much time to properly test the concept, and when the project ended in May there was still much work left. Neither the diffusion of the developed knowledge nor implementation of the developed concept had yet been addressed. 


\section{Chapter 5}

As the concept in the initial two-weeks test period was perceived as successful, it was agreed that the project would be extended another six months. During this time, the concept would be further tested, refined, and implemented. Sam was still part of the work, but not to the same extent as he had been during the first six months, and it was mainly Ulla that oversaw and drove this work.

The focus during the extra six months was solely on the developed concept, its implementation, and its diffusion. Even though the approach had been successful and they had found new tools and a mindset that increased the users influence and involvement, no direct efforts were made to disseminate the design approach as a means to increase user influence. As the new test period started after the summer, Ulla expected them to face new challenges and reflections in the different organizations as the concept would need to be adjusted to fit in the new organizations structures.

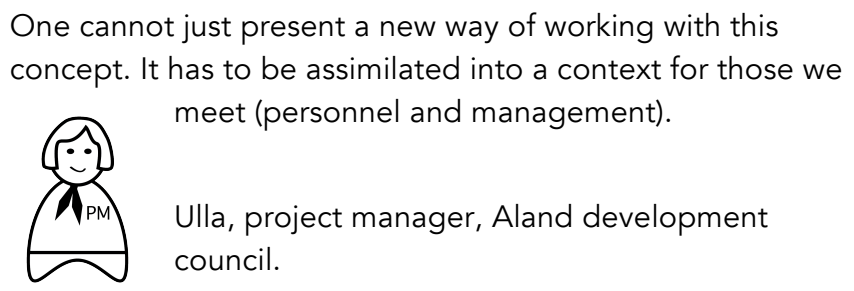

Ulla thinks that much of the motivational work will be related to a change in perspective and approach. Therefore, the research and analysis phase were important components in the design process to get things right, as she sees it.

Sam says that although the validation and implementation of the concept is a long term process, in the middle of September, three months after they presented it, the results looked very good. The concept had also gained interest from other areas within the social service such as care for the elderly. Through the networks with other regions that the regional development council was part of, the project also received attention from outside the region; thus, Ulla and Sam also had to spend time during this period traveling around the country presenting the project and its result to other regions and municipalities.

In September 2014, looking back at the project and reflecting on his experiences, Sam thought that the most important thing for a project like this was that the organizations are actively part of the co-creative process. He felt that the most important thing that he, as a designer, could pass on was the user perspective, to give those words content. Before the project, the personnel in 
Norfors said they worked with a user focus, but it was only during the project that they actually started to adjust their practice to the users and their needs, he explains. He thinks that the experiential setup, which has allowed the personnel to experience the process and insights themselves, were crucial for this change.

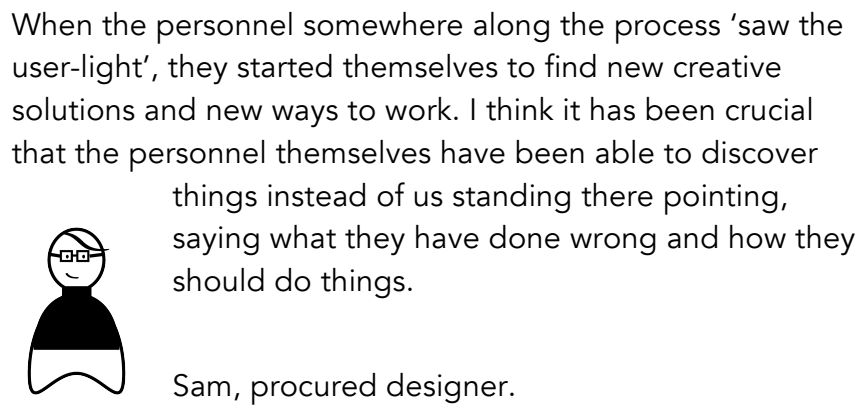

At the beginning of November, Ulla followed up on the testing of the concept conducted in Fruberg; here testing had started with two users. Also, the second observing municipality had shown interest in testing the concept, Ulla explains, but they had difficulties finding a time when they could introduce the concept, and she felt that time was running out. With the project extension, they had until the end of January 2015 before the project ended, and they wanted to collect as many experiences as possible from the users and other involved actors. In January, they would compile the material and refine and develop a final version of the concept.

At this time Ulla saw no plans for any new projects in relation to service design for the regional development council. In December 2014, she said that, as they had not yet finalized the testing of the of the concept from the pilot project, she did not want to give a final assessment of whether the service design approach and method were useful in relation to the disability area of social service and the user group that they had worked with.

Our initial problem statement was more focused on increasing the involvement and participation within the specific operation and the activities the users take part in. It turned out that this shift among the personnel came quite directly after we presented the first process map over the users' involvement. The next time we met in the design team, they had already started to change routines and ingrained 


\section{Chapter 5}

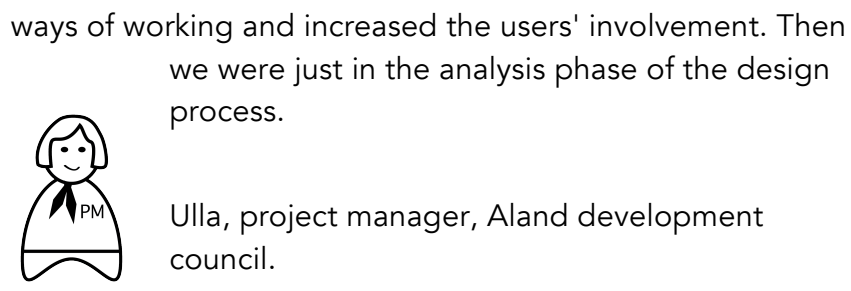

As a result of this they changed their initial problem statement a little to zoom in on a more specific problem area. This Ulla says led almost to a restart in the design process. Based on the first problem statement, she thinks that service design very quickly focused on the process and led to a change in the perspective or mindset among the personnel. In this sense, she says, service design, with its methods and tools, could contribute to an increase in the influence and involvement of the users.

Neither Ulla nor Sam thought that any of the municipalities would be able to conduct a whole design project on their own after the project ended. Ulla saw that in Norfors, where the personnel had an active part throughout the project, they were a little bolder in their reflections on and input to the concept during the test phase. When it came to reflecting on new development areas, they had more difficulties. Then they mainly relied on and followed the management's directions, Ulla says. She did not think that the personnel felt ready to use the service design approach and tools on their own based only on this project. If the municipalities had had an operational developer or similar who had participated in the project, that person or persons might have been able to generalize the methods to other or new situations and contexts, she says.

For her own part, she thinks she would be able to facilitate the process given that she has access to a guide to the four steps in the design process - research, analysis, ideation, and testing - and some of the tools associated with these. She had participated in a workshop led by the national design foundation, so she had had some practice other than their own project, which she felt was good. Again, she made connections to other processes that she had prior experience of; she says, for example, that there are similarities with Open Space, another process she has previously done a lot of work with.

In February 2015, after the project extension had ended, Ulla concluded:

Service design is a very fun and easy going, creative way of addressing a problem or change. That those who take part get involved practically and 'own the process' is very good. 
The participants can see what is accomplished all the way through. The recognition along the way is a key factor and has a pedagogic point in relation to the credibility and to make a change in small steps based on own described needs

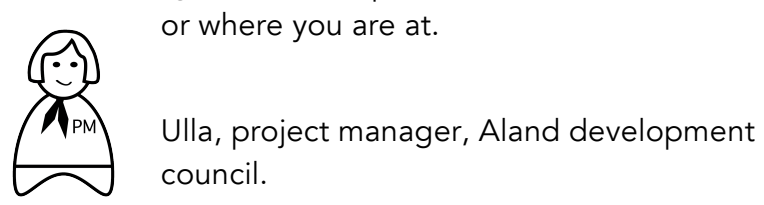

Thus ends the project and the initiative to try out how design would work as an approach to development within the social services and as a means to transfer a user-centered mindset. The narrative has presented how the initiative came about and its setup. It has focused on those who were actively involved in the initiative and, through their experiences and reflections, told the story of how design was introduced and absorbed. 



\section{Chapter 6}

\section{Case B: the Health Lab case}

Case B tells the story of Health Lab, an initiative taken within a county council to start developing an in-house design resource and the county council's design capability as a means to increase the patient centeredness of the organization and its operations.

The initiative initially received three-year national funding to support the startup and the testing of embedding design within a county council's healthcare organization, and was officially launched during the fall of 2013. The design competence embedded in the county council's healthcare organization set out to develop its design capability by conducting design driven projects with healthcare personnel and civil servants from different departments and with different functions.

In this chapter a narrative of this initiative is presented, based on the accounts given by the informants together with written documentation in reports. In the narrative, we hear the voices of the head of operations for Health Lab; an operations developer in the county council and Health Lab; the county council director; another representative of the top management; representatives from the healthcare personnel; and civil servants from within the county council. All informants, apart from the county council director and the top management representative, were actively involved in the two different design driven projects that were followed.

As with case A, the narrative presents the uninterpreted reflections of the informants. The interpretation and analysis of the events and reflections on the case are presented, together with the analysis of case A, in chapter 7 . 
Chapter 6

Table 6. Information box the Health Lab case.

\begin{tabular}{|c|c|c|}
\hline Duration & \multicolumn{2}{|l|}{2013 - ongoing } \\
\hline Number of projects & \multicolumn{2}{|l|}{21 of which 13 are finished ${ }^{13}$} \\
\hline $\begin{array}{l}\text { Actors involved in the } \\
\text { initiative }\end{array}$ & Roles involved in the projects & Informants \\
\hline $\begin{array}{l}\text { National research } \\
\text { foundation's service } \\
\text { lab }\end{array}$ & Not involved & None \\
\hline Academic partner & Not involved & None \\
\hline Beland county council & $\begin{array}{l}\text { Head of operations Health Lab, } \\
\text { project managers, director of the } \\
\text { county council, In-house design } \\
\text { resources, healthcare personnel, } \\
\text { civil servants }\end{array}$ & $\begin{array}{l}\text { Gustav: head of } \\
\text { operations, Health Lab }\end{array}$ \\
\hline
\end{tabular}

${ }^{13}$ According to the Health Lab's homepage in august 2016 


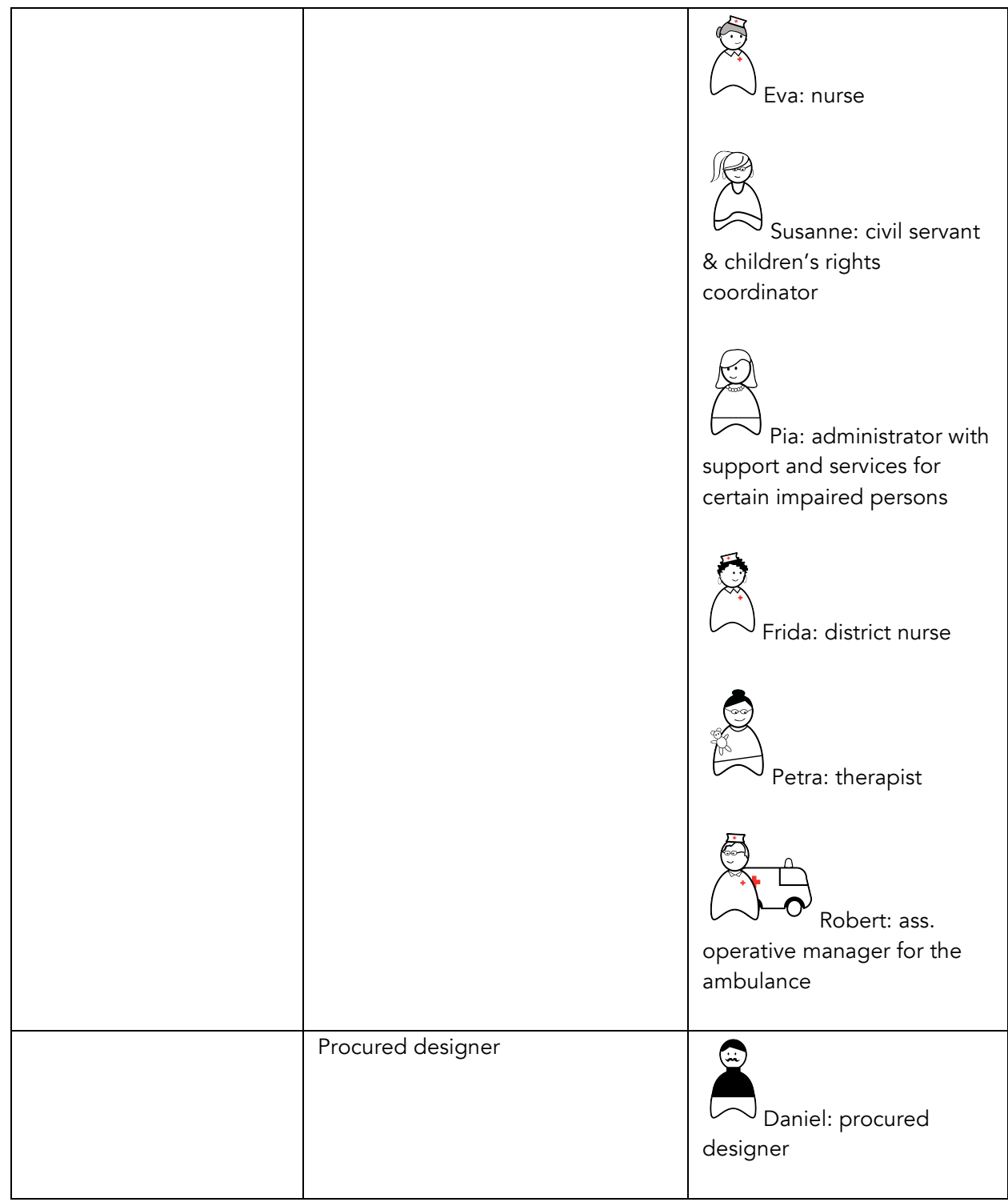

The narrative is presented as a timeline, where we initially are presented with the background, motivation, actions, and events that led up to the establishment of Health Lab. This background is mainly given by the head of operations, who drove the initiative. He then also describes the structure and organization of Health Lab within the county council. Unlike case A, the Health Lab initiative does not cover just one project, but is a venture that entails several projects conducted over time. In this narrative, after the presentation of the background 


\section{Chapter 6}

and organizational structure, we follow two of Health Lab's earliest projects: the care coordination process $(\mathrm{CCP})$ and the design training. As these projects are presented, we hear the reflections and comments of their project managers, the participants, and the project owners in regard to the, planning, expectations, experiences, and results. The narrative ends with reflections from Health Lab's head of operations and a project manager on what they have learnt during the first three years of the initiative and what challenges they still see ahead.

\subsection{Leading up to the establishment of the Health Lab}

In 2013 the county council of Beland ${ }^{14}$ initiated a venture to introduce design as a tool to increase the person-centeredness of the development and delivery of healthcare services within the county council. The venture was set up as a learning project called Health Lab within the county council's healthcare organization. An in-house design department/innovation lab with design and operational development competence was established. The aim of Health Lab was to create a platform within the organization, creating a meeting between healthcare and design where knowledge and skills could be shared, exchanged, and developed ${ }^{15}$. They wanted to create an arena for participation and involvement that would stimulate curiosity and challenge traditions in order to increase the patient value and create sustainable operational development.

In the initial mission statement of Health Lab, the involvement of users was stated as part of their strategy, and design was described as both an approach and a tool. They stressed that the user includes patients, relatives, and personnel. The mission statement said that Health Lab should initiate and drive innovation projects with a focus on the patient's journey through the healthcare system and entailed methodical learning about the use of design methods.

One of the champions behind the establishment of Health Lab was Gustav, who became the head of operations for Health Lab. Gustav had no formal design training, but had several years of experience working with design and innovation - as project manager for example - within the national design council. Most recently, prior to his position as head of operations at Health Lab, he worked

\footnotetext{
${ }^{14}$ All names of organizations, individuals and places mentioned in the case are fictionalized to ensure the anonymity of the informants.

${ }^{15}$ As stated in Health Lab's initial mission statement.
} 
as a project manager for a regional innovation incubator, supporting county council employees to pursue and develop ideas into potential innovations. Gustav had a wide network of contacts within both the design field and academia. For Gustav, the main objective was the issues of user involvement; from his perspective design was a tool to address this.

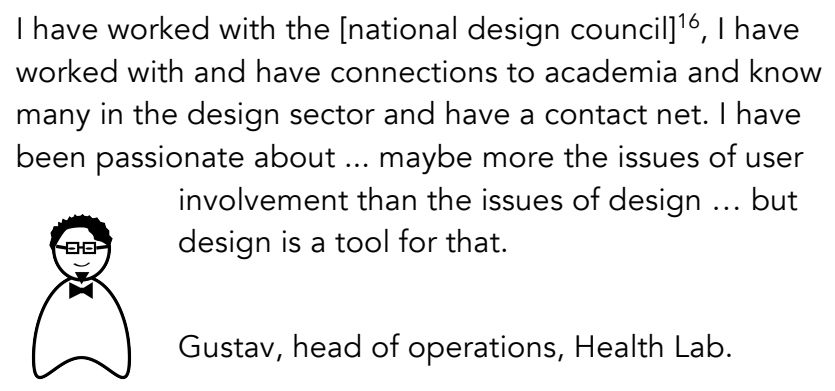

Gustav says that, as with most initiatives like this, there are many reasons why they come about. He thinks there were several different things that led up to the establishment of Health Lab. Beland county council had, in the years before Health Lab was initiated, taken a strategic decision that person-centeredness should be an area in which they would invest. This decision was based on several factors - demographic and economic, for example-but also on a budding understanding that the patients are an unused resource both in relation to carrying out part of the care themselves and operational development, Gustav explains. He thinks it also coincided, as in many county councils, with the Beland county council's desire to work with a LEAN approach, and a strategy for LEAN work with a focus on process innovation or thinking was taken. In parallel with this development, the county council also started to look at and think about how to work and organize itself according to processes rather than the functional silos that it had traditionally worked within. This work, Gustav means, was well disseminated and agreed upon within both the political management and the civil servant management.

I think ... but I'm not sure, it's maybe more a feeling I have.

That our county council was relatively early when it came to thinking along these lines. Not in any way alone or nationally leading or so ... but that it is there and it is quite well rooted

\footnotetext{
${ }^{16}$ Exact name of the organization is left out to maintain anonymity
} 
in the management structure. Both among the civil servants and the politicians, but maybe especially among the civil

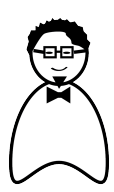
servants.

Gustav, head of operations, Health Lab.

In the fall of 2012, Beland county council set up a strategy group in relation to the investment area person-centeredness to look at how these matters should be addressed. The group was led by two members from the county council board, the head of medicine and the information and communications director of Beland county council. Gustav was invited to be part of the group because of his role as a project manager for the regional innovation incubator. Gustav then chose to have his workplace and desk at the county council's office rather than at the regional innovation incubator's office, where he still had his position officially, giving him more direct contact with the county council. Within the county council, he now started doing some initial service design projects, as experiments, through the innovation incubator.

At the same time that Gustav was working at the innovation incubator, one of the national research institutes was commissioned to establish a service innovation lab in the regional capital of Beland, where the county council also had its headquarters. Gustav initiated discussions with one of the project managers, Ian, at the research institute, and together they wrote an application to the National Innovation Agency for funding for a patient-focused service innovation pilot. The application was approved and they received funding for a pre-study. This coincided with Gustav becoming part of the strategy group and led to many of the group's discussions and work becoming part of this pre-study. The work resulted in the board of the county council realizing and deciding that if the county council were to work with patient participation then solely working on improving the current services and processes would not suffice. They would also have to dare to think afresh. Inspired by the work with experience based design in the British NHS and the design thinking and work at the Mayo Clinic and Kaiser Permanente in the US ${ }^{17}$, the board therefore decided to start developing something that could become an innovation lab for service innovation within the county council. The

\footnotetext{
${ }^{17}$ For background about the work with EBD in the British NHS see for example (Bate \& Robert, 2006) and for background on the design thinking and work at the Mayo clinic (Duncan \& Breslin, 2009) and Kaiser Permanente https://share.kaiserpermanente.org/article/kaiser-permanentes-innovation-consultancyfeatured-in-harvard-business-review/
} 
Bland county council starts a strategy group related to the investment area personcenteredness

The national research institute get a commission to start a service design lab in Beland's regional capital

Beland county council decides to start some kind of innovation lab. An application for a full scale pilot is written

The care coordination process project is comissioned in January 2013

The design training project goes on for $\sim 6$ weeks

Health Lab moves into the line organization

In January Beland county council make the decission to continnue running the Health

Lab after the pilot funding ends in January 2017
Autumn2012

Gustav moves his workstation to the county councils office

Gustav writes an application together with lan at the research institute for a patient focused service innovation pilot and it gets approved

Spring 2013

The full scale pilot application is approved, implying 3 years founding for a patient focused service innovation lab

\section{Sept 2013}

Oct 2013 The Health Lab is officialy inaugurated in October 2013

Nov / Dec 2013

Spring 2014

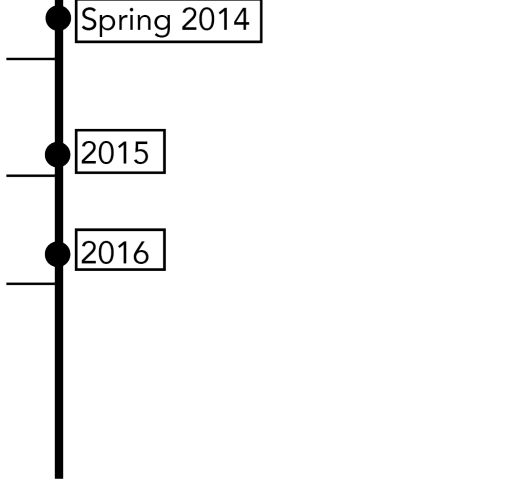

Figure 21. The Health Lab initiative started to take form in the autumn of 2012 and is still ongoing. 


\section{Chapter 6}

pre-study also resulted in a new application, this time for funding for a full-scale pilot, in which the county council's new plans were described. Since they, to their understanding, were the first to try this within public sector healthcare in the nation, the ambition to develop some sort of platform that could become a national center for patient-focused service innovation was stated in the application. The governmental innovation agency approved the application, and the county council together with the research institute received funding over three years to develop a platform and a pilot of a patient-focused service innovation lab. The pilot was formed into and officially established as Health Lab in the fall of 2013 with Gustav as head of operations. The Health Lab initiative was funded through the county council together with the national research institute and the funding from the governmental innovation agency. As part of the conditions of the funding, the initiative also had an academic partner (Figure 22).

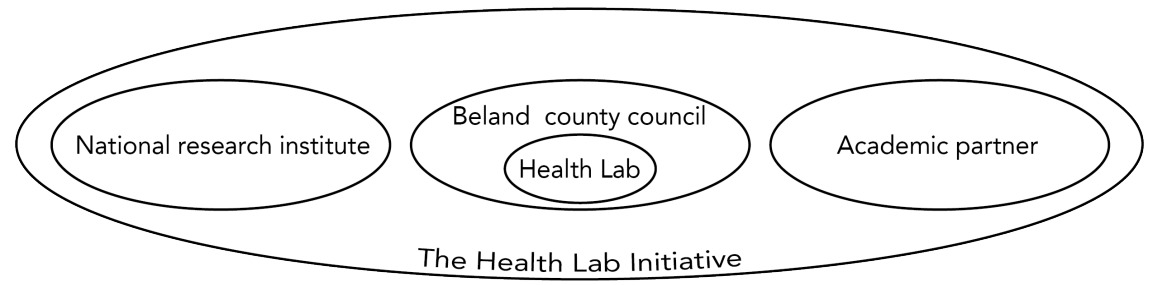

Figure 22. The Health Lab initiative involved the national research institute, Beland county council and an academic partner.

\subsection{The initial structure and organization of Health Lab}

As Health Lab was in the beginning a project, the Health Lab team consisted of a mix of temporary employed personnel and personnel that were borrowed from other departments in the county council organization-designers, project managers, and communicators. The county council organizational structure is divided into different functions - human resources, healthcare, economy, and administration, for example. Health Lab became organized within the healthcare function (see Figure 23), which Gustav's manager was the head of. Gustav says that the reason they were organized under this function was that they wanted Health Lab to organizationally belong with the people actually doing healthcare. The head of the healthcare function had administrative and personnel responsibility, but Gustav was the operative leader of the group and its work. By 
borrowing personnel from other functions, Health Lab became automatically integrated into the county council's organization.

At the beginning of the Health Lab venture, Gustav also had support from a steering committee consisting of: the head of healthcare, the head of medicine (chairman of the committee), the head of administration, and the information and communications director. The steering committee discussed, for example, the projects, economy, and development of Health Lab. They also became a link to the rest of the county council organization and could support Health Lab's connection and communication with other units or roles within the organization. When Health Lab, for example, needed approval to do a project or something in a project - for example, if they needed to free up personnel from a unit to take part in a project - the steering committee would use their network and influence to prepare the persons in charge for the request and connect Health Lab with them.

If we need a decision from the county council director, for example, then it is the head of medicine [chairman of the steering committee] who will go to the director. Or if we need accept on something. //: ... :// If we take a practical example, next week we launch a project in which we have eight people that we want to spend eleven days on, and they [their unit] will not get paid. We do not use the national funding to compensate the unit, but we will have eight personnel for eleven days that we want available for this project we are doing that involve different parts of the county council's operations. In that case, the head of medicine will prepare the board so I can come. Because it is, of course, I who will do the presentation to all the division leaders, 'this is a project I would like to do, I think it is good because of this: you will get these things out of it. If you agree then it would be a good idea that you order or enable personnel [to participate]'. Because it will imply that we take healthcare personnel from their ordinary tasks. //: ... :// In this case they thought it was a good idea, which in practice implies that we borrow eight people for eleven days [from the units]. That is

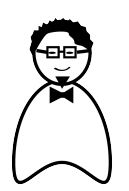
almost ninety workdays that we borrow for a project //: ...: //, as an example of how it works.

Gustav, head of operations, Health Lab. 


\section{Chapter 6}

Health Lab also had an advisory board that gave a national connection and connections to academia (Figure 23).

As part of the national funding, the county council has also had two external partners, the research institute and an academic partner. Together with these partners they wrote the funding application. The connection to the research institute was important, according to Gustav, because they were both a discussion partner and they were cofounding the pilot through working hours that they would put into the initiative.

... [The research institute's service innovation lab] and lan,

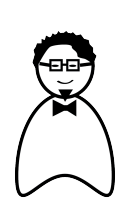
who I spent half the lunch on the phone with. We talk every day, several times a day almost, so lan is central.

Gustav, head of operations, Health Lab.

Gustav also describes that he has a wide network within the healthcare and welfare sector that could be a support and inspiration for the initiative. He has contacts in many other county councils and municipalities. He also has many contacts within the design field, both among design agencies and academia.

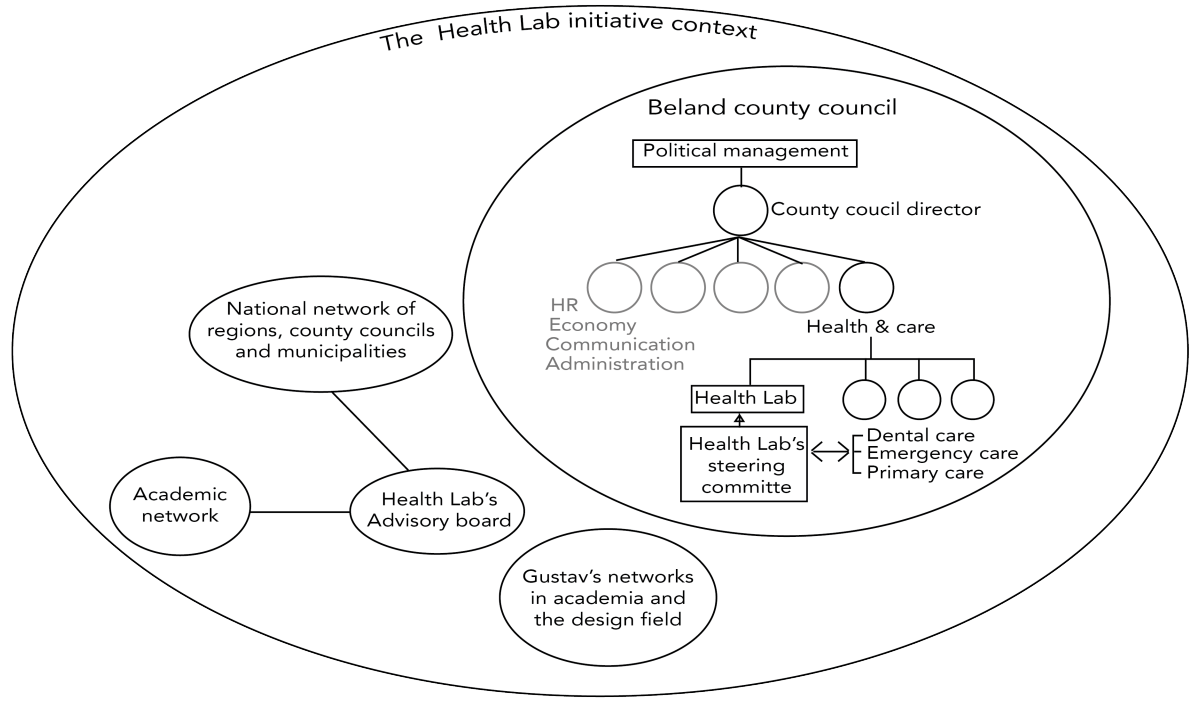

Figure 23. The Health Lab initiative's organizational setup and context. 
Although Health Lab had gained quite a lot of attention early, almost before they had really started, and other organizations sought them out asking for help and advice on how to become more person-centered, Gustav says that his vision has never been for Health Lab to become a commercial actor. The aim from the outset was to make good things within their own organization, so that the county council would choose to continue the funding after the national funding ended.

Gustav says that one of the perks, as a design lab, of being embedded in the organization is that you can have a different strategy. Often when design projects are set up, they take a route through politics, to get political decisions, he explains. As part of the organization, they can take another way. The head of medicine, for example, sometimes says that if they feel that they want and need designers for their development work then they could go together with some other division leaders and agree that together they spend part of their budget on this, and they do not have to go through the politics, Gustav retells. The division leaders have a mandate to decide over their division budgets and could employ service designers instead of traditional operational developers.

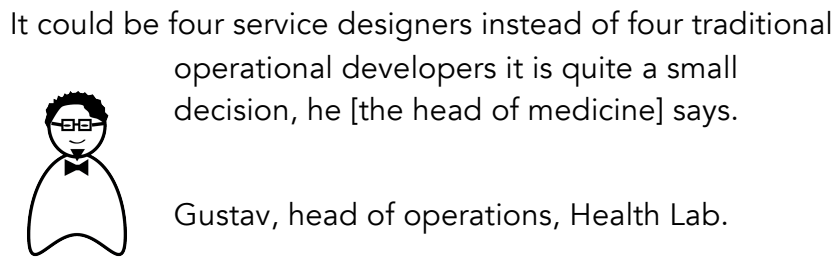

That was why Gustav saw it as important to consolidate their position in Beland county council as a first step, and hopefully later get other similar organizations to follow. If they were to sell services it would be as education or project management to other county councils, he thought.

During the approximately three years that Health Lab was running the organization, the team grew and underwent changes. In the beginning, Gustav noticed that they had some growing pains. In just eight months they went from a project on paper to a team of twelve employees with a steering committee and an advisory board. They were then in a phase where everyone was very enthusiastic and inspired by where they were heading. But at the same time, everyone in the team was trying to find their role and Gustav recalls that it was a little chaotic and messy. At this time, Gustav found it hard to find time to both develop and deliver projects and at the same time be a good boss in the mix of it all, but as he saw it as they were all new to this and trying it out. 


\subsection{The Health Lab projects}

Health Lab had two kinds of projects. The first were projects with a knowledge development focus. Here, the contribution to the experiences and the improvement of the patients was not as explicit, but rather the projects resulted in an understanding of an issue or how to work with something, i.e. new knowledge. The second kind of project was more direct and would take its starting point as an issue owned by the core operations. For these kinds of projects, the units or functions that initiated a project together with Health Lab should have an issue or opportunity that they wanted to work with, and they should provide resources in terms of personnel and time.

In Health Lab's own view, they were not to be perceived as an in-house consultancy that would develop solutions for units and departments, but as a resource that the other functions within the organization could use as support in their development work. It was therefore important that a unit working with Health Lab was the project owner, and that Health Lab supported the work by facilitating it. Another important factor for the projects was that they had to entail some sort of new design issue. When describing the character of the projects and the vision for Health Lab at its start, Gustav emphasized this aspect. He meant it would assure that Health Lab would never become a regular development unit that other departments or units could commission development work from.

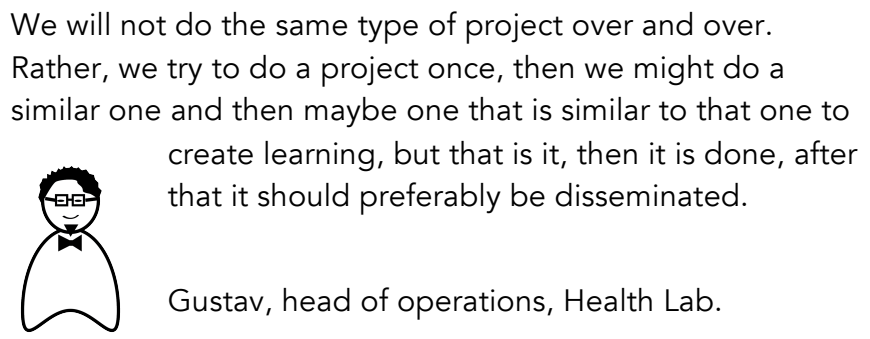

Health Lab's projects varied in both scope and focus depending on the underlying question and the resources of the project-owning unit. During the three first years, the initiative had funding from the governmental innovation agency, which covered the costs of Health Lab's personnel. Units or functions within the county council collaborating with Health Lab during this time covered their own expenses, but did not pay for the time Health Lab spent on the project. 
In this study two of Health Lab's initial projects were followed and will be described in more detail: The care coordination process project (the CGP project) and the design training project.

\subsubsection{The care coordination process project}

Although originally initiated outside the Health Lab initiative, the CCP project became one of the first projects Health Lab was involved in. The CGP was set up to map out pain points and issues in the interfaces between different actors and different silos in the care coordination of elderly patients. Johan, one of the county council's operational developers and the project manager of the CCP project, became interested in the possibility of using design methods in the mapping process when he met Gustav as he was planning the project. This was at the same time that Health Lab was being established, so Johan got support from two of its first in-house designers.

\subsubsection{The CCP prologue}

The project started at the beginning of 2013 when Irene, who was then the head of health and care in the county council, commissioned Johan to map the careplanning process. Irene would later change position and become the director of the county council. The mapping of the care-planning process was part of the budding work to change from the silo structure, which divided the healthcare organization based on function and professional expertise, to a more process focused organization. In other words, an organization based on the processes related to care flow rather than professional functions such as orthopedics and radiology. The functional silo structure had been good at having the patient in focus, but that in each different silo Irene said, now they should have the patient's focus instead. One of the county council's strategic objectives was to improve the work across the organizational silos; another was to increase of patient influence and involvement. In the CCP project both these objectives were met, Irene says.

\footnotetext{
Because we have been talking very very much about the patient in focus, and we have been good at having the patient in focus, in every organizational box. But having the patient's focus that is something else. So, what Johan was asked when he started, as an improvement leader actually, and in charge of mapping a process was that, it should be
} 


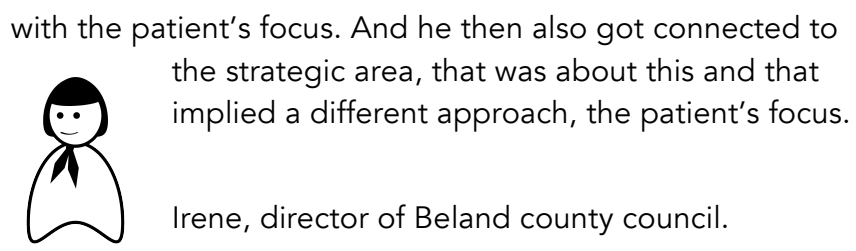

The project had been preceded by a project mapping the stroke process. This project had been carried out in a traditional manner, where different actors connected to the stroke process had gathered in workshops and made flowcharts with boxes and arrows to map what happened when a patient came into the hospital and were diagnosed with a stroke, Johan explained. The stroke process had been chosen because it had initially been perceived as straightforward and simple. The work, however, had revealed a much more complex process than anticipated as they realized how many different paths different patients took through the system. An issue after this project had been that the results - the picture of these different paths - had not been disseminated to the rest of the organization, but stayed among the personnel that had been part of the project. Another insight from the project had been that the organization had to start encouraging development work at the management and middle management levels of the organization. Irene and André, her successor as head of health and care, explained that the organization had to support and encourage a cultural change, implying a move from a focus on budget to a focus on quality.

Johan does not have a clinical background, so when he was first commissioned to look at the care-planning process, he did not understand what it implied. He understood that the care plan is something that is done at the end of a patient's hospitalization to give information and plan potential follow up care; however, he thought maybe they needed to also look at where it starts. He discussed this with Irene, who was then still the project owner, and said that they should look at the entire patient journey, from falling ill and being transported to the hospital to being sent home. He called it the care coordination process. Looking at the whole process also implied the involvement of not only the county council's operations, but also the care functions run by the municipalities as part of the journey would imply coordination between the different organizations.

\subsubsection{Booking up and coordinating people}

When Johan started to plan the project, he thought about how they had worked when they mapped the stroke process. He felt that, as before, they needed a mixed 
group of personnel who were in some way involved in the process. He started to contact and book up people within different parts of the organization. It was important to do this early, even if he did not know exactly how the project setup would look, as getting hold of people is a problem, Johan explained. He felt that he had to frame what they would map because mapping the entire healthcare would not be feasible. However, getting the division managers to free up personnel so they could participate would take time, so he started working on this directly as he had commissioned the project and had discussed with Irene that they should focus on the whole patient journey and not just the care planning.

I simply started to book people up. Because that is not easy, it is a rather big problem that everyone is so busy with the things at hand. //: ... :// How things would be done I did not really know then, it was not ready yet. Well, I knew I would be able to put them in a [conference room]. But I was thinking that ... and that is why it was so important to me to frame what is this, what is it that should be mapped, because otherwise I would map the whole healthcare and that would not be feasible ... Eeh ... Well, so, I booked people up and this was sometime during spring, early spring. Just to get

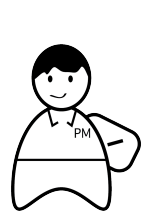
people to the project, to get people to get the division leaders to allocate people.

Johan, project manager, Health Lab.

He also approached managers at the municipalities in the region and asked for them to send participants as the patient journey does not only involve the county council's healthcare, but also functions run by the municipalities. He had to be persistent and remind people, including both the municipality managers and the county council division leaders, to allocate people who could participate. He finally managed to get 11 representatives from the municipalities and 18 from the county council who would take part in the mapping.

I was out talking to managers in all municipalities and presented the project, that we should cooperate, could you give me some staff. And then it was just to bring out the whip so to speak. I had to be persistent but finally I got 11 people from 10 municipalities in the region. We have 16 municipalities so it is not too bad. And then the other uhm ... 


\section{Chapter 6}

18 then were from the county council. But, there I also had to be persistent, start a fire under their bottoms and ask every division leader because not all of them sent

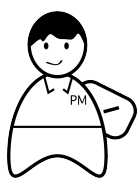
someone and some people where replaced back and forth.

Johan, project manager, Health Lab

Due to the time it takes to coordinate people, he realized they would have to postpone the start of the project until after the summer. This would give everyone time to prepare and coordinate schedules. It is important to make sure everyone would be present during all the meetings otherwise there will not be any continuity, he says.

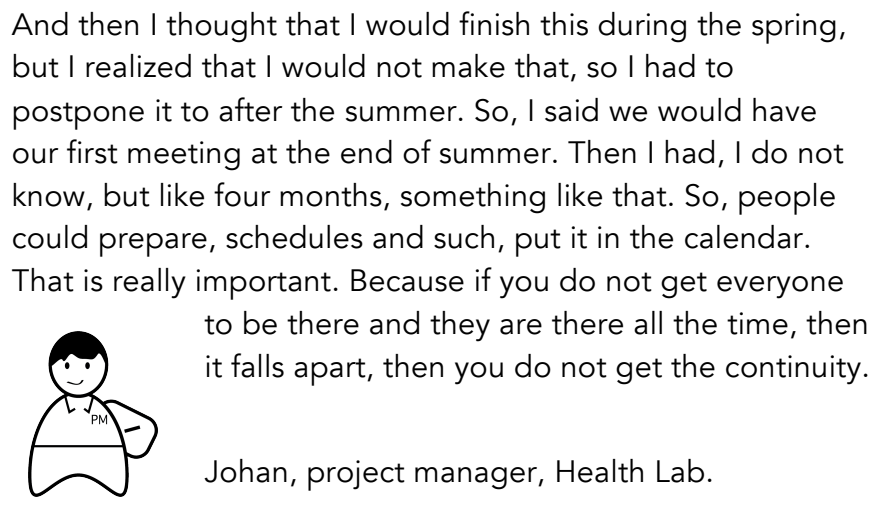

The participants also noted difficulties in finding time and in coordinating so that the core operations were not negatively affected by a project. Kaj, who works as a physician, was asked by his division leader to take part as they wanted to have someone from each division and a mix of backgrounds in the group that would be part of mapping the process. Kaj was part of a department with only two physicians, so when he was away to participate in the project, his colleague had to do both their jobs.

... We are only two physicians that share an assignment, which implies that when I'm gone she, my colleague, has to do my job too. So, well it was something we had agreed upon before. I mean we had several discussions if we should take part or not. //: ... :// But, then we decided after all that I 
should take part. But, that didn't mean that only I had to set aside time, it had consequences for the whole practice and it

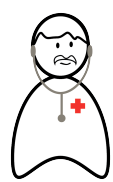
must have been like that for everyone who took part.

Kaj, physician, Beland county council.

Eva, a nurse with forty years of experience, was also hesitant to say yes to participation, but figured she should do as her manager said. One of the first things she thought when asked to join the project was how it would work with her schedule.

Oh my God, is what I thought to be frank. Who had planned this, to have meetings eight Fridays in a row? Firstly, Friday is not a good day to have meetings you know. And then for me to schedule, well well. So, it was reluctantly that I said yes, but I thought that I should do as I was told. I mean when the boss tells you to go there is not many reasons to say no.

Eva, nurse, Beland county council.

\subsubsection{Design gets involved}

While Johan was planning the CCP project, he met Gustav who sent him to a seminar at the National Innovation Agency about lead users. At the seminar, Johan met people from a design agency who he told about the project. He asked them how they would have approached it. The designers then told him about a project they had done where they had used user journeys to experience and identify user needs. Johan thought this sounded interesting, so he asked if they thought something similar would be possible for this project for which he had booked up 30 people over eight Fridays. The designers thought it sounded interesting and got inspired, Johan says. Their interest in turn inspired him, so when he got back home he contacted the designers again through Gustav. They became engaged and wanted to support him. Within the county council they already had one designer who had been employed through the regional innovation incubator and now another one was employed through Health Lab. These inhouse designers were now commissioned to plan the setup of the CCP project with 


\section{Chapter 6}

support from the designers at the design agency who suggested that they should role-play.

Johan then presented the proposal to the board of health and care within the county council. Irene says the frames of this project, that it should be conducted from the patient's perspective, made it difficult to do it in a traditional manner, i.e. sitting a group of people in a conference room. This would not give them access to and include the patient's perspective. She remembers that one of the first ideas Johan had for how they would go about it had been to shadow a patient, but that he then proposed the idea that they should role-play. Johan presented his idea for the project setup and pointed out why he believed this would be a successful approach by pointing to how they had conducted the mapping of the stroke process and how they had only gained an organizational perspective when they did that.

Ehm, well I'm a bit of a salesman, so I described it quite dramatically. I described how an ambulance would come here on the 1st of September with red lights, slam on the brakes outside the entrance, and someone in this group had fallen ill. So, the idea was that it [the role-playing] would start here [at the county council office] and then they would go through [the patient journey] ... And no one said no. No one said, no, we can't do that. They were like, wow, this is something new, of course we should do this, we should experience the process. That is something completely different. And I described, I showed the conference room where we would sit, I showed how it could look and I showed the stroke process. The result and said we do something else now; we try something new because I do not really believe in this. We must do something else and find ... A critique that could be voiced about the stroke process was that we did not have any patients in the group. So, we did not have a patient focus. It was first after we had gotten a bit into the mapping that we realized, but where is the patient? Everything was focused on the practice. And the issues that are identified, well some of them are of course the patients, but most are the practice problems that affect the patient of course, since it is part of the process all along. Nah, so I think they thought it was a bit fun and it is very seldom this crowd becomes silent. There are usually some comments and often 


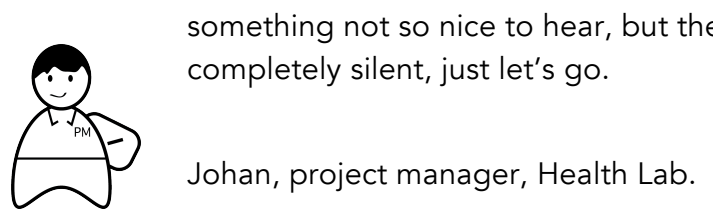

Despite usually being a tough crowd, Johan had, through his enthusiasm and ardor, convinced the board of health and care that they should role-play a patient's journey through healthcare to experience it from the patient's perspective and ensure the issues that were identified were relevant to the patients and not only the organization.

\subsubsection{The setup}

After this, the actual planning of the patient journeys began. For this, Johan had a project group of five people - personnel from the healthcare nurses and some development leaders. These five were not part of the group that would later do the mapping.

The project group prepared three patient journeys based on patient files from actual patients. In total, there were about 30 participants in the project, who were now divided into three smaller groups for the journeys and the mapping. The journeys were to be played out over three workshops. In each group, they had five roles for the personnel to play: a patient, a detective, a photographer, a note taker, and an observer. For each role, the designers had prepared a notebook and some props - a camera for the photographers or some blurred glasses that would simulate cataracts for the person playing the patient, for example (Figure 24). The idea was that every person in the group would have a role and that they could switch between the workshops if they wanted. Each patient journey was divided into three sessions. In between each session, the groups met for a debriefing workshop.

The planning and coordination of the journeys was also tricky, Johan says, as a patient journey involved very many stops and required contacts in all units of healthcare to get access. The journeys were to be played out in the actual live practice with the medical staff they met

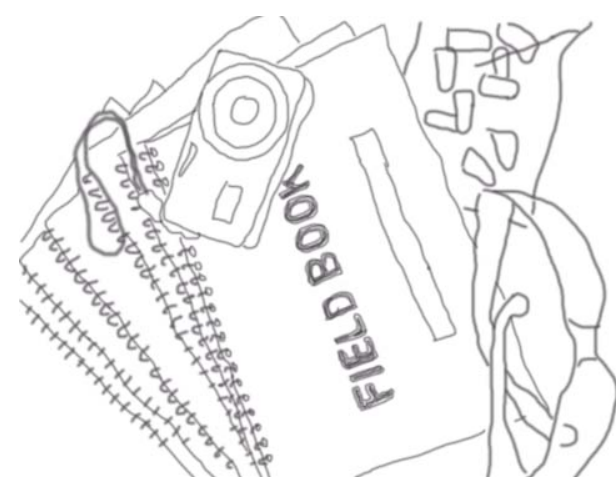

Figure 24. Field books and props for the different roles. 


\section{Chapter 6}

acting as they would with any regular patient. Setting up this was a matter of using contacts, so at this stage the people in the project group who were practicing nurses were very important as they had a large contact network, Johan explains.

They had to play everything out during just three half-days, while in reality the patient journeys would have lasted about two weeks, which made the experience a little skewed, Johan says. They had to tell the personnel playing the patients that "now you are lying here two days," for example. Each of the mapping groups had a game master who knew the story beforehand and directed the journey; none of the others knew beforehand what would happen next.

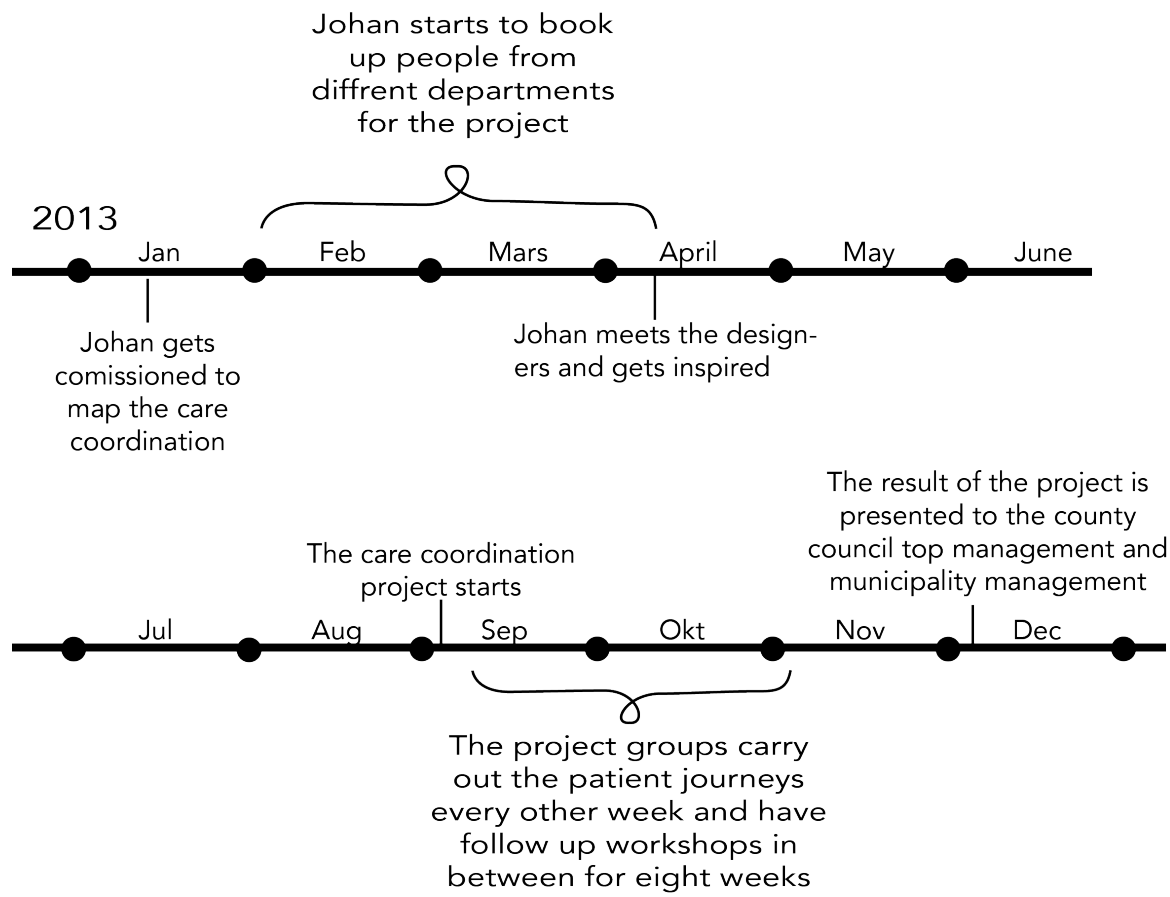

Figure 25. The project was commissioned in the January 2013 but did not start for real until September the same year.

For the personnel that were part of the mapping groups, the project started in the beginning of September 2013 with a normal meeting where Johan first presented the project (see Figure 25 for a time line over the project). This was the first time the participants found out that they would not do a traditional process mapping, but that they would use service design methods and tools and that they would experience the care process through role-playing. 
The expectations and reactions were mixed. Some were positive. Eva was excited when she heard about the setup as she had expected some dull Fridays in a conference room. She felt safe in her role as a nurse and working as a care coordinator she felt she had something to contribute. At the same time, she felt a little intimidated when she looked at the list of participants, most of whom had management positions of different levels. As she remembers, she was one of the few who were working in direct contact with patients. Robert, the assistant operations manager for the ambulance, had been part of this kind of process mapping before; however, these had all been from the perspective of the organization and of practice. In his role as assistant operations manager for the ambulance, he knew a little about the setup beforehand as the ambulance had been contacted by the project group during the preparations for the patient journeys. He knew it would be different. He felt that doing it from the patient's perspective this time made this project much more interesting to be part of.

Some were not positive. Irene also attended the first meeting and she remembers:

I was there the first day when they gathered and Johan had told me, 'don't tell them [laughs], they will get to know the first day that they will not do this as usual.' So they sat there a bit reserved and when Johan started describing this I saw how some of the physicians kind of started to [shows how they sat a bit reclined with arms crossed over the chest],

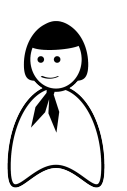
'role-playing, I think I will drop out' [laughs]. It was not just the physicians, there were others too.

Irene, director of Beland county council.

After Johan had presented the setup of the project, the designers gave a brief introduction to what service design is as it was probably a new concept to most participants. They also presented some ethnographic tools, such as interviewing and observing, which the participants then got to try out on each other as a way to get to know each other.

When I came there the first time, I had probably never heard the expression service design before. Design to me was some good-looking chair or something like that, Alvar Aalto and such stuff. But that was the first they did, describe what it 


\section{Chapter 6}

was in an easy, almost childlike easy way. But, it was really good; they showed, I think it was a bus journey, a person that is going by bus. And where the issues were and kind of how one could think. And then you understood quite

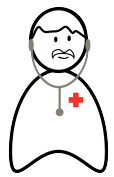
soon what it was they were after.

Kaj, physician, Beland County council.

In the workshop the participants also got to familiarize themselves with the material they would use, the notebooks, and the props. In the groups, they also got to flesh out the character of the patient who's journey they would follow. This way they got to know the patient's persona a little before the first part of the patient journey was played out.

The second time the groups met, it was time to play out the first parts of the patient journeys. Each group got to play through the first events of their patient's journey. The person playing the patient met with the medical staff and got to experience the process from a patient perspective. The other people in the group observed and documented what they saw, heard, and thought as the journey proceeded. The first journey Johan joined one of the three groups. They were standing on the parking lot outside the nursing home and divided the roles - who would be the patient, who would be the photographer and so on-before they were met by two nursing assistants. They were taken into a meeting room and sat down when Johan's phone rang, so he went out again. He had to direct the ambulance that would come and take the patient to the hospital. When Johan came back, the room was empty. The whole group had gone into one of the patient rooms. The patient lay in a bed and the role-playing had begun automatically. However, at the next stop, the emergency room, it felt more like a field trip as the physician explained more what he would do than actually acting it out, Johan says.

And when I got back, there was no one there. They had left the room and went to a room with a bed and laid down there. And they started to play automatically like, 'how are you?' Stroking the hand of the patient, taking the pulse and the temperature. And she who played patient started playing 'yes, yes, it is difficult to breath' and so on. They started acting and then it became a role-play automatically somehow. ... And then that continued. //: ... :// at the ER it became more of a field trip. She [the patient] was lying there, 
but he [a physician] was telling more than doing. It might be due to whom you meet and such, but somehow these

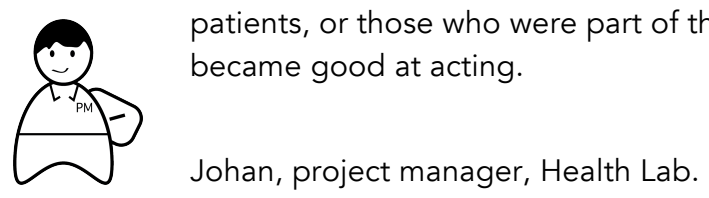

Eva the nurse played the patient in her group, and she said it felt as if she became the patient when she played him (Figure 26). She felt that, unlike a normal work situation, they were allowed to and could actually feel.

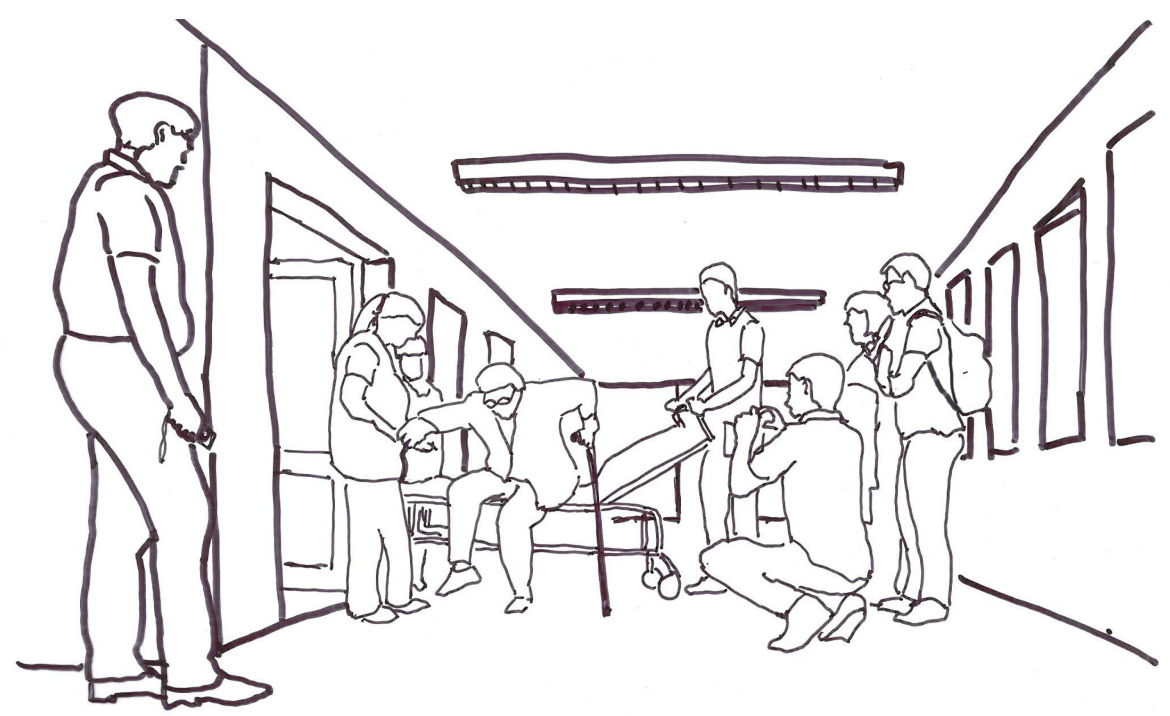

Figure 26. Eva playing the patient "Arne" while her colleagues observe and document.

They put on a pair of cheap glasses that took away my sight and then something happened.

$/ /: \ldots: / /$

And you are not allowed to feel as a professional but, here that was kind of, one of the things all the time. How do you experience this? How do you feel now? What do the others see, how do they think you feel, or how you experience 


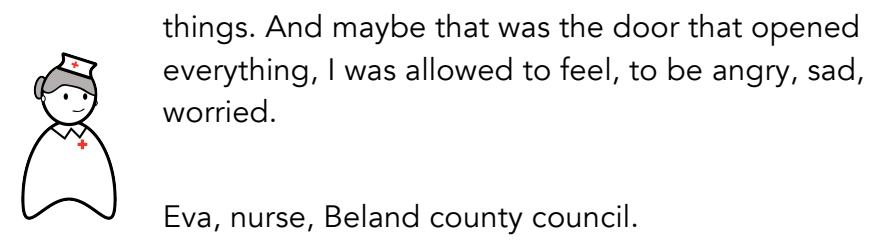

A week after the first journey the groups had their first debrief workshop. The debrief workshop was facilitated by the two Health Lab designers and the three groups were asked to share their observations and reflections within the groups. This was then discussed and turned into insights. Johan remembered that the first debrief workshop was a little chaotic. It is not easy to understand the design language with words like insight or need, he says, but he saw it as learning situation.

Eva felt that the main issue during the workshops was time. They had so much to talk about and everybody had experienced so much. Kaj felt the workshops could have benefitted from more structure.

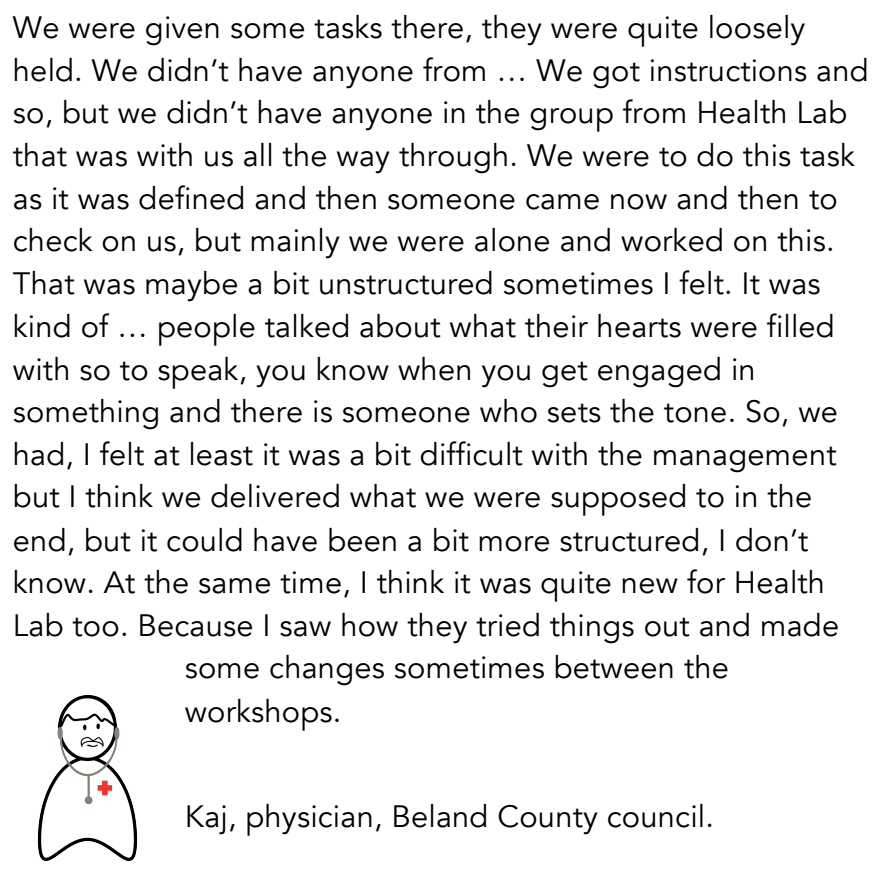

After the debrief workshop, the project continued with yet two role-playing segments and two debrief workshops. 
As word spread in the organization about the project after the first role-playing segment, Johan felt that it became easier to get access to places like the emergency room or cardiology. The units welcomed the two later role-playing segments, and said it would be really interesting to be part of this, Johan explained. He remembers that after the first role-playing segment, they even asked if they should play along. He thinks that the experience was valuable, not just for the personnel that were part of the mapping group, but also the healthcare personnel that they met during the journeys. They too got an opportunity to reflect over their practice when they met the groups and the detective and other roles asked questions.

Even though Eva felt that she became the patient, she realized and found it difficult to remind herself that a regular patient probably would not be fluent in the hospital jargon as she was. Kaj also felt that the main challenge during the journeys was to act out the roles and not get stuck in his familiar role as a physician simply because they were in a familiar setting; not just for those who were part of the mapping group, but for those they met. They were used to seeing and acting towards him in his role as a physician, not as a detective or observer, he says. He thinks it is important that the personnel they met kept acting as if it was a real patient in order to actually be able to identify issues and not act different in some way because it was them.

It became, as you say a bit of a role-play, even if it was just one who played the patient, you were still part of it all and had to lift yourself away from the old comfortable role in the old familiar context where you have created a role for yourself over the years. To kind of step out of that role then and try to look with new eyes. It is of course a challenge to not see with the eyes you have seen with for thirty years, but try to turn it around. It is a clear challenge. //: ... :// And those you meet too, who should carry out their job with this patient, and then I come, having been a physician there for twenty years, and they are supposed to disregard that and act as normal. That is a difficulty definitely, but I guess that is true for all role-plays maybe. But it is important in order to make sure the issues are really caught and that the personnel

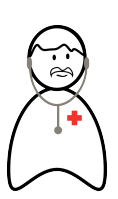
don't act different just because this group is coming.

Kaj, physician, Beland county council. 


\section{Chapter 6}

The CGP project ended with a presentation of the results for the county council's top management and representatives from management in the municipalities. This presentation was initially planned to be held shortly after the final project workshop, but it became delayed. In the debrief workshops, the group had identified issues in the process and discussed and identified opportunities based on interest groups related to the identified issues. The issues and opportunities had then been assessed in relation to feasibility and viability. Eighteen opportunities for improvement were identified through the CCP mapping, of which Irene, the director of the county council (who used to be the head of health and care and initiated the project), chose three that the organization should continue to focus on.

\subsubsection{Reflections and conclusions after the project}

After the project ended, Eva tried to use the workshop format in a training session for nurses as a way to capture experiences. They had done a simulated care planning, but she felt she did not have enough experience to do it well. She thought that it should be complete - that it cannot solely be acting or roleplaying - and that the follow up with the debrief discussion was crucial for catching important reflections and experiences. She thought that the workshops gave an opportunity to collect and conclude the impressions and reflections of everyone from the patient journeys.

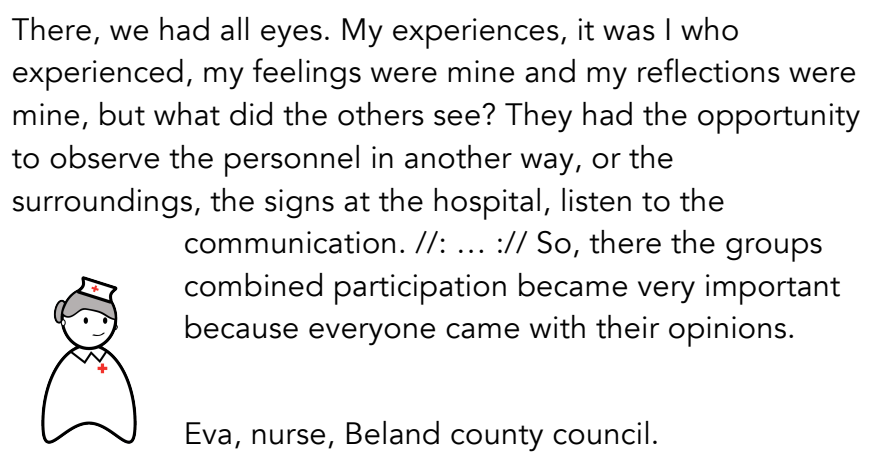

Robert from the ambulance says that after the project he is convinced by this way of working with the patient's focus. He says that as personnel you often think that you know what the patient needs and wants because you meet them all the time; but he realized, through the patient journeys, that there is a lot that the personnel miss. 
I'm probably as biased as everyone else, I think I know this is how it works and this is how the patients experience it. But, I'm more convinced now, after this, that this is how we should work. We can send out surveys, we can do interviews, but I don't think we can reach what we did here

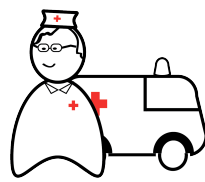
that way.

Robert, ass. operations manager for the ambulance, Beland county council.

Johan says that an interesting side result of the project, which they had hoped for, was an indication of cultural change from an operations and professions focus to a user focus - in this case, a patient focus. As the workshops went on, Johan noticed that the personnel who, at the beginning of the project, were confined to and focused on their regular professional roles and mainly asked questions related to those, gradually changed focus. Towards the end, they also asked a lot of questions related to the patient such as "how do you feel now?". Through the project and the journeys, Johan think the personnel developed new empathy for the patients.

Irene feels that through the project they have learnt to take advantage of a different kind of competence. Prior to the project, design was a rather unknown competence in the organization, but through the project they saw that it was a useful competence, she says.

We won't be able to do these kind of patient journey roleplays continuously, but we have learnt a method. And I think we have learnt how to take advantage of a different competence. I mean service design was rather unknown

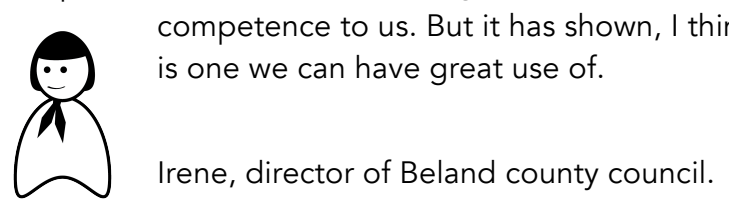

Almost a year after the project, Johan and also some of the participants felt that not much had happened with the results in relation to the hotspots identified and the new empathy developed. From the beginning, there were thoughts about how to maintain the group of people who had participated in the project and bring their experiences back to their regular practice, Johan says. How could their interest and engagement be kept? He felt that what had been done after the 


\section{Chapter 6}

project was quite meager. He saw that a clear management decision on what the next step should be was missing and felt that the personnel must be informed so that they can see that something is happening; otherwise, there is a risk that they will feel that the time they spent was useless.

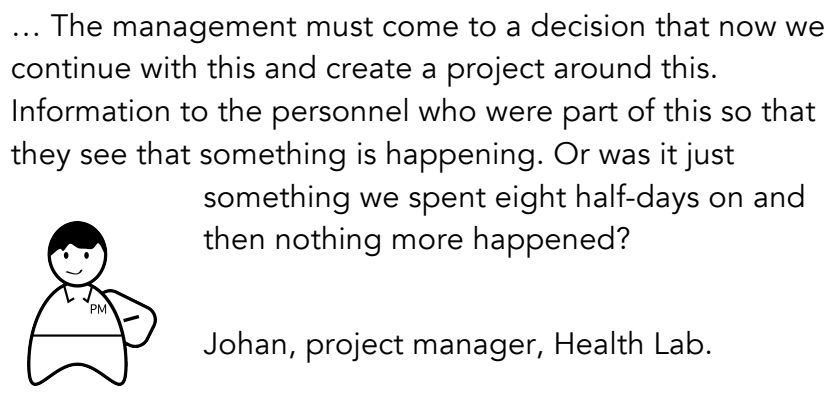

They had informed the participants about what had happened and sent them the project report, but no decision was taken on how to continue, he says, and to his awareness no projects were initiated as a result of the issues and opportunities that were identified. The ambulance did start to develop one of the ideas that came up during the project and wanted to prototype it, but it had come to a halt due to budget issues and needed to be discussed on a higher management level, Johan says.

Despite this, Johan thinks that for the personnel that participated, the project had left some positive results. The experience of the patient's perspective was something that would stay with them and they had tried some new tools and methods. He believes that the user-centered focus is something that cannot be carried centrally, but has to come with the personnel.

\footnotetext{
But then I think that just having been part of this ... It carries itself a bit inside the personnel that have been out because they will always keep it with them, they will always be able to take the patient's focus because they have done so once. It is not like they will reverse and forget it; they will always have this with them. They have also gotten to try some new tools, how to interview and role-play. //: ... :// I mean, somewhere it is happening, this development can't be carried centrally, but if you give people an opportunity to take a different focus then they will have that with them, it will be inside
} 


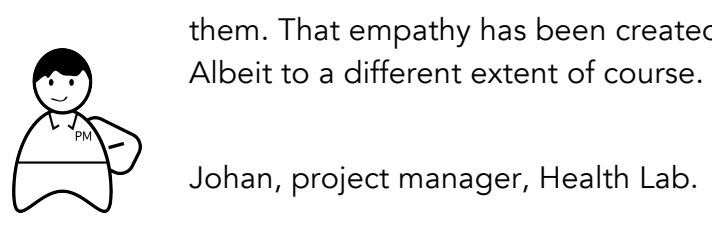

What they are doing now, Irene explains, is developing a new management structure led by André and his fellow head of health and care. The new structure will enable more systematic work within the different improvement areas. Therefore, the CCP project's results were put on hold for a little while, she says; they are currently working back office, as André explains it.

Robert felt that, as one of the participants in the project, he had a responsibility to share and disseminate the experiences within the organization afterwards. He felt that it is important that the results are disseminated. Eva also felt this responsibility, but she is in in her sixties and will retire soon. She felt that the results from the project would take too long and that she lacked the ability to influence or share her experience given her position in the organization as a nurse. In specific situations, yes - such as when she was meeting students or when it was only her and an assistant nurse - but not in the entire workgroup with both nurses and physicians. Because of this she chose to end her position as a nurse within the county council a while after the project. Instead, she started as a nurse at a municipal nursing home where she was the only nurse among nursing assistants. This has given her a position in which she is listened to, she says, and she uses this to share the user-centered mindset.

Johan believes that the cultural change implied by taking the patient's focus rather than the organization's has to be driven both top-down and bottom-up. Management can think that something is really important and make decisions about it, but if the operative personnel does not also feel that it is important or do not see its potential it will be very difficult to make any changes, he means. He believes in a combination of management enabling and encouraging a usercentered approach and personnel doing it and experiencing the value. The CAP project would never have happened the way it did if the management had not trusted him and given him the mandate to go with it, Johan says. He had a history of bold but successful projects, which he believes was the reason the management dared to let him go on and try something new. It made them comfortable with not really knowing where it would end, but still trying it out, rather than turning it down directly. Having both the political and the civil servant management onboard was vital, Johan says. 


\section{Chapter 6}

Working with development and improvement in the county council is sometimes like trying to repair a broken train while it is still running, Johan says. There are constant queues in the healthcare and no time to fix things. He sees this as an incentive to try a new approach, but one that requires courage and that it is enabled-one in which management ensures that the personnel have time to develop and improve things in their practice.

One can see the county council or healthcare as just being
queues all the time. There is an enormous amount on our
shoulders. We don't have time to take care of this, and then
maybe it is time to change this, the traditional ways to
approach development work. It has to be changed, do
something exciting and find new methods. Like what I
described to you yesterday about these people that had
been part of service design training, what happened to them.
Stop there and now they are back in their regular practice
again. But, it is ... to create conditions, to enable time. That
is also a factor that to consider. Like, management, that it has
courage and dare. Support, that conditions are enabled in
terms of time. That time is set aside for development work
and it is not seen as something that, well, you should do this
because it is your job to be a nurse and then you should
make improvements to your practice. Yes, but when you do
not even have time to take care of patients, how should you
... then management must enable time for these people.
Okay you are not to work with patients today,
you should do this.

Robert also points to the importance - as for all development or change work - of support from top management. In this project, he felt that they did have the managements support; but, he explains, all managers must, for example, follow the same line, they need to share the opinion that the director has. It is a matter of political management as well, he thinks; showing that this is how development work should be approached by making room for it in the budget. It has to permeate the whole organization. If projects are initiated, but the results are never taken the whole way and implemented, Robert feels that people will lose the motivation to participate and work with development. 
Saying: yes, do change or development work, but do it within the current frames. That we have neither personnel nor economic resources for. //: ...: :/ Then it is better to refrain from development work until the resources are there.

Otherwise, it will be like shooting oneself in the foot if there is no possibility to go all the way. And there it is important that management express their intentions.

$/ /: \ldots: / /$

The risk is that, otherwise, it can't be finished because there is not enough money and then it crashes and then something new is begun and that too comes to nothing and then there will be suspicion among the personnel and a frustration

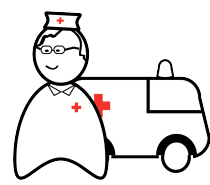
among those that work with development.

Robert, ass. operations manager for the ambulance, Beland county council.

André, the new head of health and care, believes that through the CCP project they were able to identify issues that they would not have noticed with another approach. However, he thinks that if service design or, more specifically, Health Lab, should be able to deliver that effect then management and the organization must also be clear about what it is they want to know. Irene, however, stresses that Health Lab should not be the ones that develop the healthcare; their role is to facilitate development and it is still the practice that holds the responsibility.

Andre: Health Lab is full of creative people, and creative people come up with creative ideas, but it is not certain they are in line with what it is the healthcare is in need of. These individuals will keep busy whether we feed them with commissions or not.

Irene: Yes, but I believe it also has to be very clear that, and this we must communicate. That it is not Health Lab that should develop the healthcare, they shall support with methods and tools so that the practice actually can develop 


\section{Chapter 6}

its operations. So that the practice does not disclaim its

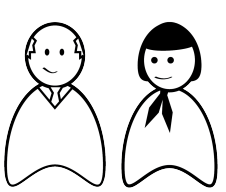
responsibility.

André, head of health and care \& Irene, director of Beland county council.

André also believes that in order for the county council to exploit the value of service design some kind of maturity or insight must be developed. They need to disseminate the awareness of design in the organization and think about when it might be valuable to take a service design perspective.

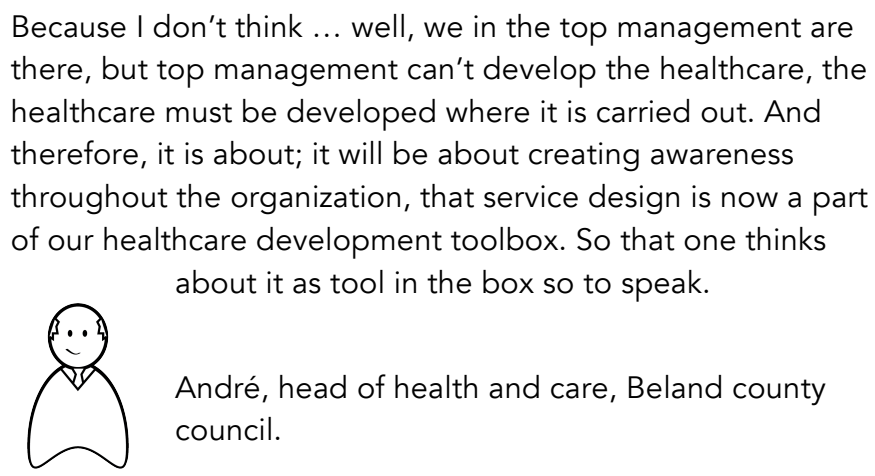

To be better able to support the healthcare in thinking beyond these frames and think anew, Kaj, Robert, and Irene all see a need for a more developed knowledge about the healthcare culture, language, and routines among the designers who will work with healthcare. However, it is also important that the designers are aware of the rules and regulations in the healthcare, that they understand and acknowledge the fact that these might cause prerequisites that cannot easily be changed, André says.

A year after the CGP project ended, it can be concluded that not much had happened with the direct results of the project. As Irene points out, it had, however, made the organization aware of a potentially valuable competence and as a result of that it has also inspired other design driven projects in the organization. 


\subsubsection{The design training project}

The design training project was a project aiming to transfer awareness of design and knowledge in design methods and tools to a group of healthcare personnel with the objective that they would then be able to use these methods in further development work and disseminate it to their colleagues.

However, it was originally commissioned by the county council politicians to Susanne, a civil servant coordinating children's rights issues in the county council and a member of the board for the healthcare function. It was a call for actions to better meet article twelve in the conventions of the rights of the child $(\mathrm{CRC})^{18}$. The project should result in better involvement of children and youth both in their direct care, but also in the development of services directed towards them. The initial request was to form a child and youth reference group. Susanne, however, did not really believe that was a suitable solution to the issue; so, when Gustav approached her with the suggestion of a design training project that would potentially give the healthcare personnel tools with which children and youth could be involved, she became interested.

\subsubsection{The design training prologue}

Gustav, the head of operations at Health Lab, has a background in pedagogy and had, since the initiative started, thought about a project where healthcare personnel would be taught and trained in design methods and tools. When it was clear that the initiative would receive funding, but Health Lab had not yet been established, he met with some of his contacts in the design field to discuss his ideas and get feedback and potential support. One of the design agencies he spoke to, Design Inc., had previous experience of an action-learning project in which they had trained civil servants from a municipality in design methods and tools as a means to meet and involve their citizens. They had only tried this once and it had been abroad, so they were very interested in translating it and trying it out in their home environment as well. Gustav and Design Inc. discussed how this could fit with and be done in relation to Health Lab, and eventually they had an idea for a setup and a plan for how the cost would be split. This would be a project that

\footnotetext{
${ }^{18}$ The Convention of the Rights of the Child Article 12 (Respect for the views of the child) states that: When adults are making decisions that affect children, children have the right to say what they think should happen and have their opinions taken into account. This Convention encourages adults to listen to the opinions of children and involve them in decision-makingnot to give children authority over adults.

http://www.unicef.org/crc/files/Rights_overview.pdf retrieved: 2016.06.07
} 


\section{Chapter 6}

would benefit the design agency as well as gaining an opportunity to try out their training in a new context. Now they needed a suitable project in which the training could be applied.

Susanne was commissioned to undertake the project about children's involvement about half-a-year after Health Lab had officially been established. When the Health Lab steering committee informed Gustav about the project, he saw an opportunity to apply the training as part of it. Subsequently, he went to Susanne to suggest his idea about design training for a group of healthcare personnel. The design methods and tools they would learn could be used to better involve the children; this would be another way to approach the issue and objective, he suggested.

Susanne had heard of Health Lab before since she had been in contact with some of its personnel in relation to other matters and knew a little about what it was and the work they did. In dialogue with the head of the healthcare function, under which Health Lab was organized, Susanne decided that they would try and initiate a group working with children's rights issues in relation to the service design and service innovation context. Although she had actually been commissioned to undertake the issue with article twelve in the CRG, Susanne experienced that the head of the healthcare function, under which Health Lab was organized, made sure Health Lab would be involved somehow. The final decision, however, was made in dialogue, and she could have said, no, this is not an appropriate approach for this project, she says. She felt that the willingness to test was there, both among the politicians and the group focused on children's rights that she coordinated.

When the idea that the project would be set up as design training was presented to Susanne, she found it exciting. It felt new, she says, that, wow, here they had an opportunity to legitimize something that they otherwise would not have been able to do in the organization due to culture and traditions. It would have been difficult to come and say that we have a new way of changing routines or the view of the meeting with children and youth in the healthcare culture otherwise, she explains. She felt as if they were going undercover and if they failed completely, the trust or reputational capital would not be that damaged because someone else had said that they should work with new methods and tools. She felt that it was really exciting, but at the same time she was a little hesitant.

... At the same time, I had a thought, a concern or something. It was about, we who work with children's rights 
issues, we know there have been many initiatives taken, many projects based on grown-ups' initiatives to involve children and the youth that in the end does not at all have the actual intention to involve or enable the participation of youth, but is only about decor and manipulation.

$/ /: \ldots: / /$

And I felt a bit, is there a risk that we would legitimize something, that we say we are going to create something new, create a new way of thinking around this issue, make children and youth involved, the politicians have commissioned it. This was also to be done with a very wellknown company, Design Inc. I mean it is not without effort you say to a company like Design Inc. that you don't believe in this; that you think something is off. To come there as coordinator from a small county council and be cocky towards a company that has won several prizes

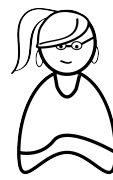
and so.

Susanne, civil servant, children's rights coordinator, Beland county council.

She felt a mix of horror and delight. Her experience was that she, as the coordinator for the project, was probably the one who was most hesitant, on her toes, and questioning things as the project went on. She felt a great deal of responsibility for how it would end up. She also looked forward to seeing how the new methods would potentially break new ground in these issues, which could be complex to solve.

It was kind of as if she and Health Lab had approached each other as the project came about, Susanne felt. She explains that the county council knew from experience that one of their main challenges was to fully implement and live up to the articles in the GRC. For example, in a healthcare meeting, the communication tended to be directed towards the parents, and things are often done above the child's head even though article 12 says that a child has the right to be heard and make decisions related to itself. It could be difficult, she said, and she felt that a reference group was probably not a solution that would suffice, but that Health Lab now proposed a potential approach. The question was how would this 


\section{Chapter 6}

approach meet the original commission of a reference group made by the politicians.

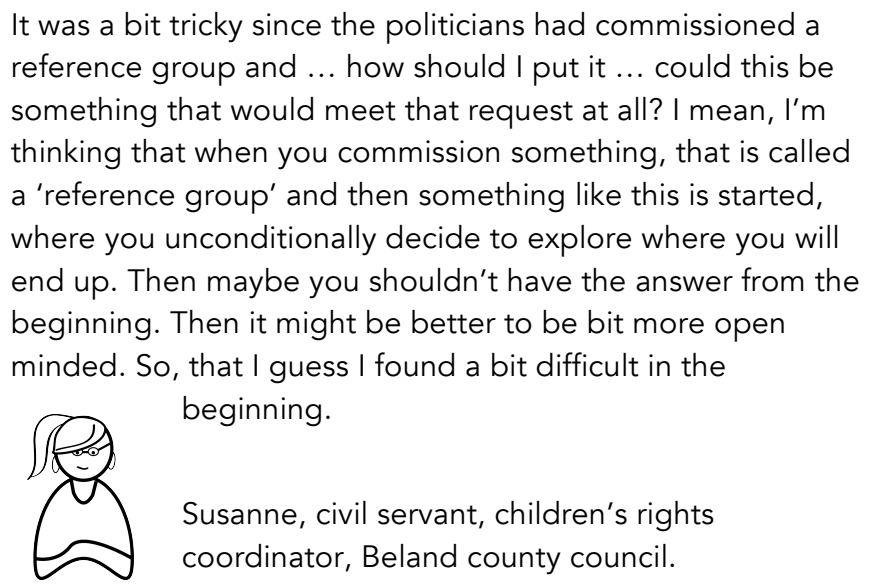

In order to get away from the original request for a reference group that the politicians had made, the commission was reframed as "a forum for children and youth's involvement and participation" and the project was initiated based on the action learning setup that Gustav and Design Inc. had talked about.

\subsubsection{The setup}

A group of healthcare personnel working with children's rights would be trained in design methods and tools through a design driven project. The idea was that the user focus mindset of design and its tools and methods would provide means to increase the involvement of children and youth, both in their interactions with the healthcare and in the development of the healthcare services directed towards them.

For the personnel who would take part in the course, the project would require quite a lot of time away from regular practice and thus a rather high degree of cofunding with internal means from the county council. Therefore, the project also needed to get the green light from the board of the healthcare function. Health Lab and Design Inc.'s time in the project was covered by funds from the National Innovation Agency. However, when Gustav presented an initial plan for the setup, it was turned down by the board. The division leaders felt the setup required too much time for the personnel away from their regular practice. The core operations could not set aside that many personnel for so many hours. 
We asked for way too much time. It was a big lesson for, I think, both Design Inc. and us for future projects. That we can't ask someone, we can't empty the health clinic in [e.g.] Hedenfors because there are just two nurses. Then we can't send one of them on a sixteen-day training. //: ... :// So, we had to go home and rethink and then come back to the board and present again. //: ... :// Both present how we would work with the children and why it is important to work

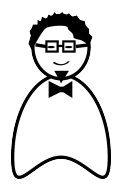
with the involvement of children in this way and that we wanted to test working with this [design].

Gustav, head of operations, Health Lab.

Gustav points out that the training of personnel was in line with the objective of the Health Lab initiative described in the mission statement. There was, in other words, a legitimized agreement for Health Lab to work with the training and dissemination of the design approach and methods. The second proposal for a setup was approved by the board of the healthcare function, and all division leaders commissioned someone related to the children's rights group led by Susanne to participate in the project and spend their time on that rather than their regular practice. That implied the county council co-funded the project by allocating working hours, Gustav explain. They did this because of a will to work with the children's issues as well as the will to give the design tools a try, he says.

In the final setup, the project was to run over eleven days, with six workshop days structured around the different phases of a design process (Figure 27). The workshops where facilitated by designers from Design Inc. who introduced design and the different phases, methods, and tools related to a design project.
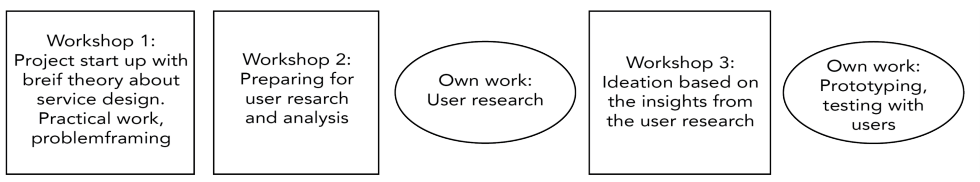

Workshop 4 Presenting the results and reflectthem forward

Figure 27. The design training project was structured with workshops introducing the different phases in a design process and time in between these for the participants to practice the tools and methods on their own.

Six healthcare personnel from different divisions and practices took part in the training. All six had previous experience of the children's rights area. Johan, the project manager who had led the CCP project, was now a member of the Health 


\section{Chapter 6}

Lab team and took part in the training to gain a better knowledge and understanding of design and its methods. Apart from the six workshop days, they also had five days that the participants were to spend on practicing the design methods and tools presented in the workshops on chosen problem areas.

Daniel, one of the designers from Design Inc., said that the action learning setup led to the expectation of two outcomes from the project. As he experienced it, there was an expectation of finding and creating solutions, of innovating the problem areas they set out to work with in the design projects among the participants. There was also the learning objective, which Daniel says was the main objective, which was to let the personnel learn service design tools and methods by practicing and experiencing them in relation to problem areas relevant to themselves and their regular practice.

The double aim of the project is also reflected in the participant's reflections on their expectations of the project and its outcomes. For two of the participants, Petra (who works as a play therapist supporting the healthy aspects of a hospitalized child) and Pia (an administrator with support and service for certain impaired persons), the focus during the project was on creating solutions that could increase the involvement and influence of children in their encounters with the healthcare; whereas Frida, who normally worked as a district nurse, thought from the beginning that this was about learning the approach, methods, and tools so that she could later share this knowledge with her colleagues. Initially, both Petra and Pia found it a little difficult to understand how design would contribute. What kind role could design play in their work, Pia asked herself, as Design Inc. presented some of its previous work, which was related to a completely different context. However, as she read the material about the training, she thought it sounded a little exciting and the fact that it could be a potential approach to increase the involvement of children and youth spoke to her. Petra felt skeptical, but hoped introducing a design approach could lead to common ground in the meetings and work with children, something she felt was missing at times.

Daniel describes Design Inc.'s role in the project as facilitation. They held short, perhaps thirty-minute long, presentations about the design phases and suitable tools and methods for doing the design work in each phase. They guided the county council personnel as they tested the tools and methods in the workshops before going out and applying them in practice. Design Inc. also made sure that the project maintained momentum by putting up a frame for what the personnel were expected to have done on their own in between the workshops back in their respective practice. 


\subsubsection{Experiences from the workshops and design practice}

The idea with the setup was to let the participants themselves find and prioritize problem areas against the available resources (time and people) they had for the project and then go through the typical moments and methods of a design process. Daniel remembers that the prioritization, deciding what was a feasible task, was something the participants needed some help with. The focus of the first workshop was to get going, and, after an introduction, the participants got to discuss and brainstorm to find which problem areas they were to address. The idea was that the group would find one problem area to focus on together based on the needs they had seen through their practice.

During the problem framing discussion, Design Inc. realized they had ten clients in the room that all expected to end the project with a solution to a problem in their particular practice Daniel says. However, after some work, they started to see that some of the issues were similar and eventually managed to agree on three different problem areas to work with and thus divided the group into three design teams (Figure 28).
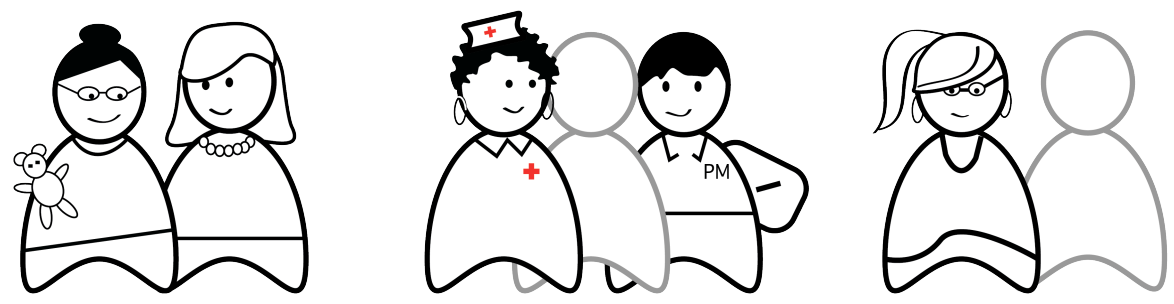

Figure 28. The participants were divided into three design teams each working on a different design problem.

Many of the participants experienced the start of the project as a little confusing. Johan remembers that when they first started working with defining the problem areas, the work felt very tough. Although they had gotten an introduction to how the project would be set up and how they would work, it felt like some background information was missing, he says. It felt as if they started without really understanding what they were supposed to do. Frida shared this feeling; she thinks it was because it was so new to everyone. However, there was not only confusion regarding the design setup; there was also confusion about the children's rights and how what they were doing would answer the initial call from the politicians, Johan says. He describes that, at the end of the first day, although they had gotten some insights, it felt that everyone was wondering 'what will this come to?'. He says that 


\section{Chapter 6}

instead of starting with a safe and comfortable feeling in the group, they started out with confusion.

Susanne thinks that the start was difficult for her because she was thinking about how the result should fit with what the politicians had requested. Would they recognize the result as being what they had requested and would the group be able to say that they had developed something that many children would come to use based on this and that the children had not just been involved as a decoration or an alibi?

After the first and second workshop, both conducted at Design Inc.'s office in the national capital during two days, the participants went home to Beland and their regular practice. They were now, during a two-week period, to conduct research around their problem areas in parallel with their regular work as nurses, coordinators, et cetera. They had five days scheduled in total for this kind of practical work outside of the workshops during the design project. The teams made observations and interviewed users (children or youth visiting the healthcare facilities). During the period of practical work, they had contact with and support from the designers at Design Inc. over phone and email.

For Petra, who was used to observing in her role as a therapist, this method felt familiar and she could directly see things in the children's reactions as she observed the healthcare meetings. Her observations were then also confirmed as they spoke with the child and its parents afterwards, she says. She describes one insight the teams had: older children and youth tended to be more involved in their healthcare meeting than the younger children as the healthcare personnel then tended to address and communicate with the parents rather than the child directly. Susanne says it was an interesting experience observing and mapping the events and reactions in the room during the healthcare meeting between the child and personnel. Frida also appreciated the new approach. She felt that being out observing the practice and testing with the users felt as if they were truly involving them.

It was very fun because ... our work ... it was to make children and youth involved. And that was the amazing part to find methods, or learn methods with which we could go out and ask children and youth what they thought about things. We had a plan, an idea, and to then listen to them. That they too could be part of the creation. That is really to 
make children and youth involved, not just some fancy words

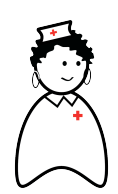
in a document. So, that I found exciting.

Frida, district nurse, Beland county council.

In their work, all the teams noticed the importance of ensuring that they had the personnel they came across during their design work on board; making sure, for example, that during the observations in the research phase, the personnel they met were okay and comfortable with them being there.

Johan also noticed that in his team, the tools they used to support the research were much appreciated, and he thinks for some they may have almost been perceived as synonymous with design, although they only had time to try out a few.

This was just one method, one way. I mean for them this became, this is service design; we go out and make customer journeys. There are many other ways, but we were, we didn't

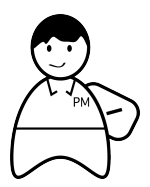
have time to try out more than one, maybe two, things.

Johan, project manager, Health Lab.

The third workshop started with a debrief where the teams shared and discussed their experiences and reflections from the practical work with each other and the designers. The workshop then focused on working with the research material and generating ideas based on the insights from the research. The teams had brought the material they had collected during the research and with help from the designers they analyzed and synthesized the material before working with idea generation. The generated ideas were then brought back to and tested with users in context during a second period of practical work. Also, during this period the teams had phone and email contact with the designers.

The project ended with a fourth workshop, which also started with a debriefing over the experiences from the practical work. It then went on to evaluate the test results and narrow down the ideas to a few, which were further detailed before a final period of user testing in context. 


\section{Chapter 6}

\subsubsection{Participant's reflections on finding and coordinating time for the project}

In the design training, as with the CCP project, coordinating time and personnel resources were an issue for the participating personnel.

Petra had been asked by her division leader to take part in the training, but was hesitant as it would imply taking time from her regular practice as a play therapist, time away from the children, she said. Despite a general interest in development work and although the objective of this particular project was close to her heart, she hesitated, she says, because there were barely even two full-time therapists in her department. If she took time off from her regular practice, it would have a big impact, she explained. After having thought about it and related it to the bigger picture of how many children this could benefit in the future, she eventually decided to say yes and participate despite the time it would take from the children currently being hospitalized.

For Frida, the challenge related to time was that the dates for the different workshops were communicated with a short notice. This made it difficult for her to plan patient appointments and coordinate her regular schedule with colleagues at the clinic, she explained.

\subsubsection{Insights and general reflections on the experiences}

Even though the initial trouble with confusion and mixed expectations in the first workshop was sorted out, some participants felt is continued to be a little confusing throughout the project. Both Frida and Petra described their experience of the training as being on a roller coaster ride.

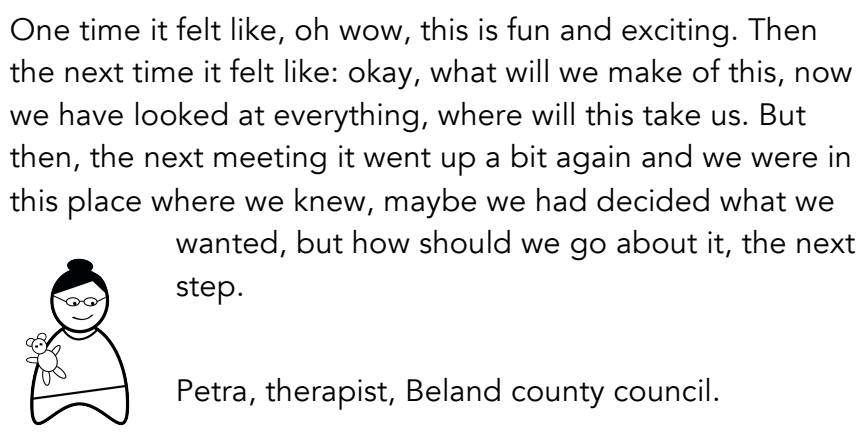

It took time to find a balance between the new ideas and the existing conditions in the organization and culture, Petra says. Even though the methods and tools they 
were taught were good, it was tricky to find out how they could work and what they could see. They were working in a delicate area, she stresses; while working based on the children's perspective, they also had to account for the complex machinery the healthcare organization implies, with regulations, policy, and structures, for example.

Johan noticed, as they worked in his design team, that there was a fear of making mistakes or doing something wrong ingrained in the organization's culture. He sees this as an issue because if you never allow yourself to take a leap and risk making a mistake, then innovations will never be made. Innovations imply mistakes, but often quick mistakes that can be fixed or that you can learn from, he says. In Johan's opinion, mistakes can imply realizing that an idea did not work as expected or stepping outside the lines. He gives an example from his team's work. Based on input from the children, they had made some design decisions that went against the official graphical guidelines of the county council, which made the others in his design team nervous.

We were out testing it with some colors and asked the kids about that. It was both boys and girls there and they started to discuss: 'we don't like blue'. And blue is our county council's color. But the kids didn't think that was good, they thought orange because it was the most gender neutral or something like that. It wasn't green, yellow or red, it was orange. So, we made it orange. But then during one of the [team] meetings we had, the discussion about the color pops

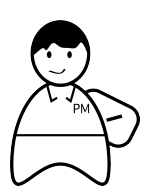
up and the fear: 'Is it okay to do this, isn't it wrong?'

Johan, project manager, Health Lab.

Johan tried to explain to them that they had a good argument for breaking the rules as the decision was based on the input from the children. Despite this the others were worried they would be told off by the communications department. He acknowledges that there are certain boundaries that must be respected, but thinks that it is important that there are people who push the harmless ones.

Other participants also reflected that there was a culture in the organization that inhibited development and change. Both Petra and Susanne experienced the design approach as encouraging a more open-minded thinking than they were 


\section{Chapter 6}

used too. Susanne felt that the permissive attitude in the project affected both people and the work.

But then I think that when you are part of group like this, where the culture is permissive, where people are encouraged to think freely. //: ... :// It does something to us, it opens up locks or doors that we maybe normally wouldn't ... because then we think budget, we think resources, we think, no, but that won't work. Or we think about the grumpy attending physician who never would allow it, well yes, you know. And then we close the doors before. But here, we said or I coined the expression in this group; I said that now we are sailing under the Health Lab flag. It was I who said it because I felt, well now we can think freely and we dare to do so because if someone should come and say 'What are you doing?!' No, but we are doing this with Health Lab [laughs], we can think freely, we can test, it is nothing. We can't put up a fence before we have tested. The fence we will put up after that in that case, what is realistic of all this that we have come

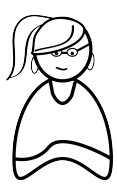
up with.

Susanne, civil servant, children's rights coordinator, Beland county council.

There are many ideas and reflections about things that could be developed or improved among the personnel, but that they are fostered in a culture that says there is no space for that, that there are always some barriers to ideas, Petra says. After the project, she tried to pass on the open mindset to other colleagues, and she thinks that the organization needs to find ways to enable free time for development work.

I believe the county council has to rethink, start creating space for these kind of approaches. For even if this [the design approach] is much faster, there still has to be time for it. And it has to be like sanctioned within all departments and functions. Within all departments, I would say there has to be room for development work. This is a very appealing way since it is not so restricted, even if it requires opening up 


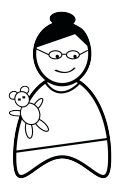

wide and then funneling down, because that is what we did ...

Petra, therapist, Beland county council.

Johan thinks it was important that the participants felt comfortable and had fun. His experience was that they felt liberated by sailing under the Health Lab flag, he says.

Petra says that for her, the main insight from the project was how the opportunity to think in new ways could render such results. They are stuck in old ways and it makes it difficult to get started, she says. The problem they worked with is something they could have addressed a long time ago, she says, but now, when they have an assignment to do so, it felt that they were allowed to think freely and there was time set aside to do so. Susanne says that although she felt that the creativity benefitted from the open and permissive attitude in the design process, she was not convinced that they could not have reached the same results, in terms of the concepts, by using other approaches had they only been given the same amount of time.

\subsubsection{Reflections about the project's legacy and what happens next}

After the training, Daniel was impressed. He felt that the healthcare personnel had a natural talent for using design methods and tools. However, he also pointed out that for the healthcare sector to be able to benefit from design, it is not just a matter of training healthcare personnel in design or about finding the right design consultancy to procure. He means that it is also important to have people within the organization that are aware of and understand design even though they are not necessarily directly involved in the design work. Gustav also noticed the healthcare personnel's talent for using the design tools. He means that healthcare personnel already have many of the qualities that are valued in design - they have a strong empathic capability, are good at listening, and are good at finding creative solutions - because they are used to working with what they have at hand, he says.

Suzanne says that, generally, she believes in service design as an approach for dealing with future challenges; they cannot continue in their old footprints forever. But, she also feels that when something new is introduced and tested, it is 


\section{Chapter 6}

important to have a structure and make it feel predictable. She felt that there was a lack of sense of coherence ${ }^{19}$ in this project, which made it difficult to fully take in.

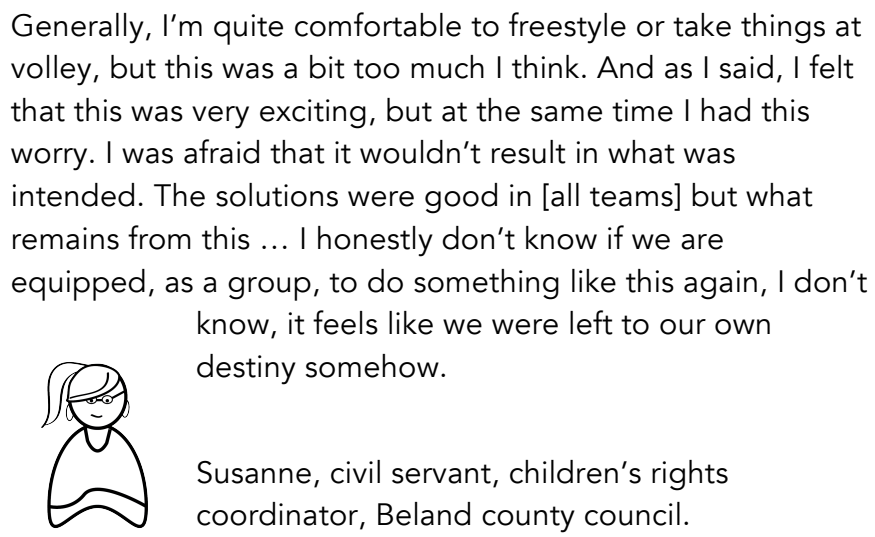

Susanne is stressing that these are her feelings. Although she was one of the participants in the training, she also had a responsibility towards the politicians in her role as the coordinator, she says. For her the strength in the approach was that they followed a structured process, listened to the users, and did not distort their needs, but used them as base in the work.

She thinks, however, the sense of coherence is important in order to let go of the control and be okay with not knowing what the solution will be from the start. Johan also noticed that there was a little resignation in what it all would lead to among the other participants. Now and then during the project, his team members felt insecure in relation to what they were doing. At these points, he tried to support and encourage them. It is hard to work with the uncertainty of the result, he says, but he had confidence that it would turn out well, and he managed to convince his team members so that they could continue.

Frida thinks that the transferred knowledge will definitely be useful in future projects, but she also says that it would have been easier if they had not been more than one from each practice that had taken part in the training. Being two or more who share the experience and knowledge, she feels, would make it easier to uphold. When you are alone, it is easy to forget or it is not prioritized when there are many other things on your to-do list. As Frida's focus in the project was to

\footnotetext{
${ }^{19}$ As noted earlier Sense of Coherence is a theory originally developed by Antonovsky that refers to how humans function related to, for example stress.

https://en.wikipedia.org/wiki/Salutogenesis\#Sense_of_coherence.
} 
learn in order to then disseminate the knowledge to her colleagues, she started reflecting early on how the results of the project could be taken forward. From where would she take the time to uphold and disseminate the knowledge? She already had a full-time position as a district nurse at the clinic. During the project, they all had $20 \%$ of their time set aside for this work, but how it would be after the project, she felt, was never sorted out. After the project ended, she has left the county council for a new position in another public sector organization. She was a little disappointed that nothing really seemed to happen after the project, at least not while she was still there. She thinks that how things should be taken forward after the project should have been discussed more and decided from the beginning because they cannot be expected to carry on the dissemination and future development work on top of their regular work load.

I can feel it's a shame that it was not decided from the beginning ... now they put a lot of effort and resources on us who took this course. //: ... :// It should have been decided from the beginning, an agreement that this is how we think: this should be disseminated to the rest of the county council and we think like this, and it can take this much time and these resources.

$/ /: \ldots: / /$

Design Inc. tried, we got to write down a bit how we ourselves would uphold it. But depending on our different positions, we came from the dental care, me from the child health center and another from the child clinic; we all had full-time assignments where we were. And then it is a bit frustrating to not know. I mean we can't do this on top of that work. It has to be agreed among management that this is something we should do and it can take this much time. But that never came as long as I was there at least. And that was a frustration and a shame I feel because I would have loved to disseminate it. We were really psyched to 


\section{Chapter 6}

Petra and her manager had also been wondering about the continuation after the project. They had been wondering if she was going to continue work with this and if it would take more time. She says that she gets these questions from her colleagues regardless of their attitude to the project and whether they thought it was good or not. She herself would not mind continuing, but she feels that she would not be able to do so without support from the Health Lab team because this kind of development work is something one could be doing full-time, she says. She was okay with taking time off from her normal position to participate in the design training, but it cannot be too much.

In an initial state, Petra thinks that the personnel who participated in the training should stay on; they have to drive the implementation of the developed concepts until they are established in the practice. However, she also thinks an important part in the dissemination is to simply encourage county council personnel to think anew and work with development with support from Health Lab. Those who were part of the design training cannot be the support, but they can be advocates for this way of working, she says. However, Petra thinks that how the result was to be carried forward should have been part of the assignment. There has to be room for implementation within the project framework, she says.

In Petra's opinion, it is also important that the healthcare takes advantage of and cares for people who show interest and competence in working with development - that time is freed in their schedules and reimbursed in the practice so that development work is not something that is done on top of the regular work or "when there is time," she says. This is something the organization has to rethink.

In the final workshop, the teams presented their results to each other. They also evaluated the training and discussed implementation and how the results, the work, and the group would continue. Despite this discussion, Susanne felt that this part of the project was weak. It was unclear who were responsible for the next step, for upholding the group and the results, she says.

It felt a bit as if this was left to its destiny. We were supposed to have some follow up meeting with Health Lab, but it didn't happen. We showed up but they [Health Lab] didn't.

$/ /: \ldots: / /$ 
It has felt kind of, as if it has not been properly upheld somehow. But then, I don't know, it was a bit unclear if it was us who were to uphold it or if it was actually Health Lab who

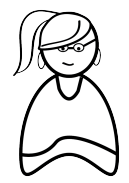
should have been supporting that.

Susanne, civil servant, children's rights coordinator, Beland county council.

In the group there were different views on who should have taken the responsibility for this.

Some thought that Health Lab should have taken the responsibility for making sure that the work they had done in the project did not die out. Susanne thought this should be the case at least until the group felt confident to continue on their own as this was the first time that they had done anything like this within the county council. Pia also viewed Health Lab as the ones responsible for taking things forward. Health Lab should have stayed on after the training to support the implementation and diffusion, she says. Susanne felt as if Health Lab had maybe been more interested in starting things than following up on what already was, with the risk of the project not fulfilling its potential. It made her think the project was not perceived as that important.

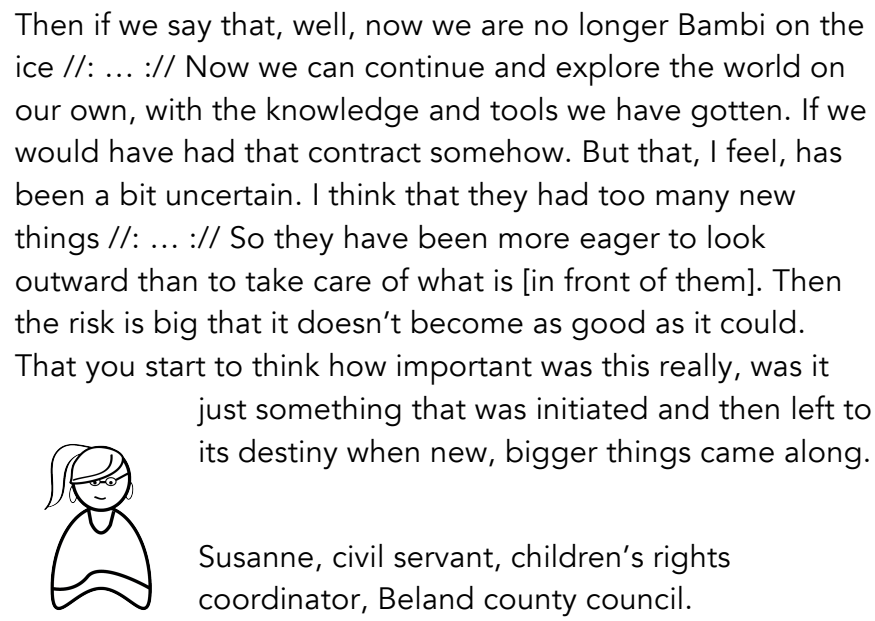

Frida on the other hand was not sure who the project owner was, but says that it was Susanne, who was originally commissioned to undertake the project and was closest to the politicians and could thus maybe push the questions of how this 


\section{Chapter 6}

could be taken forward. However, as with Petra, who saw the participants as potential advocates for the approach, Frida also pointed out that she and the others who had participated could contribute by raising the issue with their managers to get a central decision for the whole organization.

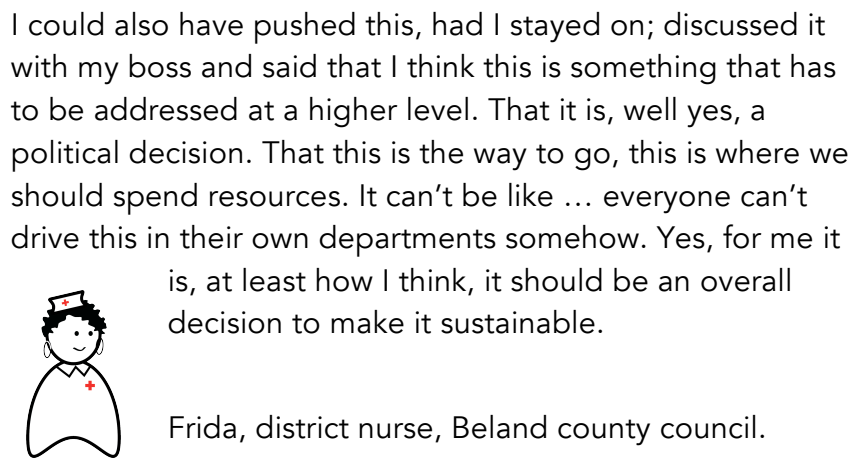

Pia and Petra, who made up one of the three design teams, did continue to drive the finalization and implementation of the concept they had developed after the project. They stress that the support they got from management was vital at that stage. For example, when they did a second iteration testing of their solution, they made sure they had a management decision that all physicians at the children's clinic should use the prototype during the test period. Many of the physicians felt threatened; they felt that they are already listening to and involving the children, Petra explained. She says that in the testing of the prototype the physicians felt as if it was they who were being judged, even though Petra had explained to them several times that they were developing a concept to increase the involvement and that it was the concept that was being tested, not them.

So, I said it can't be a free choice to work with [the prototype]. Because I felt that if we have put in so much resources and energy and taken this training and want to try to make something, then it can't get stuck because some say they won't participate, that it is unnecessary. So then, it had to be a management issue. The clinic management took a decision that [the concept] would be tested during a month 


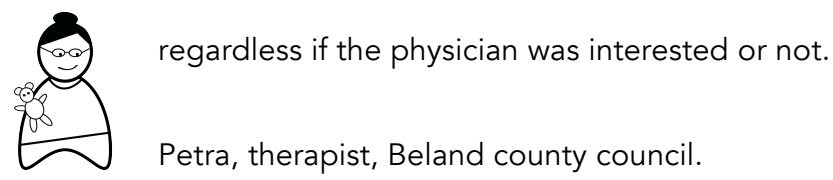

Pia says it was important to have some kind of support, if only to handle the reluctance to change among some colleagues. She feels that not much resistance was needed for them to give up as they were driving the implementation on top of their regular work since the design training project ended.

In relation to the continued work with the concept, they also mentioned the process with which it was developed at some of the reoccurring workplace meetings with the staff at the children's clinic. However, it is difficult to explain the process and its implications to someone that has not experienced it and their focus had been on presenting the concept they developed, Pia and Petra says. Petra says that it is difficult to get the time to go into the process as this is just one thing among all others that is addressed during the meetings.

\subsubsection{The Health Lab actor's hindsight reflection on the project}

There was never really a plan for how the results from the design training would be implemented, Johan says. Like the participants from the healthcare personnel, he also thinks this is something that they should probably have addressed during the training. They have to acknowledge that the result from a project like this has to be maintained, otherwise it will only be a course alongside all the other courses that are put in the mental backpack and lay there dormant, he says. He thinks that it is not only a matter of maintaining the knowledge, but that the management within the county council must also reflect on how the competence can be exploited now that it has been developed.

The management has to in some way tell those who have developed a new competence that; next we would like you to do this. So they have something to take a bite of. I believe the personnel probably use this or at least think about this in their regular work, but if it could be done more in a project 


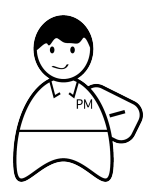

//:...:// we apply the knowledge in this problem area.

Johan, project manager, Health Lab.

He also thinks that supporting the work's progress from a final concept to the implementation of the solution is something to consider in the future. It is one thing to create and test a prototype, another to get that implemented, he says. This design training did not entail implementation, yet Johan see that the teams tried to continue and drive implementation on their own. He saw that the personnel were really engaged in their solutions. He thinks this is important - when a group has done something they feel strongly about, then it can be taken forward. In Johan's opinion, Health Lab will never be able to drive implementation. This has to be done by the personnel, with potential help from other actors such as operational developers, he says. Johan sees three main factors that uphold the results from a project like the design training, and in relation to all three, he highlights that the management must take its responsibility: the first is maintenance of the knowledge; the second is to demand that people who have participated in training continue and do new projects where the knowledge is applied; and the third is to support and push for the implementation of developed solutions.

Looking back at Health Lab's first years, Gustav says one can notice that not all of their projects had the quality that they potentially could have had. The design training project is one such project he thinks. There was some disagreement around this among the people involved in Health Lab, he explains, but that from his perspective this was a bit of a strategic choice. They focused on doing many things in order to develop the platform on which Health Lab stands. This was at the cost of quality in individual projects. The design training project started and ran at the same time as Health Lab was pitching a major project with national funding together with a neighboring county council. He acknowledges that it could probably have been handled better; that they could have followed up better. But Health Lab did not let go fully, Gustav stressed. Johan was still keeping in contact with the participants and following up on the implementation of the developed solutions, he says.

Whether or not Health Lab should take responsibility for taking project results further and following up on projects, Gustav sees as a question of what position Health Lab should take. Should Health Lab have personnel who spend time on following up and continuing the support after a project has ended to ensure 
implementation and the continued work by a group such as the one formed by the personnel in the design training project or should that be the responsibility of the project owners, he asks rhetorically. This, Gustav means, is an important question for the steering committee to address as they continued the development of Health Lab. He could see the pros and cons of this kind of support being part of Health Lab's responsibility as well as it being the project owners'. However, given the way they have worked thus far, especially in this design training project, they were the ones who were perceived as responsible since they were the ones who had suggested and facilitated the setup of the project, he says. That means that they must take some kind of responsibility if they see that no one else does, Gustav says. However, he hopes that it will develop so that user involvement and the development of services within the healthcare will and should be carried out by the people in the healthcare; that Health Lab will only be a catalyst and facilitator for this.

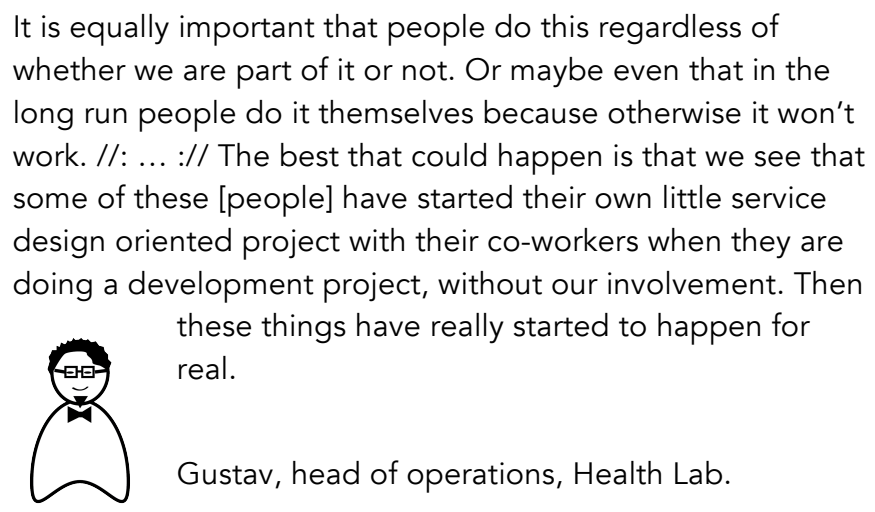

For that vision to become true however, Gustav thinks something like Health Lab will be needed on the way. About six months after the design training project, two solutions are in the process of being implemented and further disseminated in the practice, despite the lack of inclusion in the project setup. Later, one of the participants also moved on to become a manager for a new department and works to use the transferred approach as a natural part of the department's development work. 


\subsection{Three years, still ongoing}

The two projects that are presented here were, as mentioned, among the first that Health Lab planned or took part in. Since it started, Health Lab has been involved in 21 different projects of which 13 are finished ${ }^{20}$.

At the end of 2014, one year after the official opening of Health Lab, Gustav reflected on what they had accomplished thus far and the challenges that he saw lay ahead. He thought that the county council personnel would pick up on the design tools because the need for a change in relation to the patients and development was real. However, something they had learnt through the projects they had conducted thus far was that diffusing the transferred design knowledge and budding cultural change is difficult, he said, and it was something that they at that time had not yet figured out how to solve. He estimated that between thirty to fifty people had somehow taken part in Health Lab facilitated projects thus far, some in a more direct manner and others more on the periphery. People talked about it and in that way were also part of the dissemination of the patient-focusmindset and the design approach, Gustav said. He saw, as mentioned in the reflections on the legacy of the design training project, that both dissemination and implementation were questions related to the roles and responsibilities that Health Lab should take in the organization. Since the establishment of Health Lab, the steering committee had had many different ideas and discussions about how to disseminate the design approach and methods in the organization, Gustav said, and the design training project had been one way that they had now tested. They had also had a lot of discussions about how to then maintain and uphold the knowledge and practice developed from such a project. For example, what kind of responsibilities and possibilities Health Lab had in relation to this. However, at this point, the question about Health Lab's role remained unanswered. This was despite the fact that Gustav's vision for Health Lab was clear and shared, for example, by Johan; that it should act as a facilitator and support but not as a project owner with responsibility for taking results further (as discussed in the reflections on the legacy from the design training).

Apart from the direct impact Health Lab had had during its first year through the projects they had been involved in, Gustav also thought that the organizational changes in the county council that went on then, at the end of 2014, and involved Health Lab, were an effect of the development of Health Lab and its work thus far. He experienced that the management, on a strategic level, had realized the

\footnotetext{
${ }^{20}$ According to Health Lab’s homepage in August 2016.
} 
contribution design could make to the development of the organization and its practices, and thus wanted to make it an established way of working. In the new organization, Health Lab would become a part of a unit that focused on operational development together with the regular operational developers, the internal innovation incubator, which Gustav had worked for before the establishment of Health Lab. This would imply an increase in the internal funding of Health Lab from the county council by moving the cost of Gustav's position from the national funding for the pilot to the county council, he explained. This, Gustav said, would make Health Lab even more deeply embedded in the county council organization.

Gustav felt that as they had now gotten started within the county council, over the remaining two years with national funding they needed to also start focusing on exploring the possibilities of turning Health Lab into a national center, as this had also been part of the funding application. As Health Lab moved forward after the first year, they made a mental division whereby some of the personnel focused on projects within and in relation to Beland county council and others set out to focus on exploring the possibilities to form a national center. Gustav thought that the challenges related disseminating and maintaining design knowledge were relevant for both strands, but that the solutions and way forward probably would be different. He believed that a way forward for dissemination within the county council, after the action learning setup had been tried in the design training project, could be to work together with human resources. To get it into the regular training - as a part of the management training that the county council offered, for example.

Finding a way to disseminate and uphold the knowledge and competence developed through the projects was something they did not know how to do yet, but they were aware that it was an issue they had to solve, Gustav said. In his opinion, it was maybe one of the most important issue that they had ahead of them during the remainder of the period with national funding.

Thus far, Health Lab had been very careful to emphasize all their projects as successful or at least highlight the successful aspects in them, Gustav stressed. He explained that this had been necessary to gain acceptance in the county council's results focused culture. However, he saw that as they moved forward, in order to create a more open and permissive culture it would be important to also acknowledge and admit that not all projects will be successful, and to convey that this is okay and a natural part of innovation. 


\section{Chapter 6}

In January 2016, when Health Lab had been running for a little more than two years, Beland county council made the decision to continue with Health Lab and make it permanent within the organization from the beginning of 2017 when the funding from the National Innovation Agency ended. The new organization meant, as described above, that Health Lab now formed a new unit together with the innovation incubator and regular operational development and was part of the line management. This meant that they were further away from the top management than before, and the steering committee was dissolved as they were now managed as part of the line management unit. It also meant that they were more embedded in the organization, which at the time, Gustav said felt good.

However, despite this progression they still battled with issues related to the diffusion and upholding of the knowledge and competence that were developed through the projects that Health Lab facilitated. Over the course of the venture, Johan's experience was that they had become better at judging which projects to initiate and support. He said that now, when initiating projects, they took better care that it had a clear project owner in the department or practice where the project would be conducted; someone who could take responsibility and ensure the project would go to implementation and not fade out after the ideation and concept development. This was something they had learnt through their first projects, he said. For example, even though the CCP project was never intended to be more than a mapping project, he thought that it still lacked someone who took care of the results afterwards.

Although they had made progress, Johan still saw challenges: they had, for example, learnt from the design training project that, sure, there was a lot of engagement and action during the training, but after the project ended it came to a halt. This was one reason that they now made sure that each project had a project owner at the unit of the department in which it took place, who was in charge of managing the project, planning the time, booking up people, enabling people to take part, et cetera. Johan had noticed that, even though the personnel who had been part of a project believed in it and were inspired by the new approaches and methods that they had used and learnt in a project, once the project ended, they got sucked back into the core practice. In the core practice, all focus is naturally on curing, nursing, et cetera, he said, and described it as a black hole that devoured time and resources.

It is very difficult to allocate personnel to be part of dedicated development work, Johan said, due to the lack of resources in the core operations. He predicts that this will only get worse as the healthcare in general will have a tighter budget 
but more to do. He saw that it was difficult to allocate personnel due to their tight and complex schedules, which require the coordination of meetings or workshops to be done a very long time in advance, as discussed in relation to both the CCP project and the design training project. He also saw that it would be difficult to allocate personnel to development projects that cut across the functional silos as design driven projects often did because of the holistic approach; it created a mismatch with the current silo organization and culture in the county council. Involving people across the silos increased the complexity of coordinating people, and, Johan explained, in his experience the departments were hesitant, maybe even reluctant, to spend their resources and free up their personnel to work on an issue in another department. Reluctance to engage in issues in another department before it was clear that they affected their own function was something that André, the new head of health and care after Irene, also brought up as a reason why the stroke process and CCP mapping were important. It showed how the functions were connected and affected by one another's actions and problems.

As Johan reflected on how to make the design approach become part of the county council's toolbox, he identified four aspects that he saw as important: 1 . Freeing time to develop; 2. Providing tools for patient centered development; 3. Support implementation; 4. Management engagement.

1. He uses the example of personnel who had been part of the design training directly being sucked back into the core practice. There must be time allocated specifically for development work so that it is not expected to be done on top of or in between the regular practice of a nurse, physician, or of disability support coordination.

2. Allocating time will however not be enough as Johan sees it. A key aspect is that the healthcare personnel are provided with tools for patient centered development work; for example, that they learn how to do user research and do customer journeys. However, they must also be provided with support in using these tools, Johan says; for example, support from designers to do the analysis and synthesis of the user and context research or help with facilitating workshops. He strongly believes that experiencing the tools and methods is a key factor in acquiring the tools as it will enable the person to create his or her own feel for the method. That is why learning-by-doing is important, Johan feels. He gives an example of one of the chief medical officers in the county council who was very interested in the work of Health Lab and had, along the way, created her own experience of the tools and methods. She is now, Johan says, quite able to stand on 


\section{Chapter 6}

her own two feet and no longer has the same need for facilitation support. In order to get there, he believes one first has to experience the tools oneself.

3. Maintaining and disseminating the Health Lab way of working is also connected, Johan means, to handling the problem of core practice being a black hole. He believes that there is a need to support implementation because the core practice is the natural main focus in the organization and it takes much resources and energy. The healthcare personnel do not know design or development because it is not part of their profession, Johan says, and therefore someone like him is needed who can offer support when they come to implementationsomeone who can support by pushing a little, make sure there is a momentum in the work, or see a need and call in someone who can help visualize or facilitate depending on what is needed.

4. Management must support the dissemination and upholding of the new approach by commissioning development work projects, Johan felt. For example, giving the design training participants an assignment in which they will use the knowledge gained from the training, he said.

The personnel who took part in the design training are a perfect example of the need for these things, Johan says. They were given the tools and methods and had time freed up during the project, but were not given time or support after the project ended to continue implementation or to find new projects to practice the tools in.

As Johan understood it, the lack of support for taking ideas further and implementation could be one reason that many projects had trouble going all the way. However, he also thought that strong focus on the process among the designers could play a part. In his experience, the lack of focus on what would come after the process had been gone through and a concept been developed led to an unbalance. It is important to be pragmatic and be able to depart from the process if necessary, Johan says. He experienced the first part of a design process as similar to any form of pre-study or investigation, which the county council does a great deal of anyway, he said. He thought that the cool thing about the design approach was that it continues beyond the investigation to develop ideas that can be tested. The second part of the process is thus more about doing than just producing paper as the results of investigations, Johan said.

The competence needed to give the support needed to drive a project forward and keep it in motion (and when the everyday chores take over) does not have to be those of a designer, Johan thinks. He sees three different characteristics of support needed during a project, three roles that he takes on as he project 
manages. First, he is a catalyst, someone who helps the department get going, see things from new perspectives, and maybe reframes the problem. The second characteristic is the facilitator who supports the use of the tools by facilitating, for example, workshops and pushes the work forward. The third characteristic is that he does things, creates prototypes, frameworks, creates conditions, or enables things to happen. This characteristic he believes is especially important for support at the end of a project if the implementation is to get all the way. In the middle of 2016, the Health Lab team consisted of sixteen people with varying competences and backgrounds - designers, project managers, IT-coordinators, academic design researchers, and a physician. As he looked at them, he saw all these characteristics in the team members, but with different balances he said. Some were more catalysts and others more facilitators, for example. Johan stressed that these roles should be there as a support for the project owner and manager from the practice. It is important that they stick to that, even though, as he pointed out earlier, they now demand a project owner and manager from the practice in all their projects, he said. He saw a risk that the designers who were there to support and facilitate the work got drawn into the black hole as well. When the personnel who were originally intended to do the design and development work do not have time because of the constant need from the core practice, the designers go in and do it instead in order to keep the project moving, Johan explained. He has seen this in their projects and claimed that a consequence of this is a risk that responsibility for the finalization and implementation then falls on the designers, he said. A role and responsibility that they might not be able to take if they do not have project management competence or the characteristics of the generator, Johan reflected. Another issue is that they might lack a mandate to make the changes necessary for implementation, he continued. This, Johan said, is a key reason why the ownership and project management must remain the responsibility of someone at the department where the project is run.

Just as having experienced the tools and methods plays an important role in the ability to understand them, Johan had also noticed that many of the projects Health Lab had done over the years had some kind of connection to their prior projects. The projects were not direct spin-offs, but new projects had, for example, been suggested or initiated by someone who had participated in an earlier project or seen the results of a prior project and then gotten an idea for the new one. Networks and relationships had thus been an important aspect in the dissemination of Health Lab's work, Johan said. 


\section{Chapter 6}

The Health Lab venture is an ongoing project whose story continues and evolves over time as the organization learns and matures. The story given here has presented how the venture was initiated and the motivation and drive behind it. It has focused on the work inside and with the county council and followed two of the initial projects that were conducted. Based around those projects, the story shows the reflections, thoughts, and experiences of some key actors in the venture, as well as representatives from the healthcare personnel who had been part of Health Lab projects. I have followed Health Lab mainly through the two projects and during its first two years. In the early fall of 2016, Health Lab had been running for almost three years and was about to move on to its next chapter as a fully funded part of Beland county council; the story thus continues ... 


\section{Chapter 7}

\section{Patterns in the development of design capability}

In the thematic analysis of the empirical data, a set of patterns were identified. These patterns relate to how the participants in the initiatives studied received design, how the initiatives were set up, and how they contributed to the development of the organizations design capability. Five themes stood out, which will be further presented below: learning-by-doing; design: unfamiliar yet familiar; the focus of the knowledge transfer; the black hole: discordance with the existing practice and culture; and finally ownership: who will enable design?

\subsection{Learning-by-doing}

In the two cases, the main objective was not to learn about design or how to practice design. The objective of the Health Lab initiative was to increase the patient centeredness and the ability to develop solutions that are sustainable and increase the patient value. Similarly, in the Social Service case, the main objective was to increase the user involvement and influence in their services. Introducing and disseminating design and developing internal design capability were in both cases a means to an end.

User centeredness was a central part of the design approach and transferring knowledge about design was therefore seen as a step on the way towards increased patient and user-centeredness in the healthcare and social service practice.

Health Lab had an ambition to work as a learning platform where the healthcare field can learn about using design as an approach to development, and design can learn about the conditions and regulations of healthcare. As part of this, 
Health Lab had the ambition to diffuse awareness about design, but also to train the healthcare personnel and civil servants in using design in order to make it a natural part of the continuous development work.

The design training project was their first attempt at disseminating design knowledge to the healthcare personnel. In the CGP project, knowledge transfer was not an articulated aim. However, through the application of design methods as a means to include the patient perspective in the mapping, knowledge about a user-centered mindset and design methods was also transferred to the participants.

Transfer of design knowledge was also part of the original aim of the project in the Social Service case, although testing design as an approach and developing a solution within the day center service, which would increase user involvement, was the main objective of the pilot project. Sam, the designer, said that by engaging the personnel and allowing them to experience the design process, he wanted to show them that it need not be complicated or difficult. He wanted to make development work more accessible and give them confidence to try out ideas.

Thus, all three projects transferred design knowledge through the application of design methods and tools in a design driven project and through the participants' experiences of this. In particular, the design training project from the Health Lab case and the pilot project in the Social Service case had a very similar setup where the participants experienced a design process from research to prototype testing; the only difference being the active involvement of the designer in the pilot project in the Social Service case.

In both projects, the participating personnel had been introduced to theory and methods for each phase of a design process (research, analysis/synthesis, ideation, and testing) through workshops before experiencing the application of them. The projects had a learning-by-doing setup with focused on the methods and tools associated with design.

The importance of the experiences the personnel had in relation to understanding and accepting the new approach and methods can be seen in comments from the informants in both cases. Experiencing the process and methods gave the participants an understanding of how design works and what it can contribute. Even in the CGP project, which did not have an articulated learning aim, the insights from using the design methods led to a budding cultural change, according to Johan the project manager. Ylva, the division manager in Norfors and part of the Social Service case pilot project, experienced that being an active part of the design work, experiencing the new (to them) user-centered mindset made the personnel understand and accept it. 
The value of the experience of the participants is also seen in the difference in engagement in the project between the personnel that took part in the project from Norfors and the Fruberg personnel. The personnel from Norfors, who were more actively involved in the design work and could make direct relations to their practice (as it was the object for the project) were more engaged and seemed to have better acquired design than the Fruberg personnel, who only took part through the project workshops.

\subsection{A roller coaster ride: design unfamiliar yet familiar}

In both cases, the design-novice participants were at first uncertain about what to expect when they were introduced to the idea of design as a means to support development in their contexts. Design was perceived by most of them as a practice related to the development of physical objects and styling. Design felt distant from their own practice, and it was at first difficult for the design-novice participants to grasp what design could contribute in the healthcare or social service setting. Despite this confusion, in both cases the informants all expressed openness and curiosity to the new methods and tools that were introduced through the projects.

For many the possibility of finding a way to involve the users or patients and ensure their voices were heard in the development was a motivation, even though some believed that they were already user focused. Robert from the ambulance, who was part of the CGP project, expressed that he went in with the mindset that he already knew the patients' needs and desires based on several years of experience meeting and interacting with the patients. Fairly soon in the project, however, he realized that there were many issues that he did not think of as he normally did not reflect on the service from the patients perspective. For him, and the rest of the project team, this was an important insight beside the pain points and opportunities for improvement that they identified as part of the CCP mapping. Robert expressed that these issues they would not have found using any of their regular methods and approaches.

As the participants experienced the design approach and methods in the projects, they started to understand the value that this way of working could bring to the organization and its practice. They found aspects in the design driven process that they could relate to and found familiar. Most often, the user-centered mindset was related to the empathy that they felt for their users or patients. They felt that the initial user and context research gave them confidence in what they 


\section{Chapter 7}

developed and in how they could increase the user involvement. Daniel, the design consultant involved in the design training project in the Health Lab case, observed that the healthcare personnel had a natural talent for the user-centered methods and tools. They were used to interacting with and observing people and using empathy to pick up on how a patient feels. Similarly, in the Social Service case, the day center personnel are also used to observing and interpreting the needs and desires of their users. Empathy is a core ability among the personnel in both healthcare and social service, an ability that they use daily.

Individuals that had previous experience of working with the development of improvement work also found similarities in the structure and process of the design approach with other approaches that they had experience with. Karin and Ulla, who initiated and led the Social Service initiative, as well as Susanne from the Health Lab design training project, made associations and put the design approach in contrast with LEAN and other development approaches that they have previous experience of working with.

As the participants experienced the application of a design mindset, methods, and tools through the respective projects, their understanding of what design entailed and their awareness of its potential value to the healthcare or social service context developed. The confidence in design as a knowledge and approach of interest grew. However, this was not necessarily accompanied by the confidence in how to take it forward and apply it in future projects. In the design training project, the participants describe the project journey as a roller coaster. They found it difficult to grasp the process and the contribution of the different phases in it while they were still in the midst of it all. Ulla expressed a similar experience from the Social Service case. It was only when they had gone through the project and came out on the other side that she could see the red line. This was also, she explained, the reason why Sam and herself did not want push the participants from the municipalities to reflect on how they could apply the design approach and methods in their practices in the future before they had gone through the whole process. They felt that the personnel had their hands and heads full with understanding and reflecting over what it was they were doing in the project.

After the design training project, the participants also felt it was difficult to explain the process to others. It was difficult to express the value in the methods to those that had not experienced it and for example, to get the colleagues to understand that it was just a prototype that they were testing, not the final solution and that it therefore did not have full function. Petra and Pia both felt that it was difficult to point out the red line for someone that had not experienced the process. 


\subsection{The focus of the knowledge transfer}

The experiential focus in the learning-by-doing setup that was used in the three projects resulted in a focus on transfer of knowledge related to the user-centered mindset, and the methods and tools that accompany it. The focus on the design process and the practical work around applying methods and tools seems to have also led to a focus on the development of a solution. Even in the design training project, the focus among some of the participants shifted to developing solutions rather than on learning a new approach. This, despite the main objective of the project being transfer of knowledge that could create a foundation for continued development with the child's perspective at the center.

The focus among the participating personnel in both the design training project from the Health Lab case and the Social Service case pilot project had mainly been to develop a concept or solution. There had been little reflection on the tools or methods used, what they had contributed, or how they could be applied in future projects. This is apart from a general reflection on how the approach and method allow for the user focus.

In the Social Service case the user-centered approach was specifically addressed and discussed as part of the setup. The approach was, however, mainly discussed in relation to the personnel's roles in the day center practice and was not discussed in relation to how the methods and tools used in the project contributed. Thus, it did not support a deeper understanding of how design methods and tools can contribute as means for a user-centered practice and how this could be used in future projects.

In the design training project, the experiences from the application of the learnt methods and tools were discussed in a debrief at the beginning of each workshop. However, the focus remained mainly on the development of solutions to the defined problems. In the last workshop, the implementation and upholding of the solutions and knowledge from the project were discussed briefly and the participants were asked to write a letter to themselves reminding them how they would continue the work. No actions in connection to this or support for how to uphold and disseminate the transferred knowledge were discussed.

The lack of reflection and discussion on how the transferred knowledge could be further applied and upheld as part of the project setup left the responsibility for this with the individual participants.

In particular, the informants from the design training project - the project with the most articulated knowledge transfer objective- expressed criticism over the lack of support in the setup relating to how the approach, process, and methods 


\section{Chapter 7}

could be further applied. Susanne, how were commissioned what became the design training project, felt that for the group to be able to continue with design driven work on their own and extrapolate what they had learnt to future projects, they would have needed a better understanding of not only the process and methods, but also the context and conditions in which these could and would be used - in other words, the coherence.

The setup in the projects had thus supported the participant's ability to experience the new way of thinking and working, but there was little or no support for reflection on which situations or how this kind of approach could be useful in future work. This kind of reflection or discussion was neither supported by the project setup nor was it specifically facilitated through exercises or discussions in the workshops.

\subsection{The black hole: discordance with the existing practice and culture}

Looking at how design was received by the organizations that were involved in the two cases and the budding integration of design, several examples of discordance between design and the existing practice and culture can be identified-aspects where the attitude and approach of design does not fit with the routines, structures, or processes currently active in the organizations.

In both cases, the informants expressed an understanding of the user-centered focus, but also reflected on and demonstrated that a shift in perspective is not made overnight.

What drives and motivates a solution in the design approach when compared to prior approaches that have been used in the organizations, is one example of discord. In both cases the informants give examples of how the development had previously been driven by the organization's perspective on need and conditions. The organization had taken the right to interpret the needs of the patients or users. This clashed with the design approach, which takes a holistic perspective, looking at all involved stakeholders and putting the users' needs and desires at the center of the development. This shift in perspective was even one of the objectives for introducing design and developing design capability.

This discordance is, for example, seen in the story told by Kai, one of the physicians that took part in the CCP project. He explains how it was difficult at first to step out of his regular role as a physician when they met the coworkers 
during the patient journeys and instead look at what was happening from the perspective of the patient, he had to remind himself.

In the Social Service case, Ulla also described how the personnel initially, during the ideation generation, had problems keeping the users perspective and fell back into generating or criticizing ideas based on the organizations perspective. Ylva and Hanna also say that they are worried that once the project is over it will be difficult not to fall back into old habits and forget the user's perspective as they make changes or plan new things.

Even though the participants appreciate the value that design contributes and how it invites the users into the development, accommodating and adjusting to the organization's constraints is deeply rooted in their mindset. Petra says that they are fostered in a culture that always has some objection to ideas involving change and as a contrast to this, she appreciated the open attitude in design. However, she also pointed out that while acknowledging and exploiting the values of the users' perspective as a driver for development, the organization's perspective cannot be discarded completely. Healthcare and social services are complex contexts where the organization's constraints are central to the success of a development project. This comment indicates that the setup of the design driven project has not managed to convey the holistic perspective of design. Design has mainly been understood as an approach to involve and include the patients' or users' perspectives.

In her comment about the development culture, Petra touches on another aspect that differentiates the traditional development practice from the design driven projects. Design is an open-ended approach that keeps an open mind towards both a problem's scope and ideation. A design driven project does not define the solution at the beginning of the project, contrary to the result focused development culture often found in the public sector. With this approach comes an open and permissive attitude that encourages ideas and trying things out. This was unfamiliar at first, especially to the personnel in the Health Lab case.

To test ideas and not view ideas that do not work out as failures is another part of the open and permissive attitude of design that clashes with the result oriented focus of traditional development work. In design, to test ideas is part of the learning process that goes on in development work. Through testing the design, the team develops an understanding of how an idea works in relation to the needs, desires, and constraints of the problem's scope. An idea that does not work out is not a failed idea, it has taught the team new things about the stakeholders and the context in which the idea should live. Testing ideas that go outside of the 


\section{Chapter 7}

prescribed conditions and constraints is a way to understand where the line goes, what is actually possible and what is not. To test ideas or to go against conditions that have been setup is not common practice in public sector development.

Sam, the designer in the Social Service case, had noticed that before the pilot project there had been a hesitance towards change among the personnel. They were afraid that change would upset or cause disturbance among the users. By inviting the personnel to take part in both creating the prototype and conducting the testing, Sam wanted to show the personnel that trying out an idea or testing a solution need not be a big deal. He wanted to transfer the mindset that an idea that did not pan out should not be perceived as a mistake or a failure, but as an opportunity to develop new knowledge that goes into further development or a new idea. He wanted to build confidence among the personnel that they could test their ideas themselves. This, he claimed, would make development more accessible to everyone in the organization.

Also, Johan, the project manager from Health Lab, noticed as he took part in the design training project that there was a fear among the personnel of doing something wrong. They were nervous about going against the structures setup in the organization.

Although the permissive attitude of design was welcomed and described as liberating and increased creativity, in the Health Lab case there was also a tension. The personnel in the design training project were not completely comfortable with working in a manner that did not conform to the expectations and traditions of the organization. They expressed that it felt comfortable and safe to have Health Lab as an excuse and explanation to why they were approaching the problems without considering constraints, in case they were questioned about it.

The informants in the Health Lab case recurrently go back to how the culture and attitude in the organization discourages ideas and initiatives for development work. The discord seen in both cases in relation to the open-endedness and testing is mainly related to cultural aspects of how things are done in the organization. Routines and structures are indirectly affected by choices that are made based on expectations and attitudes related to the development culture. To overcome this discord is a matter of a change in attitude and mindset, a cultural change rather than just a matter of which processes or methods are used, even though the choice of methods and tools can be affected by the mindset.

There are also other barriers for design practice that are not only related to discord between design and the current development practice, but barriers to development practice in general, which also affect design driven development. 
In both cases, participants reflect over how the design process gave them a structure for working with development that had not been available before. The structure in the design process drove the development forward and made sure the issues and solutions were actually relevant for the end user. In the Health Lab case, Petra expresses that the structure of the design process gave the development work a momentum that she had felt was missing in earlier projects, which had just kept running without really going forward. Olivia, from the Social Service case, also reflected on how they worked in the design driven project and concluded that the social service in their municipality had never worked in such a structured manner when generating and developing an idea before. Sam, the designer, also noted the lack of structured development work within the social services. This was one of the reasons he wanted to transfer the design knowledge to the personnel. However, he also stressed that successful development work is not just a matter of making change and development accessible to the personnel by developing their knowledge in tools and methods, is also necessary to give them resources, time, and the mandate to use this knowledge.

Time to work with development was brought forward as an issue in the Health Lab case in particular. Finding resources - in other words, time for development work - is brought up as a general issue. When involving actors from across the functional silos - as is often the case in design driven projects as they take an holistic perspective - time is even more of an issue; finding time for the development work that suites all involved actors and deciding from whose budget that time will be paid. In the CCP project, the project manager, Johan, started to book up people more than six months in advance to make sure they had dates that worked for the workshops.

For personnel that are part of the core practice, such as nurses or physicians, being part of a development project also implies taking time away from regular duties. This means finding ways to restructure schedules or tasks so that the practice and, in other words, the patients are affected as little as possible; as was brought up by several of the informants in the Health Lab case.

In the projects studied in the Health Lab case, time is also an issue in relation to how developed solutions are taken forward and implemented and how the transferred knowledge is upheld. Implementation or how the results were to be taken forward was not part of the setup in either of the projects, as concluded above. Consequently, there was no time set aside for work on taking the results forward. About half-a-year after the GCP project ended, the participants felt that nothing had happened with the results that they had delivered. Johan, the project 


\section{Chapter 7}

manager, says that there had been no structured efforts made for taking the results forward or for disseminating the insights from the project, nor had there been any efforts made to uphold the changed mindset among the participants.

Similarly, after the design training project, the responsibility for the implementation, diffusion, and upholding of the transferred knowledge was placed on the participants. However, although the participants were inspired and motivated to continue the development work involving users, they did not see how they would be able to. As Frida said, how would they be able to do development work on top of their already fulltime positions in the core practice?

When the implementation and diffusion of knowledge are not included in the project setup, these things have to be addressed afterwards when then personnel are back at their regular work in the core practice. A core practice that is described by Johan, from the Health Lab case, as a black hole that devours everyone's time. Development work and other things not directly related to the immediate care of patients are not prioritized, a reality also described by Frida.

The issues with time seen in the Health Lab projects indicate a need for structures or routines in relation to development work that enable departments to free personnel to take part in such work.

Apart from time, the cultural structures of the organization also presented a barrier to the diffusion and practice of the user-centered, design driven way of working. Eva from the CCP project, for example, felt that she could not make her voice heard when she wanted to share her experiences because of her position as a nurse. In the Social Service case, the day center personnel were nervous about how other professions that had previously had more influence would react to their new approach, in which the users who had mostly been spoken for would now have a stronger say. Ylva and Hanna described how the project affected the work in the day center, not only through the concept that was developed, but also through the insights it created about their mindset and culture. The reflections and discussions that they had during the project about user involvement and influence had disrupted the prevailing balance as roles and responsibilities among the personnel were questioned. They describe this as a little uncomfortable at first.

The discordances identified above between the organization's current structures, routines, and processes for development, as well as their culture and the structures and approach within design practice, imply that for design practice to take place in the organizations and contribute in a long term perspective, the culture of the organizations must be adapted. There is a need for updated, adapted, or even disrupted structures and routines for how development work is 
carried out within the organization. These are aspects that are difficult to change by an individual nurse or physician.

\subsection{Ownership: who will enable design?}

A clear difference that can be seen between the two cases is the degree to which the initiatives were legitimized in the respective organizations' management before they started.

In the Health Lab case, the strategic management of Beland county council was well informed about the initiative and objectives to develop Health Lab. Before embarking on the venture, Gustav, who managed the Health Lab initiative, had made sure that the form and objectives of Health Lab had been legitimized within the county council management through discussions and negotiations about the setup. Before Gustav approached them, there had already been a shared understanding among the strategic management about the need to develop a more person-centered care. When the idea to establish Health Lab was presented, it was seen as a potential element for achieving that.

In the Social Service case, on the other hand, the discussions preceding the initiative, to legitimize and establish a foundation for it, were not carried out directly in the three municipalities, but in the regional development council. The legitimization of the initiative in the projects was achieved as Karin and Ulla approached the managers in the municipalities and asked about their interest in taking part in the project. The legitimization of the initiative was thus not done on a strategic level in the municipalities in the Social Service case as it was in Beland county council in the Health Lab case.

When reviewing the comments from the municipality participants about their expectations before the project, it is clear that the three municipalities did not have shared images and expectations for the setup and objectives of the design project in the Social Service case as it started. For example, the Fruberg personnel were mainly expecting an opportunity for the personnel from the different municipalities to meet and share experiences. The expectations from Norfors, the pilot municipality, showed a clear focus on the development of a solution. The second objective of the Social Service case initiative - to transfer knowledge about design - does not seem to have been clear to either of the participants. When asked about this, Ulla also says that as the project progressed this objective was left behind. 


\section{Chapter 7}

These differences in how the initiatives were legitimized in the organizations' management can potentially be partly explained by the vast difference in scope between the two cases. The three-year scope of the Health Lab venture and the articulated aim to be a learning project with the end objective to develop a new approach to development, compared to a six-month project in the Social Service case, with the aim to try out design as an approach, requires a little more groundwork to even start. For Gustav, it was important to establish legitimacy for the initiative within the county council, as the objective was to create a long-term change in the development and improvement work of the Beland county council organization.

The position of the initiators in relation to the organizations and the prior knowledge of the initiators is also likely to have affected the way the initiatives were described and legitimized. Gustav on the one hand, had an extensive prior experience of working with design. He was also acting from an internal position within the county council and was familiar with its current development culture and structures. Karin and Ulla on the other hand were both design novices and external actors in relation to the municipalities, as they worked at the regional development council. Consequently, they lacked direct knowledge about the structures and culture of the municipality organizations and did not know themselves what could be expected from the introduction of design. These are factors that likely have influenced the view and understanding of the initiative and its objectives that they communicated to management in the municipalities before the initiative started.

Although the understanding and legitimacy of the Health Lab initiative was well established on a strategic management level, similar discord to that is seen in relation to expectations in the Social Service case can also be seen on the project level in the Health Lab case. Both cases show a hesitance among the informants to how the transferred knowledge would be upheld after the end of the projects in which design had been applied. In the CCP project the participants were a mix of roles and functions but in neither the design training project nor the Social Service case project (with the exception of Ylva) were management represented in the projects. The managers had been involved in making the decision to free time for the personnel to take part in the projects, but were not s actively involved or experienced the design driven projects themselves.

The operative and tactical level management had thus been aware of and approved the projects. However, it seems that in each of the three projects, no legitimacy was established in relation to the underlying objectives of using a design 
driven approach or the knowledge about this way of working that were transferred through the projects. Such legitimization could have encouraged the continued application of a design driven approach. As the managers were not themselves involved in the knowledge transfer they did not gain the experience and understanding for design and its contributions that the personnel had gained and which could have been a way to establish legitimacy.

As noted above, the barriers to the development of a design capability that is sustained and can contribute to the long-term perspective of the organizations are mainly related to structural issues about how to enable the way of working that comes with a design approach, as prior development work was structured in a different manner. This implies, a change in the culture and structures related to development work and thus the need for an active involvement from management.

In both of the Health Lab projects, the participants had expressed that there had been a lack of engagement from management in relation to how the results could be taken forward and how the knowledge that was transferred could be upheld. In the CCP project, it was clear who owned the project, but in the design training project it was less clear. Susanne had been commissioned to undertake the project by the politicians and could thus be understood as the project owner. However, when Health Lab suggested the design training setup and took over the management of the project, the ownership became blurred. Susanne expressed a feeling of responsibility for the result from the project towards the politicians; at the same time, she felt that Health Lab had introduced something completely new in terms of the design approach and methods, they thus were the ones responsible for taking the result forward and for enabling further application and diffusion of the transferred knowledge. Among the participants, the understanding of who was responsible was mixed. Some participants share Susanne's feeling that Health Lab was responsible for supporting the continued work and diffusion, whereas others thought that the responsibility to drive this was Susanne's and that Health Lab's role was to offer support when necessary. From Health Lab's perspective, both Johan and Gustav stressed that Health Lab cannot take responsibility for taking results forward after a project. This would require mandate within the concerned function, which Health Lab did not have. Gustav, however, acknowledged that because, in the design training project, they had taken over the management of the project and introduced something that was new to everyone else, they should have taken responsibility for supporting the continuation when they realized no one else had. 


\section{Chapter 7}

Similarly, in the Social Service case, there was no clear project owner. Karin and Ulla, who initiated the project together with Sam, pointed to a reference group in the development council-where all municipalities were represented, together with people from the county council and experts from academia- as the project owner. However, in the participating municipalities, there was no articulated ownership of the project and thus no one in the municipalities who were responsible for taking care of the results from the project. The reference group had no mandate to intervene or tell the participating municipalities how to act and could thus not be in charge of taking the results of the projects further.

As a result of the unclear or ill placed ownership of the projects, there has been an absence of leadership to drive the implementation of developed solutions forward as well as the diffusion and upholding of the transferred design knowledge. After the design training project, for example, many of the participants were wondering what would happen next. Petra and her operative manager questioned where the time for upholding and disseminating the knowledge would be taken. They had both felt that it had been okay to take the time from Petra's regular work for a shorter period to be part of the project, but it could not be a permanent solution; so, how would things continue?

In all three projects, the responsibility for taking the knowledge diffusion and application further, and thus the capability development, had ended up being with the individual personnel that had been part of the projects. This was regardless of their role or mandate in the organization and thus their ability to reach out to the rest of the organization.

In both cases, the informants express a feeling of responsibility as advocates for the design approach, but they are at the same time clear about not being able to take on the responsibility for the upholding and diffusion of design knowledge. They do not feel able to drive this type of development work on their own due to a lack of time and mandate. Neither do they feel competent in the design methods and tools after having experienced them just once. They still feel a need for support from trained designers. Petra and Pia from the design training project, tried to share what they had learnt, but found it difficult to explain to others that had not experienced it. In addition, because the results from the design training project was just one thing among many others that needed to be covered during the workplace meetings, which were their arena to disseminate it, they did not have very much time and thus focused mainly on the solution they had developed. 
Workplace meetings were also, in the Social Service case, the main channel for disseminating the new knowledge to the operative manager in Norfors and to colleagues that had not participated actively in the project.

In the three projects studied the design work conducted had not on its own been problematic or run into barriers as it was conducted within the frames of the agreed upon projects. The identified discordances in the two cases was thus based on the participants' reflections on what had happened to the results after the projects had ended, and why and how this way of working could be further applied. Many of the barriers identified through these reflections indicated the need for the active engagement of management in the capability development process. It is therefore problematic that management had not actively been part of the studied projects and had not been able to create their own understanding of the necessary conditions and motivations to take the transferred knowledge further.

Both cases exhibit an unbalance where the introduction of design on the one hand seems to have been successful, the personnel have experienced a value in the design driven way of working and express the projects have been positive. On the other hand in both cases there are also several indications on things that have not worked or have been unsatisfying. One reason for this could be that the projects have developed an individual understanding of the tools, methods, and designs potential contribute but that the lack of support in the setup for reflections about further application as well as the lack of management engagement has made it difficult to make design part of the organizations' knowledge bas and capabilities.

See Table 7 for a comparison between the two cases regarding setup, results and identified barriers.

\subsection{Chapter conclusion}

The patterns seen in the empirical material show that developing an understanding of how design relate to and can contribute in the own practice is an important start of the introduction of design in a public sector healthcare or social service context. However, although design may feel distant at first, through experiencing the application of a design approach, methods and tools this understanding is soon developed.

The empirical material also show that focusing on transfer of methods and tools through their application in a learning by doing set up could led to a focus on development of concepts and solutions rather than the knowledge transfer. 


\section{Chapter 7}

It also shows that just training personnel how to use methods and tools of design is not enough to develop the organization's ability to work with design as a natural part of a continuous development work. The knowledge has to be upheld and disseminated in the organization. In both cases this has been the difficult part of the development of design capability, how to make the new knowledge fit in and sustain in the midst of old routines and culture. The empirical material shows that the barriers to integrate design as a natural part of a continuous development work are not only directly related to design. Some are also related to the general development culture or lack there of in the organizations.

These aspects of the knowledge transfer and capability development have not been supported in the set up of the three studied projects. Because of this, the organizations have not had any plans for how to continue and take the knowledge further after the projects have ended. The responsibility of upholding and disseminating the design knowledge has thus been put on the individual participants from the projects. This has been problematic, as most of them have not been in a position or had mandate to address the practical or cultural barriers to integrate design as a natural part of the development work.

In the following chapter, the themes identified in the empirical material will be discussed in relation to the tentative framework for development of design capability within public sector that was derived from the theoretical literature in chapter 4 . 
Patterns in the development of design capability

Table 7. A comparison between the two cases.

\begin{tabular}{|c|c|c|}
\hline & The Social Service case & The Health Lab case \\
\hline Main objective & $\begin{array}{l}\text { Test out design as potential } \\
\text { approach }\end{array}$ & $\begin{array}{l}\text { Develop the organizations } \\
\text { design capability }\end{array}$ \\
\hline Legitimization & None & $\begin{array}{l}\text { Well legitimized on top } \\
\text { management level }\end{array}$ \\
\hline Designer involvement & Active in the design work & Only facilitating \\
\hline Roles of the participants & $\begin{array}{l}\text { Operative personnel + one } \\
\text { manager }\end{array}$ & $\begin{array}{l}\text { A mix but mainly operative } \\
\text { personnel }\end{array}$ \\
\hline Initiative results & $\begin{array}{l}\text { A developed understanding } \\
\text { of how design can contribute } \\
\text { among the participants }\end{array}$ & $\begin{array}{l}\text { A developed awareness } \\
\text { among the participants from } \\
\text { the projects. An } \\
\text { understanding of a need to } \\
\text { address enabling structures. }\end{array}$ \\
\hline The participants' focus & Developing solutions & Developing solutions \\
\hline Project results & $\begin{array}{l}\text { A concept ready for second } \\
\text { iteration testing }\end{array}$ & $\begin{array}{l}\text { The CCP project: identified } \\
\text { hotspots and initial ideas } \\
\text { The design training project: } \\
\text { tested concepts }\end{array}$ \\
\hline Perceived value in design & The user focus & $\begin{array}{l}\text { The user focus }+ \text { a structured } \\
\text { permissive process }\end{array}$ \\
\hline Identified barriers & $\begin{array}{l}\text { A worry related to } \\
\text { change } \\
\text { Lack structure for } \\
\text { development in } \\
\text { general } \\
\text { A focus on the } \\
\text { organization that is } \\
\text { easy to fall back into } \\
\text { Hierarchy }\end{array}$ & $\begin{array}{ll}\text { - } & \text { Time } \\
\text { - } & \begin{array}{l}\text { Culture that does } \\
\text { not encourage } \\
\text { ideas }\end{array} \\
\text { - } \quad \text { Fear of doing } \\
\text { something wrong } \\
\text { - Organizational } \\
\text { structure } \\
\text { Hierarchy }\end{array}$ \\
\hline
\end{tabular}





\section{Chapter 8}

\section{Understanding development of design capability through an absorptive capacity lens}

Thus far the research presented has created an understanding of design capability based on previous literature, and developed a tentative understanding of how design capability is developed based on a synthesis of the theory on organizational learning and design capability. It has also through the observations of the two cases developed an empirically based understanding of what design capability implies in practice and how it is developed in the studied contexts.

In the following sections, the understanding of what design capability is and how it can be increased in public sector organizations is further developed through a discussion of the relation between the theoretical and empirical insights. First, the notion of what design capability implies is discussed, followed by how design knowledge is absorbed in the organizations and developed into this capability.

\subsection{Design capability, theory and practice}

The literature review on design capability identified three key aspects related to an organizations ability to utilize design: awareness of design, access to design resources and the need for structures that enable design practice (i.e. enable the utilization of the design resources). Accordingly, the understanding of design capability as made up of these three aspects was developed. The three aspects were also later recognized in the empirical material. 


\section{Chapter 8}

In the Social Service case developing awareness about the design approach as a way to work from a more user-centered perspective was part of the objective of the initiative. The designer, Sam, also aimed to transfer some knowledge about design methods and tools, thus developing internal design resources to make development work more accessible in the organization. Similarly, in the Health Lab case, the setup of the projects aimed to transfer awareness about the design approach to the participants. In the second project in the Health Lab case the aim was also to develop internal design resources through training the healthcare personnel in design methods and tools.

The process-oriented approach of the design work is familiar to many of the informants as well as some aspects of the methods and tools and thus relates to their prior knowledge base. This resonates with Junginger's (2009, 2015) and Lin's (2014) argument that design is in fact not new to these organizations and that the introduction and development of design related skills and competences alone is thus not a way to develop design capability. This supports the understanding that design capability is made up of more than just one of the identified aspects. Junginger (2015) had acknowledged, in her argument for the recognition of silent design already present in an organization, that the way that skills and competence are utilized through silent design might not always be the most efficient or value contributing. In the two cases, silent design can be recognized in the connections the informants make to processes or methods they have prior experience of. That they see the design approach and methods as contributing something new, despite recognizing similarities, supports the notion that the capabilities related to silent design does not manage to contribute the same value as the design approach. This suggests that the development of design capability is more about how skills and methods are used rather than that they are used, which resonates with Lin's (2014) description of public sector design capability as the organization's ability to use the design skills and methods to make the processes and services of the public sector understandable and accessible to the citizens.

In both cases, the development of awareness about design among the participants has been fairly straightforward, and thus an understanding of how the use of design can contribute in their contexts. The development of resources also seems to start off well in the sense that the design novice personnel pick up on and accept the design approach and methods quite quickly in the projects. However, in both cases it is clear that what is developed through the knowledge transfer projects is rather awareness about design methods and tools than awareness of design or design resources. Only one project has not been sufficient to develop 
design competence and the confidence to apply design efficiently and successfully without the support of trained designers. As discussed in the previous chapter, although the informants believed in the approach and methods, they did not feel confident in applying them again on their own.

In addition to knowledge about methods and tools, design competence also implies an understanding of what goes into those tools and methods. This understanding is the basis for the ability to choose a relevant method or adjust it to the specific conditions of a project. Designers often modify or invent methods or tools to fit the situation at hand. Bason (2010) and Dorst (2015) argue that novice designers or people new to working with design tend to be result focused, whereas more experienced designers use their expertise to make reflective decisions in relation to the situation. This reflective practice lies beyond the methods and tools and is relevant for delivering successful project results. This aspect is left out when, as seen in the two cases, focusing only on transferring tools and methods of design. The same focus can be recognized in many other projects that aim to develop design capability, as discussed in the theory chapter.

It is difficult to develop an understanding of the relations between methods and their results after just one experience of using the methods, as was the case for the interviewed personnel. The empirical material show that the focus on the application of design tools and methods left little or no room for reflection on what the tools and methods imply and how they can be generalized to other future projects. Being part of one design driven project has, in other words, supported the single loop learning (see e.g., Argyris \& Schön, 1978) that developed the individuals awareness of the methods and their knowledge of how to apply the specific methods and tools used in the project to projects of the same character. However, it did not provide support for the double loop learning (ibid.) that is required when relating one situation to another in order to assess which methods or tools would be suitable in a new situation, or the knowledge necessary to adjust a method or tool to suit a new situation. This also suggests that a focus on experiencing methods and tools in only one project will not develop design capability that is based on awareness of how design methods and tools can be used in the organization's practice as brought forward as central by for example Lin (2014).

Regardless of whether the resource is developed through training personnel, hiring or procuring people with design competence. For it to become a organizational resource the awareness of the competence existents and possible 


\section{Chapter 8}

contributions must also be diffused in the organization in the same manner as the awareness of design.

The empirical material, especially from the Health Lab case in which continued use and practice of design was an articulated aim, also shows that the development of design resources is not enough to enable the use of design. The participants for example discussed the different attitudes in design and the development approaches they were used to, how these differences could make it difficult to use design, and the need for management support to work with development in general; in other words, the need for structures that enable design practice. This too supports the notion that design capability cannot be developed by focusing on one aspect, as discussed by Body (2008), for example. The need for structures - management support, for example - to enable the use of design also after the dedicated knowledge transfer projects end, suggests that the development of design resources by training current employees in design is also dependent on the enabling structure aspect of design capability. To ensure the personnel get to practice design and gain enough experience and confidence to apply it without the support of trained designers, routines, and other structures cannot hinder the design approach.

\subsubsection{Knowledge about and ability to design; a development of the understanding of design capability}

Given the insights from the cases that design resources, in terms of internal design competence disseminated in the personnel group, cannot develop without the support of structures that enable the use of design, design capability can be understood as consisting of two parts: knowledge about design (i.e. awareness of design) and the ability to design (Figure 29). As already concluded in the theory chapter, only being aware of design and what potential value it could contribute to the organization will not suffice as design capability; just knowing about it will not unlock its value. The organization must also be able to make use of design (i.e. have the ability to design). The empirical material, particularly from the Health Lab cases, shows that this part is, to a large extent, about having structures that enable the use of the available design resources. 
Development of design capability through an absorptive capacity lens

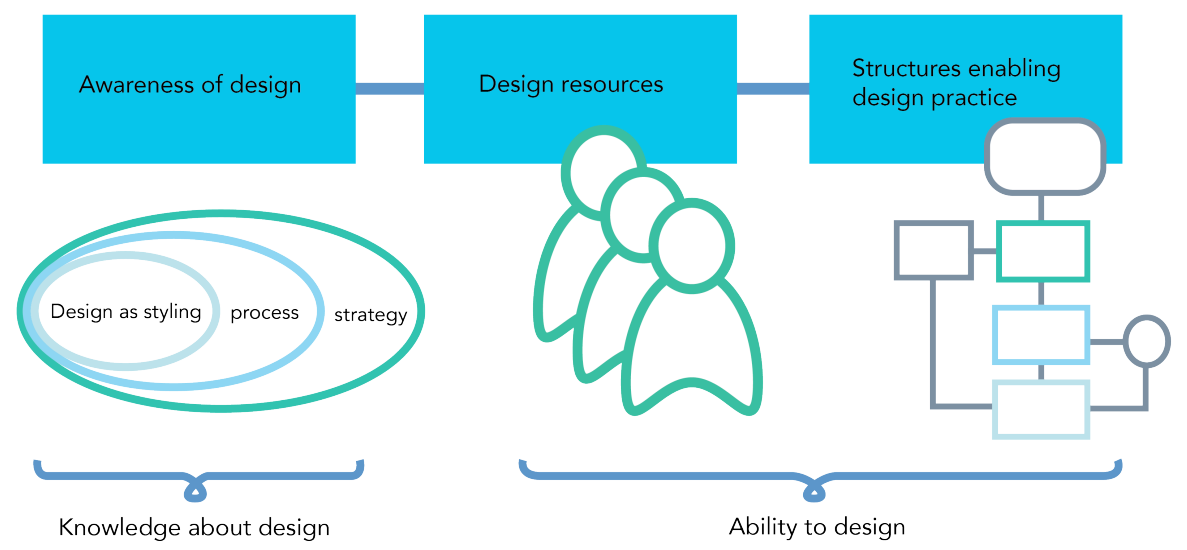

Figure 29. The understanding of what design capability implies is developed. Design capability is now understood as consistent of knowledge about design and ability to design.

The development of design capability would thus be understood as development of knowledge about design and ability to design. From an absorptive capacity perspective knowledge about design, what it implies, how it works, and what and how it can contribute would be understood as developing through the organization's acquisition of design. As the organization is introduced to design, its awareness of design and design's potential contribution to the organization develops through the assessment and recognition of design as a potentially valuable knowledge for the organization (Cohen \& Levinthal, 1990; Lane et al., 2006). The ability to design, which is based both on access to design resources and the structures in the organization that enables the use of these resources, would be understood as developing through the assimilation of design. Through transformative learning, design is assimilated in the organization to enable its exploitation (Lane et al., 2006). During transformative learning, how design fits with existing structures and cultures is assessed and structures that prevent the utilization of the new knowledge, in this case design, are disrupted, adjusted, or created (Todorova \& Durisin, 2007; Lane et al., 2006). The assimilation of design thus implies developing access to design resources and ensuring that processes and routines, et cetera, enable the use of these resources. 


\subsection{Absorbing design knowledge and developing design capability}

In the following sections, the acquisition, assimilation, and exploitation of design in the organizations that were involved in the studied initiatives will be discussed. Support or challenges to the development of design capability that have been identified in the approaches and the setups that were used will be articulated and discussed in relation to the theoretical framework.

\subsubsection{Acquisition of design}

The absorption of new knowledge starts, as described by Cohen and Levinthal (1990) and Lane et al. (2006), with the acquisition of the new knowledge. Given the tentative understanding of how design is absorbed and design capability developed described at the end of the theory chapter, this is when the awareness of design starts to develop in the organization.

In this phase of the knowledge absorption, the prior knowledge of the organization and the boundary spanners or gatekeepers play an important role in the assessment of whether the new knowledge is worth absorbing (Cohen \& Levinthal, 1990). System and socialization capabilities could also affect the assessment of the new knowledge (Van den Bosch et al., 1999) that occurs through the exploratory learning (Lane et al., 2006).

\subsubsection{Boundary spanners}

Individuals in the organization influence its absorptive capacity in their roles as (Cohen and Levinthal, 1990). Whether a new knowledge is worth absorbing or not is initially assessed by boundary spanners who keep a look out for new knowledge however it also have to be accepted by gatekeepers (ibid.).

In the Health Lab case, Gustav can be identified as one of the organization's boundary spanners. To some extent, the acquisition of design had already begun before the Health Lab initiative was established. The acquisition began when Gustav first started to apply design methods in some of the Innovation incubator's projects, and thus started to disseminate awareness of design in the county council organization through the projects. Although, at this point, the dissemination of design was not articulated. He then moved on to further promote design and its potential contribution to part of the top management during the pre-study, thus diffusing awareness of design to actors with gatekeeper positions within the 
organization. Had these actors not seen design as a potentially valuable knowledge, the absorption of design would have stopped, or at least come to a halt, here and the establishment of Health Lab would not have happened as it did.

At this stage, the recognition of design as valuable knowledge for the organization was still limited to a few individuals. In order to be acquired by the organization, design had to be further disseminated and accepted in the organization (Cohen \& Levinthal, 1990; Van den Bosch et al. 1999; Lane et al. 2006). However, design as a means for user-centered development had been legitimized within the top management, and the further diffusion of the awareness of design in the organization was part of the Health Lab's objectives.

In the Social Service case, both Karin and Ulla from the regional development council had boundary spanning roles. The setup with a regional development council makes the personnel at the regional development council boundary spanners in relation to the development council's member organizations. When the designer, Sam, first approached Karin and Ulla with the suggestion that design could contribute in the social services, they made an initial assessment of whether design could be of interest to their member organizations. As discussed in the presentation of the patterns seen in the empirical material, the legitimization of the projects and design was not done on a strategic level in the three municipalities, as it was in the Health Lab case. This implies that design had not been assessed and recognized as a potentially valuable knowledge by any internal boundary spanners in the municipalities before the projects started. In addition, with the exception of Ylva in Norfors, the pilot municipality, no one with a boundary spanning position in the organizations took part in the project.

\subsubsection{Prior knowledge and design's perceived contribution}

The ease with which design was recognized as relevant knowledge suggest that there were already existing skills or knowledge in the organization that design could be related to, as the recognition of new valuable knowledge to a large extent depends on its relation to the existing knowledge base of the organization (Cohen \& Levinthal, 1990). These skills could be part of the silent design (Gorb \& Dumas, 1987) that Junginger (2009, 2015) argues is already present in the organizations. However, for design to be perceived as a valuable addition to the knowledgebase, it is not enough to be recognized, it must also be assessed as contributing a new value that is not too similar to the already existing knowledge (Lane \& Lubatkin, 1998). 


\section{Chapter 8}

In both of the studied cases, the expectations of what using a design approach would contribute were primarily related to user-centeredness and finding ways to increase user involvement and influence. This is also what the participants articulated as design's contribution compared to their usual way of working after having experienced design through the projects. The user-centered focus and approach of design could thus be understood as the key differentiator seen by the organizations between the existing knowledge base, for example the silent design, and what is perceived as valuable in design.

The user-centered approach in design was, as discussed in the previous chapter, recognized by most informants regardless of their roles or positions in the organizations. Its connection to empathy, an ability that is already well established within both healthcare and welfare, could be understood as a frame of reference when the personnel assess design.

Informants that have prior experience of development or improvement work also made connections to other tools or processes that they had come across to create an understanding of design and its potential contribution. For example, Ulla from the Social Service case and Susanne from the Health Lab case expressed that they saw similarities to methods they have used in prior projects following other processes. They made comparisons to these methods and processes when reflecting on the design process and methods they have experienced in their respective projects. However, other informants who had not expressed prior experience of working with operative development did not make comparisons to other methods or processes in their reflections and also reflected less on how design could be further applied. Ulla made the reflection that personnel with experience from operational development would probably have been better equipped to take the transferred knowledge further and apply it in new projects. This resonates with the role of prior knowledge in the absorption of new knowledge put forward within the absorptive capacity construct (Cohen \& Levinthal, 1990). Personnel that lack prior experience of active participation in development work thus lack a frame of reference against which future applications of design could be discussed and reflected on. The analysis of the two cases showed that in both cases, there was very little reflection and discussion about how design could be further applied. This suggests that in initiatives aiming to develop design capability one must pay attention to the prior experience of the actors involved in order to facilitate and support a reflection about how design can be applied further. 


\subsubsection{System and socialization capabilities affecting the acquisition of design}

System and socialization capabilities are described in the absorptive capacity literature as potential barriers to the acquisition of new knowledge as routinization or strong cultures could hinder the exploration and thus the recognition of the new knowledge's potential (Van den Bosch et al., 1999; Jansen et al., 2005). However, in the acquisition of design, a new patient and social service user legislation (Patientlag, SFS 2014:821), in other words a system capability, related to personcentered healthcare and welfare can be understood as supporting the assessment of design as a valuable contribution to the knowledge base. The general insight about the need for a more person-centered healthcare and welfare can thus be understood as having played a role in the assessment of design's potential contribution. This insight relates to an ongoing paradigm shift within healthcare and welfare, which in itself entails knowledge that is to be accepted and absorbed within the organizations. The new legislation ensures patients' and social service users' right to influence, and the user-centeredness of design is seen as a means to address this demand. The societal values on which the new legislation is founded have also influenced some of the organization's socialization capabilities through the move towards a person-centered culture. This implies a match between these values and the user-centered attitude of design; in other words, similarities with the characteristics of the design knowledge, which according to Lane et al. (2006) support the knowledge acquisition.

In the Social Service case, the connection between the absorption of personcentered care and design is especially evident; here, design is used as a means in the project to disseminate and legitimize person-centeredness and user involvement. The insights from using design methods support the assessment of user involvement, what it implies, and how it is new in relation to the traditional or historical way of working with the users, where the focus had been on the users rather than the focus of the users. This suggests that in this case, the acquisition of design is linked to the absorption of a person-centered care mindset within the organization and that the new legislation creates a system capability that potentially supports the assessment of design as worth absorbing. However, there is also a risk that the understanding of design that is developed is equated with usercenteredness, which could influence the further absorption. 


\subsubsection{Developing awareness of design through exploratory learning}

As discussed in the previous chapter, to experience design and work with a mindset and tools related to design helped the participants to create an understanding of design in relation to their own context. Lane et al. (2006) argued that the acquisition of new knowledge is done through exploratory learning, and here the participants got to explore what design implied and experience how it could contribute through the application of design tools and methods in projects.

However, in both cases, design had mainly been perceived and discussed as a means for increasing user involvement and centeredness in development. This implies focusing on a limited part of what is brought forward in the literature as the potential contributions of design. Design is also described as able to contribute by reframing problems (Dorst, 2015), handling the ambiguity of ill-defined problems (Cross, 2004), breaking up barriers to innovation through its open and permissive approach, and mitigating the fear of failure through its iterative process (see e.g., Bason, 2010; McNabola et al., 2013). Using design in a proactive manner is also brought up in the literature as a means to support the development of strategies or policy (Ramlau, 2004; McNabola et al., 2013; Koostra, 2009). The empirical material, however, shows no reflections on how the design approach and the tools and methods could be used in ways other than those that increase the user-centeredness in the organizations.

This, however, has to be understood in relation to the fact that the projects followed in the two cases had all been initiated with the specific objective of increasing user-centeredness in the healthcare and welfare. In the Health Lab design training project and the social service pilot project, the objective was even more specific: to increase the user involvement and participation. This focus sets a frame within which the exploration of design and its potential contribution takes place and thus within which the awareness of design is developed. Prior related knowledge and other factors that influence the acquisition of design would thus also influence the development of the awareness of design.

Apart from the frames set by the project objectives that limit the exploration of how design can contribute value, another critique that could be raised towards the setup in the studied initiatives is the focus on tools and methods, which also creates specific frames within which design can be explored and understood. Similar to many previous and parallel initiatives, as discussed in chapter four, there had been a focus on and a preconception of design knowledge as transferable through the experience of the application of design methods and tools. This too must be 
understood as having affected the awareness of design, as design practice and expertise to some extent becomes reduced to and equated with its tools and methods.

These insights suggest that attention must be paid to how design is portrayed and what frames for the exploration are set up within the initiatives that are aiming to develop design capability. It also suggest that full awareness of design and its potential contributions is difficult to convey through a single project.

However, as discussed in chapter four, design capability is not understood as a constant capability that is developed once, but one that has to evolve with the needs and conditions of the organization (Body, 2008; Mutanen, 2008). The usercenteredness that dominates these projects could thus be understood as a gateway for the absorption of design. As design had been accepted and assimilated, other potentially valuable ways of exploiting design, such as for development of policy, could be further explored in new projects and the awareness further developed.

The experiential setups of the projects studied in this work are thus understood to have supported the development of the awareness of design, albeit only within the given frames. There are several examples in the empirical material that indicate that the development of a user-centered mindset among the personnel who were involved in the projects was successful. The participants reflect over how the design approach has given them better knowledge and insights about their users.

The awareness of design and its potential contribution is, at this stage, acquired on an individual level; it resides in the individuals that were part of the projects and experienced design. For the knowledge to be absorbed on an organizational level and become part of the organization's knowledge base, it is dependent on the networks and connections between units in the organization (Van den Bosch et al., 1999; Lane et al., 2006); it must be further disseminated in the organization and assimilated with the organization's already existing knowledge and practice.

\subsubsection{Assimilation of design}

During the assimilation phase of the knowledge absorption, the new knowledge is integrated through transformative learning in the organization's existing structures, routines, and processes in order to later be exploited (Lane et al., 2006). The assimilation phase of the absorption of new knowledge can thus be understood as a phase that ensures that the organization can exploit the new knowledge, a phase during which the organizations ability to design is developed. 


\section{Chapter 8}

This entails, as discussed at the beginning of this chapter, the development of both access to design resources and enabling structures. In this phase of the knowledge absorption, the organization's combinative capabilities start playing a bigger role (Van den Bosch et al., 1999; Jansen et al., 2005).

\subsubsection{Developing design resources}

From the outset, in the Health Lab initiative, there has been an aim to develop internal design resources in the organization. The county council had employed trained designers within the Health Lab, but the aim had also been to develop the resources further by training healthcare personnel and civil servants in design by transferring knowledge about methods and tools.

In the Social Service case, the main aim was to develop an awareness of design. Developing internal design resources was a secondary, not as articulated objective, although they wanted to disseminate an understanding of how the municipalities could work with design methods and tools to ensure person-centered services. Quite early in the project, however - after about one month - the objective to disseminate design was set aside, and the full focus was turned to developing a solution that would support the increase of user-centeredness. Sam, the designer, however, hoped that the setup of the project, which included the personnel in the work, would still support knowledge transfer about methods and tools. Through enabling the personnel to experience the process and tools, he hoped to show them that development work could be approached with small means and thus encourage and enable more development work. In both cases, there had, in other words, been ideas about how to develop the organization's design resources by training the personnel in mindset, methods, and tools related to design; however, not as articulated and structured in the Social Service case.

As discussed above, the exploratory approach through which the design-novice personnel got to experience and explore design through the application of design methods and tools in a project seem to be well suited to supporting the acquisition of design and developing an awareness about design. However, when describing design expertise, as discussed in the theoretical review of design capability, framing and reframing (Dorst, 2015), handling "ill-behaved" problem scoping (Cross, 2004), and reflection-in-action (Schön, 1983) are often brought up as key aspects of design competence. Some aspects of the knowledge that make up design expertise, such as reflection-in-action or problem framing, could be facilitated and practiced through methods and tools, but not all knowledge that goes into design competence can be condensed into the recipe of a method. In the Social Service 
case, the expertise of the designer was perceived as vital for the project's success, but what this expertise implied, apart from introducing methods and tools and facilitating the project by leading the participants through it, was not reflected upon.

The lack of reflection upon what methods, tools, and other aspects of design competence imply, what it contributes, and what conditions it requires has resulted in the knowledge being individually acquired but not yet organizationally acquired. The personnel had acquired the knowledge, but not yet assimilated it fully as they do not yet have the experience or confidence to select or modify methods or tools to suit projects with characteristics or conditions other than those experienced. For the development of design resources to de understood as absorbed in the organization and not only individually acquired, the design competence, or at least the awareness of its existence in the organization and how it can be used, must be diffused and shared between units in the organization (Lane et al., 2006; Van den Bosch et al., 1999). Bailey (2012) found that the dissemination of design was successful in the cases where the personnel had been able to disseminate their new knowledge through further application in new projects or workshops. This, Bailey (ibid.) argued, both strengthened their knowledge and their confidence. These results and the absorptive capacity notion that the knowledge must be disseminated in the organization to be absorbed on an organizational level, support the argument made earlier that one design driven project is not enough to develop design resources.

\subsubsection{Making design fit in: disseminating design and developing enabling structures}

The assimilation of design in the organization implies the dissemination of the awareness of design; the acceptance and integration of the knowledge about design; and how to apply the design approach throughout the organization. This could be understood as building a culture for development work that enables a design approach to be applied to the development. Rauth et al. (2014) argue that adaption of the cultures of design and the organization to create a fit is an essential part in creating legitimacy for the use of design. Accordingly it must be understood also as an essential aspect of developing design capability. The importance of structures, such as culture, that enable the design practice is also seen in the empirical material from the two cases presented in this work. The development of a design culture or a development culture that enables design can be understood as the creation, adjustment, or disruption of structures to make design fit in. From an 


\section{Chapter 8}

absorptive capacity perspective, this would be understood as happening through the transformative learning in the assimilation phase (Lane et al., 2006; Todorova \& Durisin, 2007) as design is integrated into the current knowledge, culture, and practice of the organization.

Unlike the acquisition, where the exploratory learning stage was well supported through the experiential setup in the studied projects, this stage of the absorption does not seem to have been supported in the projects or in the overall approaches of the two initiatives. The informants give witness to several issues related to the assimilation of design. Moreover, neither the participants nor the project managers in any of the three projects had a vision or a plan for how to take things forward after the projects ended. This implies that there were no plans for how to share and communicate the knowledge acquired through the projects to other members or units of the organization. As the capacity to absorb new knowledge successfully resides in the networks within the organization (Van den Bosch et al., 1999), this is a part of the knowledge absorption that is vital to ensure the knowledge is absorbed on an organizational level (Cohen \& Levinthal, 1990; Van den Bosch et al., 1999; Lane et al., 2006).

Health Lab's care coordination process $(\mathrm{CCP})$ project never had the objective of transferring knowledge, and it can thus be understood that the upholding and diffusion of the transferred knowledge, in terms of mindset or methods, was not part of the project setup. However, reflections and discussions about what would happen after the projects were also scarce in the two other projects - Health Lab's design training and the Social Service case's day center pilot project. In both these projects, knowledge transfer was an articulated objective.

The participants in Health Lab's design training project felt left to their own devices after the project ended. They expressed a frustration that the project had not covered how things would be taken forward and continue. In the Social Service case, Ylva and Hanna expressed worries about how they would be able to uphold the new user-centered mindset that had been developed through the project. The lack of activity after the projects, and of reflection on how to disseminate and further apply design, suggests difficulties in moving from the exploratory learning phase to the transformative learning phase and thus to the assimilation of design.

Todorova and Durisin (2007) point out that how well the new knowledge fits with the current knowledge and practice of an organization could affect the assimilation and the transformative learning. Also, Lane et al. (2005) discuss the influence of the knowledge characteristics on knowledge absorption. New 
knowledge that is similar to or matches the existing knowledge can be directly assimilated, whereas knowledge that does not fit directly must first go through transformation before being assimilated (Todorova \& Durisin, 2007). The analysis of the empirical material shows several examples of how the characteristics of design do not comply with the ways of working with development that the organizations are used to and have established structures for.

The initial confusion, described in Health Lab's design training project as a rollercoaster ride, about what they were doing and how it would lead to a relevant result can be understood as related to the ambiguity that comes with the open ended and divergent approach of design, something that was not familiar to the participants. The holistic perspective, with focus on both users and the organization, during the development is also different from how the development work has traditionally been set up in the studied organizations. As expressed by the informants in both cases, the user focus is not entirely new, but previously the focus was from the organization's perspective not the user's. Involving users also disrupts the hierarchical culture that can be seen in the Health Lab case. The open attitude that characterizes the diverging and converging design process - through problem framing, research, ideation testing, and refinement - and that implies not knowing from the start what the result will be are further examples of how design is differentiated from the existing practice. This attitude goes against the resultoriented culture of the public sector (Bason, 2010) and creates a barrier to direct assimilation. It can be associated with an ambiguity that the informants described as being on a roller coaster ride. For example, in the Health Lab case, Susanne, who was originally commissioned to undertake the project that became the design training, discussed these differences as she reflected on how the open and permissive attitude in the design training project differed from how they were used to thinking when looking for new solutions. Although she found working in this way valuable, she also felt that it was going against the culture and practice of the organization and it felt safe being able to disclaim this by declaring that "they were sailing under the Health Lab flag," should someone question their work.

Attitude, openness, and culture are all aspects related to socialization capabilities, as described by Van den Bosch et al. (1999). Socialization capabilities are, according to Jansen et al. (2005) and Noblet, Simon, and Parent (2011), understood to support the assimilation of new knowledge depending on their character. Conversely, Van den Bosch et al. (1999) argued that organizations with a strong culture, for example, are often are reluctant to change and the socialization capabilities could thus impede the assimilation process. According to 


\section{Chapter 8}

Van den Bosch et al. (1999), whether socialization capabilities support or hinder knowledge absorption depends on the character of the new knowledge in relation to the old. This can also be seen in the empirical material, where some socialization capabilities support the absorption, but others form obstacles for the acceptance of the design approach and thus the absorption of design. The fundamental values of user-centered design, such as empathy with the user and putting the user at the center of the development, are easy to relate to values that are shared in the healthcare and welfare organizations such as empathy with patients and a will to help others. Here, in Lane et al.'s (2006) words, there is a match with the knowledge characteristic of design, which supports the assimilation. However, other socialization capabilities (Van den Bosch et al., 1999) — which the risk avoiding culture of public sector (Mulgan, 2014a; Bason, 2010) or the hierarchical structures could be described as - collide with the approach and attitude of design; its characteristics, as discussed above could, thus hinder or impede the assimilation. Johan, the project manager in the Health Lab, described how the risk avoiding culture made the personnel afraid of stepping outside and breaking even harmless rules in the Health Lab case. The hierarchical culture led, in the Social Service case, to a fear of how personnel with professional titles would react to not being included, as they were used to in projects. In the Health Lab, Eva, who took part in the CCP project, described how she felt that it hindered her abilities to disseminate what she had learnt.

The need for new or adjusted structures - new perspectives, mindsets, or routines, for example - that is seen in the empirical material can to a large extent be related to the management of development work or the management of the use of the design approach and resources. Acklin (2013a) argues that it is the balance between new and old knowledge in the organization, between design related knowledge and the knowledge already existing in the organization, that causes difficulties and friction in the collaboration between designers and design-novice organizations. Management aspects related to design, she argues, are easier for an organization to absorb as they are managerial in their nature and thus have a clear relation to prior knowledge in the organization. This resonates with Todorova and Durisin's (2007) argument that the relation between the new and old knowledge affects the assimilation. Acklin (2013a) based her claim on studies of mainly private sectors companies from varying markets. However, when focusing on public sector organizations in healthcare and welfare, the observation Acklin made does not seem to be valid. In this setting, aspects related to management are not easily absorbed and thus not developed, whereas the concrete design activities, methods, 
and tools are fairly easily picked up by the personnel involved (Malmberg \& Wetter-Edman, 2016). Also, Bailey (2012) noticed a friction in the collaboration between designers and design-novice organizations. He argues that the establishment of a design language is one of the first parts of developing design capability, creating a platform that can then further the development of design capability. The suggestion of a design language can be understood as a design enabling structure that must be developed in order for the organization to be able to exploit design. The suggestion is relevant but very design centric as it requires the novice organization to adapt in order to work with design. Taking an absorptive capacity perspective, the transformation that precedes the assimilation when the new knowledge does not comply fully is a matter of give and take (Todorova \& Durisin, 2007). The organization will make adjustments in its structures but will also adjust the new knowledge. Given this perspective, the suggestion would rather be to find a language that relates to the prior knowledge of the organization and can thus support the assimilation.

The examples seen in the two cases of how design challenges the existing culture, process, and routines for development in the organizations suggests that the absorption of design must go through the transformation stage before being assimilated - as suggested by Todorova and Durisin (2007) - for the absorption of knowledge that does not fit in directly. From Lane et al.'s (2006) perspective, this transformation takes place through the transformative learning as part of the assimilation. When looking at the empirical material through the lens of the absorptive capacity and the tentative model for development of design capability developed at the end of the theory chapter, many of the barriers or challenges to the assimilation of design that are seen, as discussed above, can be recognized as combinative capabilities. This suggests that the development of structures that enable design implies adjustment, creation, or disruption of combinative capabilities in the organization. The assimilation of design would then imply altering the discord between the current culture, routines of development, and the characteristics of the design approach through an adjustment of their combinative capabilities.

The combinative capabilities that create obstacles for the use of design in projects could also have a negative influence on the diffusion of the awareness of design and the acceptance of design as an approach to development. An acceptance of the approach and methods applied as part of the design practice is, as discussed Mutanen (2008) and Body (2008), an important aspect of the design capability in an organization. 


\section{Chapter 8}

In line with understandings from the absorptive capacity perspective that the new knowledge must be shared between units and functions in the organization, Johan, the Health Lab project manager, noted that networks and relationships (i.e. coordination capabilities) had played an important part in the dissemination of design in the county council organization. Issues seen as related to the dissemination of design in the organizations that had been involved in the two initiatives seem to be largely due to weak coordination capabilities for example, opportunities, and platforms for sharing information and knowledge. In both cases, other than unofficial relationships, the workplace meetings are brought up as the main arena and possibility for disseminating the newly acquired knowledge. Coordination capabilities play, as discussed in the theory chapter, an important role in the dissemination of new knowledge (Van den Bosch et al., 1999; Jansen et al., 2005). Jansen et al., (2005) also points to its importance in relation to supporting the interpretation of problems, overcoming differences, and building an understanding for the new knowledge. The coordination capabilities play an important role, particularly for organizations that are structured based on functional silos (Van den Bosch et al., 1999). Silo structures otherwise have a tendency to impede knowledge sharing and development between the organizations units and functions (ibid.). As the organization in the Health Lab case is structured by functional silos, the coordination capabilities could be expected to play an important role here. The insight that the organization needed to move from having a functional (silo) focus when developing, to a focus on the patient flow, is one aspect brought up as a motivation to the establishment of Health Lab by Gustav, Health Lab's head of operations. Apart from focusing on the patient flow rather than the professional functions in their two studied projects, they had also involved a mix of personnel from different functions within the healthcare system. The setup of the projects in the Health Lab case can thus be understood as having acted like a coordination capability. However, as pointed out by the informants after the projects ended, they had been alone in their endeavors to further disseminate or apply the transferred knowledge, and there was no plan set up for how to maintain or continue the knowledge and information sharing between the units and functions that had participated.

It can thus be concluded that although the experiential setup that was used in all three projects supported the acquisition of design, the way it was facilitated in these two cases, it did not address the transformative learning or support for the dissemination or development of enabling structures. 
Lane et al. (2006, p. 846) suggests that there is an "underlying assumption that mere acquisition [of knowledge] will enhance a firm performance". This assumption is reflected in these projects as they focus on acquisition and does not address or give support for the other phases of knowledge absorption. In the studied projects, the focus on the design driven project and its results tend to overpower the learning objective even though the projects initially had a dual aim. This suggests the need for perseverance in the articulation of a project as a learning project, in order to not lose this objective and result.

Because the setup of the projects had not facilitated or encouraged reflection on how the knowledge acquired by the individuals in the projects should be further absorbed on an organizational level, there was no plan in any of the three projects for how to continue the diffusion after the projects. The responsibility to further disseminate and apply the design knowledge had thus come to rest with the individuals that had been involved in the projects. The empirical material showed that this had been difficult due to socialization capabilities, which the personnel then had to face on their own, and also because of practical issues, such as a lack of time, as development and knowledge diffusion is not part of their regular position. The participants in Health Lab's design training project in particular, expressed a wish that the management should have been more engaged and involved in the project, something that will be further discussed in the next section.

\subsubsection{Management's engagement and involvement}

In public sector organizations, where socialization capabilities are usually strong, Richards and Duxbury (2014) emphasize the importance of management engagement in the knowledge absorption. The management's actions and engagement shows that the new knowledge is valued and encouraged (ibid.). That the management have a mandate and the ability to disrupt structures that hinder the assimilation or create new ones that support the sharing and utilization of the new knowledge is also brought forward as arguments for their role in the absorption (Van den Bosch et al., 1999). When studying the empirical material, the lack of engagement and involvement of management could stands out as one aspect that has influenced the knowledge absorption negatively.

For example, in the Social Service case, the lack of management engagement, apart from Ylva in the pilot municipality, implied that design were never assessed by actors with a mandate to take the absorption further and influence the 


\section{Chapter 8}

assimilation in the two observing municipalities. There was, in other words, no one with a mandate that could naturally take the responsibility to drive a continued absorption after the projects ended and awareness of design was developed.

Projects that preceded Health Lab's CGP project had led to insights about the need for the organization to work with the development culture in general on management and middle management levels to encourage a cultural change. The focus needed to move from focus on budget to focus on quality. Despite this only operative personnel were involved in the design training project, which was expected to render support and tools for such a cultural change through the transferred design knowledge.

The personnel in both cases felt a responsibility, as advocates, to encourage and remind each other in order to change the culture, but they also felt a need for support and encouragement from management to maintain the new user-centered mindset and the design approach. In their reflections about the lack of direction for how the work that had been initiated through the design driven projects should continue and the knowledge be disseminated, the lack of management engagement and involvement in the project was one aspect brought up by many of the informants from the Health Lab case. They had no directions for how much time and resources they could spend on applying and disseminating the developed knowledge. Overall there was a lack of consensus about who was responsible for maintaining and taking the knowledge results forward after the projects. This is especially evident in the design training project.

Moreover, both the operative personnel and Johan, the project manager, argue that the management must act by commissioning projects where design is applied, otherwise they fear that design is likely to wither away unpracticed. This resonates with results seen in other studies. Bailey (2012) found that, although the use of a design-led approach to development was well established in the management in both the case of the British NHS's Institute for Innovation and Improvement and in Skills Development Scotland, it was difficult to get the practice to sustain as the operative personnel fell back to the previous system-led development approach. He observed that the dissemination of design was most successful when the personnel got to disseminate design through application in new projects (ibid.). Sangiorgi (2015) noted that the efforts to develop design capability can be erased if the personnel are not engaged and motivated or if they are not enabled and supported to use their new skills. The operative personnel from Norfors, the pilot municipality in the Social Service case, as well as the personnel that took part in Health Lab's design training project, had been positive and inspired afterwards. 
They had been eager to use the new knowledge further, and the Norfors personnel even started to apply their new insight in other parallel projects before the pilot project had ended. Despite their inspiration and engagement, the personnel also expressed worry about how they would be able to maintain and practice their new knowledge after the structure of the projects was gone. These observations and the description of the core practice as a black hole that devours all resources, suggests that the problem that personnel revert back to old habits and a system-led development approach is related to lack of management support and structures that enable the design-led practice, rather than to a lack of motivation and engagement among the personnel.

The management's role as boundary spanners is one aspect to their importance in the knowledge absorption process; their mandate to handle combinative capabilities and thus support the acquisition, assimilation and exploitation is another. The barriers to assimilation of design that are seen in the empirical material also point to the engagement of and actions by management as a critical aspect for the continued absorption of design. As discussed in the previous chapter, in the Health Lab case the introduction of design and the establishment of inhouse design resources was supported and promoted on a strategic management level, but there was a lack of engagement and involvement by middle management in the two studied projects. Richards and Duxbury (2014) argue that middle management often holds the role as boundary spanners. It is therefore important that they understand not only their role in the knowledge absorption in order to support the acquisition, assimilation, and exploitation of design, but also that they themselves acquire design knowledge to ensure a successful contribution of design in the organization (Hesselmann \& Walters, 2013). Bailey (2012) argued that in the development of design capability it is important that the management is given time and space to develop the awareness of design themselves in order for them to be able to support the design practice. This resonates with Wrigley and Bucolo's (2012) argument that the efforts made to develop design capability are impeded by the lack of insight that development of design capability also entails developing the awareness about design within the organization's management. The lack of involvement by middle management that is seen in the projects implies that they had gained neither an understanding of what design entails and could contribute to the organization (i.e. an awareness of design), nor an understanding of what barriers or challenges there are for design to be assimilated in the organization and enable the exploitation of design. 


\section{Chapter 8}

The importance of boundary spanners as the ones who assess the knowledge during the acquisition is highlighted by Cohen and Levinthal (1990); in these cases, however, the data shows that it is equally important to make sure there are boundary spanners with a mandate to act in relation to the transformative learning. Otherwise, the knowledge absorption risks coming to a halt before the design can be exploited by the organization. Many of the issues seen in the empirical material related to the assimilation of design are not specific for design but related to development in general. This implies that for design to be assimilated to a point where it can be exploited there is a need to address the culture and structures around development work as a whole and for this management must be involved.

\subsubsection{Exploitation of design}

The final sequence of the knowledge absorption - the exploitation of design - has not yet been reached by any of the organizations in the two cases as the knowledge has not yet been fully assimilated by the organizations. Design is thus not yet a natural part of the organization's development culture and continuous development work. Any comments or reflections about the exploitative stage of the absorption of design and development of design capability will thus be tentative. However, as described in the theory chapter, design capability is not a constant capability but one that must evolve and stay up-to-date with the needs of the organization in relation to the surrounding context (Body, 2008; Mutanen, 2008; Beltagui, 2014). Lane et al. (2005) describe the exploitative learning as the learning that occurs in relation to the use of the new knowledge and in the synthesis and combination of the new knowledge with other parts of the organization's knowledge base.

The exploitative learning that occurs in the final sequence of the absorption of design could thus be understood as the continued learning that occurs as design is applied and contributes to the organization. Insights about further adjustments in the enabling structures, the use of design, or potential new contributions are here based on the application of design and combination with the other knowledge areas of the organization. This continued learning would be vital to ensure the design capability is sustained in the organization. 


\subsection{Concluding discussion}

Given an absorptive capacity perspective, the interpretations of how design capability has developed in the two cases have shown both similarities and differences. In this concluding discussion the development of design capability will be discussed in relation to the different approaches and scope of the initiatives. Potential implications for the development of design capability given the sequential description of the knowledge absorption described in the absorptive capacity literature (e.g., Cohen \& Levinthal, 1990; Lane et al., 2006) is also discussed. The section ends with the implications of this for efforts and initiatives aimed at developing design capability within public sector healthcare and social services.

\subsubsection{Different approaches}

The two initiatives differ greatly in scope and thus also in their approaches to the introduction of design and development of awareness about design.

In the Health Lab case, the absorption of design could, be seen as initiated prior to the establishment of the Health Lab. Boundary spanners like Gustav had already started to diffuse awareness of design and it had been assessed as a potential contribution to the organization by some of its key gatekeepers, for example, the county council director. Thus, the establishment of Health Lab can be understood as part of the transformative learning and the assimilation of design. Although described as a learning project in the original mission statement, the establishment of the Health Lab with Beland county council can also be understood and described as the development of a design lab.

The studied projects facilitated by Health Lab have diffused awareness of design and to some extent initiated the development of design resources. However as the experiential set up of the projects has mainly supported the exploratory learning phase and not focused on transformative learning, the dissemination and assimilation of design is still a challenge for the initiative. This implies that the studied projects have contributed to raising the awareness of design but have not yet fully diffused this awareness in the organization. The projects have initiated but not completed the development of design resources, neither have they addressed the aspect of enabling structures, which are needed to ensure a continuous and systematic exploitation of design. The awareness of design could thus be understood as on its way to being acquired on an organizational level, while design resources and enabling structures are not yet fully there (Table 8). 


\section{Chapter 8}

Table 8. Developed design capability in the Health Lab case.

\begin{tabular}{|l|l|l|l|}
\hline $\begin{array}{l}\text { Awareness about } \\
\text { design }\end{array}$ & $\begin{array}{l}\text { Acquisition } \\
\text { leveloped on the }\end{array}$ & $\begin{array}{l}\text { Initiated but not yet } \\
\text { fully developed on an } \\
\text { organizational level. } \\
\text { Requires attention to } \\
\text { diffusion }\end{array}$ & $\begin{array}{l}\text { Not yet } \\
\text { developed }\end{array}$ \\
\hline Design resources & $\begin{array}{l}\text { Initiated but not yet } \\
\text { fully developed on } \\
\text { the level of the } \\
\text { individual }\end{array}$ & $\begin{array}{l}\text { Initiated but not yet } \\
\text { developed on an } \\
\text { organizational level. } \\
\text { Requires attention to } \\
\text { diffusion }\end{array}$ & $\begin{array}{l}\text { Not yet } \\
\text { developed }\end{array}$ \\
\hline Enabling structuresy & $\begin{array}{l}\text { Not addressed or } \\
\text { developed through } \\
\text { the projects. Although } \\
\text { some needs have } \\
\text { been identified }\end{array}$ & $\begin{array}{l}\text { Not yet } \\
\text { developed }\end{array}$ \\
\hline
\end{tabular}

The initiative taken in the Social Service case has been of a much smaller scope than the one in the Health Lab case. Here, it was just one project through which design was to be introduced and assessed. A difference from the Health Lab case is also that in this case the acquisition of design actually started through the project in the initiative. An aim of the project was to assess whether design could be a valuable approach and accordingly a valuable knowledge to the organizations. Ulla and Karin who initiated the project have in their role as boundary spanners made an initial assessment of design. However, they have not yet fully acquired design as they have not yet finished their assessment of whether it is a valuable knowledge to the organizations or not. They stressed that the purpose of the project was primarily exploratory and as a secondary objective they mentioned a potential knowledge transfer related to the application of design and conducting design driven projects. This project can thus be understood as mainly focused on the acquisition of design and the exploratory learning, it is therefore understandable that the setup have focused on the exploratory learning. The participants from the municipalities were operative personnel with the exception of 
Ylva, the division manager in the pilot municipality. The operative personnel's lack of mandate in the organizations and little prior experience of competence development suggest it would be difficult for them to act as boundary spanners. Although the project was perceived as successful and the participants expressed that they gained new insights related to user centeredness, their acquisition of design is not clear. The focus among the personnel has mainly been on developing the solution. They do express that the design driven way of working has been good but convey no reflections about making the approach part of the development practice or disseminating it in the organization. As the acquisition is not clear on an individual level and the project has not focused or supported dissemination design cannot be understood as acquired on an organizational level and thus not assimilated or exploited either (Table 9).

Table 9. Developed design capability in the Social Service case.

\begin{tabular}{|c|c|c|c|}
\hline & Acquisition & Assimilation & Exploitation \\
\hline $\begin{array}{l}\text { Awareness about } \\
\text { design }\end{array}$ & $\begin{array}{l}\text { Initiated but not } \\
\text { clearly developed } \\
\text { yet on the level of } \\
\text { the individual }\end{array}$ & $\begin{array}{l}\text { Not addressed in the } \\
\text { project, not yet } \\
\text { developed on an } \\
\text { organizational level }\end{array}$ & $\begin{array}{l}\text { Not yet } \\
\text { developed }\end{array}$ \\
\hline Design res & $\begin{array}{l}\text { Initiated but not } \\
\text { yet fully developed } \\
\text { on the level of the } \\
\text { individual }\end{array}$ & $\begin{array}{l}\text { Not addressed, not } \\
\text { yet developed on an } \\
\text { organizational level }\end{array}$ & $\begin{array}{l}\text { Not yet } \\
\text { developed }\end{array}$ \\
\hline Enabling structures & & $\begin{array}{l}\text { Not addressed, not } \\
\text { yet developed }\end{array}$ & $\begin{array}{l}\text { Not yet } \\
\text { developed }\end{array}$ \\
\hline
\end{tabular}

Comparing the two initiatives, it is clear that even though there have been difficulties with the assimilation in both cases, being positioned as a lab as in the Health Lab case, has created a platform for practicing design, which has been 


\section{Chapter 8}

valuable. The lab approach implies a possibility to work successively with the dissemination of design and development of design resources, as well as the development or adjustment of organizational structures to enable design practice. An initiative based on only one project, as in the Social Service case, must place larger emphasis on addressing all phases of the knowledge absorption and not only the explorative learning in order to facilitate all three aspects of design capability (i.e. awareness of design, design resources, and enabling structures). Otherwise the individuals that have participated in the project will have to manage the development of design resources and enabling structures through further diffusion and application of the transferred knowledge after the project has ended, which as seen in both cases can be difficult.

The importance of creating knowledge networks has been highlighted by La 27e Région as part of their success (Hillgren \& Süczs Johansson, 2015). A lab approach could provide support for individual actors in the organization when they lack competence or confidence to apply design in projects themselves.

\subsubsection{The sequential structure of the absorptive capacity framework and the development of design capability throughout an organization}

Lane et al. (2006) describe the knowledge absorption as a sequential process based on the exploratory, transformative and exploitative learning. Based on the observation of the two cases presented in this work it is difficult to see the process as strictly sequential. The acquisition and assimilation are rather semi parallel, where the acquisition overlaps the assimilation.

The dissemination of the understanding of the new knowledge and recognition of its potential contribution in the organization, which will lead to acquisition of the knowledge on an organizational level, is described as part of the transformative learning and thus assimilation (Lane et al., 2006). The dissemination of the knowledge in the organization will also reveal new insights about how the knowledge or structures must be transformed for it to be successfully assimilated in the organization. For the knowledge to be acquired on an organizational level however, the knowledge must still be individually acquired by the people in other units and departments of the organization that it is diffused to.

Especially in the Health Lab case, frustration among the participants over the lack of structures that enable them to use their new knowledge after the projects, as well as the lack of discussion and reflection related to this is evident. Based on these 
observations it can be concluded that the projects have not supported assimilation, despite the understanding that the establishment of the Health Lab could be seen as part of the assimilation of design.

Design capability implies both knowledge about and knowledge to design and the results in both the studied cases suggest that the assimilation of design implies a change in the culture related to development. This cultural change has to permeate the entire organization. In the cases, the three knowledge absorption phases can be understood as semi parallel as the acquisition on an organizational level is tightly linked to the dissemination, and the operative personnel's assessment of design as worth absorbing seems to be linked to an expectation that enabling structures will also be addressed.

If the knowledge absorption is seen as a strictly sequential process, the acquisition in itself will not lead to any direct changes or be applicable in the practical work, given the existing structures, as these are not addressed until the assimilation. Efforts aimed to develop and diffuse awareness of design (i.e. knowledge about design) in order for the organization to acquire design then risks being perceived as not worthwhile by the personnel since they might see the potential value but not how it could be applied. The motivation to learn new things and the interest in the new knowledge is thus lost as described by Bailey (2012) and Sangiorgi (2015). Knowledge that was initially assessed as worth absorbing by boundary spanners could thus run into difficulties when it should be accepted and perceived as valuable in the acquisition on an organizational level.

Taking an absorptive capacity perspective, this could be understood as an effect of poor prior experiences of knowledge development attempts and change, which have created a socialization capability that impede the organization's absorptive capacity in general. It suggests that focus on the transformative learning and assimilation become even more important.

\subsubsection{The implications on design capability development initiatives}

The analysis of the empirical material and the theoretical framework show that design capability implies more than just awareness of design. It also requires access to design resources such as competence as well as structures that enable the use of these resources.

The findings from the two cases suggest that the strong focus on experiencing the mindset, methods and tools, seen in all three projects, have supported the 


\section{Chapter 8}

acquisition of design as it has given the personnel an opportunity to explore design in relation to their own context. This suggests the set ups have supported the development of awareness of design.

Being involved in only one design driven project, through which tools and methods are transferred, has however not been sufficient to develop a design competence that can be used by the organizations as a self-sufficient internal design resource. Experience from one project does not adequate confidence among the personnel to apply design on their own in future projects. Neither is it enough to ensure a double loop learning (see e.g., Argyris \& Schön, 1978) through which they develop competence to chose and adjust methods and tools to fit the problem at hand.

Lack of facilitation of reflection about how the transferred design knowledge can be further applied as well as poor management engagement and involvement implies the set up in the projects have not supported transformative learning and assimilation of design. Issues brought up in the cases related to diffusion and future application of design suggest the knowledge character of design is too different from the organizations current structures, which implies design cannot be assimilated directly, it has to first go through a transformation stage, as suggested by Todorova and Durisin (2007).

That many of the barriers to assimilation of design, seen in the empirical material, are related to socialization capabilities and discord between the organizations existing culture and structures and the characteristics of design suggest that attention to the transformative learning phase and assimilation of design is important for the development of design capability.

Issues related to dissemination suggest the knowledge does not get absorbed on an organizational level but resides in individuals. This, together with the continuing issues of socialization and system capabilities that impede the use of design resources, suggests that neither design resources nor enabling structures have been developed through the projects and consequently not the organization's ability to design either.

The insights presented above indicate that projects that only focus on an experiential set up to transfer design knowledge are not a sufficient platform for full knowledge transfer and the subsequent development of design capability. This type of setup focuses on sending design knowledge but does not considering how that knowledge will fit in and be assimilated in the receiving organization. The results indicate that initiatives aiming to develop design capability must also acknowledge the assimilation sequence and facilitate the transformative learning to 
support the assimilation of design and the development of the organization's ability to design not just its awareness of design.

The findings indicate that prior knowledge, which according to the absorptive capacity perspective supports the acquisition (Cohen \& Levinthal, 1990; Lane et al., 2006) of design, is also relevant in the facilitation of reflection about how design will fit in and be further applied. Furthermore, the results point to the importance of involving boundary spanners and other actors with mandate to transform structures in the organization in these types of initiatives. Had the management been actively involved and engaged in the studied projects, they would have gained their own knowledge and understanding of the design approach and therefore been better equipped to address and support the actions taken to address some of the identified barriers to assimilation.

Finally, both cases show that development of design capability is not done through just one design driven project; it takes time. Time to develop design resources and time to develop enabling structures. 



\section{Chapter 9}

\section{Contributions, limitations and suggestions for future research}

This work set out to explore the development of design capability within public sector healthcare and social service organizations in order to develop a richer understanding of how design capability can be introduced, accepted and sustained in these contexts.

The insights from the two cases together with the theoretical background about organizational knowledge development and design capability have contributed to a better understanding of how design capability is developed within the public sector organizations as well as what aspects should be acknowledged and addressed in efforts made to develop design capability. In this chapter the contributions of the research are highlighted and the limitations as well as suggestions for future research are discussed. The work ends with a reflection about the research quality and an afterwords.

\subsection{Contributions}

The work presented in this thesis contributes to the understanding of advancing public sector organizations' ability to use design as a means to address current and future challenges through the development of design capability. There are three main contributions in the work: Firstly, a collected overview of the different aspects brought up in relation to design capability in the literature is presented as a result of the conducted literature review. Based on this a synthesized understanding of design capability, a concept that in previous research is used eclectically and sometimes in a reified manner, is put forward (Figure 29 page 205). A second 


\section{Chapter 9}

contribution is the identification of aspects related to development of design capability and their implications for the development of design capability in public sector organizations, based on the observations in the two studied cases. Insights about implications for the development of design capability in this context have also led to an understanding of aspects that efforts and initiatives undertaken to develop design capability should acknowledge and address. A third contribution is the discussion about how the approaches and setups, used in the studied initiatives and many other efforts reported in prior and parallel research, support the development of design capability and what aspects of design capability they focus on.

Primarily, the research has shown that many of the initiatives undertaken to introduce design and develop design capability in public sector organizations focus on developing awareness about design and training public sector personnel in design methods and tools to develop the organizations' access to design resources. The third aspect that was identified in the literature as being part of design capability, structures that enable design practice, is not acknowledge or addressed in the studied cases or in prior and parallel efforts.

The empirical data shows that this aspect is a vital part of design capability. A need to acknowledge organizational structures, which enable design practice, as an important part of design capability has been identified. Furthermore, this aspect needs to be addressed in efforts that aim to develop design capability, through a focus on the assimilation of design in the organization. It is not sufficient to only develop awareness of design or design competence (i.e. resources). If design practice is not also assimilated in the organization, through the adjustment or development of enabling structures, it will be difficult to extract the potential value that was originally recognized and therefore it will be difficult to exploit design.

The research also has shown that although having ambitions to develop design resources the setups used in the projects studied has not been sufficient to develop design resources on an organizational level, for example due to lack of attention to assimilation. This implies the efforts develop knowledge about design but not ability to design ( Figure 30). 


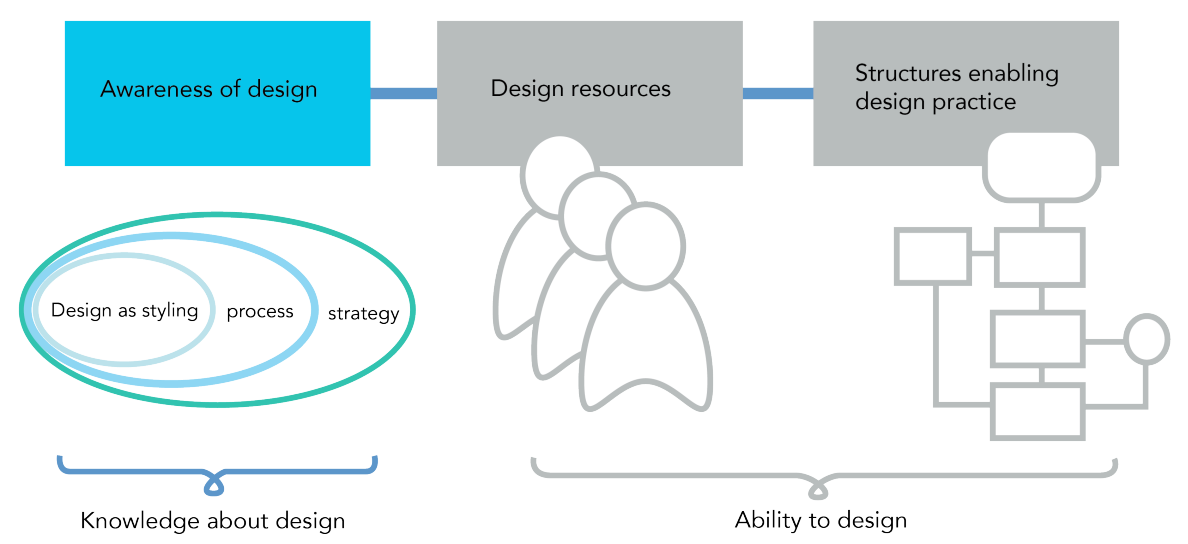

Figure 30. Focusing only on experiential learning and acquisition of design will support development of knowledge about design but not the ability to design (i.e. to use design).

The work critiques the learning-by-doing setup that was used in terms of its focus on the application of tools and methods; its lack of room for or facilitation of reflection on the design practice; and its lack of further dissemination and application of the transferred knowledge. The empirical material shows that the development of design capability in public sector healthcare and social services has to look beyond the transfer of knowledge related to design tools and methods. This approach has been common, as can be seen in the presentation of prior and parallel work in chapter 4, not only in the studied cases, but also in other initiatives. With support from the empirical material-showing the consequences of focusing on knowledge transfer of just methods and tools - the work points to aspects beyond the development of an awareness of design and the transfer of methods and tools. Aspects - such as disseminating the developed knowledge; developing structures that enable design practice; and the application of design tools and methods - must also be part of the actions taken to develop design capability.

Finally, the work indicates that to develop design capability that is sustained in the organization and is not tied to and/or dependent on individuals in the organization, it is not enough to only acquire design through exploratory learning. To develop design capability also entails structures that enable the use of design competence and practice. The absorption must make it to, and successfully pass, the transformative learning sequence, as this is where the awareness of design is disseminated throughout the organization, and where attitudes, routines, and 
processes are created, adjusted or disrupted so as to assimilate design into the organization.

\subsection{Limitations and suggestions for future research}

As with all research there have in this work also been limitations to what can be identified and said given the frames and approach of the research. Being an exploratory and qualitative work based on a hermeneutic perspective it makes no claim of producing results that will be generalizable. The knowledge produced is based on the specific conditions and events that have occurred in the two cases. However, it is my firm belief that the knowledge produced is transferable to organizations displaying the same characteristics as the organizations involved in the studied initiatives, as similar patterns have been seen in both cases despite the different approaches of the initiatives.

Despite their differences as discussed, the initiatives have also had similarities like the experiential approach that has been used in all three projects, which is also common in many other initiatives as seen in the prior and parallel research. The findings have shown that the experiential setup has supported the exploratory learning and acquisition of design but that the focus on tools and methods has led to a lack of emphasis and support for transformative learning and assimilation of the knowledge. This leaves us with questions about how the assimilation phase of the knowledge absorption can be better achieved in initiatives aiming to develop design capability; this needs to be further studied.

To further advance the understanding of how design capability can be effectively and successfully developed within public sector it would, given the homogeny of the experiential setup in the two cases, be of interest to study other approaches to understand how they support the development of the different aspects of design capability. Would for example an initiative using an infrastructure approach (Hillgren \& Süczs Johansson, 2015) or friendly hacking as in the La 27e Région's approach (La 27e Région, n.d.) capture all aspects of design capability. How do these approaches support the development of enabling structures?

Being exploratory in nature, this research has focused on developing an understanding for the development of design capability in public sector and how this development is influenced by the characteristics and conditions of the public sector organizations. The knowledge developed is thus focused around identified 
aspects influencing the development and how these are or are not addressed in the setups applied in the different projects. Therefore the research cannot give any formative suggestions for how the development of design capability could become more efficient or successful. Hence, future research focusing on these issues is suggested.

Following an absorptive capacity perspective, this research has focused mainly on how antecedents related to the absorbing organizations have influenced the development of design capability. However, as many initiatives to introduce design are setup and driven by actors with a design background it would also be interesting and potentially valuable to look at the knowledge absorption from another perspective, such as how antecedents related to the sender side affect the knowledge transfer and the development of design capability. For example, the experiential approach used in the studied cases as well as in many other initiatives can be understood as a legacy of the classical studio based design training, where the craft is learnt through building experiences through experiential projects, which can then be reflected upon. This could also be a potential explanation to the inherent assumption of design knowledge being transferable through application of design methods and tools.

The Health Lab case has been running for three years and although the initiative have come a long way and learned a lot, design cannot yet be understood as assimilated in the organization and exploited on an organizational level. From this we can learn that the development of design capability is a long-term endeavor. It would be interesting to keep following the Health Lab initiative to see how the knowledge absorption continues and how the design capability develops.

The paradigm shift towards a more user-centered focus in healthcare and social services is still ongoing and this research has focused on the first stumbling steps of introducing and embedding design as a means to achieve this. Over the years that this research has been conducted many more organizations than the ones represented in the two cases here have also started to work with a design approach in their development work and there are several initiatives aiming to support the development of design capability. Also for many of these organizations, assimilation has proven difficult for similar reasons as the ones identified and discussed in this work. The development has not continued after the first project, supported by trained designers, has ended. Others have been more successful and managed to maintain the design driven way of working taught through the project, even after the initial initiatives. To further advance the knowledge about how to successfully develop design capability that can be 


\section{Chapter 9}

sustained within an organization, it would be interesting to study some of these successful initiatives and organizations that have managed to continue the design driven work and the further development of their design capability.

Finally, as the examples of initiatives and organizations that have initiated a development of design capability are now increasing it would also be interesting to survey how widespread the dissemination of design capability has been and what kind of design knowledge is developed within the organizations.

\subsection{A reflection on the quality of the research}

Yin (2009) has argued that for case study research of an exploratory nature there are three aspects to pay attention to in order to ensure and evaluate the quality of the research. Construct validity, external validity and reliability.

The construct validity is in this work ensured through the review of the design capability concept and description of the understanding of the concept that has been used in this work as well as the description of and discussion about antecedents influencing knowledge absorption and thus the development of design capability based on the absorptive capacity perspective. Yin (2009) describes the use of multiple sources and member checking (Creswell, 2014) as tactics to ensure construct validity, both of which have been used in this work as described in the section on validity in the methods chapter.

The external validity should according to Yin (2009) ensure the domain to which the results from the study can be generalized. As already discussed above in relation to limitations, given the hermeneutic perspective that the developed understanding is based on the dialog between the whole and parts, there are no claims made that this work can be generalized as each case will have its own whole and parts. But as mentioned the results are believed to be transferable given the same characteristics of the organizations. These characteristics are described both through the description of the cases and the contextualization of the work given in the methods chapter.

Given the hermeneutic perspective and belief that the researchers interpretations of the observations as well as the theory are affected by her previous knowledge and experiences this work neither claim to be able to be repeated with the exact same results, which according to Yin (2009) is a measure for reliability. However, the reliability of the interpretations made in the work has been ensured through both member checking (Creswell, 2014) and the search for support of the interpretations in other sources from the same informant, event, 
culture or era (Alvesson \& Sköldberg, 2008) as described in the validation section of the methods chapter. This together with the description of the set up and methods used in the research should ensure reliability of the work.

\subsection{Afterword}

To pursue this research has been interesting, difficult and rewarding. I have personally learnt so much about both the development of design capability in the public sector context and how to conduct research.

It is my firm belief and hope that design can and will contribute in the development of our society not only through development of products or commercial services but also through the development of our public sector.

However, it will take patience and stamina. As shown in this research, design capability is not just awareness of design or access to design resources. Design is not magic and expecting all the pieces to fall into place as a result of simply introducing design as means for increased person-centeredness is, to be frank, naïve. Design capability is, as shown, also about having the structures and culture that enable the exploitation of the design resources. To change the culture in an organization and adapt or disrupt structures is not done over night and it will require efforts other than showing the potential contributions of design.

Design is only part of the solution to public sector development and we have to make it fit in. Otherwise design risks to soon become a disappointment, yet another discarded approach that did not deliver the hoped-for value. Although, it was never really given the chance to truly contribute. I hope the contributions made through this research will help design get an honest chance.

Let's go out and make it happen!

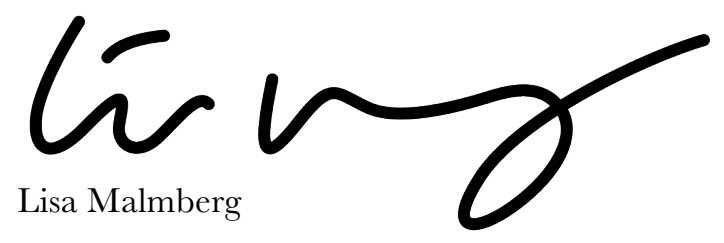

January 2017 



\section{Bibliography}

Abecassis-Moedas, C., \& Mahmoud-Jouini, S. B. (2008). Absorptive Capacity and Source-Recipient Complementarity in Designing New Products: An Empirically Derived Framework*. Journal of Product Innovation Management, 25(5), 473-490. https://doi.org/10.1111/j.1540-5885.2008.00315.x

Ackerby, S. (2005). Kommer vi att ha råd med sjukvården? SKL. Retrieved: 2015- 03-01 from: http://webbutik.skl.se/sv/artiklar/halso-ochsjukvard/kommer-vi-att-ha-rad-med-sjukvarden-ettdiskussionsunderlag-om-halso-och-sjukvardens-framtida-finans.html

Acklin, C. (2011). Design management absorption model-a framework to describe the absorption process of design knowledge by SMEs with little or no prior design experience. In New Thinking in Design Management proceedings of the 1st Cambridge Academic Design Management Conference (pp. 7-8). Cambridge.

Acklin, C. (2013a). Design Management Absorption Model: A Framework to Describe and Measure the Absorption Process of Design Knowledge by SMEs with Little or no Prior Design Experience. Creativity and Innovation Management, 22(2), 147-160. http:/ / doi.org/10.1111/caim.12022

Acklin, C. (2013b). Design management absorption in SMEs with little or no prior design experience (PhD). Lancaster University, Lancaster. Retrieved: 2015-08-19 from: http://eprints.lancs.ac.uk/64556/

Acklin, C., Cruickshank, L., \& Evans, M. (2013). Challenges of introducing new design and design management knowledge into the innovation activities of SMEs with little or no prior design experience. In Crafting the future proceedings of the 10th European Academy of Design Conference, Gothenburg.

Alvesson, M., \& Sköldberg, K. (2008). Tolkning och reflektion: vetenskapsfilosofi och kvalitativ metod. Lund: Studentlitteratur.

Argyris, C., \& Schön, D. A. (1978). Organizational learning: a theory of action perspective. Reading, Mass.: Addison-Wesley.

Badding, S., Leigh, K., \& Williams, A. (2014). Modes of thinking: Assessing the components of the design thinking process. In Design 
Management in an Era of Disruption Proceedings of the 19th DMI: Academic Design Management Conference. London.

Bailey, S. G. (2012). Embedding service design: the long and the short of it: Developing an organisation's design capacity and capability to sustainably deliver services. In $\mathrm{Co}$-Creating Services. Proceedings of The 3rd Service Design and Service Innovation Conference, Espoo, Finland. Retrieved: 2015-09-16 from: http://www.ep.liu.se/ecp_article/index.en.aspx?issue=067; article= 004

Bailey, J. (2016). A View from the Other Side: UK Policymaker Perspectives on an Emergent Design Culture. In Service Design Geographies. Proceedings of the ServDes2016 Conference (pp. 14-26). Linköping University Electronic Press. Retrieved: 2016-06-10 from: http:/ / www.ep.liu.se/ecp/article.asp?issue $=125 \&$ article $=002$

Bason, C. (2010). Leading public sector innovation : co-creating for a better society. Bristol, UK: Policy Press.

Bate, P., \& Robert, G. (2006). Experience-based design: from redesigning the system around the patient to co-designing services with the patient. Quality and Safety in Health Care, 15(5), 307-310. https://doi.org/10.1136/qshc.2005.016527

Beltagui, Pawar \& Reidel (2011). Design Capabilities in Dynamic Environments. In New Thinking in Design Management Proceedings of the 1st Cambridge Academic Design Management Conference, Cambridge

Best, K., Wolf, B., \& van Wijk, K. (2012). Conducting Design Research Internationally: A Dutch-German Approach. Design Management Review, 23(1), 64-72. https://doi.org/10.1111/j.19487169.2012.00172.x

Bevan, H., Robert, G., Bate, P., Maher, L., \& Wells, J. (2007). Using a Design Approach to Assist Large-Scale Organizational Change "10 High Impact Changes" to Improve the National Health Service in England. The Fournal of Applied Behavioral Science, 43(1), 135-152. https:/ / doi.org/10.1177/0021886306297062

Blyth, S., Kimbell, L., \& Haig, T. (2011). Design Thinking and the Big Society: From solving personal troubles to designing social problems. London: Actant and Taylor Haig. Retrieved 2016-06-12 from: http://taylorhaig.agincourt.radiatecms.com/assets/taylorhaig_designthinkingan dthebigsociety.pdf

Body, J. (2008). Design in the Australian Taxation Office. Design Issues, $24(1), 55-67$.

Brady, T., \& Davies, A. (2004). Building Project Capabilities: From Exploratory to Exploitative Learning. Organization Studies, 25(9), 1601-1621. http://doi.org/10.1177/0170840604048002 
Braun, V., \& Clarke, V. (2006). Using thematic analysis in psychology. Qualitative Research in Psychology, 3(2), 77-101. http://doi.org/10.1191/1478088706qp063oa

Buchanan, R. (1992). Wicked Problems in Design Thinking. Design Issues, 8(2), 5-21. http://doi.org/10.2307/1511637

Buchanan, R. (2001). Design Research and the New Learning. Design Issues, 17(4), 3-23. http://doi.org/10.1162/07479360152681056

Cantamessa, M. (1999). Design Best Practices, Capabilities and Performance. Fournal of Engineering Design, 10(4), 305-328. http://doi.org/10.1080/095448299261227

Carr, V. L., Sangiorgi, D., Büscher, M., Junginger, S., \& Cooper, R. (2011). Integrating Evidence-Based Design and Experience-Based Approaches in Healthcare Service Design. HERD: Health Environments Research \& Design Fournal, 4(4), 12-33. https://doi.org/10.1177/193758671100400403

Cohen, W. M., \& Levinthal, D. A. (1990). Absorptive Capacity: A New Perspective on Learning and Innovation. Administrative Science Quarterly, 35(1), 128-152. http://doi.org/10.2307/2393553

Cohen, L., Manion, L., \& Morrison, K. (2007). Research Methods in Education (6 edition). London; New York: Routledge.

Cooper, R., Junginger, S., \& Lockwood, T. (2011). The handbook of design management. Oxford: Berg.

Cooper, R., \& Junginger, S., (2011). General Introduction: Design Management - A Reflection. In Cooper, R., Junginger, S., \& Lockwood, T. (Eds.) The handbook of design management. Oxford: Berg.

Creswell, J. W. (2014). Research design: qualitative, quantitative, and mixed methods approaches. Los Angeles, Calif.: SAGE.

Cross, N. (2004). Expertise in design: an overview. Design Studies, 25(5), 427-441. http://doi.org/10.1016/j.destud.2004.06.002

De Mozota, B. B. (2008). A Theoretical Model for Design in Management Science. Design Management Fournal, 3(1), 30-37. https://doi.org/10.1111/j.1948-7177.2008.tb00004.x

De Mozota, B. B., \& Kim, B. Y. (2009). Managing Design as a Core Competency: Lessons from Korea. Design Management Review, 20(2), 66-76. http://doi.org/10.1111/j.1948-7169.2009.00009.x

Dorst, Kees. (2015). Frame innovation: creative new thinking by design. Cambridge, MA: MIT Press.

Duncan, A. K., \& Breslin, M. A. (2009). Innovating health care delivery: the design of health services. Fournal of Business Strategy, 30(2/3), 1320. https://doi.org/10.1108/02756660910942427

European Commission (2010) Rationale for Action, Commission Staff Working Paper, accompanying document Europe 2020 Flagship Initiative Innovation Union, SEC (2010) 1161, Brussels, 6.10.2010, COM. European Commission. Retrieved: 2013-12-19 from: 
http:/ /ec.europa.eu/research/innovationunion/pdf/rationale_en.pdf

Fuller, M., \& Lochard, A. (2016). Public policy labs in European Union Member states (No. EUR 28044). Luxemburg: European Union. Retrieved: 2016-12-05 from:

http://publications.jrc.ec.europa.eu/repository/bitstream/JRC102 $665 /$ final $\% 20$ report $\% 20 \mathrm{w} \% 20$ identifiers.pdf

Gericke \& Maier (2011). Scenarios for Coupling Design Thinking with Systematic Engineering Design in NPD. In New Thinking in Design Management Proceedings of the 1st Cambridge Academic Design Management Conference, Cambridge

Giacomin, J. (2014). What Is Human Centred Design? The Design fournal, $17(4), 606-623$.

https://doi.org/10.2752/175630614X14056185480186

Gorb, P., \& Dumas, A. (1987). Silent design. Design Studies, 8(3), 150-156. http://doi.org/10.1016/0142-694X(87)90037-8

Hartley, J. (2005). Innovation in governance and public services: Past and present. Public Money and Management, 25(1), 27-34.

https://doi.org/10.1111/j.1467-9302.2005.00447.x

Harvey, G., Skelcher, C., Spencer, E., Jas, P., \& Walshe, K. (2010). Absorptive Capacity in a Non-Market Environment. Public Management Review, 12(1), 77-97. http://doi.org/10.1080/14719030902817923

Hesselmann, S., \& Walters, A. (2013). A Critical Assessment of the Design Management Staircase Model Factors. Presented at the 2nd Cambridge Academic Design Management Conference, Cambridge.

Retrieved: 2015-11-03 from:

http://www.researchgate.net/profile/Andrew_Walters2/publicatio n/270579668_A_Critical_Assessment_of_the_Design_Managemen t_Staircase_Model_Factors/links/54d388ee0cf28e0697285409.pdf

Heskett \& Liu. (2012). MODELS OF DEVELOPING DESIGN

CAPACITY: PERSPECTIVE FROM CHINA. In Leading innovation through design proceedings of the DMI 2012 International Research Conference. Boston: Design Management Institute.

Hillgren, P.-A., \& Szücs Johansson, L. (2015). Designlabb för social innovation. Malmö: Mötesplats Social Innovation. Retrieved: 2016-11-30 from: http:/ /socialinnovation.se/wpcontent/uploads/2012/02/MSI_Designlabb_150305.pdf

Hirsch, E. D. (1967). Validity in interpretation. New Haven: Yale U.P.

Hughes, A., Moore, K. And Kataria, N. (2011) Innovation in Public Sector Organisations, NESTA

IDEO (n.d). http://www.designkit.org/. Viewed: 2017-01-30

Innovationsguiden (n.d). http://innovationsguiden.se/. Viewed: 2016-1108 
Jansen, J. J. P., Bosch, F. A. J. V. D., \& Volberda, H. W. (2005). Managing Potential and Realized Absorptive Capacity: How Do Organizational Antecedents Matter? The Academy of Management Fournal, 48(6), 999-1015. http://doi.org/10.2307/20159726

Junginger, S. (2009). Design in the Organization: Parts and Wholes. Design Research Fournal, 2/09, 23-29.

Junginger, S. (2015). Organizational Design Legacies and Service Design. The Design Fournal, 18(2), 209-226. http://doi.org/10.2752/175630615X14212498964277

Kimbell, L., \& Macdonald, H. (2015). Applying Design Approaches to Policy Making: Discovering Policy Lab. Brighton: Center for Research and Development Faculty of Arts, University of Brighton. Retrieved: 2016-04-11 from:

https://researchingdesignforpolicy.files.wordpress.com/2015/10/ki mbell_policylab_report.pdf

Kootstra, G. L. (2009). The incorporation of design management in today's business practices An analysis of design management practices in Europe. Rotterdam. Retrieved: 2014-02-12 from: http://www.dmeaward.com/results/

La 27e Région (n.d). http://www.la27eregion.fr/. Viewed: 2016-11-30

Lane, P. J., Koka, B. R., \& Pathak, S. (2006). The Reification of Absorptive Capacity: A Critical Review and Rejuvenation of the Construct. The Academy of Management Review, 31(4), 833-863. http://doi.org/10.2307/20159255

Lane, P. J., \& Lubatkin, M. (1998). Relative absorptive capacity and interorganizational learning. Strategic Management fournal, 19(5), 461477. http://doi.org/10.1002/(SICI) 10970266(199805)19:5<461::AID-SMJ953>3.0.CO;2-L

Le Masson, P., Hatchuel, A., \& Weil, B. (2011). The Interplay between Creativity Issues and Design Theories: A New Perspective for Design Management Studies? Creativity and Innovation Management, 20(4), 217-237. https://doi.org/10.1111/j.14678691.2011.00613.x

Levitt, B., \& March, J. G. (1988). Organizational Learning. Annual Review of Sociology, 14, 319-340.

Lin, J.-Y. (2014). Design Capabilities in Public Sector. In Design Management in an Era of Disruption Proceedings of the 19th DMI: Academic Design Management Conference. London.

Lindström, A., Fogelin, J., Feuk, C., \& Eriksson, C. (2015). Förändra radikalt- gör annorlunda, bättre och billigare. SKL. Retrived: 2016-01-13 from:

http://webbutik.skl.se/bilder/artiklar/pdf/5415.pdf?issuusl=ignore

Liu \& Bolton (2011). The Strategic Role of Empathic Design Methods in Developing New Tools for Design-Driven Innovation on Chinese 
Product Design. In New Thinking in Design Management Proceedings of the 1st Cambridge Academic Design Management Conference, Cambridge

Malmberg, L. \& Wetter- Edman, K. (2016) Design in public sector:

Exploring antecedents to sustained design capability. In Inflection point: Design research meets design practice Proceedings of the 20th DMI: Academic Design Management Conference. Boston.

Mantzavinos, G. (2016). Hermeneutics. In Zalta, E. N. (Ed.), The Stanford Encyclopedia of Philosophy (Fall 2016). Retrieved: 2016-11-18 from: http://plato.stanford.edu/archives/fall2016/entries/hermeneutics/

Mattelmäki, T. (2006). Design probes. Helsinki: University of Art and Design.

McNabola, A., Moseley, J., Reed, B., Bisgaard, T., Jossiasen, A. D., Melande, C., Whicher, A., Hytönen, J. \& Schultz, O. (2013). Design for public good (pp. 1-50). Design council. Retrieved: 2014-04-24 from:

http://www.seeplatform.eu/docs/Design \%20For\%20Public\%20G ood\%20May\%202013.pdf

Micheli, P., \& Gemser, G. (2016). Signaling Strategies for Innovative Design: A Study on Design Tradition and Expert Attention. Fournal of Product Innovation Management, 33(5), 613-627. https://doi.org/10.1111/jpim.12308

Millward, H., Byrne, C., \& Lewis, A. (2006). Enhancing the Design Capabilities of Small and Medium-Sized Enterprises Through Knowledge Transfer. The Design Fournal, 9(3), 3-13. https://doi.org/10.2752/146069206789331438

Mortati, M., Villari, B., \& Maffei, S. (2014). Design Capabilities for Value Creation. In Design Management in an Era of Disruption Proceedings of the 19th DMI: Academic Design Management Conference. London.

Moultrie, J., Clarkson, P. J., \& Probert, D. (2007). Development of a Design Audit Tool for SMEs*. Journal of Product Innovation Management, 24(4), 335-368. http://doi.org/10.1111/j.15405885.2007.00255.x

Moultrie, J. \& Livesey, F. (2009). International Design Scoreboard: Initial indicators of international design capabilities (No. ISBN 987-1-902846-742). Cambridge: University of Cambridge. Retrieved: 2015-03-01 from: http://www.designcouncil.org.uk/knowledgeresources/report/international-design-research

Mulgan, G. (2014a). Innovation in the Public Sector | Nesta. Retrieved: 201512-15 from: http://www.nesta.org.uk/publications/innovationpublic-sector

Mulgan, G. (2014b). Design in Public and Social Innovation | Nesta. Retrieved: 2015-12-12 from: http://www.nesta.org.uk/publications/design-public-and-socialinnovation 
Mutanen, U.-M. (2008). Developing organisational design capability in a Finland-based engineering corporation: the case of Metso. Design Studies, 29(5), 500-520. http://doi.org/10.1016/j.destud.2008.03.005

Noblet, J.-P., Simon, E., \& Parent, R. (2011). Absorptive capacity: a proposed operationalization. Knowledge Management Research $\mathcal{E}^{\circ}$ Practice, 9(4), 367-377. http://doi.org/10.1057/kmrp.2011.26

Patientlag, SFS 2014:821. Retrieved: 2017-01-02 from: http://www.riksdagen.se/sv/dokument-lagar/dokument/svenskforfattningssamling/patientlag-2014821_sfs-2014-821

Rae, J. (2015). Design Value Index. Design Management Review, 26(1), 4-8. http://doi.org/10.1111/drev.10307

Ramlau, U. H. (2004). In Denmark, Design Tops the Agenda. Design Management Review, 15(4), 48-54. http://doi.org/10.1111/j.19487169.2004.tb00182.x

Rauth, I., Carlgren, L., \& Elmquist, M. (2014). Making It Happen: Legitimizing Design Thinking in Large Organizations. Design Management Fournal, 9(1), 47-60. https://doi.org/10.1111/dmj.12015

Richards, G. S., \& Duxbury, L. (2014). Work-Group Knowledge Acquisition in Knowledge Intensive Public-Sector Organizations: An Exploratory Study. Fournal of Public Administration Research and Theory, muu034. http://doi.org/10.1093/jopart/muu034

Rittel, H. W. J. (1972). On the Planning Crisis: Systems Analysis of the "First and Second Generations." Institute of Urban and Regional Development. Retrieved: 2016-06-10 from: http://courses.cs.vt.edu/ cs5984/spring_2005/reading/Rittle.pdf

Rosensweig, R. R. (2011). More than Heroics: Building Design as a Dynamic Capability. Design Management Fournal, 6(1), 16-26. https://doi.org/10.1111/j.1948-7177.2011.00025.x

Sangiorgi, D. (2015). Designing for public sector innovation in the UK: design strategies for paradigm shifts. Foresight, 17(4), 332-348. https://doi.org/10.1108/FS-08-2013-0041

Saviranta \& Eloranta (2014). Transforming organizations - Linking Design Practices to Managing Organizational Capabilities. In Design Management in an Era of Disruption Proceedings of the 19th DMI: Academic Design Management Conference. London.

Schön, D. A. (1983). The reflective practitioner: how professionals think in action. New York: Basic Books.

Simon, H. A. (1996). The sciences of the artificial. Cambridge, Mass.: MIT Press.

Social Innovation Lab Kent (n.d.). http://socialinnovation.typepad.com/silk/home-page-1.html. Viewed: 2016-11-30 
Stock, G. N., Greis, N. P., \& Fischer, W. A. (2001). Absorptive capacity and new product development. The Journal of High Technology Management Research, 12(1), 77-91. https://doi.org/10.1016/S10478310(00)00040-7

Storvang, P., Jensen, S., \& Christensen, P. R. (2014). Innovation through Design: A Framework for Design Capacity in a Danish Context. Design Management Fournal, 9(1), 9-22. http://doi.org/10.1111/dmj.12006

Swiatek, P. (2016). Supporting Public Service Innovation Using Design In European Regions. Retrieved: 2016-04-11 from:

http://www.thespiderproject.eu/wpcontent/uploads/2016/04/SPIDER_EvaluationReport_V1_Marc h2016.pdf

Thomson and Koskinen (2012) Design for growth and prosperity - Report and Recommendations of the European Design Leadership Board. Helsinki.

Todorova, G., \& Durisin, B. (2007). Absorptive Capacity: Valuing a Reconceptualization. The Academy of Management Review, 32(3), 774786. http://doi.org/10.2307/20159334

Topaloğlu \& Er (2011). Strategic Use of Design in the Process of Becoming a Global Brand: The Case of Vitra Bath, a Leading Sanitary Ware Manufacturer from Turkey. In New Thinking in Design Management Proceedings of the 1st Cambridge Academic Design Management Conference, Cambridge

Van den Bosch, F. A. J., Volberda, H. W., \& de Boer, M. (1999). Coevolution of Firm Absorptive Capacity and Knowledge Environment: Organizational Forms and Combinative Capabilities. Organization Science, 10(5), 551-568. http://doi.org/10.1287/orsc. 10.5.551

Walton, T. (2004). Design as Economic Strategy. Design Management Review, 15(4), 6-9. https://doi.org/10.1111/j.19487169.2004.tb00176.x

Ward, A., Runcie, E., \& Morris, L. (2009). Embedding innovation: design thinking for small enterprises. Fournal of Business Strategy, 30(2/3), 7884. http://doi.org/10.1108/02756660910942490

Wetter-Edman, K., \& Malmberg, L. (2016). Experience and Expertise:

Key Issues for Developing Innovation Capabilities Through Service Design. In Service Design Geographies. Proceedings of the ServDes2016 Conference (pp. 516-521). Linköping University Electronic Press.

Whicher, A., Raulik-Murphy, G., \& Cawood, G. (Eds.). (2011). Bringing Innovative Ideas to Market using Design (SEE Policy Booklet No. 04). Cardiff. Retrieved: 2015-01-12 from: http://www.seeplatform.eu/docs/SEE\%20Policy\%20Booklet\%204 \%20June\%202011(2).pdf 
Wormald, P. W., \& Evans, M. A. (2009). The integration of industrial design capability within UK SMEs: The challenges, opportunities and benefits. International Fournal of Product Development, 9(4), 343-356.

Wrigley, C. and Bucolo, S. (2012). New Organisational Leadership Capabilities: Transitional Engineer the New Designer? In Leading Innovation Through Design, Proceedings of the DMI 2012 International Research Conference. BOSTON, MA. USA

Yin, Robert K. (2009). Case study research: design and methods. 4. ed. London: SAGE

Zahra, S. A., \& George, G. (2002). Absorptive Capacity: A Review, Reconceptualization, and Extension. Academy of Management Review, 27(2), 185-203. http://doi.org/10.5465/AMR.2002.6587995 



\section{Appendix A}

\section{List of sources for the design capability literature review}

In the following sources a search for design cap* was made.

\begin{tabular}{|l|}
\hline Journal \\
\hline Journal of Engineering Design \\
\hline Creativity and innovation management \\
\hline journal of product innovation management \\
\hline Design Management Review \\
\hline Design Management Journal \\
\hline Design Management Journal Academic Review \\
\hline Design studies \\
\hline The Design Journal \\
\hline International journal of enineering education \\
\hline International journal of Produc development \\
\hline Design Research Journal \\
\hline Design Issues 1997-2016 \\
\hline Journal of design history \\
\hline Proceedings \\
\hline 1 st Cambridge Academic Design Management Conference 2011 \\
\hline Cambridge academic design management conference 2013 \\
\hline
\end{tabular}


Appendix A

DM: International design management research conference 2012:

Leading innovation through design

DMI: ADMC 19th

Reports or other documentation from organizations

European Comission

Design council http://www.designcouncil.org.uk/

SVID http://www.svid.se/

Design Society Denmark http://designsociety.dk/

Mindlab www.mind-lab.dk

Nesta www.nesta.org,uk

Helsinki design lab http://www.helsinkidesignlab.org/

Le 27e Région http://www.la27eregion.fr/

Design for europe http://designforeurope.eu/

SEE-platform http://www.seeplatform.eu/

DeEP http://www.deepinitiative.eu/ 
Linköping Studies in Science and Technology

No 14 Anders Haraldsson: A Program Manipulation System Based on Partial Evaluation, 1977, ISBN 917372-144-1.

No 17 Bengt Magnhagen: Probability Based Verification of Time Margins in Digital Designs, 1977, ISBN 91-7372157-3.

No 18 Mats Cedwall: Semantisk analys av processbeskrivningar i naturligt språk, 1977, ISBN 91- 7372168-9.

No 22 Jaak Urmi: A Machine Independent LISP Compiler and its Implications for Ideal Hardware, 1978, ISBN 91-7372-188-3.

No 33 Tore Risch: Compilation of Multiple File Queries in a Meta-Database System 1978, ISBN 91- 7372-232-4.

No 51 Erland Jungert: Synthesizing Database Structures from a User Oriented Data Model, 1980, ISBN 917372-387-8.

No 54 Sture Hägglund: Contributions to the Development of Methods and Tools for Interactive Design of Applications Software, 1980, ISBN 91-7372-404-1.

No 55 Pär Emanuelson: Performance Enhancement in a Well-Structured Pattern Matcher through Partial Evaluation, 1980, ISBN 91-7372-403-3.

No 58 Bengt Johnsson, Bertil Andersson: The HumanComputer Interface in Commercial Systems, 1981, ISBN 91-7372-414-9.

No 69 H. Jan Komorowski: A Specification of an Abstract Prolog Machine and its Application to Partial Evaluation, 1981, ISBN 91-7372-479-3.

No 71 René Reboh: Knowledge Engineering Techniques and Tools for Expert Systems, 1981, ISBN 91-7372489-0.

No 77 Östen Oskarsson: Mechanisms of Modifiability in large Software Systems, 1982, ISBN 91- 7372-527-7.

No 94 Hans Lunell: Code Generator Writing Systems, 1983, ISBN 91-7372-652-4.

No 97 Andrzej Lingas: Advances in Minimum Weight Triangulation, 1983, ISBN 91-7372-660-5.

No 109 Peter Fritzson: Towards a Distributed Programming Environment based on Incremental Compilation, 1984, ISBN 91-7372-801-2

No 111 Erik Tengvald: The Design of Expert Planning Systems. An Experimental Operations Planning System for Turning, 1984, ISBN 91-7372- 805-5.

No 155 Christos Levcopoulos: Heuristics for Minimum Decompositions of Polygons, 1987, ISBN 91-7870133-3.

No 165 James W. Goodwin: A Theory and System for NonMonotonic Reasoning, 1987, ISBN 91-7870-183-X.

No 170 Zebo Peng: A Formal Methodology for Automated Synthesis of VLSI Systems, 1987, ISBN 91-7870-225-9.

No 174 Johan Fagerström: A Paradigm and System for Design of Distributed Systems, 1988, ISBN 91-7870301-8.

No 192 Dimiter Driankov: Towards a Many Valued Logic of Quantified Belief, 1988, ISBN 91-7870-374-3.

No 213 Lin Padgham: Non-Monotonic Inheritance for an Object Oriented Knowledge Base, 1989, ISBN 917870-485-5.

No 214 Tony Larsson: A Formal Hardware Description and Verification Method, 1989, ISBN 91-7870-517-7.

No 221 Michael Reinfrank: Fundamentals and Logical Foundations of Truth Maintenance, 1989, ISBN 917870-546-0.

No 239 Jonas Löwgren: Knowledge-Based Design Support and Discourse Management in User Interface Management Systems, 1991, ISBN 91-7870-720-X.

No 244 Henrik Eriksson: Meta-Tool Support for Knowledge Acquisition, 1991, ISBN 91-7870-746-3.
No 252 Peter Eklund: An Epistemic Approach to Interactive Design in Multiple Inheritance Hierarchies, 1991, ISBN 91-7870-784-6.

No 258 Patrick Doherty: NML3 - A Non-Monotonic Formalism with Explicit Defaults, 1991, ISBN 917870-816-8.

No 260 Nahid Shahmehri: Generalized Algorithmic Debugging, 1991, ISBN 91-7870-828-1.

No 264 Nils Dahlbäck: Representation of DiscourseCognitive and Computational Aspects, 1992, ISBN 91-7870-850-8

No 265 Ulf Nilsson: Abstract Interpretations and Abstract Machines: Contributions to a Methodology for the Implementation of Logic Programs, 1992, ISBN 917870-858-3.

No 270 Ralph Rönnquist: Theory and Practice of Tensebound Object References, 1992, ISBN 91-7870-873-7.

No 273 Björn Fjellborg: Pipeline Extraction for VLSI Data Path Synthesis, 1992, ISBN 91-7870-880-X.

No 276 Staffan Bonnier: A Formal Basis for Horn Clause Logic with External Polymorphic Functions, 1992, ISBN 91-7870-896-6.

No 277 Kristian Sandahl: Developing Knowledge Management Systems with an Active Expert Methodology, 1992, ISBN 91-7870-897-4.

No 281 Christer Bäckström: Computational Complexity of Reasoning about Plans, 1992, ISBN 91-7870-979-2.

No 292 Mats Wirén: Studies in Incremental Natural Language Analysis, 1992, ISBN 91-7871-027-8.

No 297 Mariam Kamkar: Interprocedural Dynamic Slicing with Applications to Debugging and Testing, 1993, ISBN 91-7871-065-0.

No 302 Tingting Zhang: A Study in Diagnosis Using Classification and Defaults, 1993, ISBN 91-7871-078-2

No 312 Arne Jönsson: Dialogue Management for Natural Language Interfaces - An Empirical Approach, 1993, ISBN 91-7871-110-X.

No 338 Simin Nadjm-Tehrani: Reactive Systems in Physical Environments: Compositional Modelling and Framework for Verification, 1994, ISBN 91-7871-237-8.

No 371 Bengt Savén: Business Models for Decision Support and Learning. A Study of Discrete-Event Manufacturing Simulation at Asea/ABB 1968-1993, 1995, ISBN 91-7871-494-X.

No 375 Ulf Söderman: Conceptual Modelling of Mode Switching Physical Systems, 1995, ISBN 91-7871-5164

No 383 Andreas Kågedal: Exploiting Groundness in Logic Programs, 1995, ISBN 91-7871-538-5.

No 396 George Fodor: Ontological Control, Description Identification and Recovery from Problematic Control Situations, 1995, ISBN 91-7871-603-9.

No 413 Mikael Pettersson: Compiling Natural Semantics, 1995, ISBN 91-7871-641-1.

No 414 Xinli Gu: RT Level Testability Improvement by Testability Analysis and Transformations, 1996, ISBN 91-7871-654-3

No 416 Hua Shu: Distributed Default Reasoning, 1996, ISBN 91-7871-665-9.

No 429 Jaime Villegas: Simulation Supported Industrial Training from an Organisational Learning Perspective - Development and Evaluation of the SSIT Method, 1996, ISBN 91-7871-700-0.

No 431 Peter Jonsson: Studies in Action Planning: Algorithms and Complexity, 1996, ISBN 91-7871-7043.

No 437 Johan Boye: Directional Types in Logic Programming, 1996, ISBN 91-7871-725-6.

No 439 Cecilia Sjöberg: Activities, Voices and Arenas: Participatory Design in Practice, 1996, ISBN 91-7871728-0.

No 448 Patrick Lambrix: Part-Whole Reasoning in Description Logics, 1996, ISBN 91-7871-820-1. 
No 452 Kjell Orsborn: On Extensible and Object-Relational Database Technology for Finite Element Analysis Applications, 1996, ISBN 91-7871-827-9.

No 459 Olof Johansson: Development Environments for Complex Product Models, 1996, ISBN 91-7871-855-4.

No 461 Lena Strömbäck: User-Defined Constructions in Unification-Based Formalisms, 1997, ISBN 91-7871857-0.

No 462 Lars Degerstedt: Tabulation-based Logic Programming: A Multi-Level View of Query Answering, 1996, ISBN 91-7871-858-9.

No 475 Fredrik Nilsson: Strategi och ekonomisk styrning En studie av hur ekonomiska styrsystem utformas och används efter företagsförvärv, 1997, ISBN 917871-914-3.

No 480 Mikael Lindvall: An Empirical Study of Requirements-Driven Impact Analysis in Object-Oriented Software Evolution, 1997, ISBN 91-7871-927-5.

No 485 Göran Forslund: Opinion-Based Systems: The Cooperative Perspective on Knowledge-Based Decision Support, 1997, ISBN 91-7871-938-0.

No 494 Martin Sköld: Active Database Management Systems for Monitoring and Control, 1997, ISBN 917219-002-7.

No 495 Hans Olsén: Automatic Verification of Petri Nets in a CLP framework, 1997, ISBN 91-7219-011-6.

No 498 Thomas Drakengren: Algorithms and Complexity for Temporal and Spatial Formalisms, 1997, ISBN 91 7219-019-1.

No 502 Jakob Axelsson: Analysis and Synthesis of Heterogeneous Real-Time Systems, 1997, ISBN 91-7219-035-3.

No 503 Johan Ringström: Compiler Generation for DataParallel Programming Languages from Two-Level Semantics Specifications, 1997, ISBN 91-7219-045-0.

No 512 Anna Moberg: Närhet och distans - Studier av kommunikationsmönster i satellitkontor och flexibla kontor, 1997, ISBN 91-7219-119-8.

No 520 Mikael Ronström: Design and Modelling of a Parallel Data Server for Telecom Applications, 1998, ISBN 91-7219-169-4.

No 522 Niclas Ohlsson: Towards Effective Fault Prevention - An Empirical Study in Software Engineering, 1998, ISBN 91-7219-176-7.

No 526 Joachim Karlsson: A Systematic Approach for Prioritizing Software Requirements, 1998, ISBN 917219-184-8.

No 530 Henrik Nilsson: Declarative Debugging for Lazy Functional Languages, 1998, ISBN 91-7219-197-x.

No 555 Jonas Hallberg: Timing Issues in High-Level Synthesis, 1998, ISBN 91-7219-369-7.

No 561 Ling Lin: Management of 1-D Sequence Data - From Discrete to Continuous, 1999, ISBN 91-7219-402-2.

No 563 Eva L Ragnemalm: Student Modelling based on Collaborative Dialogue with a Learning Companion, 1999, ISBN 91-7219-412-X.

No 567 Jörgen Lindström: Does Distance matter? On geographical dispersion in organisations, 1999, ISBN 917219-439-1.

No 582 Vanja Josifovski: Design, Implementation and Evaluation of a Distributed Mediator System for Data Integration, 1999, ISBN 91-7219-482-0.

No 589 Rita Kovordányi: Modeling and Simulating Inhibitory Mechanisms in Mental Image Reinterpretation - Towards Cooperative HumanComputer Creativity, 1999, ISBN 91-7219-506-1.

No 592 Mikael Ericsson: Supporting the Use of Design Knowledge - An Assessment of Commenting Agents, 1999, ISBN 91-7219-532-0.

No 593 Lars Karlsson: Actions, Interactions and Narratives, 1999, ISBN 91-7219-534-7.

No 594 C. G. Mikael Johansson: Social and Organizational Aspects of Requirements Engineering Methods - A practice-oriented approach, 1999, ISBN 91-7219-541-

No 595 Jörgen Hansson: Value-Driven Multi-Class Overload Management in Real-Time Database Systems, 1999, ISBN 91-7219-542-8.

No 596 Niklas Hallberg: Incorporating User Values in the Design of Information Systems and Services in the Public Sector: A Methods Approach, 1999, ISBN 917219-543-6.

No 597 Vivian Vimarlund: An Economic Perspective on the Analysis of Impacts of Information Technology: From Case Studies in Health-Care towards General Models and Theories, 1999, ISBN 91-7219-544-4.

No 598 Johan Jenvald: Methods and Tools in ComputerSupported Taskforce Training, 1999, ISBN 91-7219547-9.

No 607 Magnus Merkel: Understanding and enhancing translation by parallel text processing, 1999, ISBN 917219-614-9.

No 611 Silvia Coradeschi: Anchoring symbols to sensory data, 1999, ISBN 91-7219-623-8.

No 613 Man Lin: Analysis and Synthesis of Reactive Systems: A Generic Layered Architecture Perspective, 1999, ISBN 91-7219-630-0.

No 618 Jimmy Tjäder: Systemimplementering i praktiken En studie av logiker i fyra projekt, 1999, ISBN 917219-657-2.

No 627 Vadim Engelson: Tools for Design, Interactive Simulation, and Visualization of Object-Oriented Models in Scientific Computing, 2000, ISBN 91-7219709-9.

No 637 Esa Falkenroth: Database Technology for Control and Simulation, 2000, ISBN 91-7219-766-8.

No 639 Per-Arne Persson: Bringing Power and Knowledge Together: Information Systems Design for Autonomy and Control in Command Work, 2000, ISBN 91-7219796-X.

No 660 Erik Larsson: An Integrated System-Level Design for Testability Methodology, 2000, ISBN 91-7219-890-7.

No688 Marcus Bjäreland: Model-based Execution Monitoring, 2001, ISBN 91-7373-016-5.

No 689 Joakim Gustafsson: Extending Temporal Action Logic, 2001, ISBN 91-7373-017-3.

No 720 Carl-Johan Petri: Organizational Information Provision - Managing Mandatory and Discretionary Use of Information Technology, 2001, ISBN-91-7373-1269.

No 724 Paul Scerri: Designing Agents for Systems with Adjustable Autonomy, 2001, ISBN 9173732079.

No 725 Tim Heyer: Semantic Inspection of Software Artifacts: From Theory to Practice, 2001, ISBN 91 73732087.

No 726 Pär Carlshamre: A Usability Perspective on Requirements Engineering - From Methodology to Product Development, 2001, ISBN 9173732125.

No 732 Juha Takkinen: From Information Management to Task Management in Electronic Mail, 2002, ISBN 91 73732583.

No 745 Johan Åberg: Live Help Systems: An Approach to Intelligent Help for Web Information Systems, 2002, ISBN 91-7373-311-3.

No 746 Rego Granlund: Monitoring Distributed Teamwork Training, 2002, ISBN 91-7373-312-1.

No 757 Henrik André-Jönsson: Indexing Strategies for Time Series Data, 2002, ISBN 917373-346-6.

No 747 Anneli Hagdahl: Development of IT-supported Interorganisational Collaboration - A Case Study in the Swedish Public Sector, 2002, ISBN 91-7373-314-8.

No 749 Sofie Pilemalm: Information Technology for NonProfit Organisations - Extended Participatory Design of an Information System for Trade Union Shop Stewards, 2002, ISBN 91-7373-318-0. 
No 765 Stefan Holmlid: Adapting users: Towards a theory of use quality, 2002, ISBN 91-7373-397-0.

No 771 Magnus Morin: Multimedia Representations of Distributed Tactical Operations, 2002, ISBN 91-7373-4217.

No 772 Pawel Pietrzak: A Type-Based Framework for Locating Errors in Constraint Logic Programs, 2002, ISBN 91-7373-422-5.

No 758 Erik Berglund: Library Communication Among Programmers Worldwide, 2002, ISBN 91-7373-349-0.

No 774 Choong-ho Yi: Modelling Object-Oriented Dynamic Systems Using a Logic-Based Framework, 2002, ISBN 91-7373-424-1.

No 779 Mathias Broxvall: A Study in the Computational Complexity of Temporal Reasoning, 2002, ISBN 917373-440-3.

No 793 Asmus Pandikow: A Generic Principle for Enabling Interoperability of Structured and Object-Oriented Analysis and Design Tools, 2002, ISBN 91-7373-479-9.

No 785 Lars Hult: Publika Informationstjänster. En studie av den Internetbaserade encyklopedins bruksegenskaper, 2003, ISBN 91-7373-461-6.

No 800 Lars Taxén: A Framework for the Coordination of Complex Systems' Development, 2003, ISBN 917373-604-X

No 808 Klas Gäre: Tre perspektiv på förväntningar och förändringar $i$ samband med införande av informationssystem, 2003, ISBN 91-7373-618-X

No 821 Mikael Kindborg: Concurrent Comics programming of social agents by children, 2003, ISBN 91-7373-651-1.

No 823 Christina Ölvingson: On Development of Information Systems with GIS Functionality in Public Health Informatics: A Requirements Engineering Approach, 2003, ISBN 91-7373-656-2.

No 828 Tobias Ritzau: Memory Efficient Hard Real-Time Garbage Collection, 2003, ISBN 91-7373-666-X.

No 833 Paul Pop: Analysis and Synthesis of Communication-Intensive Heterogeneous Real-Time Systems, 2003, ISBN 91-7373-683-X.

No 852 Johan Moe: Observing the Dynamic Behaviour of Large Distributed Systems to Improve Development and Testing - An Empirical Study in Software Engineering, 2003, ISBN 91-7373-779-8.

No 867 Erik Herzog: An Approach to Systems Engineering Tool Data Representation and Exchange, 2004, ISBN 91-7373-929-4.

No 872 Aseel Berglund: Augmenting the Remote Control: Studies in Complex Information Navigation for Digital TV, 2004, ISBN 91-7373-940-5.

No 869 Jo Skåmedal: Telecommuting's Implications on Travel and Travel Patterns, 2004, ISBN 91-7373-935-9.

No 870 Linda Askenäs: The Roles of IT - Studies of Organising when Implementing and Using Enterprise Systems, 2004, ISBN 91-7373-936-7.

No 874 Annika Flycht-Eriksson: Design and Use of Ontologies in Information-Providing Dialogue Systems, 2004, ISBN 91-7373-947-2

No 873 Peter Bunus: Debugging Techniques for EquationBased Languages, 2004, ISBN 91-7373-941-3.

No 876 Jonas Mellin: Resource-Predictable and Efficient Monitoring of Events, 2004, ISBN 91-7373-956-1.

No 883 Magnus Bång: Computing at the Speed of Paper: Ubiquitous Computing Environments for Healthcare Professionals, 2004, ISBN 91-7373-971-5

No 882 Robert Eklund: Disfluency in Swedish humanhuman and human-machine travel booking dialogues, 2004, ISBN 91-7373-966-9.

No 887 Anders Lindström: English and other Foreign Linguistic Elements in Spoken Swedish. Studies of Productive Processes and their Modelling using Finite-State Tools, 2004, ISBN 91-7373-981-2.
No 889 Zhiping Wang: Capacity-Constrained Production-inventory systems - Modelling and Analysis in both a traditional and an e-business context, 2004, ISBN 9185295-08-6.

No 893 Pernilla Qvarfordt: Eyes on Multimodal Interaction, 2004, ISBN 91-85295-30-2.

No 910 Magnus Kald: In the Borderland between Strategy and Management Control - Theoretical Framework and Empirical Evidence, 2004, ISBN 91-85295-82-5.

No 918 Jonas Lundberg: Shaping Electronic News: Genre Perspectives on Interaction Design, 2004, ISBN 9185297-14-3.

No 900 Mattias Arvola: Shades of use: The dynamics of interaction design for sociable use, 2004, ISBN 9185295-42-6.

No 920 Luis Alejandro Cortés: Verification and Scheduling Techniques for Real-Time Embedded Systems, 2004, ISBN 91-85297-21-6.

No 929 Diana Szentivanyi: Performance Studies of FaultTolerant Middleware, 2005, ISBN 91-85297-58-5.

No 933 Mikael Cäker: Management Accounting as Constructing and Opposing Customer Focus: Three Case Studies on Management Accounting and Customer Relations, 2005, ISBN 91-85297-64-X.

No 937 Jonas Kvarnström: TALplanner and Other Extensions to Temporal Action Logic, 2005, ISBN 9185297-75-5.

No 938 Bourhane Kadmiry: Fuzzy Gain-Scheduled Visual Servoing for Unmanned Helicopter, 2005, ISBN 9185297-76-3.

No 945 Gert Jervan: Hybrid Built-In Self-Test and Test Generation Techniques for Digital Systems, 2005, ISBN: 91-85297-97-6.

No 946 Anders Arpteg: Intelligent Semi-Structured Information Extraction, 2005, ISBN 91-85297-98-4.

No 947 Ola Angelsmark: Constructing Algorithms for Constraint Satisfaction and Related Problems - Methods and Applications, 2005, ISBN 91-85297-99-2.

No 963 Calin Curescu: Utility-based Optimisation of Resource Allocation for Wireless Networks, 2005, ISBN 91-85457-07-8.

No 972 Björn Johansson: Joint Control in Dynamic Situations, 2005, ISBN 91-85457-31-0.

No 974 Dan Lawesson: An Approach to Diagnosability Analysis for Interacting Finite State Systems, 2005, ISBN 91-85457-39-6.

No 979 Claudiu Duma: Security and Trust Mechanisms for Groups in Distributed Services, 2005, ISBN 91-85457$54-X$.

No 983 Sorin Manolache: Analysis and Optimisation of Real-Time Systems with Stochastic Behaviour, 2005, ISBN 91-85457-60-4.

No 986 Yuxiao Zhao: Standards-Based Application Integration for Business-to-Business Communications, 2005, ISBN 91-85457-66-3.

No 1004 Patrik Haslum: Admissible Heuristics for Automated Planning, 2006, ISBN 91-85497-28-2.

No 1005 Aleksandra Tešanovic: Developing Reusable and Reconfigurable Real-Time Software using Aspects and Components, 2006, ISBN 91-85497-29-0.

No 1008 David Dinka: Role, Identity and Work: Extending the design and development agenda, 2006, ISBN 91$85497-42-8$

No 1009 Iakov Nakhimovski: Contributions to the Modeling and Simulation of Mechanical Systems with Detailed Contact Analysis, 2006, ISBN 91-85497-43-X.

No 1013 Wilhelm Dahllöf: Exact Algorithms for Exact Satisfiability Problems, 2006, ISBN 91-85523-97-6.

No 1016 Levon Saldamli: PDEModelica - A High-Level Language for Modeling with Partial Differential Equations, 2006, ISBN 91-85523-84-4.

No 1017 Daniel Karlsson: Verification of Component-based Embedded System Designs, 2006, ISBN 91-85523-79-8 
No 1018 Ioan Chisalita: Communication and Networking Techniques for Traffic Safety Systems, 2006, ISBN 9185523-77-1

No 1019 Tarja Susi: The Puzzle of Social Activity - The Significance of Tools in Cognition and Cooperation, 2006, ISBN 91-85523-71-2.

No 1021 Andrzej Bednarski: Integrated Optimal Code Generation for Digital Signal Processors, 2006, ISBN 9185523-69-0.

No 1022 Peter Aronsson: Automatic Parallelization of Equation-Based Simulation Programs, 2006, ISBN 9185523-68-2.

No 1030 Robert Nilsson: A Mutation-based Framework for Automated Testing of Timeliness, 2006, ISBN 9185523-35-6.

No 1034 Jon Edvardsson: Techniques for Automatic Generation of Tests from Programs and Specifications, 2006, ISBN 91-85523-31-3.

No 1035 Vaida Jakoniene: Integration of Biological Data, 2006, ISBN 91-85523-28-3.

No 1045 Genevieve Gorrell: Generalized Hebbian Algorithms for Dimensionality Reduction in Natural Language Processing, 2006, ISBN 91-85643-88-2.

No 1051 Yu-Hsing Huang: Having a New Pair of Glasses Applying Systemic Accident Models on Road Safety, 2006, ISBN 91-85643-64-5.

No 1054 Åsa Hedenskog: Perceive those things which cannot be seen - A Cognitive Systems Engineering perspective on requirements management, 2006, ISBN 91-85643-57-2.

No 1061 Cécile Åberg: An Evaluation Platform for Semantic Web Technology, 2007, ISBN 91-85643-31-9.

No 1073 Mats Grindal: Handling Combinatorial Explosion in Software Testing, 2007, ISBN 978-91-85715-74-9.

No 1075 Almut Herzog: Usable Security Policies for Runtime Environments, 2007, ISBN 978-91-85715-65-7.

No 1079 Magnus Wahlström: Algorithms, measures, and upper bounds for Satisfiability and related problems, 2007, ISBN 978-91-85715-55-8.

No 1083 Jesper Andersson: Dynamic Software Architectures, 2007, ISBN 978-91-85715-46-6.

No 1086 Ulf Johansson: Obtaining Accurate and Comprehensible Data Mining Models - An Evolutionary Approach, 2007, ISBN 978-91-85715-34-3.

No 1089 Traian Pop: Analysis and Optimisation of Distributed Embedded Systems with Heterogeneous Scheduling Policies, 2007, ISBN 978-91-85715-27-5.

No 1091 Gustav Nordh: Complexity Dichotomies for CSPrelated Problems, 2007, ISBN 978-91-85715-20-6.

No 1106 Per Ola Kristensson: Discrete and Continuous Shape Writing for Text Entry and Control, 2007, ISBN 97891-85831-77-7.

No 1110 He Tan: Aligning Biomedical Ontologies, 2007, ISBN 978-91-85831-56-2.

No 1112 Jessica Lindblom: Minding the body - Interacting socially through embodied action, 2007, ISBN 978-9185831-48-7.

No 1113 Pontus Wärnestål: Dialogue Behavior Management in Conversational Recommender Systems, 2007, ISBN 978-91-85831-47-0.

No 1120 Thomas Gustafsson: Management of Real-Time Data Consistency and Transient Overloads in Embedded Systems, 2007, ISBN 978-91-85831-33-3.

No 1127 Alexandru Andrei: Energy Efficient and Predictable Design of Real-time Embedded Systems, 2007, ISBN 978-91-85831-06-7.

No 1139 Per Wikberg: Eliciting Knowledge from Experts in Modeling of Complex Systems: Managing Variation and Interactions, 2007, ISBN 978-91-85895-66-3.

No 1143 Mehdi Amirijoo: OoS Control of Real-Time Data Services under Uncertain Workload, 2007, ISBN 97891-85895-49-6
No 1150 Sanny Syberfeldt: Optimistic Replication with Forward Conflict Resolution in Distributed Real-Time Databases, 2007, ISBN 978-91-85895-27-4.

No 1155 Beatrice Alenljung: Envisioning a Future Decision Support System for Requirements Engineering - A Holistic and Human-centred Perspective, 2008, ISBN 978-91-85895-11-3.

No 1156 Artur Wilk: Types for XML with Application to Xcerpt, 2008, ISBN 978-91-85895-08-3.

No 1183 Adrian Pop: Integrated Model-Driven Development Environments for Equation-Based Object-Oriented Languages, 2008, ISBN 978-91-7393-895-2.

No 1185 Jörgen Skågeby: Gifting Technologies Ethnographic Studies of End-users and Social Media Sharing, 2008, ISBN 978-91-7393-892-1.

No 1187 Imad-Eldin Ali Abugessaisa: Analytical tools and information-sharing methods supporting road safety organizations, 2008, ISBN 978-91-7393-887-7.

No 1204 H. Joe Steinhauer: A Representation Scheme for Description and Reconstruction of Object Configurations Based on Qualitative Relations, 2008, ISBN 978-91-7393-823-5.

No 1222 Anders Larsson: Test Optimization for Core-based System-on-Chip, 2008, ISBN 978-91-7393-768-9.

No 1238 Andreas Borg: Processes and Models for Capacity Requirements in Telecommunication Systems, 2009, ISBN 978-91-7393-700-9.

No 1240 Fredrik Heintz: DyKnow: A Stream-Based Knowledge Processing Middleware Framework, 2009, ISBN 978-91-7393-696-5.

No 1241 Birgitta Lindström: Testability of Dynamic RealTime Systems, 2009, ISBN 978-91-7393-695-8.

No 1244 Eva Blomqvist: Semi-automatic Ontology Construction based on Patterns, 2009, ISBN 978-91-7393-683-5.

No 1249 Rogier Woltjer: Functional Modeling of Constraint Management in Aviation Safety and Command and Control, 2009, ISBN 978-91-7393-659-0.

No 1260 Gianpaolo Conte: Vision-Based Localization and Guidance for Unmanned Aerial Vehicles, 2009, ISBN 978-91-7393-603-3.

No 1262 AnnMarie Ericsson: Enabling Tool Support for Formal Analysis of ECA Rules, 2009, ISBN 978-91-7393598-2.

No 1266 Jiri Trnka: Exploring Tactical Command and Control: A Role-Playing Simulation Approach, 2009, ISBN 978-91-7393-571-5.

No 1268 Bahlol Rahimi: Supporting Collaborative Work through ICT - How End-users Think of and Adopt Integrated Health Information Systems, 2009, ISBN 978-91-7393-550-0.

No 1274 Fredrik Kuivinen: Algorithms and Hardness Results for Some Valued CSPs, 2009, ISBN 978-91-7393-525-8.

No 1281 Gunnar Mathiason: Virtual Full Replication for Scalable Distributed Real-Time Databases, 2009, ISBN 978-91-7393-503-6.

No 1290 Viacheslav Izosimov: Scheduling and Optimization of Fault-Tolerant Distributed Embedded Systems, 2009, ISBN 978-91-7393-482-4.

No 1294 Johan Thapper: Aspects of a Constraint Optimisation Problem, 2010, ISBN 978-91-7393-464-0.

No 1306 Susanna Nilsson: Augmentation in the Wild: User Centered Development and Evaluation of Augmented Reality Applications, 2010, ISBN 978-917393-416-9.

No 1313 Christer Thörn: On the Quality of Feature Models, 2010, ISBN 978-91-7393-394-0.

No 1321 Zhiyuan He: Temperature Aware and DefectProbability Driven Test Scheduling for System-onChip, 2010, ISBN 978-91-7393-378-0.

No 1333 David Broman: Meta-Languages and Semantics for Equation-Based Modeling and Simulation, 2010, ISBN 978-91-7393-335-3. 
No 1337 Alexander Siemers: Contributions to Modelling and Visualisation of Multibody Systems Simulations with Detailed Contact Analysis, 2010, ISBN 978-91-7393317-9.

No 1354 Mikael Asplund: Disconnected Discoveries: Availability Studies in Partitioned Networks, 2010, ISBN 978-91-7393-278-3.

No 1359 Jana Rambusch: Mind Games Extended: Understanding Gameplay as Situated Activity, 2010, ISBN 978-91-7393-252-3.

No 1373 Sonia Sangari: Head Movement Correlates to Focus Assignment in Swedish,2011,ISBN 978-91-7393-154-0.

No 1374 Jan-Erik Källhammer: Using False Alarms when Developing Automotive Active Safety Systems, 2011, ISBN 978-91-7393-153-3.

No 1375 Mattias Eriksson: Integrated Code Generation, 2011, ISBN 978-91-7393-147-2.

No 1381 Ola Leifler: Affordances and Constraints of Intelligent Decision Support for Military Command and Control - Three Case Studies of Support Systems, 2011, ISBN 978-91-7393-133-5.

No 1386 Soheil Samii: Quality-Driven Synthesis and Optimization of Embedded Control Systems, 2011, ISBN 978-91-7393-102-1.

No 1419 Erik Kuiper: Geographic Routing in Intermittentlyconnected Mobile Ad Hoc Networks: Algorithms and Performance Models, 2012, ISBN 978-91-7519981-8.

No 1451 Sara Stymne: Text Harmonization Strategies for Phrase-Based Statistical Machine Translation, 2012, ISBN 978-91-7519-887-3.

No 1455 Alberto Montebelli: Modeling the Role of Energy Management in Embodied Cognition, 2012, ISBN 978-91-7519-882-8.

No 1465 Mohammad Saifullah: Biologically-Based Interactive Neural Network Models for Visual Attention and Object Recognition, 2012, ISBN 978-91-7519-838-5.

No 1490 Tomas Bengtsson: Testing and Logic Optimization Techniques for Systems on Chip, 2012, ISBN 978-917519-742-5

No 1481 David Byers: Improving Software Security by Preventing Known Vulnerabilities, 2012, ISBN 97891-7519-784-5.

No 1496 Tommy Färnqvist: Exploiting Structure in CSPrelated Problems, 2013, ISBN 978-91-7519-711-1.

No 1503 John Wilander: Contributions to Specification, Implementation, and Execution of Secure Software 2013, ISBN 978-91-7519-681-7.

No 1506 Magnus Ingmarsson: Creating and Enabling the Useful Service Discovery Experience, 2013, ISBN 97891-7519-662-6.

No 1547 Wladimir Schamai: Model-Based Verification of Dynamic System Behavior against Requirements: Method, Language, and Tool, 2013, ISBN 978-917519-505-6.

No 1551 Henrik Svensson: Simulations, 2013, ISBN 978-917519-491-2.

No 1559 Sergiu Rafiliu: Stability of Adaptive Distributed Real-Time Systems with Dynamic Resource Management, 2013, ISBN 978-91-7519-471-4.

No 1581 Usman Dastgeer: Performance-aware Component Composition for GPU-based Systems, 2014, ISBN 978-91-7519-383-0.

No 1602 Cai Li: Reinforcement Learning of Locomotion based on Central Pattern Generators, 2014, ISBN 978-917519-313-7.

No 1652 Roland Samlaus: An Integrated Development Environment with Enhanced Domain-Specific Interactive Model Validation, 2015, ISBN 978-917519-090-7.

No 1663 Hannes Uppman: On Some Combinatorial Optimization Problems: Algorithms and Complexity, 2015, ISBN 978-91-7519-072-3.
No 1664 Martin Sjölund: Tools and Methods for Analysis, Debugging, and Performance Improvement of Equation-Based Models, 2015, ISBN 978-91-7519-071-6.

No 1666 Kristian Stavåker: Contributions to Simulation of Modelica Models on Data-Parallel Multi-Core Architectures, 2015, ISBN 978-91-7519-068-6.

No 1680 Adrian Lifa: Hardware/Software Codesign of Embedded Systems with Reconfigurable and Heterogeneous Platforms, 2015, ISBN 978-91-7519-0402.

No 1685 Bogdan Tanasa: Timing Analysis of Distributed Embedded Systems with Stochastic Workload and Reliability Constraints, 2015, ISBN 978-91-7519-022-8.

No 1691 Håkan Warnquist: Troubleshooting Trucks Automated Planning and Diagnosis, 2015, ISBN 97891-7685-993-3.

No 1702 Nima Aghaee: Thermal Issues in Testing of Advanced Systems on Chip, 2015, ISBN 978-91-7685949-0.

No 1715 Maria Vasilevskaya: Security in Embedded Systems: A Model-Based Approach with Risk Metrics, 2015, ISBN 978-91-7685-917-9.

No 1729 Ke Jiang: Security-Driven Design of Real-Time Embedded System, 2016, ISBN 978-91-7685-884-4.

No 1733 Victor Lagerkvist: Strong Partial Clones and the Complexity of Constraint Satisfaction Problems: Limitations and Applications, 2016, ISBN 978-91-7685856-1.

No 1734 Chandan Roy: An Informed System Development Approach to Tropical Cyclone Track and Intensity Forecasting, 2016, ISBN 978-91-7685-854-7.

No 1746 Amir Aminifar: Analysis, Design, and Optimization of Embedded Control Systems, 2016, ISBN 978-917685-826-4.

No 1747 Ekhiotz Vergara: Energy Modelling and Fairness for Efficient Mobile Communication, 2016, ISBN 978-91-7685-822-6.

No 1748 Dag Sonntag: Chain Graphs - Interpretations, Expressiveness and Learning Algorithms, 2016, ISBN 978-91-7685-818-9.

No 1768 Anna Vapen: Web Authentication using ThirdParties in Untrusted Environments, 2016, ISBN 978-91-7685-753-3.

No 1778 Magnus Jandinger: On a Need to Know Basis: A Conceptual and Methodological Framework for Modelling and Analysis of Information Demand in an Enterprise Context, 2016, ISBN 978-91-7685-713-7.

No 1798 Rahul Hiran: Collaborative Network Security: Targeting Wide-area Routing and Edgenetwork Attacks, 2016, ISBN 978-91-7685-662-8.

No 1813 Nicolas Melot: Algorithms and Framework for Energy Efficient Parallel Stream Computing on Many-Core Architectures, 2016, ISBN 978-91-7685623-9.

No 1823 Amy Rankin: Making Sense of Adaptations: Resilience in High-Risk Work, 2017, ISBN 978-917685-596-6.

No 1831 Lisa Malmberg: Building Design Capability in the Public Sector: Expanding the Horizons of Development, 2017, ISBN 978-91-7685-585-0.

Linköping Studies in Arts and Science

No 504 Ing-Marie Jonsson: Social and Emotional Characteristics of Speech-based In-Vehicle Information Systems: Impact on Attitude and Driving Behaviour, 2009, ISBN 978-91-7393-478-7.

No 586 Fabian Segelström: Stakeholder Engagement for Service Design: How service designers identify and communicate insights, 2013, ISBN 978-91-7519-554-4. 
No 618 Johan Blomkvist: Representing Future Situations of Service: Prototyping in Service Design, 2014, ISBN 978-91-7519-343-4.

No 620 Marcus Mast: Human-Robot Interaction for SemiAutonomous Assistive Robots, 2014, ISBN 978-917519-319-9.

No 677 Peter Berggren: Assessing Shared Strategic Understanding, 2016, ISBN 978-91-7685-786-1.

No 695 Mattias Forsblad: Distributed cognition in home environments: The prospective memory and cognitive practices of older adults, 2016, ISBN 97891-7685-686-4

\section{Linköping Studies in Statistics}

No 9 Davood Shahsavani: Computer Experiments Designed to Explore and Approximate Complex Deterministic Models, 2008, ISBN 978-91-7393-976-8.

No 10 Karl Wahlin: Roadmap for Trend Detection and Assessment of Data Quality, 2008, ISBN 978-91-7393792-4.

No 11 Oleg Sysoev: Monotonic regression for large multivariate datasets, 2010, ISBN 978-91-7393-412-1.

No 13 Agné Burauskaite-Harju: Characterizing Temporal Change and Inter-Site Correlations in Daily and Subdaily Precipitation Extremes, 2011, ISBN 978-91-7393110-6.

\section{Linköping Studies in Information Science}

No 1 Karin Axelsson: Metodisk systemstrukturering- att skapa samstämmighet mellan informationssystemarkitektur och verksamhet, 1998. ISBN-9172-19-296-8.

No 2 Stefan Cronholm: Metodverktyg och användbarhet en studie av datorstödd metodbaserad systemutveckling, 1998, ISBN-9172-19-299-2.

No 3 Anders Avdic: Användare och utvecklare - om anveckling med kalkylprogram, 1999. ISBN-91-7219606-8.

No 4 Owen Eriksson: Kommunikationskvalitet hos informationssystem och affärsprocesser, 2000, ISBN 917219-811-7.

No 5 Mikael Lind: Från system till process - kriterier för processbestämning vid verksamhetsanalys, 2001, ISBN 91-7373-067-X.

No 6 Ulf Melin: Koordination och informationssystem i företag och nätverk, 2002, ISBN 91-7373-278-8.

No 7 Pär J. Ågerfalk: Information Systems Actability - Understanding Information Technology as a Tool for Business Action and Communication, 2003, ISBN 917373-628-7.

No 8 Ulf Seigerroth: Att förstå och förändra systemutvecklingsverksamheter - en taxonomi för metautveckling, 2003, ISBN91-7373-736-4.

No 9 Karin Hedström: Spår av datoriseringens värden Effekter av IT i äldreomsorg, 2004, ISBN 91-7373-9634.

No 10 Ewa Braf: Knowledge Demanded for Action Studies on Knowledge Mediation in Organisations, 2004, ISBN 91-85295-47-7.

No 11 Fredrik Karlsson: Method Configuration method and computerized tool support, 2005, ISBN 91-8529748-8.

No 12 Malin Nordström: Styrbar systemförvaltning - Att organisera systemförvaltningsverksamhet med hjälp av effektiva förvaltningsobjekt, 2005, ISBN 91-8529760-7.

No 13 Stefan Holgersson: Yrke: POLIS - Yrkeskunskap, motivation, IT-system och andra förutsättningar för polisarbete, 2005, ISBN 91-85299-43-X.

No 14 Benneth Christiansson, Marie-Therese Christiansson: Mötet mellan process och komponent - mot ett ramverk för en verksamhetsnära kravspecifikation vid anskaffning av komponent- baserade informationssystem, 2006, ISBN 91-8564322-X. 